\title{
CYCLIC BEHAVIOUR AND DYNAMIC PROPERTIES OF SOILS UNDER SIMPLE SHEAR LOADING
}

\author{
by \\ Sentheepan Thirugnanasampanther \\ BEng (Civil), University of East London, UK (2012)
}

A thesis submitted to the Faculty of Graduate and Postdoctoral Affairs in partial fulfillment of the requirements for the degree of

Master of Applied Science in Civil Engineering
Department of Civil and Environmental Engineering Carleton University

Ottawa-Carleton Institute of Civil and Environmental Engineering Ottawa, Ontario

(C) 2016, Sentheepan Thirugnanasampanther 


\begin{abstract}
An experimental study was carried out on sensitive clays obtained from Ottawa-Quebec area (Kinburn, ON, Breckenridge and Outardes-2, QC) and relatively uniform sand obtained from the Fraser Delta $(\mathrm{BC})$. Large strain tests were conducted at over consolidated and normally consolidated states to investigate the monotonic and cyclic behaviour of sensitive clays. Small strain tests were carried out over a range of consolidation stress levels to investigate the dynamic properties of clays and Fraser River sand. All tests were performed using the Carleton University simple shear device, which was modified to enable confident measurements at very small strains.
\end{abstract}

Test results show that shear strength of clays is influenced by consolidation stress, over consolidation ratio and clay content. Further, this study reveals that these sensitive clays at the tested sites have relatively strong cyclic resistance at in-situ stress level, but cyclic resistance decreased significantly if the clays are normally consolidated.

Site-specific modulus reduction and damping ratio curves are proposed for Ottawa-Quebec area clays and Fraser River sand. These site-specific curves are unique for sensitive clays and cannot be equated to any curves published in the literature. The curves generated for Fraser River sand are close to the average and lower bound curves reported in the literature for sands. 


\section{Acknowledgments}

I would like to take this opportunity to express my sincere gratitude to my supervisor, Professor Siva Sivathayalan for his exceptional guidance, encouragement and support during the course of study. His commitment and approach helped me in an immense way to complete my Masters Research program successfully.

I greatly appreciate the assistance provided by lab technicians Stanly, Pierre, Jason and all others. Carrying out laboratory testing successfully wouldn't have been possible without their contribution.

Further, I would like to thank my friends for their support and constructive comments throughout the process. I am especially grateful to Theenathayarl, Thavakumar, Prasanna and Abdulkadhar for their guidance.

I would like to acknowledge all my teachers and mentors who guided and motivated me during my undergraduate study in both Sri Lanka and the UK.

Finally, I am most grateful to my parents, siblings and wife for their continuous support, patience and encouragement throughout my studies and life. 


\section{Table of Contents}

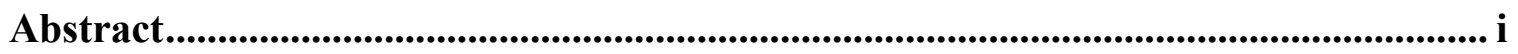

Acknowledgments ........................................................................................................................ ii

Table of Contents ..............................................................................................................ii

List of Tables .............................................................................................................................. viii

List of Figures.......................................................................................................................... ix

List of Symbols .......................................................................................................... xiv

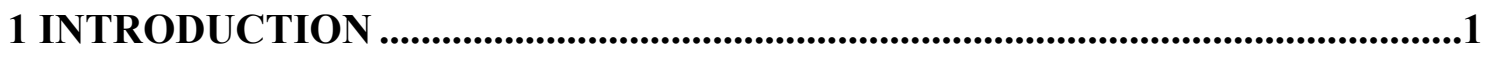

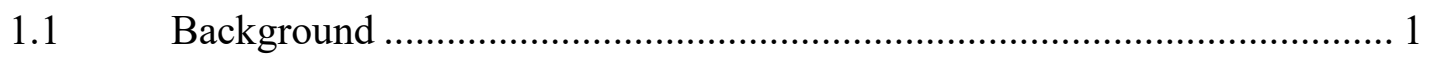

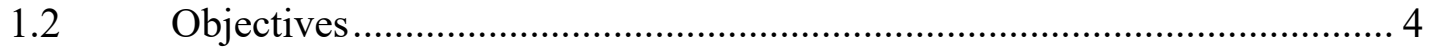

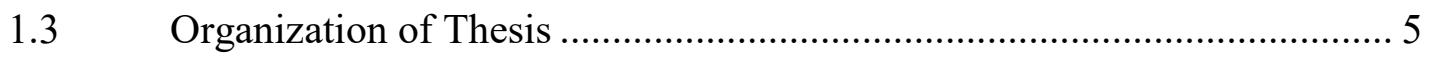

2 LITERATURE REVIEW ..............................................................................................6

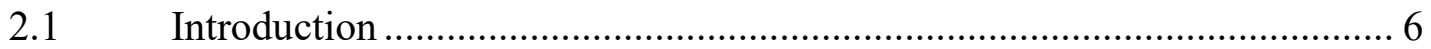

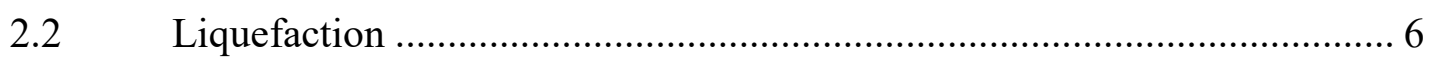

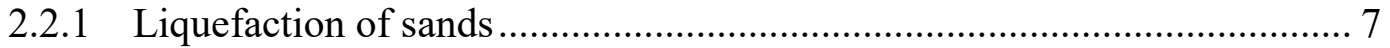

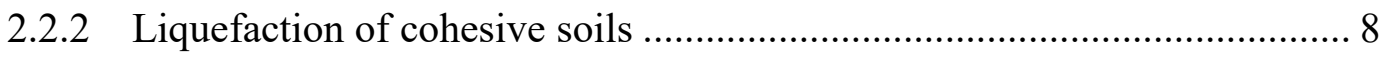

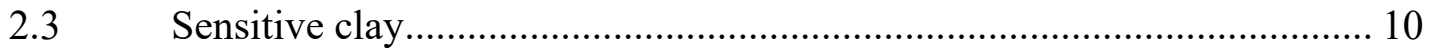

2.3.1 Mechanical behaviour of sensitive clays ............................................... 10

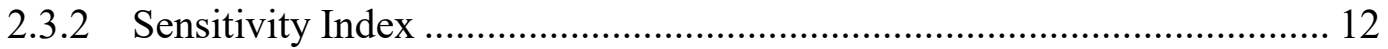

$2.4 \quad$ Undrained cyclic behaviour of soil ....................................................... 13

2.4.1 Cyclic shear stress amplitude............................................................... 14

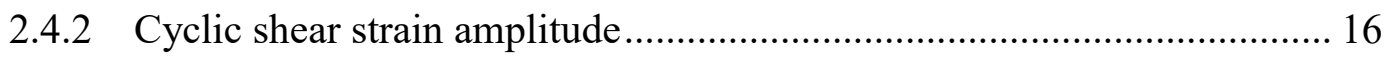

2.4.3 Influence of number of load cycles in cyclic behaviour ........................... 17

2.4.4 Influence of vertical consolidation stress.................................................. 19 
2.4.5 Influence of over consolidation ratio in cyclic behaviour ..................... 20

2.4.6 Influence of plasticity index in cyclic behaviour .................................. 22

2.4.7 Influence of loading conditions in cyclic behaviour............................. 22

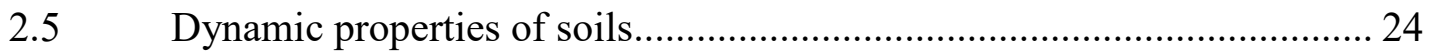

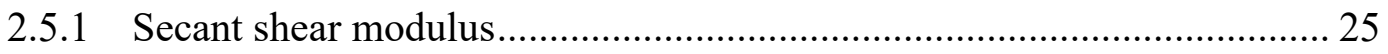

2.5.2 Factors affecting the secant shear modulus ......................................... 26

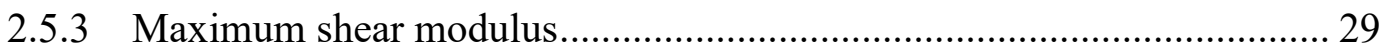

2.5.4 Factors affecting the maximum shear modulus ................................... 30

2.5.5 Damping Ratio .............................................................................. 30

2.5.6 Modulus reduction and Damping ratio ................................................. 31

2.5.7 Factors affecting the modulus reduction and damping ratio................... 35

3 EXPERIMENTAL PROGRAMME ....................................................................40

Simple shear device...................................................................... 40

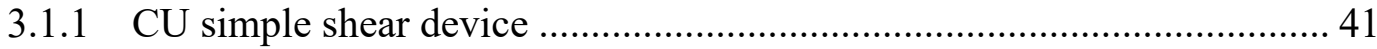

3.1.2 Measurements of stresses and strains ............................................... 43

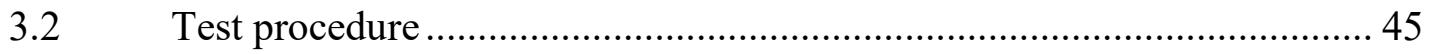

3.2.1 Preparation of simple shear mould ................................................. 46

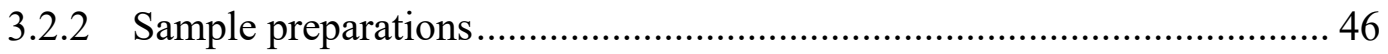

3.2.2.1 Preparation of Leda clay sample................................................... 46

3.2.2.2 Preparation of Fraser River sand sample ........................................ 48

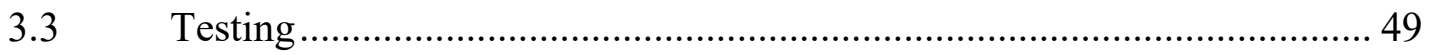

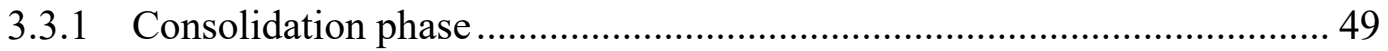

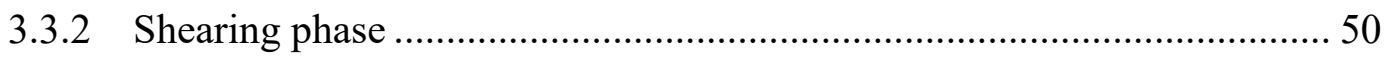

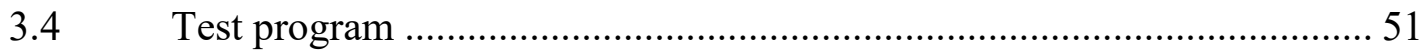

3.4.1 Test program for Sensitive clay ...................................................... 51

3.4.2 Test program for Fraser River sand ................................................... 55

3.5 Material properties of tested clay and sand .......................................... 56 


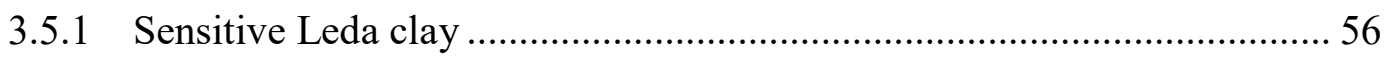

3.5.1.1 Atterberg Limits............................................................................. 56

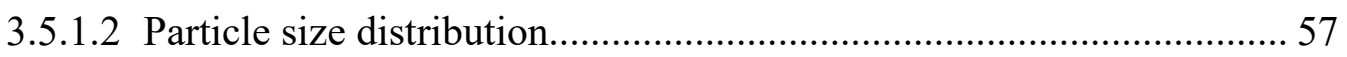

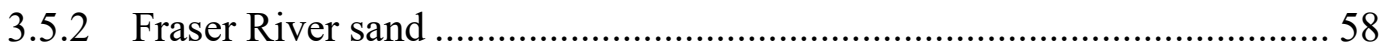

4 MONOTONIC AND CYCLIC BEHAVIOUR OF LEDA CLAY ..........................60

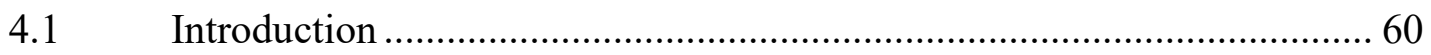

4.2 Undrained Monotonic behaviour of Sensitive Leda clays ......................... 60

4.2.1 Influence of effective vertical consolidation stress in shear strength ....... 62

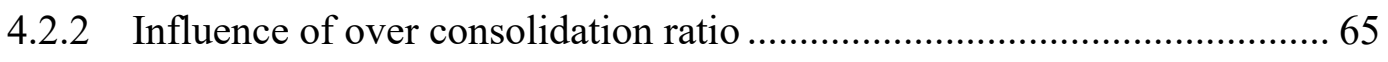

4.2.3 Variation in monotonic behaviour due to heterogeneity with depth at a site 69

4.2.4 Strength parameters of sensitive Leda clays ………………..................... 70

4.2.4.1 Peak strength parameters ................................................................. 71

4.2.4.2 Residual strength parameters ............................................................ 74

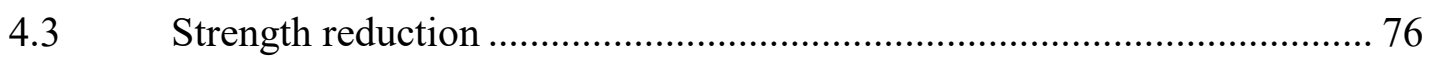

4.3.1 Influence of large quasi-cyclic shearing on undrained monotonic behaviour 76

4.4 Undrained cyclic behaviour of sensitive Leda clays ................................. 79

4.4.1 Influence of cyclic shear stress, strain and number of loading cycles ...... 79

4.4.2 Typical undrained cyclic test of sensitive clays....................................... 80

4.4.3 Cyclic tests at in-situ (OC) state and normally consolidated state............ 85

4.4.4 Cyclic resistance of Kinburn sensitive Leda clays .................................. 85

4.4.5 Comparison of the cyclic resistance at different sites and the influence of OCR 88

4.4.6 Importance of investigating the site-specific cyclic behaviour of sensitive clays 90

4.5 Post cyclic behaviour of sensitive Leda clay 92 


\section{MODULUS AND DAMPING BEHAVIOUR OF SENSITIVE LEDA CLAYS}

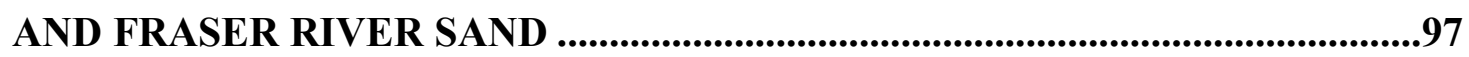

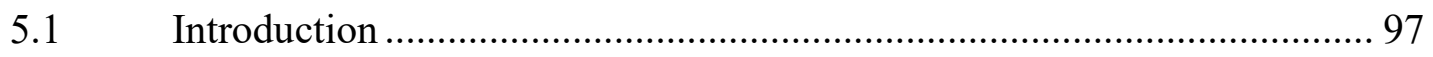

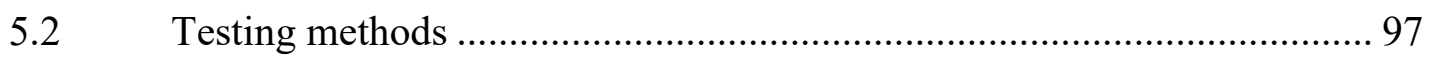

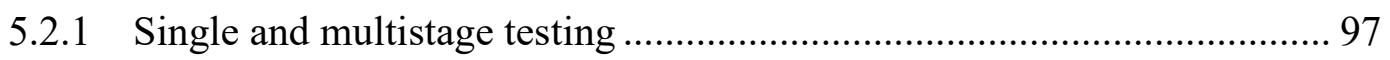

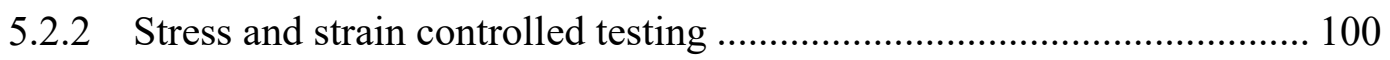

5.2.3 Enhancements to the small strain $(\gamma \mathrm{c}<0.01 \%)$ measurements.............. 101

5.2.4 Multistage strain controlled quasi-cyclic tests........................................ 104

5.3 Characteristics of secant shear modulus and damping ratio of clays ...... 106

5.3.1 Estimation of the secant shear modulus (Gs) and damping ratio $(\xi) \ldots . . . .106$

5.3.2 Estimation of the maximum shear modulus and modulus reduction values

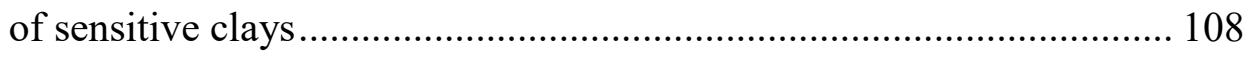

5.3.3 Modulus and damping characteristics of sensitive Leda clays ............... 111

5.3.4 Modulus reduction of sensitive clays...................................................... 118

5.3.5 Damping curves of sensitive clays........................................................ 119

5.3.6 Modulus reduction and damping curves of sensitive clay for engineering

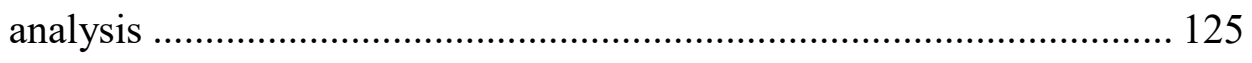

5.4 Characteristic of shear modulus and damping ratio of Fraser River sand .... 128

5.4.1 Stress-controlled quasi-cyclic tests on Fraser River sand...................... 128

5.4.2 Estimation of secant shear modulus (Gs), modulus reduction (Gs/Gmax)

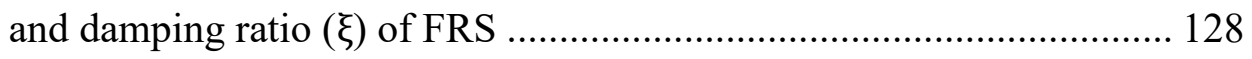

5.4.3 Characteristic of secant shear modulus (Gs) of Fraser River sand ......... 130

5.4.4 Modulus reduction and damping characteristic of Fraser River sand.... 133

5.4.4.1 Influence of relative density on modulus reduction and damping

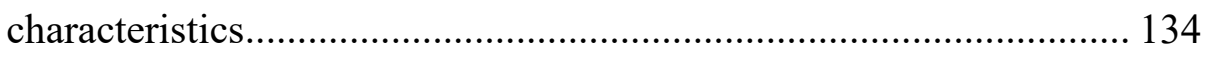

5.4.4.2 Influence of consolidation stress on modulus reduction and damping

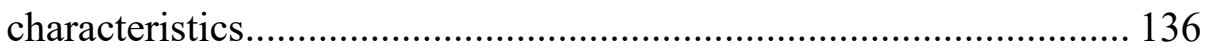

5.4.4.3 Influence of over consolidation ratio (OCR) on modulus reduction and damping characteristics................................................................. 138 
6 SUMMARY AND CONCLUSIONS.

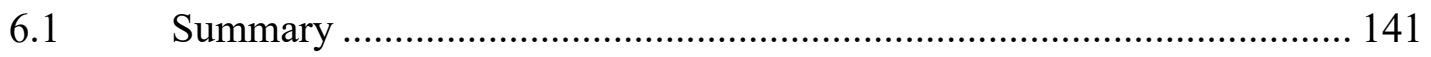

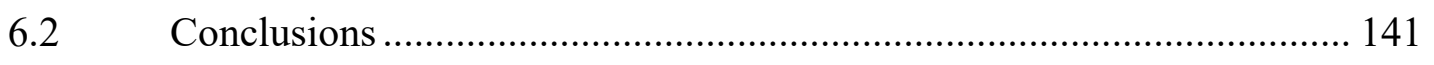

6.2.1 Undrained monotonic shear strength ............................................ 141

6.2.2 Undrained cyclic and post-cyclic shear strength.............................. 142

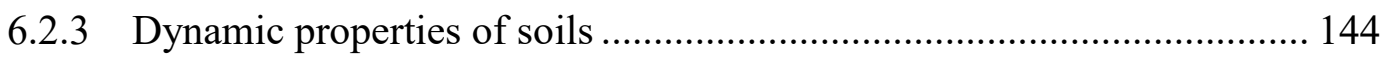

6.2.3.1 Modulus and damping characteristics of Sensitive Leda clays ......... 144

6.2.3.2 Modulus and damping characteristics of Fraser River sand .............. 145

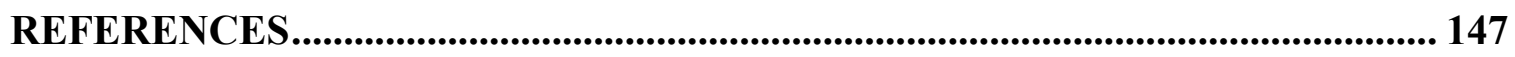




\section{List of Tables}

Table 2.1 Comparison of sensitivity index (after Kakoli, 2005) ................................. 13

Table 2.2 Influence of various factors on Gmax, Gs/Gmax, and $\xi$ of clays (modified after

Dobry and Vucetic, 1987)......................................................................... 39

Table 3.1 Details of monotonic tests on Leda clays .................................................. 52

Table 3.2 Details of cyclic tests on Leda clays ...................................................... 53

Table 3.3 Details of strain-controlled tests on Leda clays .......................................... 54

Table 3.4 Details of stress-controlled tests on Leda clays ........................................... 55

Table 3.5 Details of stress-controlled tests on Fraser River Sand ................................. 56

Table 3.6 Atterberg limits and other properties of Leda clays from different sites......... 57

Table 4.1 Comparison of strength reduction after multiple large quasi-cyclic shearing .. 77

Table 4.2 Undrained peak shear strength of OC and NC Leda clays ........................... 85

Table 4.3 Cyclic resistance ratio and normalized resistance ratio of 10 cycles.............. 91

Table 4.4 Comparison of $\mathrm{CRR}_{10}$ with calculated CSR ............................................... 91

Table 4.5 Comparison of the normalized peak shear strength $\left(S u / \sigma^{\prime} v c\right)$ and average normalized peak post-cyclic shear strength $\left(S u\left(\mathrm{P}_{-} \mathrm{CYC}\right) / \sigma^{\prime} v c\right) \ldots \ldots \ldots \ldots \ldots \ldots \ldots . . . . . . . . . . . . . .94$ 


\section{List of Figures}

Fig 1.1 Extensive deposits of sensitive Leda clay around Ottawa - Quebec area (modified after Quinn, 2009) ......................................................................................... 2

Fig 2.1 Recommendations to determine "liquefiable" soil types (after Seed et al., 2003) 10

Fig 2.2 Stress-strain curves for typical sensitive clay (after Skempton et al., 1952)....... 12

Fig 2.3 The cyclic stress-strain and effective stress path response of saturated clays (after Zergoun and Vaid 1994) ............................................................................. 14

Fig 2.4 Effective stress path moving to cyclic equilibrium below 70\% static shear strength (after Mitchell and King 1976) 16

Fig 2.5 Influence of plasticity index on threshold shear strain (after Hsu and Vucetic, 2006)

Fig 2.6 Influence of number of loading cycles and PI in cyclic behaviour (after Boulanger and Idriss, 2006 data from Romero 1995)................................................... 18

Fig 2.7 Relationship between number of equivalent uniform cycles and different magnitude of earthquakes (after Boulanger and Idriss, 2004)

Fig 2.8 Influence of initial effective confining pressure on generation of pore water pressure (after Mitchell and King 1976) ....................................................... 20

Fig 2.9 Influence of over-consolidation ratio in cyclic stress ratio (after Ishihara and

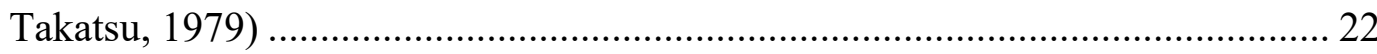

Fig 2.10 Representation of in-situ stress and simple shear loading (modified from Ha, 2003)

Fig 2.11 Load conditions along the potential failure surfaces (after Logeswaran, 2010) 24

Fig 2.12 Idealized stress-strain loop and secant shear modulus (after, Lanzo et al., 1997) 26

Fig 2.13 Factors affecting the shear (secant) modulus of sands (after Seed and Idriss, 1970) 
Fig 2.14 Differences in shear modulus of (a) Windsor clay and (b) Hamilton silt with consolidation pressure (after Kim \& Novak, 1981)........................................... 28

Fig 2.15 Factors influencing the shear modulus of sands and clays (after Lanzo et al., 1997) 28

Fig 3.1 Carleton University simple shear device ............................................................ 43

Fig 3.2 Computer interface of CU simple shear data acquisition program ..................... 44

Fig 3.3 Wire reinforced rubber membranes and platens for simple shear tests. (a) 70 and $63.5 \mathrm{~mm}$ diameter membranes; (b) Top \& bottom platens from left to right

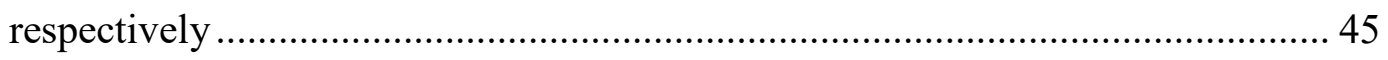

Fig 3.4 Soil lathe utilize to push the cutting ring into clay sample.................................. 47

Fig 3.5 A prepared clay sample for simple shear testing ................................................ 47

Fig 3.6 Preparation of a sample of Fraser River sand (a) siphoned off excess sand; (b) sample height from a digital dial gauge................................................................ 48

Fig 3.7 Sample setup after top and bottom pedestals were clamped firmly with their respective platforms and the split mould was removed..................................... 51

Fig 3.8 Particle size distributions of Leda clays from different sites............................... 58

Fig 3.9 Grain size distribution of Fraser River sand (after Logeswaran, 2010) ............... 59

Fig 4.1 Undrained monotonic behaviour of Leda clays under in-situ $\sigma^{\prime} v c$, (a) Stress strain behaviour (b) Stress path

Fig 4.2 Comparison of undrained monotonic behaviour of Leda clays at OC and NC states, (a) Stress-strain behaviour (b) Stress path 64

Fig 4.3 Comparison of normalized monotonic behaviour of Leda clays at OC and $\mathrm{NC}$ States, (a) Stress-strain behaviour, (b) pore- water pressure, (c) Stress path ....... 68

Fig 4.4 Comparison of monotonic behaviour of Kinburn clay at depth of $21 \mathrm{~m}$ and $11 \mathrm{~m}$, (a) Stress-strain behaviour (b) Stress path .......................................................... 70

Fig 4.5 Peak strength parameters of sensitive Leda clays ……………………….......... 73

Fig 4.6 Residual strength parameters of sensitive Leda clays ........................................ 75 
Fig 4.7 Typical monotonic behaviour of Outardes-2 clay during large strain quasi-cycles (a) Stress-strain response; (b) Stress path 78

Fig 4.8 Cyclic behaviour of OC Kinburn clay (a) $\tau c y c$ vs N; (b) PWP vs N; (c) $\gamma c$ vs N81

Fig 4.9 Cyclic behaviour of OC Kinburn clay (a) Stress-strain response; (b) Stress path 82

Fig 4.10 Normalized cyclic behaviour of Breckenridge clay (a) $\tau c y c$ vs N; (b) PWP vs N;

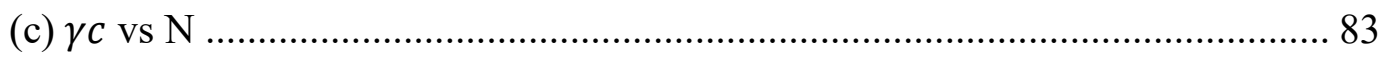

Fig 4.11 Normalized cyclic behaviour of Breckenridge clay (a) Stress-strain response; (b) Stress path 84

Fig 4.12 Comparisons of cyclic resistance of OC and NC Kinburn clays (a) CSR vs N \& (b) NSR vs N 87

Fig 4.13 Comparisons of cyclic resistance of OC and NC Breckenridge clay (a) CSR vs N

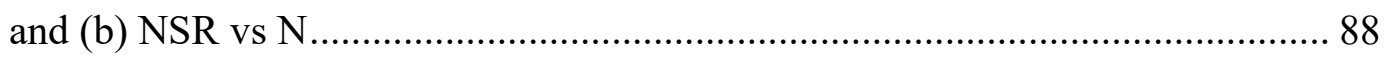

Fig 4.14 Comparisons of cyclic resistance of OC and NC Outardes-2 clays (a) CSR vs N

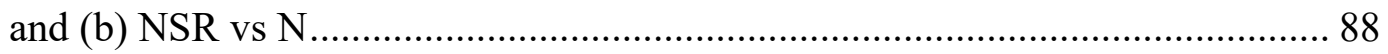

Fig 4.15 Comparison of cyclic resistance of OC Leda clays for different sites (a) CSR vs $\mathrm{N}$ and (b) NSR vs N..... 92

Fig 4.16 Comparison of cyclic resistance of NC Leda clays for different sites (a) CSR vs $\mathrm{N}$ and (b) NSR vs N. 92

Fig 4.17 Comparison of monotonic, cyclic and post-cyclic behaviour of OC Breckenridge clay. 95

Fig 4.18 Normalized post-cyclic monotonic behaviour of Breckenridge OC Leda clay (a) Stress-strain response; (b) PWP generation; (c) Stress path................................. 96

Fig 5.1 Comparison of stress-strain behaviour of Leda clays at single and multistage testing under $\sigma^{\prime} \mathrm{vc}$ of $400 \mathrm{kPa}$ 99

Fig 5.2 Comparison of stress-strain behaviour of Leda clays at single and multistage testing under $\sigma^{\prime} \mathrm{vc}$ of $800 \mathrm{kPa}$

Fig 5.3 Initial stress-strain loop slipped to one side without horizontal clamp 101

Fig 5.4 Diagram of (a) original single, and (b) new two points clamping mechanism of simple shear device. 102 
Fig 5.5 Carleton University simple shear device enhanced with horizontal clamp....... 103

Fig 5.6 Typical stress-strain loops for Fraser River Sand under cyclic loading of $0.5 \mathrm{kPa}$ ( $\gamma c$ around $0.0015 \%$ ) 103

Fig 5.7 Typical behaviour of Breckenridge Leda clay during quasi-cyclic shearing (a) stress-strain behaviour, (b) variation of pore water pressure and (c) stress path 105

Fig 5.8 Typical stress-strain loops obtained for Kinburn sample (21m) from strain controlled quasi-cyclic testing under $\sigma^{\prime} v c$ of $400 \mathrm{kPa}$. 107

Fig 5.9 Initial shear modulus changes with consolidation stress level 110

Fig 5.10 (a) Shear modulus and (b) normalized shear modulus of Kinburn clays $(\mathrm{z}=21 \mathrm{~m})$ under different $\sigma^{\prime} v c$ levels. 111

Fig 5.11 (a) Gs; (b) Gs/Gmax; and (c) $\xi$ of Kinburn clays $(\mathrm{z}=11 \mathrm{~m})$ under different $\sigma^{\prime} \mathrm{vc}$ levels 114

Fig 5.12 (a) Gs; (b) Gs/Gmax; and (c) $\xi$ of Kinburn clays $(\mathrm{z}=21 \mathrm{~m})$ under different $\sigma^{\prime} \mathrm{vc}$ levels 115

Fig 5.13 (a) Gs; (b) Gs /Gmax; and (c) $\xi$ of Breckenridge clays (z=26m) under different $\sigma^{\prime} \mathrm{vc}$ levels. 116

Fig 5.14 (a) Gs; (b) Gs/Gmax; and (c) $\xi$ of Outardes-2 clays (z=11m) under different $\sigma^{\prime}$ vc levels 117

Fig 5.15 (a) Modulus reduction and (b) Damping curves of Kinburn clays $(\mathrm{z}=11 \mathrm{~m})$ under different $\sigma^{\prime}$ vc levels 121

Fig 5.16 (a) Modulus reduction and (b) Damping curves of Kinburn clays ( $\mathrm{z}=21 \mathrm{~m})$ under different $\sigma^{\prime}$ vc levels 122

Fig 5.17 (a) Modulus reduction and (b) Damping curves of Breckenridge clays $(\mathrm{z}=21 \mathrm{~m})$ under different $\sigma^{\prime}$ vc levels 123

Fig 5.18 (a) Modulus reduction and (b) Damping curves of Outarded-2 clays $(\mathrm{z}=11 \mathrm{~m})$ under different $\sigma^{\prime}$ vc levels 124

Fig 5.19 Set of (a) Modulus reduction and (b) Damping curves of Kinburn, Breckenridge and Outardes-2 clays. 127 
Fig 5.20 Typical behaviour of FRS during stress-controlled quasi-cyclic loading (a) $\tau c y c$ with $\mathrm{N}$, (b) $\Delta u$ with $\mathrm{N}$ and (c) $\gamma c$ with $\mathrm{N}$ under $\sigma^{\prime} v c$ of $200 \mathrm{kPa}, \mathrm{Dr}$ of $50 \%$ and OCR of 2 . 129

Fig 5.21 Typical stress-strain loops obtained for FRS sample from stress controlled quasicyclic testing under $\sigma^{\prime} \mathrm{vc}$ of $100 \mathrm{kPa}$, Dr of $51 \%$ and OCR of 2

Fig 5.22 Variation of shear modulus of FRS at different $\sigma^{\prime} v c$ and OCR: (a) Dr - $50 \pm 3 \%$;

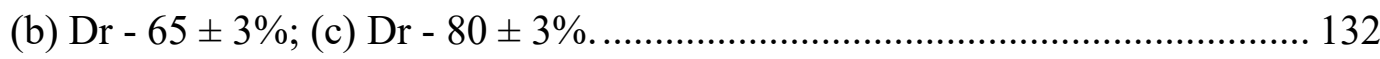

Fig 5.23 Initial shear modulus of FRS changes with consolidation stress level............ 133

Fig 5.24 Effect of relative density on (a) Gs/Gmax and (b) $\xi$ of Fraser River sand....... 135

Fig 5.25 Effect of consolidation stress on (a) Gs/Gmax and (b) $\xi$ of Fraser River sand 137

Fig 5.26 Effect of over consolidation ratio on (a) Gs/Gmax and (b) $\xi$ of Fraser River sand 


\section{List of Symbols}

\begin{tabular}{|c|c|}
\hline CSR & Cyclic stress ratio $\left(\tau_{c y c} / \sigma_{v c}^{\prime}\right)$ \\
\hline CRR & Cyclic resistance ratio \\
\hline$c^{\prime}$ & Effective cohesion \\
\hline$c_{r}^{\prime}$ & Effective cohesion at residual stress state \\
\hline$D_{r}$ & Relative density \\
\hline$e$ & Void ratio \\
\hline$G_{\max }$ & Maximum shear modulus \\
\hline$G_{S}$ or $G_{s e c}$ & Secant shear modulus \\
\hline$G_{\text {tan }}$ & Tangent shear modulus \\
\hline$K_{0}$ & Coefficient of earth pressure at rest \\
\hline LI & Liquidity index \\
\hline LL & Liquid limit \\
\hline LVDT & Linear variable differential transducer \\
\hline $\mathrm{N}$ & Number of loading cycles \\
\hline NBCC & National building Code of Canada \\
\hline $\mathrm{NC}$ & Normally consolidated \\
\hline NSR & Normalized stress ratio $\left(\tau_{c y c} / S_{u}\right)$ \\
\hline NRR & Normalized resistance ratio \\
\hline $\mathrm{OC}$ & Over-consolidated \\
\hline OCR & Over-consolidation ratio \\
\hline Ip & Plasticity index \\
\hline PL & Plastic limit \\
\hline PWP & Pore water pressure \\
\hline$S_{u}$ & Undrained shear strength \\
\hline$S_{u(r)}$ & Residual shear strength \\
\hline$S_{u(N)}$ & Normalized peak strength \\
\hline$S_{u\left(\mathrm{P}_{-} \mathrm{CYC}\right)}$ & Post-cyclic undrained shear strength \\
\hline $\mathrm{T}$ & Period \\
\hline
\end{tabular}




$\begin{array}{ll}v_{s} & \text { Shear wave velocity } \\ \mathrm{W}_{\mathrm{c}} & \text { Water content } \\ \mathrm{W}_{\mathrm{c} \_ \text {EoC }} & \text { Water content at end of consolidation } \\ \mathrm{z} & \text { Depth from ground surface } \\ \Delta u & \text { Excess pore water pressure } \\ \tau_{c y c} & \text { Cyclic shear stress } \\ \gamma & \text { Shear strain } \\ \gamma_{b} & \text { Bulk unit weight / density } \\ \gamma_{c y c} \text { or } \gamma_{c} & \text { Cyclic shear strain } \\ \gamma_{d} & \text { Dry unit weight / density } \\ \gamma_{m a x} & \text { Maximum shear strain } \\ \gamma_{t l} & \text { Threshold shear strain for linear behaviour } \\ \gamma_{t v} & \text { Threshold shear strain for volume change / pore pressure } \\ \delta & \text { Modulus degradation index } \\ \varepsilon_{v} & \text { Volumetric strain } \\ \xi & \text { Damping ratio } \\ \rho & \text { Density } \\ \sigma_{1} \& \sigma_{1}^{\prime} & \text { Major principal \& Effective major principal stress } \\ \sigma_{2} \& \sigma_{2}^{\prime} & \text { Intermediate principal \& Effective intermediate principal stress } \\ \sigma_{3} \& \sigma^{\prime}{ }_{3} & \text { Minor principal \& Effective minor principal stress } \\ \sigma_{m}^{\prime}{ }_{m} & \text { Effective mean confining stress } \\ \sigma_{v}^{\prime} & \text { Vertical effective stress } \\ \sigma_{v c}^{\prime} & \text { Vertical effective consolidation stress } \\ \sigma_{p}^{\prime} & \text { Pre consolidation stress } \\ \phi^{\prime} & \text { Effective internal angle of friction } \\ \phi_{p}^{\prime} & \text { Effective internal angle of friction at peak stress state } \\ \phi_{r}^{\prime} & \text { Undrained friction angle } \\ \phi_{u} & \end{array}$




\section{INTRODUCTION}

\subsection{Background}

Earthquake is one of the natural hazards that destroys billions of dollars' worth of properties and kills countless lives annually. Recently the 2015 Nepal earthquake $\left(M_{w}=7.8\right)$ demolished many historical sites and earth structures, and killed more than 8000 people. Earthquakes also trigger secondary disasters like landslides, lateral spreading and soil liquefaction etc. Therefore it is very important to assess the possibility of soil failure during seismic events, particularly in sites that are within earthquake prone region, consists problematic soils (e.g. loose sands, sensitive clays), within the heavily populated area (Eastern Canada) or associated with sensitive structures (e.g., nuclear plant).

Sensitive clays can be found in Eastern Canada and other parts of the world such as Sweden, Norway and South East Asia. Eastern Canada has extensive deposits of sensitive clay along the St. Lawrence River and the Ottawa valley as seen in the Fig. 1.1. This clay is generally referred to as 'Leda Clay' or 'Champlain Sea Clay'. This sensitive clay deposits were created under marine conditions of ancient Champlain Sea, which existed for about 4,000 years (from 12,000 years B.P. to 8,000 years B.P) following the last continental glaciation (Karrow, 1961; Gadd, 1962; Crawford, 1967; Locat et al., 1985). Around that period the sea level was noted near the Ottawa region which was around $226 \mathrm{~m}$ above the current sea level (Kenney, 1964; Johnston, 1917). 


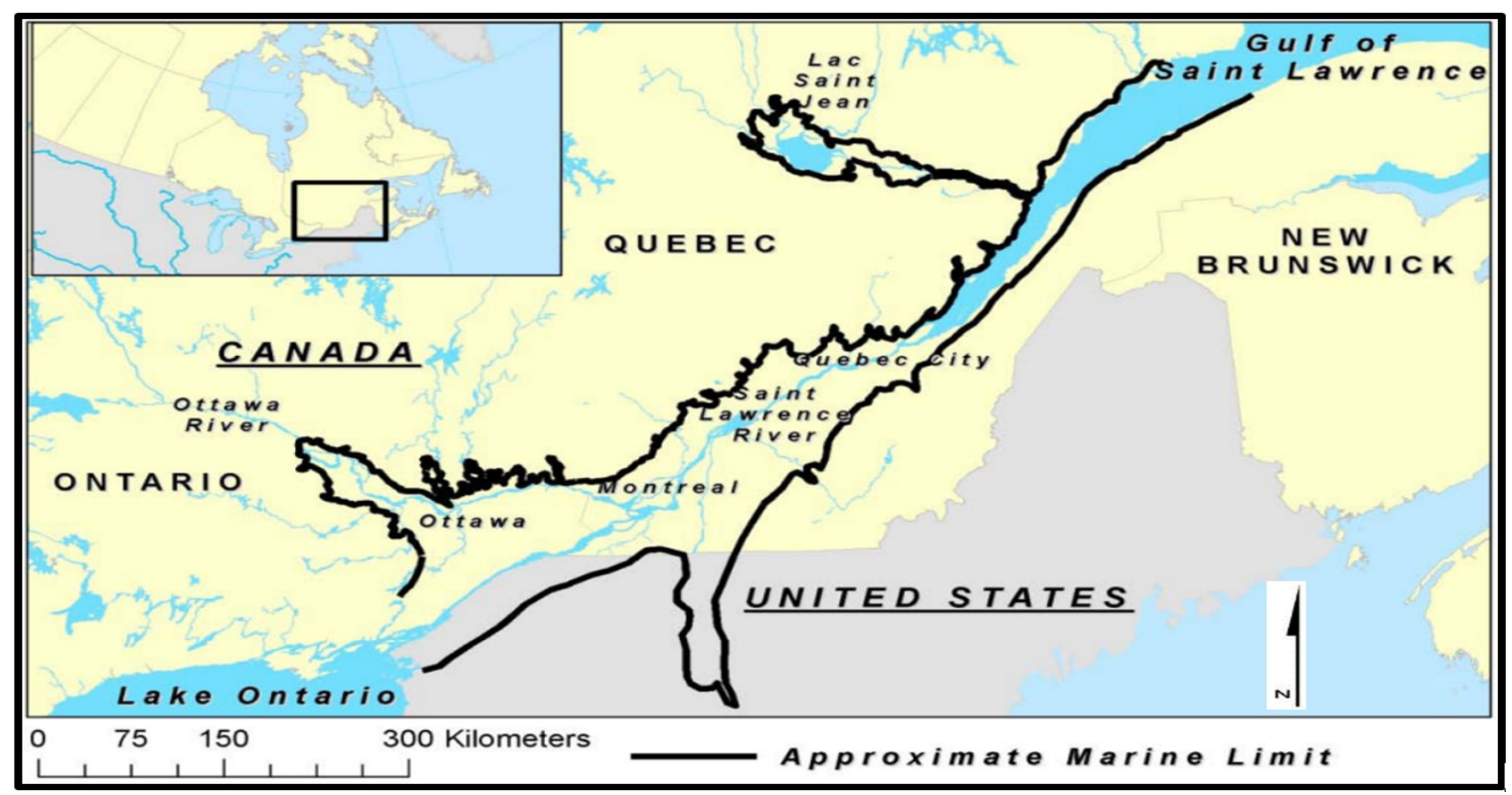

Fig 1.1 Extensive deposits of sensitive Leda clay around Ottawa - Quebec area (modified after Quinn et al, 2007)

Sensitive clay is one of the problematic soil types in geotechnical practice, because the shear strength of sensitive clay is highly dependent on its undisturbed structure. When its structure is remoulded or disturbed, sensitive clay rapidly loses its shear strength (Skempton et al., 1952). This process may lead to extensive differential settlement and catastrophic failure of earth structures during cyclic loading events such as earthquakes.

The earthquake in Saguenay, Quebec in 1988 is the largest earthquake in Eastern Canada in recent times and it had a magnitude, $M_{w}=6$. Apart from this, other smaller magnitude earthquakes have also caused significant threat to the structures founded on sensitive Leda clays. For instance, the epicenter of the Val des Bois earthquake in 2010 which had a magnitude of $M_{w}=5$ was just over $50 \mathrm{~km}$ from Ottawa, and the resulting ground shaking caused damage to some buildings and roadways.

Due to the vulnerability of sensitive Leda clays and the recent recognition of the importance of seismic risk in this region (NBCC, 2005), researchers are more concerned about 
evaluating the performance of Eastern Canadian sensitive clays under seismic loading. Especially those near the populated regions or supporting critical infrastructure.

Several studies have been carried out on sensitive Leda clays over the years to investigate the strength properties (e.g. Sangrey et al., 1969; Lee, 1979; Lefebvre et al., 1989; Lefebvre and La Rochelle, 1974; Eden and Mitchell, 1970; Silvestri et al., 1989). Most of the researchers reported significant variance in the strength properties of Leda clays from one location to another, particularly Eden and Mitchell (1970), and Mitchell (1975) reported different strength properties and failure modes for Leda clays obtained from Eastern Canada. Similarly, Lee (1979) reported considerable differences in the sensitivity of Leda clays collected closely around Outardes. Recently, Rasmussen (2012) and Theenathayarl (2015) reported significant variance in stiffness properties of Leda clay compared to the published data (Vucetic and Dobry, 1991). A review of the literature clearly indicated the need to conduct further material/site-specific investigations to obtain accurate and reliable strength and stiffness properties of sensitive Leda clays for geotechnical analysis.

Undisturbed sensitive clay samples obtained from three different sites in Ontario and Quebec provided the samples for this research. Kinburn site is situated near the heavily populated Ottawa area and has very thick Leda clay deposits ( $\sim 120 \mathrm{~m}$ thick clay layer). Breckenridge site is located near Gatineau on the other side of Ottawa River from the Kinburn site, and Outardes-2 material was obtained from a site near the Saguenay region in Quebec.

Simple shear testing is considered to be more appropriate to evaluate liquefaction susceptibility of soils in the laboratory environment, because it closely replicates the field loading condition due to the vertical propagation of shear waves during earthquake shaking. 


\subsection{Objectives}

The primary objective of this laboratory investigation is to improve the current understanding and advance the knowledge of undrained monotonic, cyclic and post-cyclic behaviour of sensitive clays, and to establish properties for dynamic analysis. In addition to measuring the monotonic and cyclic deformation characteristics of clays, soil properties required for dynamic analysis (modulus reduction and damping curves) were determined for the sensitive clays and Fraser River sand. These are critical input parameters for soil modeling and ground response analysis. Further, feasibility of measuring small cyclic shear strains $\left(\gamma_{c y c}<0.01 \%\right)$ using the Carleton university simple shear device (which was recently enhanced by Theenathayarl, 2015) would be critically assessed. Samples obtained from sensitive clay sites in Kinburn, $(\mathrm{ON})$, Breckenridge (QC) and Outardes-2 (QC), and from the granular deposits in the Fraser River Delta in BC were tested under simple shear.

This experimental study will also assess the influence of different consolidation stress, $\sigma_{v c}^{\prime}$ (at in-situ over consolidated and normally consolidated stress levels), plasticity index (Ip), and sensitivity $\left(S_{t}\right)$ on the undrained monotonic and cyclic behaviour of Leda clays, and on modulus reduction and damping characteristics. The effects of partial-remoulding on the shear strength of Leda clays, and the post-cyclic monotonic behaviour of Leda clays will be evaluated as well.

Material specific shear modulus reduction and damping ratio curves will be established for sensitive clays and its dependence on different $\sigma_{v c}^{\prime}$, Ip and $S_{t}$ will be assessed. These site specific results will be compared to the data that is widely used by practicing engineers in the region (Vucetic and Dobry, 1991). Influence of different consolidation stress $\left(\sigma_{v c}^{\prime}\right)$, relative density (Dr), and over consolidation ratio (OCR) on shear modulus 
reduction and damping ratio of Fraser River sand also will also be evaluated and the results will be compared to the data reported by Seed and Idriss (1970).

\subsection{Organization of Thesis}

Following this introductory chapter, chapter 2 presents a critical review of the related literature and highlights the significance and importance of this research. A detailed discussion is presented in this chapter regarding the soils liquefaction, characteristics of sensitive clays, and monotonic/cyclic behaviour of soils. Furthermore, an overview of the dynamic properties of soils that are necessary to carry out ground response analysis is discussed and finally the importance of the site-specific cyclic analysis is briefly highlighted.

Details of the experimental program are presented in Chapter 3. It provides information about the Carleton University simple shear device, characteristics of the material used, sample preparation techniques and test procedures. Further, details and geotechnical properties of the material tested are also discussed in this section.

Chapter 4 discusses the undrained monotonic, cyclic and post-cyclic behaviour of material specific Leda clays and influence of different consolidation stresses, and also discusses the strength reduction characteristics. The recent modifications to the Carleton University simple shear device to facilitate small strain testing, and enable confident measurements of modulus and damping characteristics are discussed in chapter 5. Finally the conclusions arrived from the research program are presented in chapter 6 . 


\section{LITERATURE REVIEW}

\subsection{Introduction}

Soils are subjected to undrained cyclic loading during earthquakes and consequently might lose their shear strength. The loss can be partial or complete, and the latter is commonly referred to as liquefaction. As a result, man-made structures founded on soils will be exposed to stability problems such as unpredicted deformations, settlement or catastrophic collapse due to earthquakes. Therefore, an assessment of the undrained cyclic behaviour and a better understanding of the dynamic properties of soils will help in the design of seismic resistant earth structures such as foundations, dams, bridges, and retaining structures. Further, evaluation of liquefaction is very vital in sites located within earthquake prone regions or heavily populated areas (e.g., eastern Canada) or that consist problematic soils (e.g. sensitive clays).

\subsection{Liquefaction}

The term liquefaction was originally used within the discipline to characterize unlimited deformation in soils following monotonic or cyclic loading. It was generally associated with the behaviour of granular material (Castro, 1969; Ishihara, 1996; Vaid and Chern, 1985), but in current practice it has been used in various contexts as noted below. Progressive generation of excessive pore water pressure leads to liquefaction (and the associated deformations) under cyclic loading. Many historical liquefaction failures have been well documented by several researchers (Seed et al., 1975; Boulanger et al., 1998; Finn et al., 1991; Ishihara et al., 1996). Modern engineering assessment and treatment of cyclic shear strength reduction of soil (or soil liquefaction) was initiated in geotechnical 
engineering practice after two devastating earthquakes in 1964; the Niigata (Japan) and Great Alaskan Earthquakes.

In general, clean sands and soils with small amounts of fines were considered as liquefiable soils, and clayey and silty soils were considered as 'non-liquefiable' soils (Thiers and Seed, 1969; Seed et al., 1983). The term has evolved in the literature and in current practice it encompasses large deformations in both granular and cohesive soils due to dynamic loading. Extensive data collected during earthquakes and experimental studies provided lessons and more awareness about liquefaction of both cohesive and granular soils. Further, increased attention was also paid to the post-cyclic strength (Vaid and Thomas, 1995; Vaid and Sivathayalan, 1996) and deformation behaviour following liquefaction in recent years (Seed et al., 2003; Sivathayalan and Ha, 2011).

Liquefaction vulnerability of soils can be evaluated using in-situ field tests, laboratory tests or even by using empirical correlations. However, fundamental understanding of the phenomenon can only be derived from experimental investigations in the laboratory. Laboratory studies can be meaningful only if they accurately simulate the in-situ material (fabric, density) and loading (stress state, stress path) characteristics. It is well recognized that laboratory testing conducted on high-quality undisturbed specimens (or on reconstituted specimens that have representative fabric) under simple shear loading are among the most suitable to study the response of natural soils during earthquakes.

\subsubsection{Liquefaction of sands}

Liquefaction potential of sands have been investigated widely and plenty of experimental studies have been carried out for a better understanding of liquefaction phenomena of sandy 
soils under both monotonic and cyclic loading conditions (Castro, 1969; Peacock et al., 1968; Castro, 1976; Finn et al., 1991; Vaid and Chern, 1985; Ishihara, 1993; Vaid and Sivathayalan, 1996). Furthermore, leading experts gathered at the National Center for Earthquake Engineering Research workshop (NCEER, 1996) to review the state of practice and recent developments in the assessment of liquefaction resistance of sand. Also they proposed the well documented NCEER guidelines (Youd et al., 2001). This is a wellreviewed and recognized documentation to assess liquefaction potential of sandy soils.

\subsubsection{Liquefaction of cohesive soils}

Clayey soils are fundamentally different than sands and behave differently when they are subjected to monotonic or cyclic loading. Therefore the criteria developed to assess the liquefiable potential of sands are not adequate to evaluate the liquefiable potential of clayey soils. Different techniques are required to assess dynamic characteristics and liquefaction potential of clayey soils.

Initial understanding and findings of clayey soils revealed that they have no potential to liquefy (Thiers and Seed 1969; Seed, 1979). However, Wang (1979) reported that finegrained soils are liquefiable based on observations and data gathered during strong earthquakes that happened in different parts of China. The "Chinese criteria" based on Wang's research has been widely used to assess the liquefaction potential of silts and clays since the early 1980s (Boulanger and Idriss, 2006).

Wang's criteria indicated that if a clayey soil satisfies the following three criteria, it may be susceptible to "liquefaction" (i.e., significant strength loss under earthquake loading) 
- $\quad$ Percent finer than $0.005 \mathrm{~mm}<15 \%$;

- $\quad$ Liquid Limit $(\mathrm{LL})<35$;

- Water Content $>0.9$ Liquid Limit.

However, further experience with more recent earthquakes (e.g. 1994 Northridge, 1999 Kocaeli, and 1999 Chi-Chi) and follow-on studies exposed the limitation of above criteria. Observations proved that "percent of clay fines" is not one of the dominant factors to assess the liquefiability of clayey soils since there is strong evidence of liquefactions in finegrained soils with more than $15 \%$ clay-sized particles. Therefore it was recommended that the fraction of "clay mineral" is more appropriate than the percentage of "clay-size" particles (Seed et al., 2003; Bray et al., 2004 (a), 2004 (b); Boulanger and Idriss, 2006).

Seed et al (2003) proposed new criteria for liquefaction potential of fine soils based on previous experimental studies, reviews and past case histories. Their assessment has proposed three main zones (Zone A, B and C) of soils as seen in Fig 2.1. If soils satisfy the Zone A criteria, then the particular soil is vulnerable to liquefaction under cyclic loading. If soil within the Zone B, then the particular soil may be liquefy, however further laboratory tests are required if the water content is $\left(\mathrm{w}_{\mathrm{c}}\right) \geq 0.85$ Liquid Limit (LL). If soil falls in Zone C (Not within the Zone A or B) then the soil has no potential for liquefaction. However, loss of strength due to remoulding is a concern if the soil is sensitive (Seed et al 2003). Therefore, the chart (Fig 2.1) is not fully applicable to sensitive clays.

Still, there are uncertainties, limitations and difficulties remain in the existing criteria of liquefaction vulnerability assessment of fine-grained soils (Boulanger and Idriss, 2006). Therefore, conducting laboratory testing on undisturbed clayey samples could provide 
more reliable information and enable confident evaluation of liquefaction susceptibility in clayey soils. (Seed et al., 2003; Boulanger and Idriss, 2006).

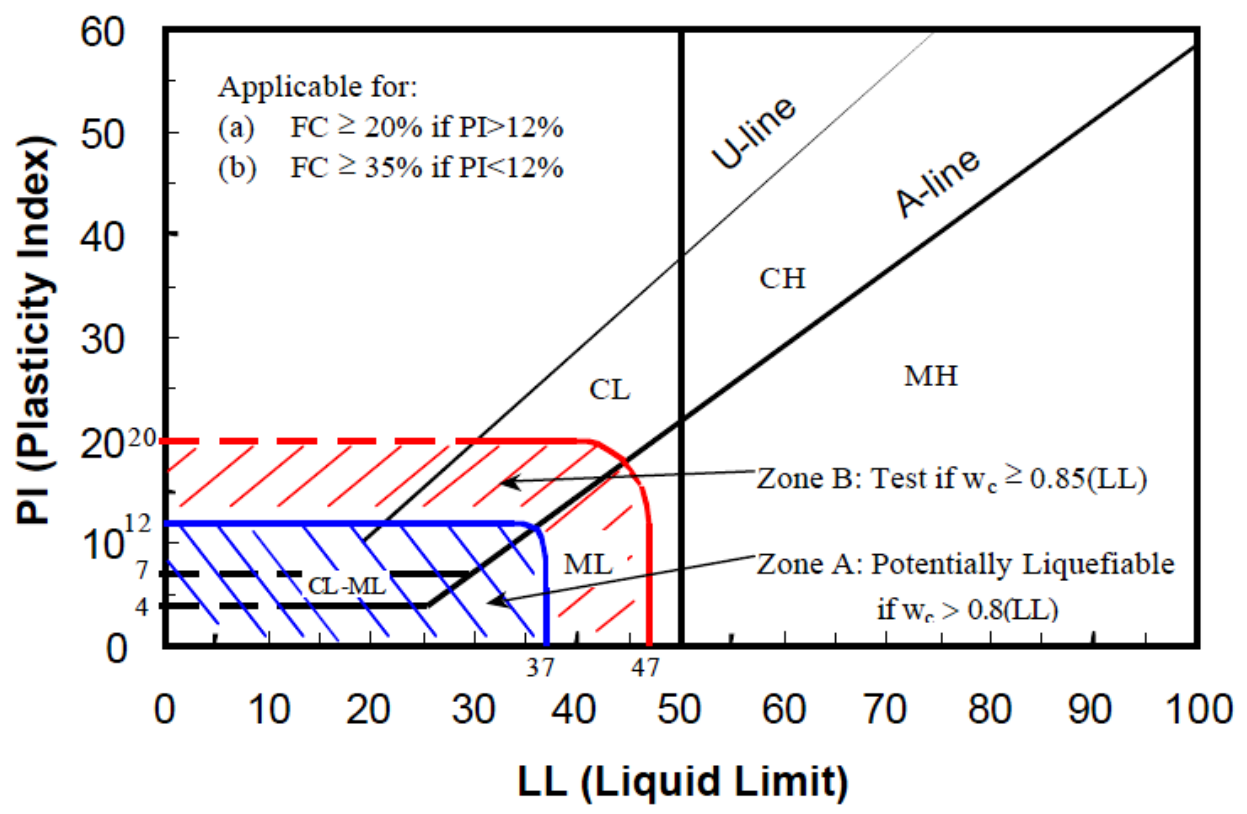

Fig 2.1 Recommendations to determine "liquefiable" soil types (after Seed et al., 2003)

\subsection{Sensitive clay}

Significant loss of shear strength may result in some clays if their natural structure is disturbed or damaged (Skempton et al., 1952; Craig, 2004). Such clays are termed sensitive clays, and treated as a problematic soil because of the potential for catastrophic failure due to remoulding. Such failures can occur on account of the deformation during undrained cyclic loading. The behaviour of sensitive clay is generally governed by three basic factors: depositional environments, geological and stress histories (Locat et al., 1985).

\subsubsection{Mechanical behaviour of sensitive clays}

Research on post-glacial clay from the Thames estuary by Skempton and Northey (1952) clearly highlighted the significant strength reduction in remoulded sample compared to 
undisturbed sample at identical water content (Fig 2.2). They suggested that mineralogy, particle size distribution, thixotropic and microstructural stability should be considered when dealing with sensitive clays. Mechanical behaviour of both chemically treated and untreated silty clays (Outardes-2) were studied under triaxial and simple shear condition by Loiselle et al. (1971). They reported that the stiffness of clay is marginally altered due the absence of cementation but it did not affect the outcome of failure. Further, they stated that there was no improvement in the strength (except under low consolidation pressure) because the cementing bonds were broken most of the time within small strains. A thorough study of the geochemical properties and sensitivity of Norwegian marine clay was carried out by Mourn et al (1971). According to their study, magnesium content in the pore water is the main factor which separates the quick clays and non-quick clays. Quick clays had magnesium contents less than $20 \mathrm{mg} /$ liter and non-quick clays had magnesium contents greater than $100 \mathrm{mg} /$ liter. Further, variance in the concentration of magnesium chloride might also influence the degree of sensitivity.

Torrance (1999) investigated the rheological response of remoulded sensitive clay which was obtained from the 1971 South Nation River landslide site using a coaxial viscometer and reported that remoulded behaviour of Leda clay is mainly controlled by physical, chemical and mineralogical factors. Also his study showed that the complicated relations between grain-size distribution, pore-water chemistry, mineralogy and other factors influenced the rheological response of sensitive marine clays. 


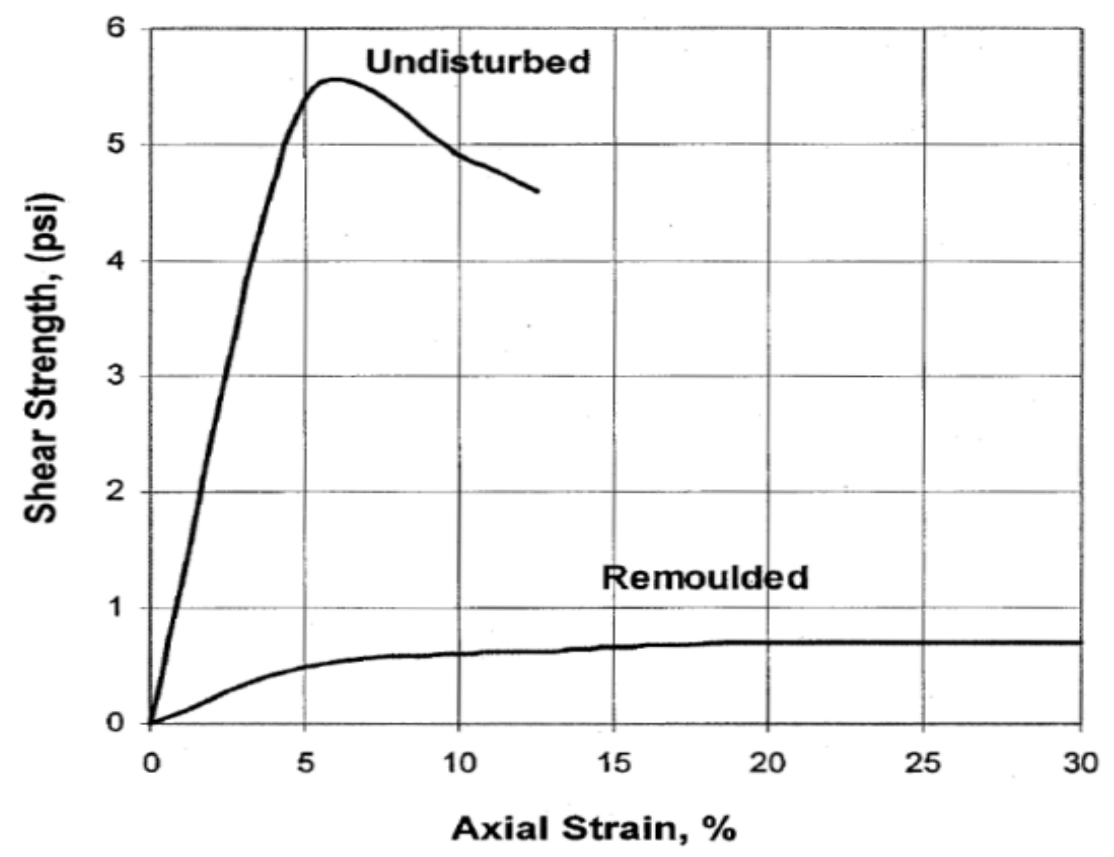

Fig 2.2 Stress-strain curves for typical sensitive clay (after Skempton et al., 1952)

\subsubsection{Sensitivity Index}

"Sensitivity" index $\left(S_{t}\right)$ is a dimensionless number which is the ratio of the shear strength of the undisturbed soil to the shear strength of the remoulded soil, as expressed in the following equation (Skempton et al., 1952).

$$
S_{t}=\frac{\text { Undisturbed shears strength }}{\text { Remoulded shear strength }}=\frac{S_{u}}{S_{u(r)}}
$$

In general, most clay's sensitivity is measured between 1 and 4 and Skempton et al considered sensitivity index between 4 and 8 as sensitive clay; the sensitivity index between 8 and 16 is referred as high sensitive clay; and sensitivity index above 16 is considered as quick clay (Skempton et al., 1952; Craig, 2004). Several classifications for sensitivity index have been proposed by several researchers. Table 2.1 presents a comparison of few 
classifications of sensitivity that are widely quoted (e.g. Skempton et al., 1952; Rosenqvist, 1953; Shannon et al., 1964; Rankka et al., 2004).

Table 2.1 Comparison of sensitivity index (after Kakoli, 2005)

\begin{tabular}{|c|c|c|c|c|c|}
\hline \multicolumn{2}{|c|}{$\begin{array}{l}\text { Skempton and Northey } \\
1952\end{array}$} & \multicolumn{2}{|c|}{$\begin{array}{c}\text { Rosenqvist } \\
1953\end{array}$} & \multicolumn{2}{|c|}{$\begin{array}{c}\text { Shannon and Wilson } \\
1964\end{array}$} \\
\hline $\mathrm{S}_{\mathrm{t}}$ & Classification & $\mathrm{S}_{\mathrm{t}}$ & Classification & $\mathrm{S}_{\mathrm{t}}$ & Classification \\
\hline$\sim 1$ & Insensitive & $\sim 1$ & Insensitive & $<3$ & Low \\
\hline $1-2$ & Low sensitive & $1-2$ & Slightly sensitive & $3-5$ & Low to medium \\
\hline $2-4$ & Medium sensitive & $2-4$ & Medium sensitive & $5-7$ & Medium \\
\hline $4-8$ & Sensitive & $4-8$ & Very sensitive & $7-11$ & Medium to high \\
\hline$>8$ & Extra sensitive & $8-16$ & Slightly quick & $11-14$ & High \\
\hline$>16$ & Quick & $16-32$ & Medium quick & $20-40$ & Very high \\
\hline & & $32-64$ & Very quick & $>40$ & Extremely high \\
\hline & & $>64$ & Extra quick & & \\
\hline
\end{tabular}

\subsection{Undrained cyclic behaviour of soil}

Soils are exposed to cyclic undrained loading during earthquakes and the cyclic deformation primarily depends on the magnitude, frequency content and time duration of the earthquake and the distance to the epicenter (Ansal, 1989). Further, the undrained response of the soil to a given earthquake varies from one site to another since soil behaviour depends on many parameters.

Extensive experimental and field studies have been carried out to evaluate the cyclic behaviour of soils in terms of stress-strain response, effective stress path and excess pore pressure generation (e.g. Sangrey et al., 1969; Anderson et al., 1988; Malek et al., 1989; Zergoun and Vaid, 1994; Ishihara, 1996; Boulanger and Idriss, 2004). 
Zergoun and Vaid (1994) studied the cyclic behaviour of normally consolidated Cloverdale clay subjected to undrained cyclic loading in triaxial condition. They noticed that continuous cyclic loading rapidly generates excess pore water pressure and simultaneously reduces the effective stress and leads to failure. During the cyclic loading, shear strain increases with the number of load cycles and it caused a significant reduction in the stiffness (shear modulus). Further, stress-strain hysteresis loops progressively enlarge in size as seen in Fig 2.3(a). In addition, effective stress path moves towards the origin of the stress axes until it hit the failure envelopes (Fig 2.3b).
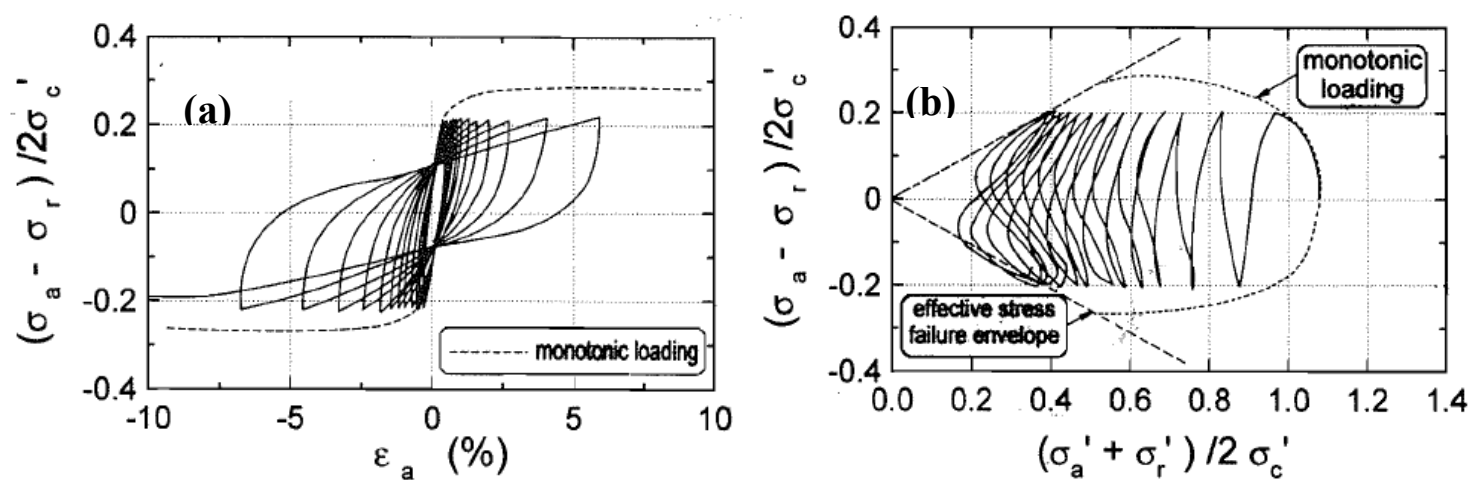

Fig 2.3 The cyclic stress-strain and effective stress path response of saturated clays (after Zergoun and Vaid 1994)

\subsubsection{Cyclic shear stress amplitude}

Cyclic shear stress amplitude $\left(\tau_{c y c}\right)$ is a dominant parameter that strongly influences the cyclic behaviour of soils and many researchers have studied the influence of $\tau_{c y c}$ on cyclic behaviour of soils. The concept of threshold cyclic stress has been proposed by many researchers (e.g. Larew et al., 1962; Sangrey et al., 1969; Mitchell and King, 1976; Lefebvre et al., 1989; Wichtmann et al., 2013). Lefebvre et al. (1989) defined the threshold cyclic stress as "the maximum cyclic stress level at which the soil will not suffer failure 
regardless of the number of applied cycles". Similarly, Ansal and Erken also reported that there was no excess pore water pressure generation below the threshold $\tau_{c y c}$ amplitude.

The behaviour of moderately sensitive clays subjected to repeat cyclic loading was studied by Sangrey et al. (1969) under triaxial condition. This study revealed that a critical level of repeated $\tau_{c y c}$ existed for any specific consolidation stress history. Further, soil may reach a non-failure elastic equilibrium below this critical level of stress and above which failure may happen. This finding is similar to the concept of a 'critical level of repeated deviatoric stress' reported by Larew and Leonards (1962).

Cyclic behaviour of Champlain Sea clays was investigated by Mitchell and King (1976) under stress controlled triaxial condition. They noticed that $\tau_{c y c}$ higher than the $70 \%$ of the static shear strength $\left(S_{u}\right)$ of soil generated large deformations and consequently led to shear failure. Further, an equilibrium condition was achieved when $\tau_{c y c}$ was less than $70 \%$ of $S_{u}$ as seen in Fig 2.4. Raymond et al, (1979) and Zergoun et al, (1994) also reported that the Canadian sensitive clays' threshold shear strength value is about $55 \%$ of its static shear strength. In addition, several marine clays were investigated by Houston and Herrmann (1980) under cyclic triaxial condition and they broadly stated that threshold $\tau_{c y c}$ values varied from $18 \%$ to $90 \%$ of $S_{u}$. Also, they reported that the stability threshold is higher for clays with high plasticity and decreases with decreasing plasticity index (Ip) values. Experimental study by Lefebvre et al (1989) on Hudson Bay region sensitive clay under the cyclic triaxial condition revealed that the stability threshold (cyclic stress amplitude) is about $60-65 \%$ of $S_{u}$. 


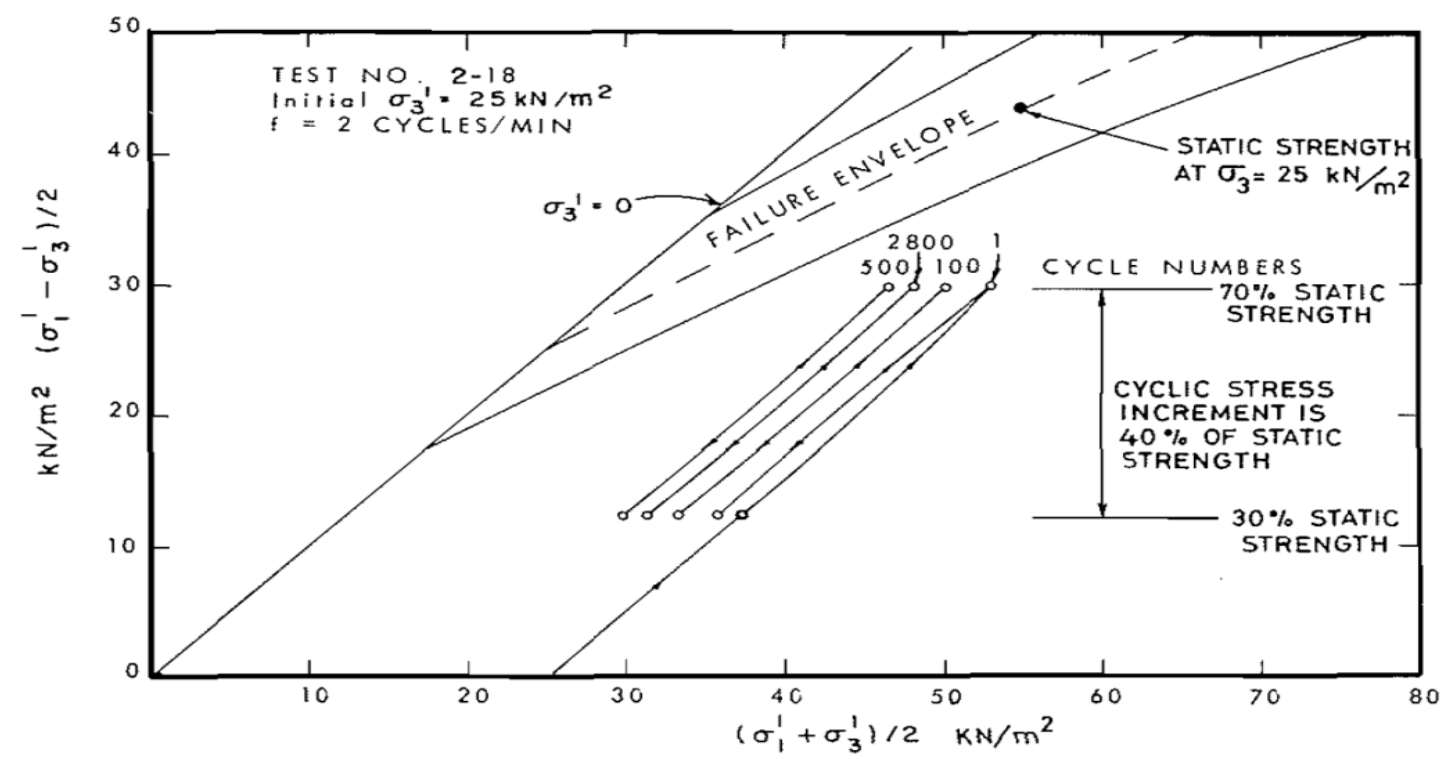

Fig 2.4 Effective stress path moving to cyclic equilibrium below 70\% static shear strength (after Mitchell and King 1976)

\subsubsection{Cyclic shear strain amplitude}

Clearly both cyclic shear stress and strain $\left(\gamma_{c}\right)$ are inter-related, but some researchers have paid attention to the strain amplitudes. Mitchell and King (1976) reported that Ottawa area clays did not fail if $\gamma_{c}$ is less than $1 \%$; and $\gamma_{c}$ between 3 and $6 \%$ created visual observation of failures and further catastrophic failures happened at $\gamma_{c}$ between 15 and $25 \%$.

Research efforts have focused on determining a threshold strain amplitude $\left(\gamma_{t}\right)$ that is required to cause failure under cyclic loading (similar to the concept of threshold cyclic stress amplitude). If $\gamma_{c}$ is less than the threshold $\gamma_{t}$ then the changes in pore water pressure will be insignificant with increasing number of loading cycles $(\mathrm{N})$. On the other hand if $\gamma_{c}$ is greater than $\gamma_{t}$ then the changes in cyclic pore water pressure will be rapid and significant with increasing N (Hsu and Vucetic, 2006). Cohesive and cohesion-less soils were studied by Hsu and Vucetic (2006) under direct simple shear condition. Their tests results 
demonstrated that cohesive soils has higher $\gamma_{t}$ than cohesion-less soils, and $\gamma_{t}$ values increases with plasticity index (Ip). Further, they reported amplitude of $\gamma_{t}$ varied from 0.025 to $0.06 \%$ for $\mathrm{Ip}=14$ to 30 and 0.01 to $0.02 \%$ for sands and gravels (Fig. 2.5). In addition, they revealed that confining stress does not influence $\gamma_{t}$ of plastic silts and clayey soils.

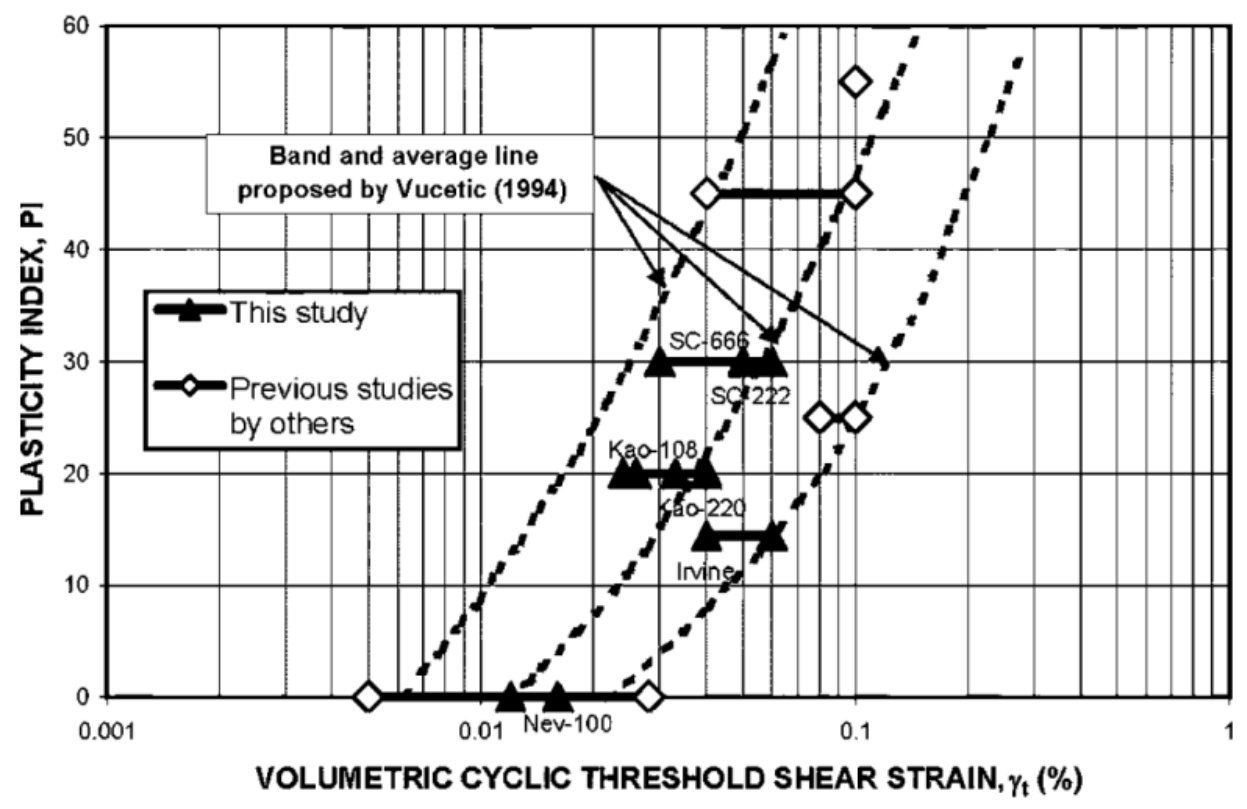

Fig 2.5 Influence of plasticity index on threshold shear strain (after Hsu and Vucetic, 2006)

\subsubsection{Influence of number of load cycles in cyclic behaviour}

Number of load cycles $(\mathrm{N})$ expected at a site is normally dependent on the magnitude of the earthquake. Liquefaction resistance is usually quantified as the intensity of cyclic loading that the soil can withstand for the given number of load cycles. This is often quantified by the cyclic stress ratio (CSR) which is the ratio of cyclic shear stress to effective consolidation stress $\left(C S R=\tau_{c y c} / \sigma_{v c}^{\prime}\right)$. Another parameter that has been used to characterize the cyclic resistance of clays is the normalized stress ratio, NSR which is the 
ratio of cyclic shear stress to undrained peak shear strength $\left(N S R=\tau_{c y c} / S_{u}\right)$. Geotechnical engineers would be interested to know the correlation between CSR and N (or NSR and N) for analytical and design purpose.

Boulanger and Idriss (2006) studied the relationship between $\mathrm{N}$ and cyclic strength parameters for normally consolidated silt samples with different Ip values. They reported that cyclic stress ratio and normalized stress ratio decreased with increasing N. Further, for a given $\mathrm{N}$, the cyclic resistance (in terms of stress ratios or normalized stress ratio) increasing with Ip values as presented in the Fig. 2.6(a) and (b).

Relationships between the magnitude of earthquakes $\left(\mathrm{M}_{\mathrm{w}}\right)$ and $\mathrm{N}$ have been proposed by many researchers (Seed and Idriss, 1982; Idriss, 1999). Fig. 2.7 shows that $\mathrm{N}$ nonlinearly increases with $\mathrm{M}_{\mathrm{w}}$. Typically, $\mathrm{N}$ ranging from 1 to 100 is important for cyclic investigation.
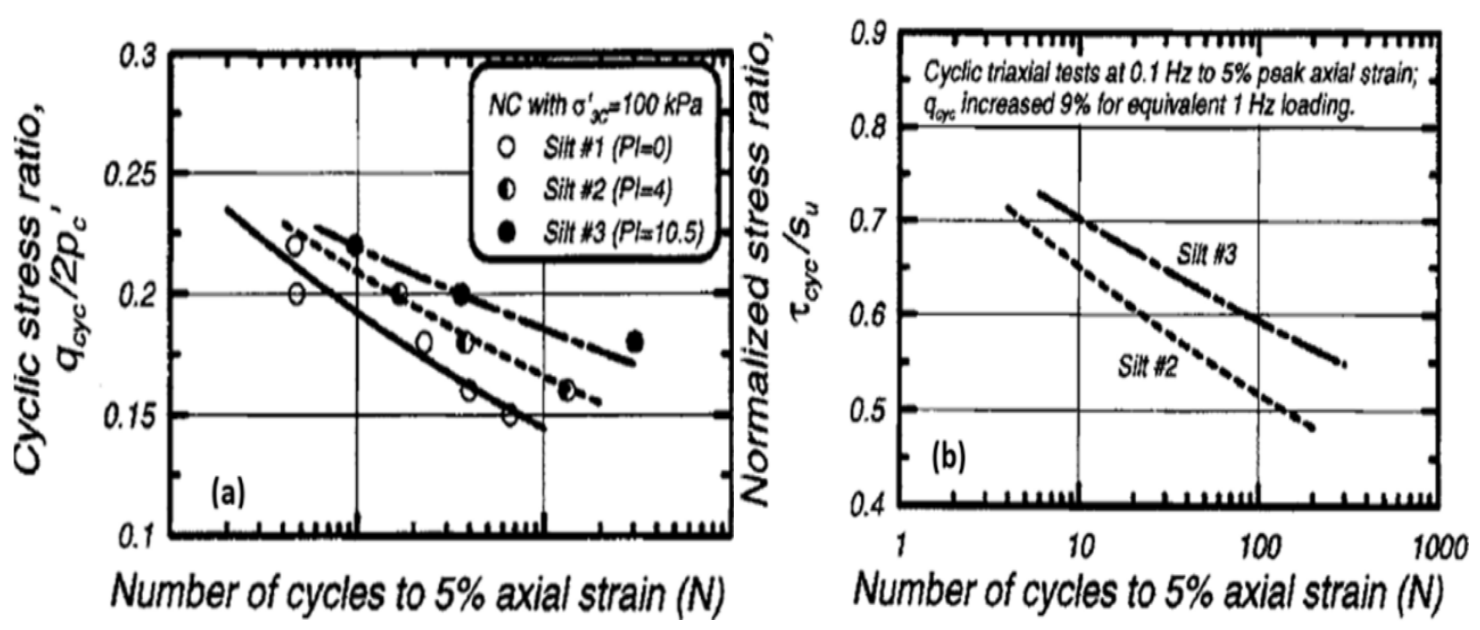

Fig 2.6 Influence of number of loading cycles and PI in cyclic behaviour (after Boulanger and Idriss, 2006 data from Romero 1995). 


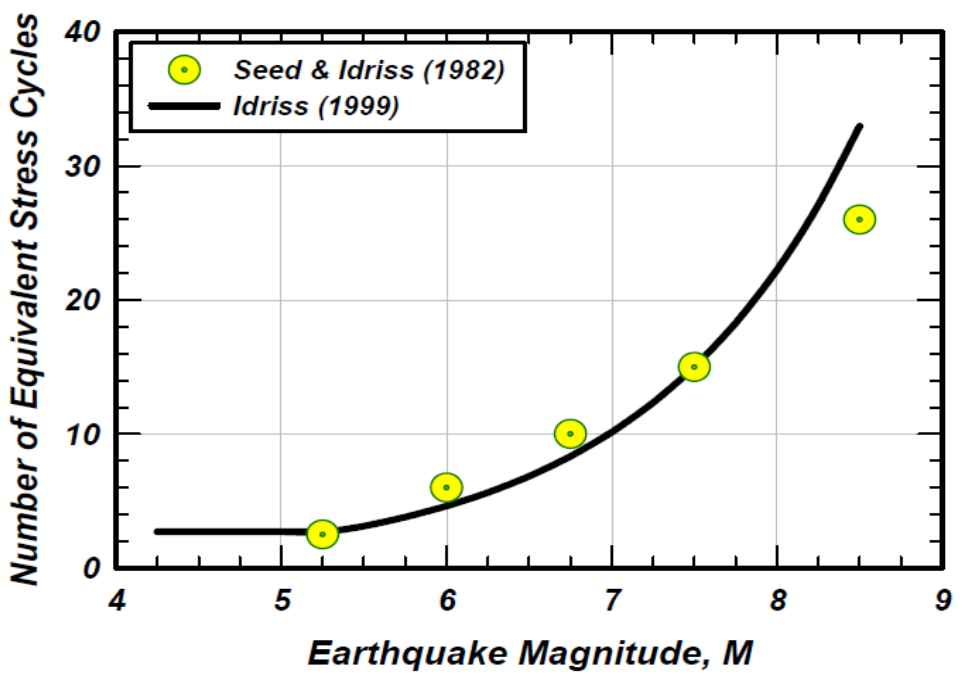

Fig 2.7 Relationship between number of equivalent uniform cycles and different magnitude of earthquakes (after Boulanger and Idriss, 2004)

\subsubsection{Influence of vertical consolidation stress}

Effective consolidation stress $\left(\sigma_{v c}^{\prime}\right)$ is another important factor controlling the cyclic behaviour of soils. Several studies have revealed that increasing $\sigma^{\prime}{ }_{v c}$ causes reduction in cyclic resistance as high $\sigma_{v c}^{\prime}$ leads to more contractive behaviour and generates higher rates of excess pore water pressure (Vaid and Chern, 1985; Vaid and Thomas, 1994; Vaid et al., 2001). Likewise, Mitchell and King (1976) investigated the Champlain Sea clay in Eastern Canada and they noticed that increased $\sigma_{v c}^{\prime}$ caused higher excess pore water pressure accumulation in clayey soils and further the number of cycles required to fail the clayey soils were reduced (Fig. 2.8). Real influence of $\sigma^{\prime}{ }_{v c}$ in cyclic behaviour was observed in 1999 Kocaeli earthquake. During this earthquake severe strength reductions (liquefactions) were observed in Turkey clayey soils that are located closer to buildings and less strength reductions were observed in open sites (Bray and Sancio, 2006). 


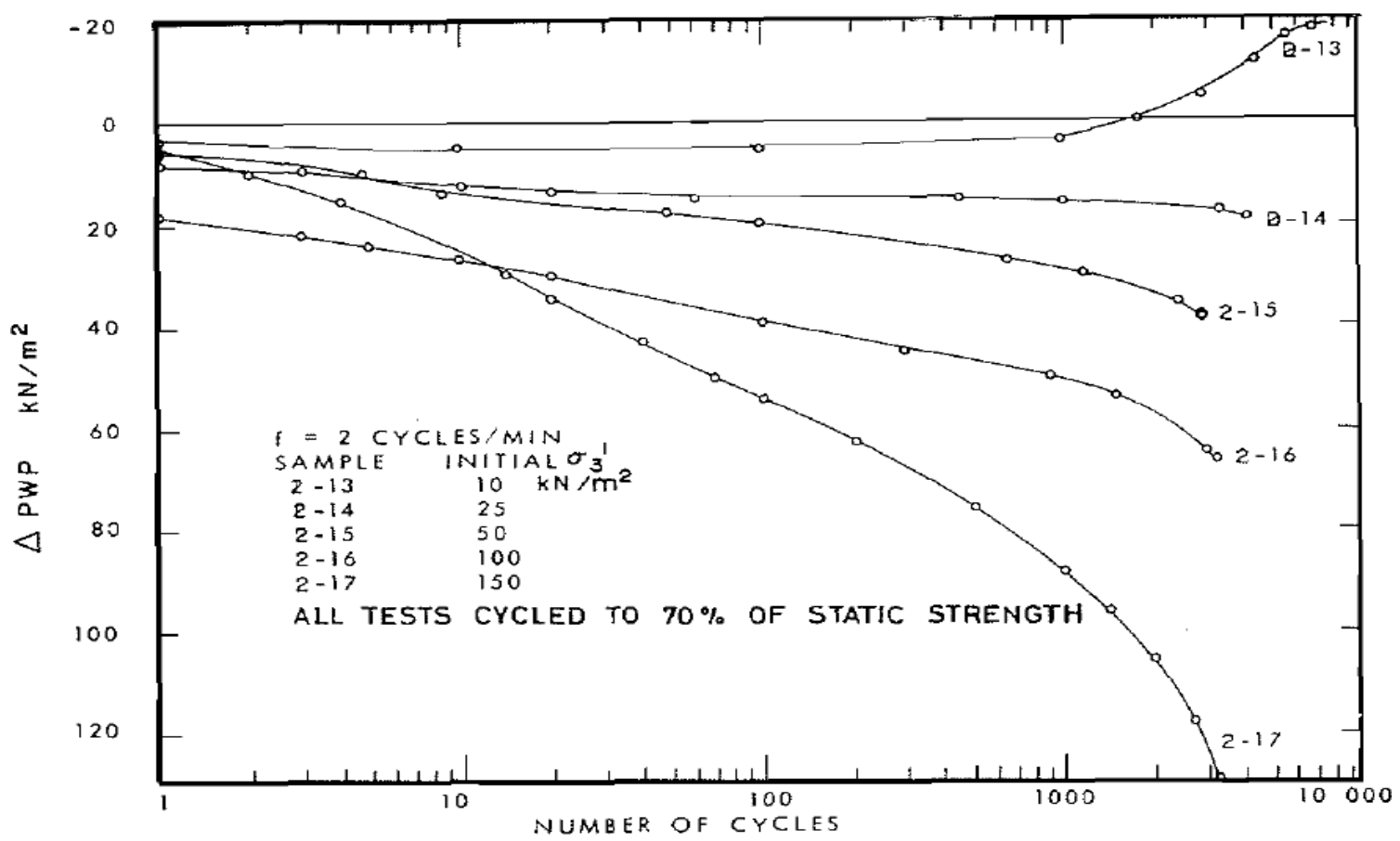

Fig 2.8 Influence of initial effective confining pressure on generation of pore water pressure (after Mitchell and King 1976)

\subsubsection{Influence of over consolidation ratio in cyclic behaviour}

Soils can exist either in a normally consolidated state or over-consolidated state depending on their stress history. Geological factors including melting of ice sheets after glaciation and erosion of top soil layers are common causes of over-consolidation. If the current effective stress is the maximum effective stress that a particular soil has ever experienced, then the soil is normally consolidated (NC). On the other hand, if the soil has been subjected to greater stress than the current effective stress then it is termed as over-consolidated (OC). Over-consolidation ratio (OCR) is defined as the ratio of the maximum effective stress to the current effective stress. Thus OCR $=1$ represents a normally consolidated soil.

Several studies have pointed out that over-consolidation ratio has significant influence on the cyclic behaviour of soils. A number of researches have been conducted to 
investigate the effect of normally consolidated (NC) and over consolidated states (OC) on soil behaviour under undrained cyclic loadings (Peacock et al., 1968; Ogawa 1973; Ishihara et al 1978; Azzouz et al. 1989). Further studies revealed that NC clays always generate positive pore-water pressure $(\Delta \mathrm{u})$. OC clay which has high plasticity initially develops negative $\Delta \mathrm{u}$ and then progressively reverses to positive $\Delta \mathrm{u}$ under undrained cyclic loading. (Andersen et al. 1980; Matsui et al. 1980; Vucetic et al. 1985; Ohara and Matsuda 1988). Initially, Dobry and Vucetic (1987) suggested that changes in the microstructure of OC clays might be the reason for the negative $\Delta \mathrm{u}$ generation. Later, Vucetic (1994) specified that higher OCR values lead to higher initial negative $\Delta \mathrm{u}$ and the generation of $\Delta \mathrm{u}$ mainly rely on consolidation loading history of the clay which affects the clay's microstructure. Similarly, Boston blue clay was studied by Azzouz et al. (1989) under the simple shear condition and it was noted that $\mathrm{OC}$ clay required a larger number of cycles for failure than NC clay at a given cyclic stress ratio. Further, they also noticed that during the cyclic shearing, NC clay generated positive $\Delta \mathrm{u}$ and OC sample initially generated negative $\Delta \mathrm{u}$, however increasing cyclic loading shortly produced positive $\Delta \mathrm{u}$ until failure occurred. Cyclic triaxial tests were carried out by Ogawa (1973) on clean sand with different overconsolidation ratio and the results showed that resistance to liquefaction nearly doubled when the OCR is increased to 5 for a sample with a relative density (Dr) of $55 \%$. Further, Ishihara et al (1978) stated that clean sands with OCR of 2 produced $30 \%$ increment in cyclic strength compared to normally consolidated sand. In addition, Ishihara and Takatsu (1979) conducted tests on clean sand samples to investigate the influence of OCR with varying $K_{0}$ (at-rest earth pressure coefficient) values on liquefaction resistance. They concluded that for OCR values ranging from 1 to 4 , regardless of $K_{0}$-value, the liquefaction 
resistance is increased by approximate proportion to the square root of the over consolidation ratio (Fig. 2.9).

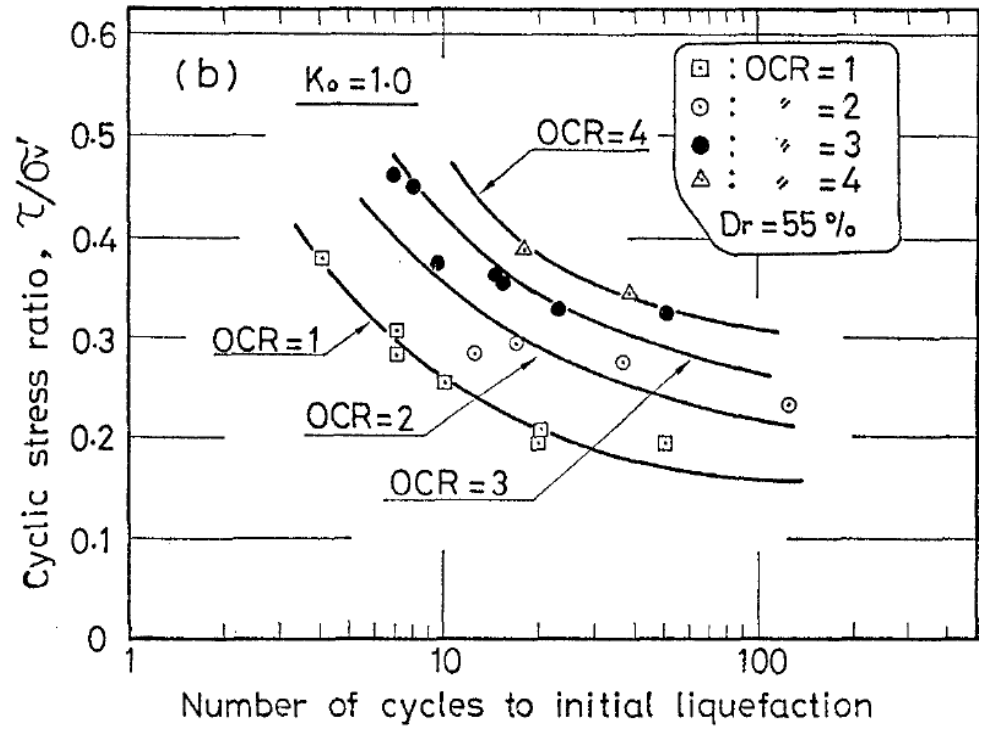

Fig 2.9 Influence of over-consolidation ratio in cyclic stress ratio (after Ishihara and Takatsu, 1979)

\subsubsection{Influence of plasticity index in cyclic behaviour}

In clayey soils plasticity index (Ip) is another important factor which controls the cyclic behaviour. Wichtmann et al. (2013) reported that undrained cyclic strength increased with increasing Ip of the clays. Similarly Boulanger and Idriss (2006) also revealed that increasing Ip of NC silty soil increased cyclic stress ratios and further normalized stress ratio as seen in the Fig. 2.6.

\subsubsection{Influence of loading conditions in cyclic behaviour}

Love (1927) noted that it is very difficult to duplicate the field (in-situ) loading conditions in the environment of laboratory testing. Further, it is very challenging to represent the initial stress and boundary conditions. However, cyclic behaviour of soil has generally been studied in the laboratory using different devices with different loading paths (e.g., 
triaxial, direct shear, simple shear, hollow cylinder torsional shear). In general, the impact of cyclic triaxial and cyclic simple shear loading conditions on cyclic behaviour have been well recognized in practice (Peacock et al., 1968; Vaid and Sivathayalan 1996). Further, simple shear represents the field loading condition during vertically propagating shear waves fairly well as shown in location "a" and "b" of Fig. 2.10. Thus, it is considered to be a more suitable device to evaluate the liquefaction susceptibility in the laboratory (Finn et al., 1977; Sivathayalan and Ha, 2004; 2011; Logeswaran, 2010). In addition, Fig. 2.11 illustrates that in-situ loading conditions along a potential failure surface might include deformation under various loading modes.

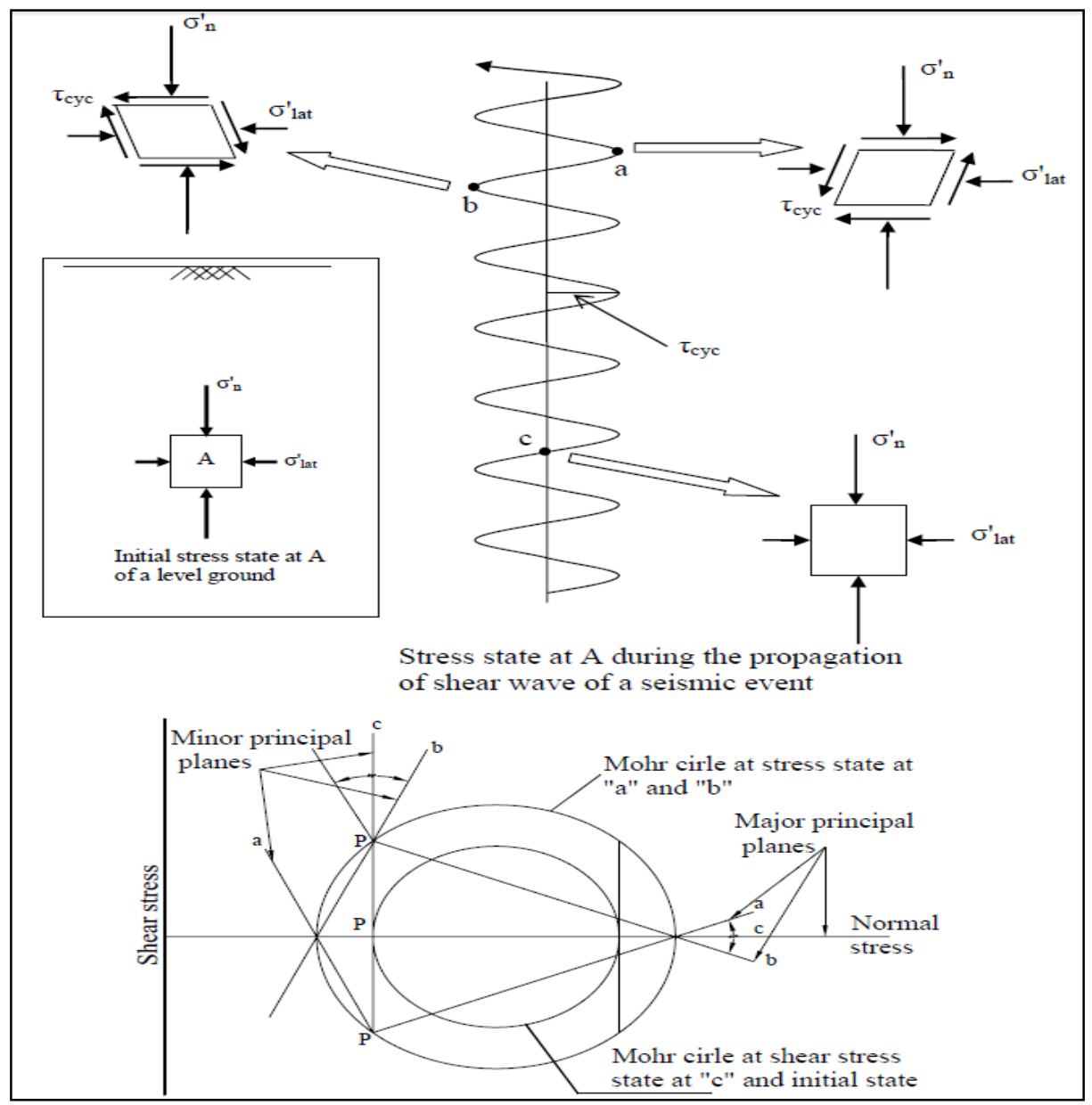

Fig 2.10 Representation of in-situ stress and simple shear loading (modified from Ha, 2003) 


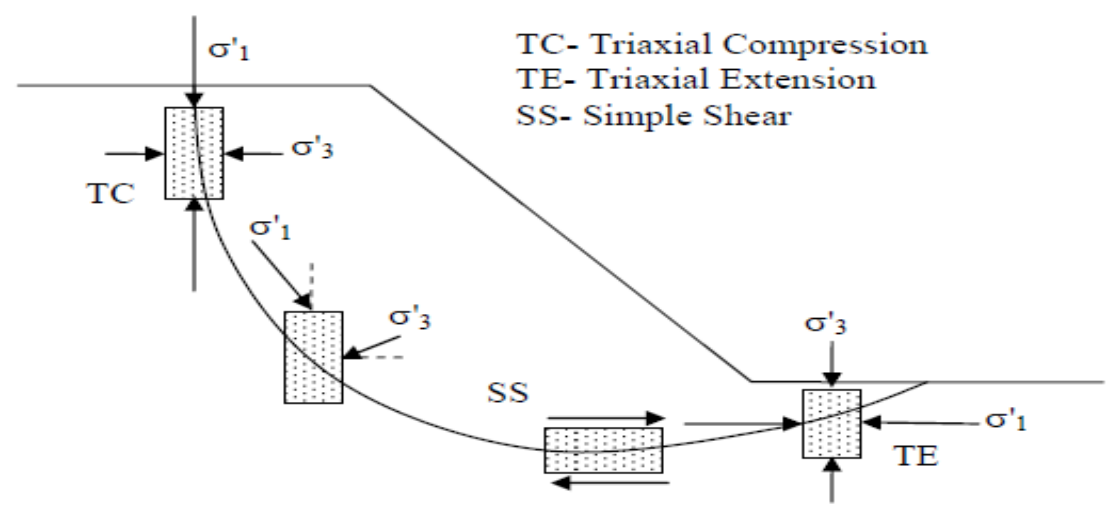

(a) Limiting equilibrium stress state beneath an embankment

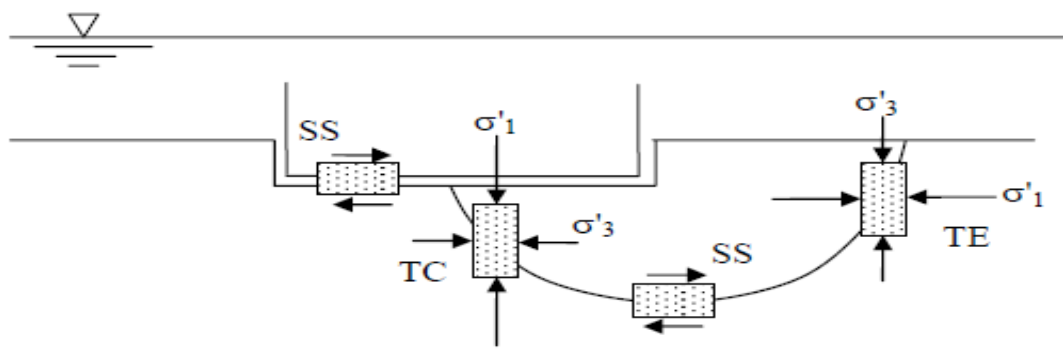

(b) Limiting equilibrium stress state beneath a gravity platform

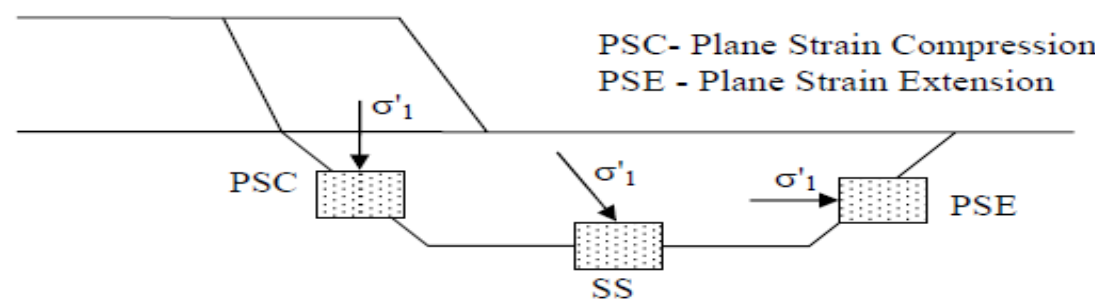

(c) Limiting equilibrium stress state in varved clay ground

Fig 2.11 Load conditions along the potential failure surfaces (after Logeswaran, 2010)

\subsection{Dynamic properties of soils}

Dynamic properties of soils such as secant shear modulus $\left(G_{s}\right)$ maximum shear modulus $\left(G_{\max }\right)$ and damping ratio $(\xi)$ are the main input parameters for soil modeling and ground response earthquake analysis. Several studied have shown that dynamic properties are not similar for all soils, and they vary from one site to another because of the their dependence on several factors including confining stress $\left(\sigma_{v c}^{\prime}\right)$, over-consolidation ratio (OCR), void 
ratio (e), plasticity index (Ip), soil type (e.g. sand, clay, silt), geological age, etc. (Seed and Idriss 1970; Hardin and Drnevich 1972; Dobry and Vucetic 1987; Ishihara 1986; Kim and Novak 1981; Kokusho et al. 1982; Vucetic and Dobry 1988). As a result of the above mentioned uncertainties and complexities, it is important that the suitability of data from the literature to a specific site should be evaluated for reliable and accurate site-specific assessment of the soil liquefaction.

\subsubsection{Secant shear modulus}

Cyclic behaviour of soils can be presented as symmetric hysteresis loop of stress-strain behaviour as shown Fig 2.12 (Lanzo et al., 1997). Under cyclic loading, soils display nonlinear stress-strain behaviour. When the cyclic shear strain amplitude $\left(\gamma_{c}\right)$ increases the secant shear modulus $\left(G_{s}\right)$ degrades. Also, when plasticity index decreases the nonlinearity increases (Dobry and Vucetic, 1987; ProShake, 2001).

Shear modulus is generally expressed as the secant shear modulus $\left(G_{s}\right)$ and it can be determined by measuring the slope of the hysteresis loop or extreme points of the hysteresis loop. Also $G_{s}$ can be expressed as ratio of cyclic shear stress $\left(\tau_{c}\right)$ and corresponding cyclic strain $\left(\gamma_{c}\right)$.

$$
G_{s}=\frac{\tau_{c}}{\gamma_{c}}
$$




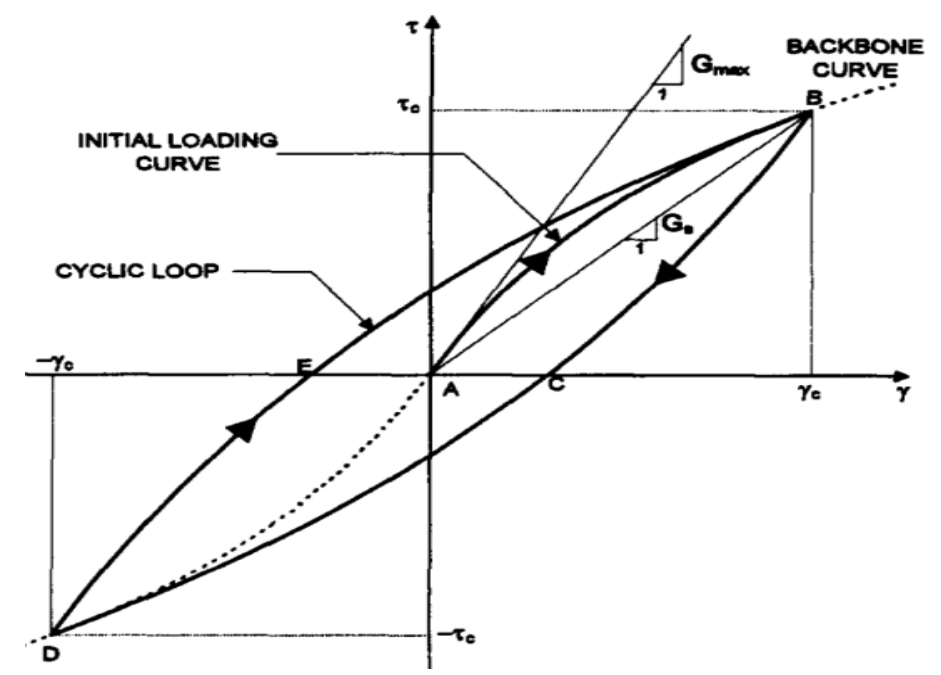

Fig 2.12 Idealized stress-strain loop and secant shear modulus (after, Lanzo et al., 1997)

\subsubsection{Factors affecting the secant shear modulus}

Several studies reported that strain amplitude $\left(\gamma_{c}\right)$, void ratio (e) and confining pressure $\left(\sigma_{v c}^{\prime}\right)$ are dominant factors that strongly affect the shear modulus values (or shear modulus coefficient, $k_{2}$ ) as presented in Fig.2.13 (a) and (b). Insignificant correlation has been noted between the $G_{s}$ and the shear strength parameter $c^{\prime}$ and $K_{0}$ (Seed and Idriss, 1970; Hardin and Drnevich, 1972; Krizek, 1974; Kuribayashi et al., 1974).

Dynamic properties of south-western Ontario cohesive soils were investigated by Kim et al (1981) and they also reported findings somewhat similar to that of Seed and Idriss (1970). However, they pointed out that $G_{s}$ of cohesive soil is possibly influenced by factors other than $\sigma_{v c}^{\prime}$, e, and over consolidation ratio. Further, they stated that confining pressure has significant influence on the shear modulus when void ratio is less than 0.8 . Conclusion arrived by them was that increasing confining pressure significantly increases the $G_{S}$ and on the other hand increasing void ratio dramatically reduces the $G_{s}$ values as illustrated in Fig 2.14. 
Lanzo et al. (1997) carried out experimental study on clays and sands to investigate the influence of the cyclic strain amplitude $\left(\gamma_{c}\right)$, plasticity index (Ip), vertical consolidation stress $\left(\sigma_{v c}^{\prime}\right)$ and over consolidation ratio (OCR) on $G_{s}$. Based on the study they reported that $G_{s}$ increased with $\sigma_{v c}^{\prime}$ and OCR and also degradation of $G_{s}$ reduced with increased Ip (Fig. 2.15). Similar outcome was reported by other researchers as well (Kokusho et al., 1982; Dobry and Vucetic, 1987; Vucetic and Dobry, 1991).

Vucetic and Dobry (1987) carried out an experimental study to investigate the shear modulus degradation of Venezuelan (North of Paria) clays with different over consolidation ratios $(\mathrm{OCR}=1,2$ and 4$)$. They pointed out that the rate of shear modulus degradation reduced with increased OCR and high plasticity clays had lower modulus degradation rate than low plasticity clays. Further, Mortezaie and Vucetic (2013) revealed that modulus degradation parameter $(\mathrm{t})$ of normally consolidated kaolinite clay decreased with increased $\sigma_{v c}^{\prime}(=220$ to $680 \mathrm{kPa})$. Moreover, they noticed that modulus degradation decreased up to $20-38 \%$ while ${\sigma^{\prime}}_{v c}$ increased from 220 to $680 \mathrm{kPa}$.
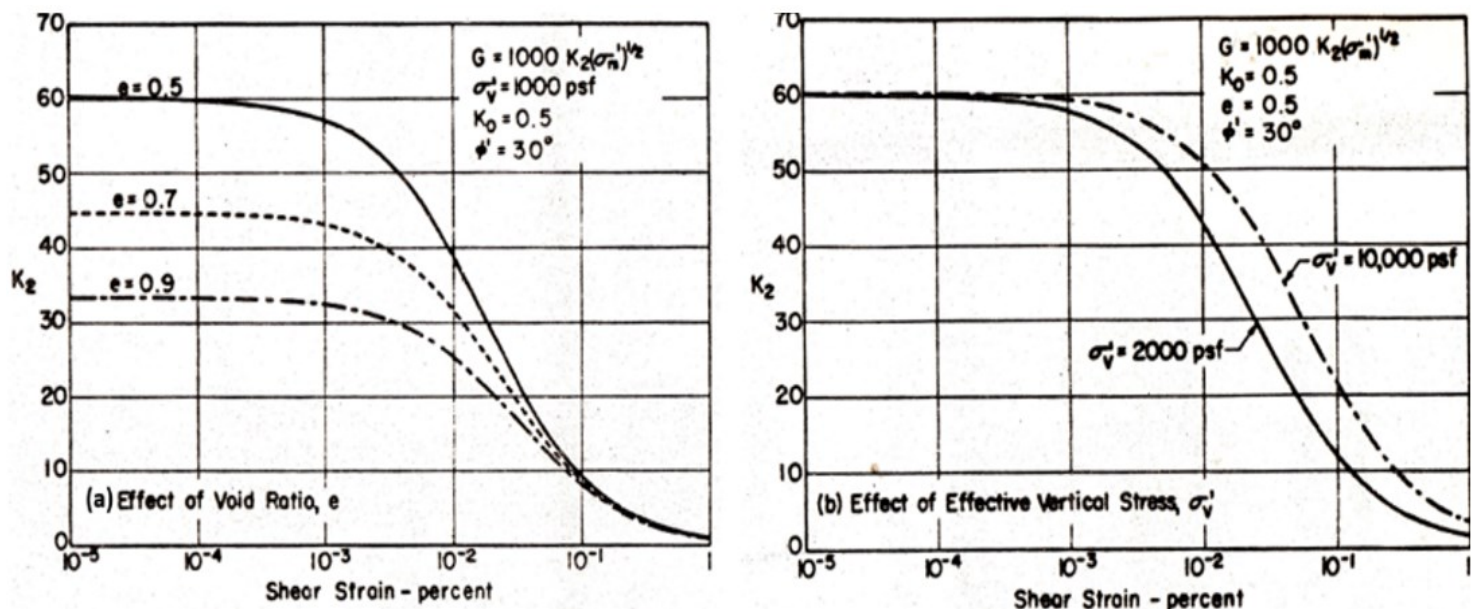

Fig 2.13 Factors affecting the shear (secant) modulus of sands (after Seed and Idriss, 1970) 

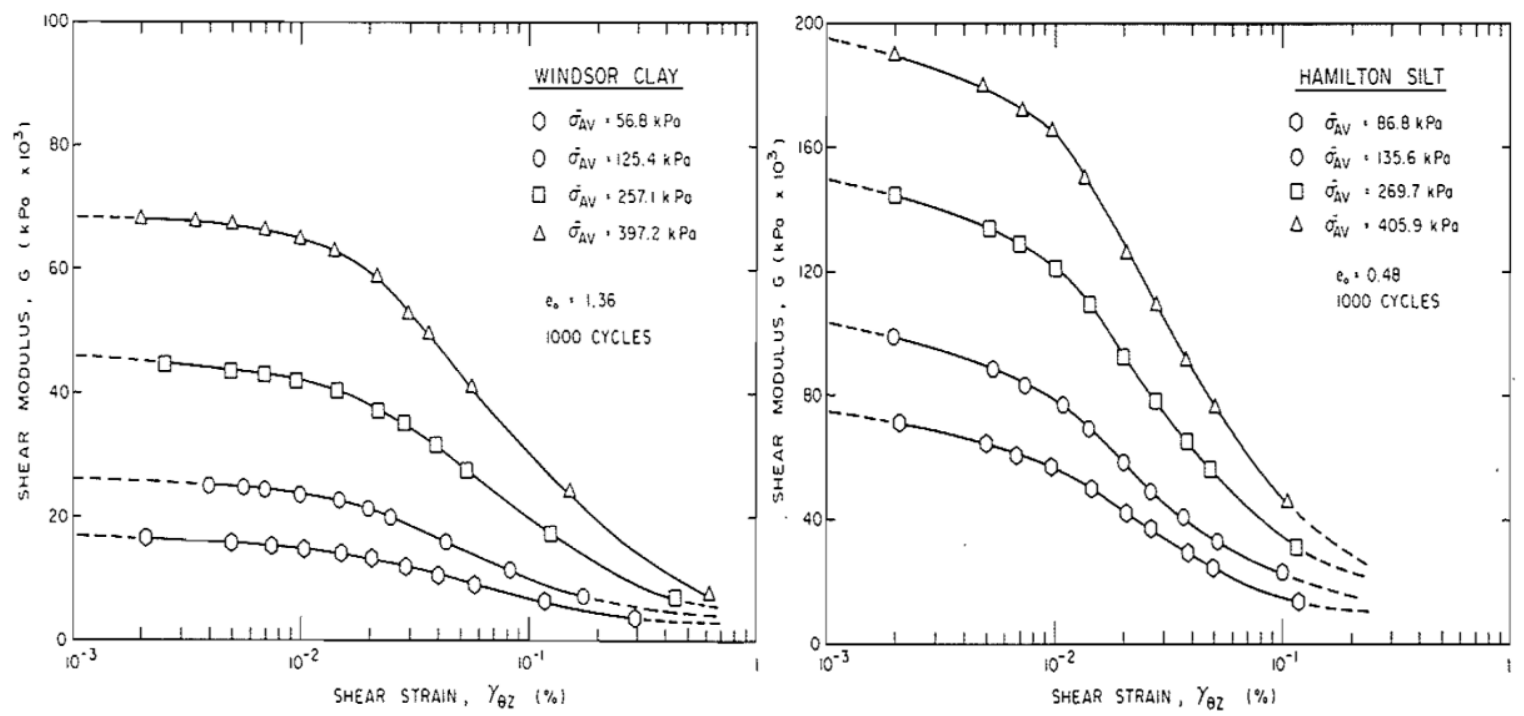

Fig 2.14 Differences in shear modulus of (a) Windsor clay and (b) Hamilton silt with consolidation pressure (after Kim \& Novak, 1981)
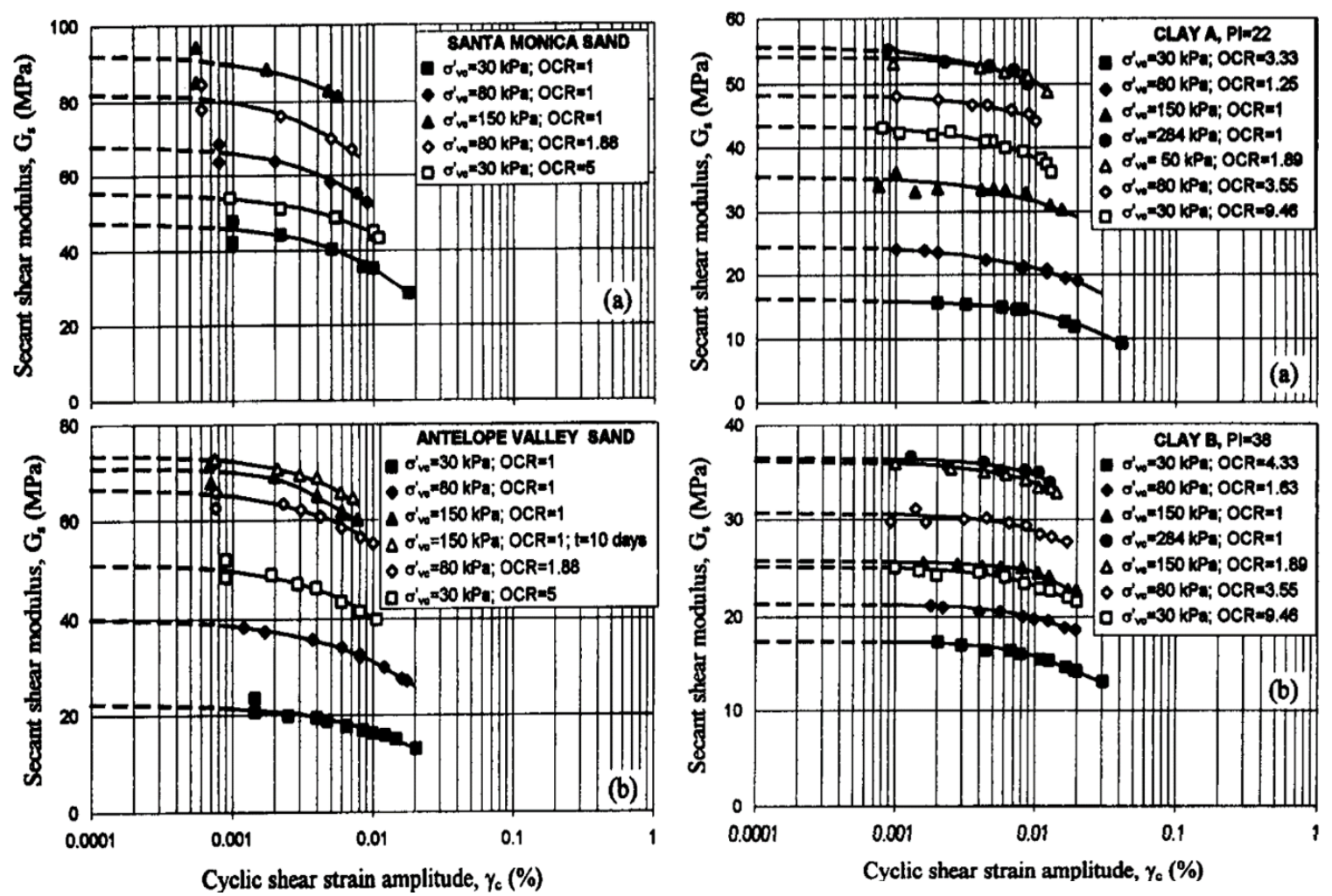

Fig 2.15 Factors influencing the shear modulus of sands and clays (after Lanzo et al., 1997) 


\subsubsection{Maximum shear modulus}

Maximum shear modulus $\left(G_{\max }\right)$ is the peak value of secant shear modulus at very low strain amplitude (in the elastic range; typically lower than $\gamma_{c}$ of $10^{-4} \%$ ). Lefebvre et al (1993) described $G_{\max }$ as a basic soil stiffness parameter and noted that it plays a vital part in dynamic-response investigations. $G_{\max }$ could be estimated from direct field tests or from laboratory testing or from empirical equations. The maximum shear modulus could be estimated using the following equation.

$$
G_{\max }=\rho v_{s}^{2}
$$

Where, $\rho$ is the density of soil. Shear wave velocity of soil $\left(v_{s}\right)$ can be measured using geophysical methods (e.g. Yan \& Byrne, 1990). Resonant column and bender elements tests are well known laboratory tests for the determination of the $G_{\max }$ (Kim \& Novak, 1981; Kramer, 1996).

Hardin and Drnevich (1970) suggested the following empirical equation to estimate the $G_{\text {max }}$ and later it has been refined by several researchers.

$$
G_{\max }=625 F(e)(O C R)^{k} p_{a}^{1-n}\left(\sigma_{m}^{\prime}\right)^{n}
$$

Where $F(e)$ - Void ratio function, k-an exponent of over-consolidation ratio, $\sigma^{\prime}{ }_{\mathrm{m}}$-the mean principal effective stress $\left[\sigma^{\prime}{ }_{m}=\left(\sigma^{\prime}{ }_{1}+\sigma^{\prime}{ }_{2}+\sigma^{\prime} 3\right) / 3\right], n$ an exponent of stress and it is often taken as $n=0.5$, and $P_{a}$ is atmospheric pressure (same units as $\sigma^{\prime}{ }_{m}$ and $G_{\text {max }}$ ). Different functions of void ratio have been proposed by several researchers including Hardin (1978) and Jamiolkowski et al (1985). 


\subsubsection{Factors affecting the maximum shear modulus}

Okur and Ansal (2007), and Jung et al. (2013) suggested that $\sigma_{v c}^{\prime}$ and OCR significantly influenced maximum shear modulus $\left(G_{\max }\right)$. The $G_{\max }$ is also affected by $\sigma_{v c}^{\prime}$, Dr, OCR and Ip (Seed and Idriss, 1970; Iwasaki et al., 1978; Kokusho et al., 1982; Vucetic et al., 1998; Stokoe et al., 1999). However, Dobry and Vucetic (1991) reported $G_{\max }$ of NC soil is not influenced by the plasticity. Further, void ratio and $\sigma^{\prime}{ }_{v}$ control the $G_{\max }$ of cohesionless soils. In addition, the effect of the time of confinement (geologic age) on $G_{\max }$ was investigated by Andersen and Stokoe (1978), and Kokusho et al. (1982). They reported that high-plasticity clays had reasonable increment in $G_{\max }$ with time compared to lowplasticity clays.

\subsubsection{Damping Ratio}

Damping ratio is another important dynamic soil property which is directly associated with energy dissipation of soil under seismic loadings (Jacobsen, 1930; Kramer, 1996). The inside area of hysteresis loop (Fig. 2.12) is associated with energy dissipation and it can be used to determine the viscous damping ratio $(\xi)$. The viscous damping ratio $(\xi)$ can be calculated by using the following equation. (Jacobsen, 1930; Seed and Idriss, 1986).

$$
\xi=\frac{W_{D}}{4 \pi W_{s}}=\frac{1}{2 \pi} \frac{A_{\text {loop }}}{G_{s} \gamma_{c}^{2}}
$$

Where $W_{S}$ is the maximum strain energy, $W_{D}$ is the dissipated energy, and $A_{\text {loop }}$ is the area of hysteresis loop. In current practice of ground response analysis, well-known damping curves such as, Seed and Idriss curves, Vucetic and Dobry curves, and Ishibashi and Zhang curves are widely used (ProShake, 2001). 


\subsubsection{Modulus reduction and Damping ratio}

Normalized shear modulus can be defined as the ratio of secant shear modulus $\left(G_{S}\right)$ to maximum shear modulus $\left(G_{\max }\right)$. The variation in normalised $G_{s}$ values with increasing $\gamma_{c}$ amplitudes is called as modulus reduction $\left(G_{s} / G_{\max }\right)$ curve. Modulus reduction curve is one of the important input parameters in dynamic analysis. Further, damping ratio $(\xi)$ also plays a significant role in the determination of dynamic response of soils. Both modulus reduction and damping ratio are dimensionless parameters and both are function of the cyclic shear strain $\left(\gamma_{c}\right)$. Figs $2.16-2.19$ clearly demonstrate how $G_{s} / G_{\max }$ and $\xi$ curves of different type soils vary with increasing cyclic shear strain $\left(\gamma_{c}\right.$ in semi-log scale).

Modulus reduction and damping curves for sand were originally proposed by Seed and Idriss (1970). They proposed three different boundary curves, namely lower, average, and upper boundary to represent different behaviour of soils (Fig. 2.16 and 2.17). Later, Vucetic and Dobry (1991) developed a set of modulus reduction and damping curves for cohesive soils. These curves were established base on different Ip values ranging from 0 to 200 as shown in Fig. 2.18 and 2.19. Further, unified formulas for shear modulus and damping ratios were proposed by Ishibashi and Zhang (1993) for both sandy and non-sandy soils. In addition, they suggested that their formulas could be extended to gravelly soils and normally consolidated clays. 


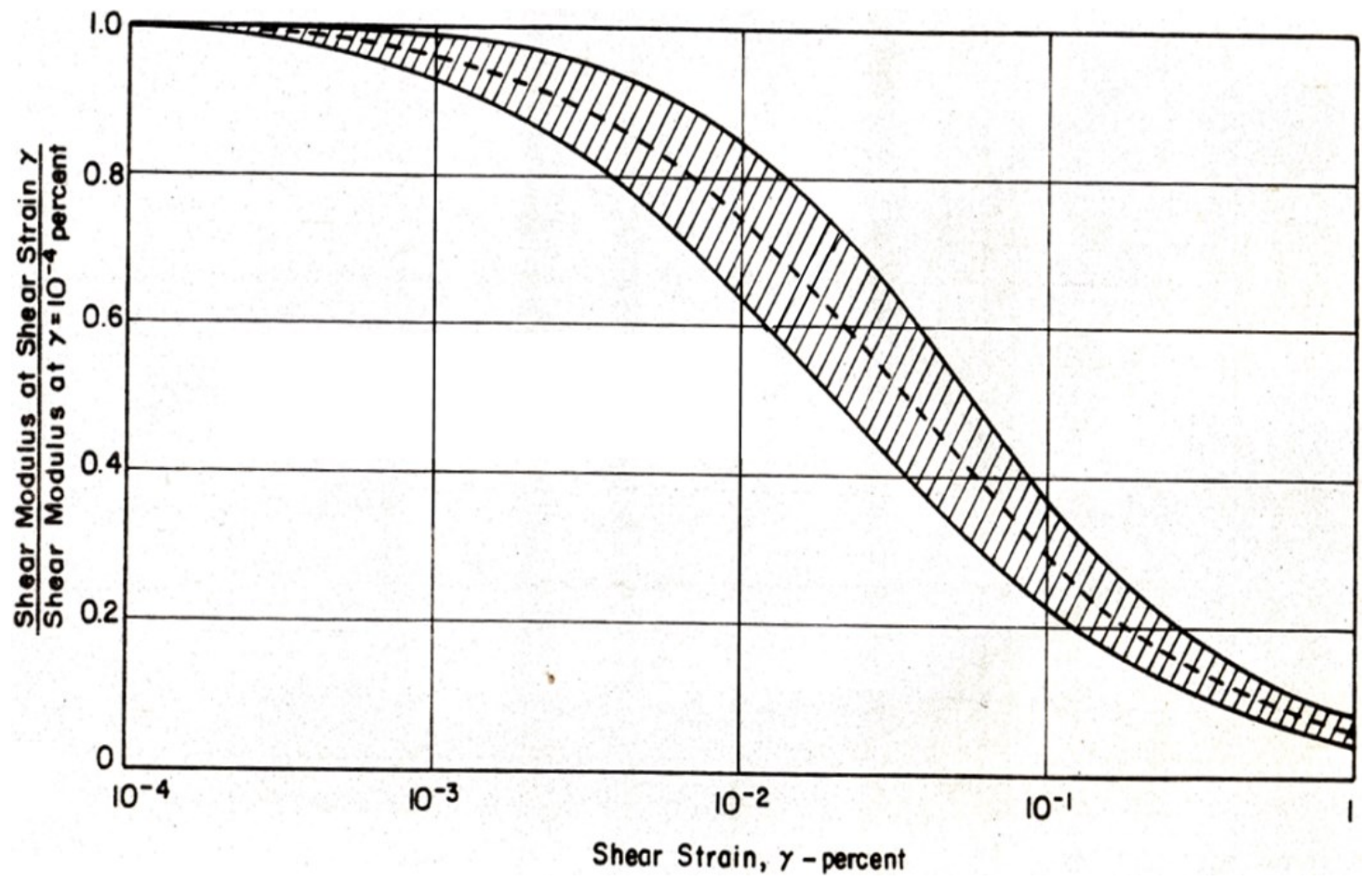

Fig 2.1 Shear modulus reduction vs shear strain for sands (after Seed and Idriss, 1970)

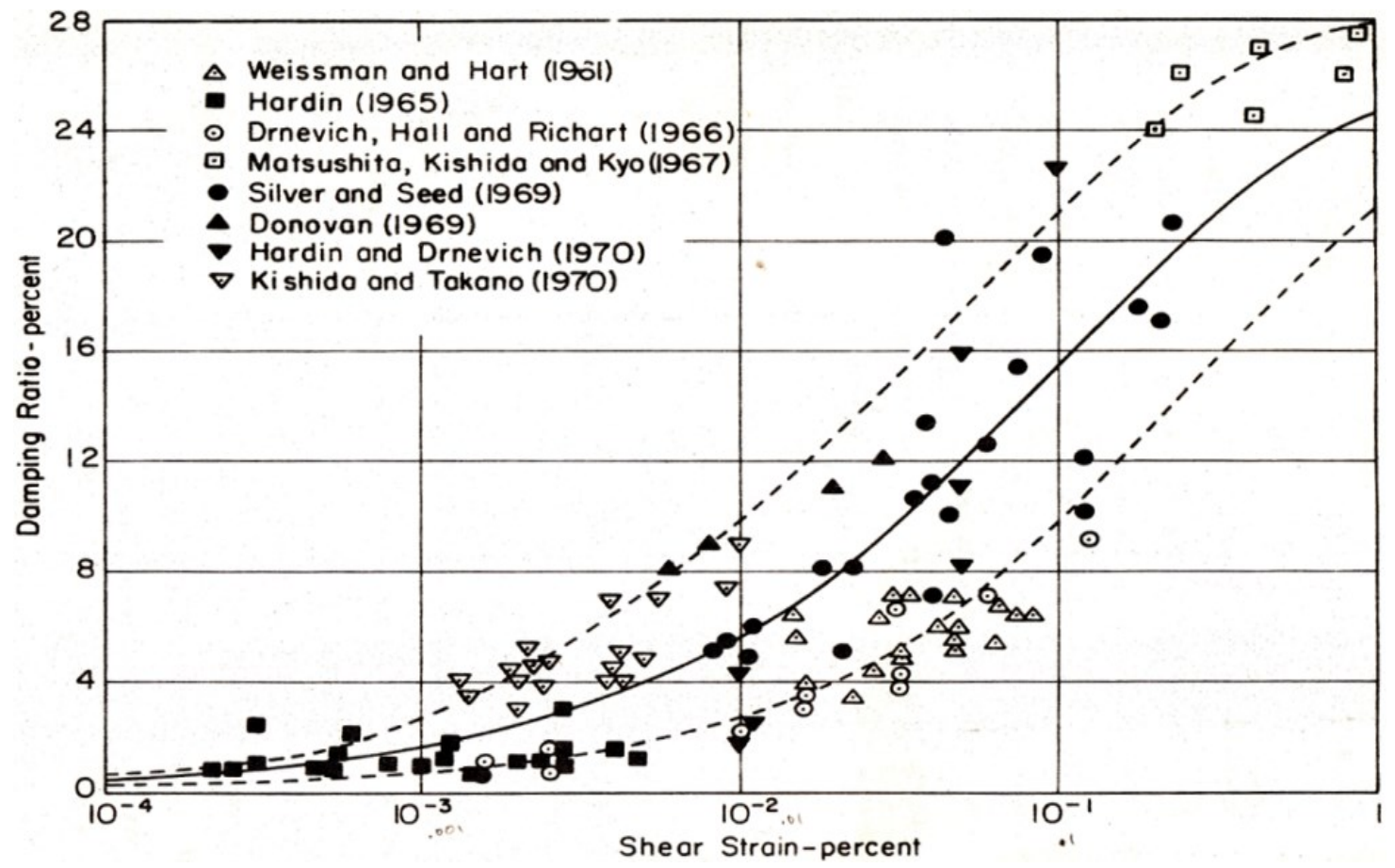

Fig 2.27 Damping ratio vs shear strain for sands (after Seed and Idriss, 1970) 


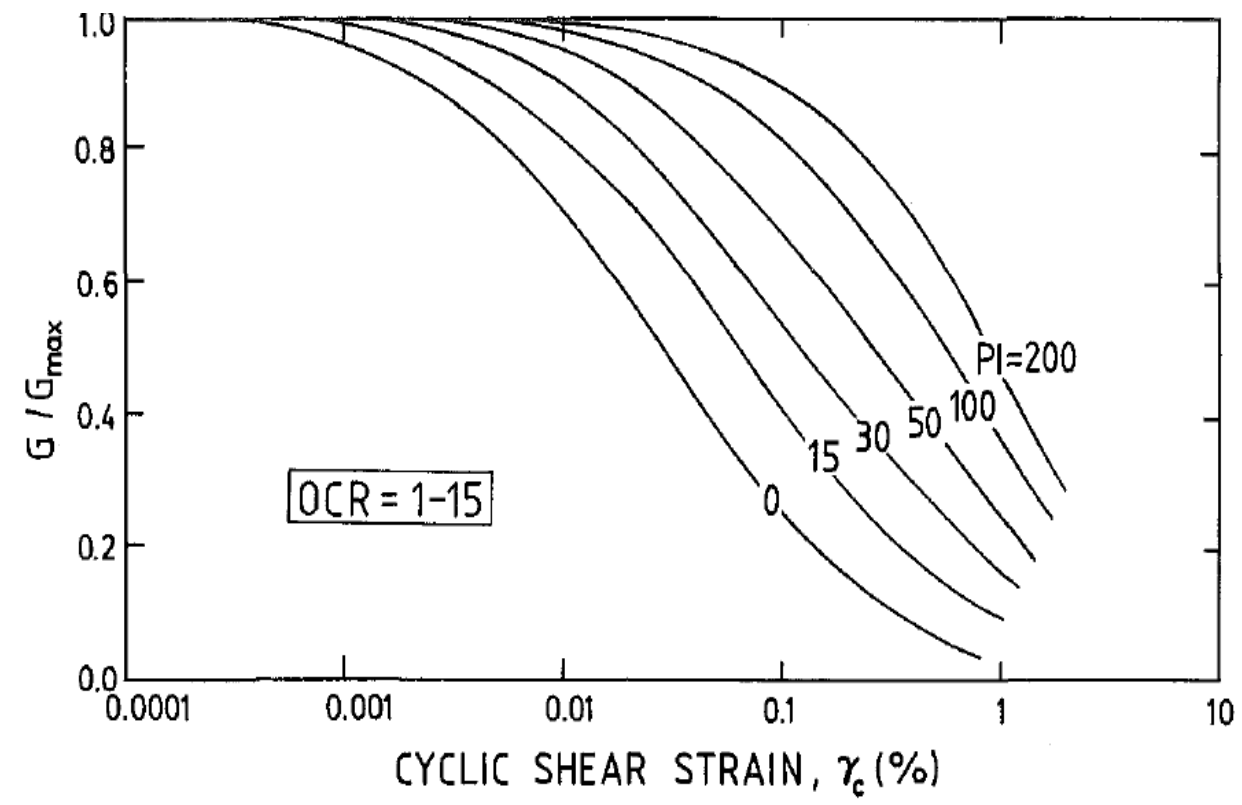

Fig 2.38 Modulus reduction curves with different plasticity indexes (after Vucetic and Dobry, 1991)

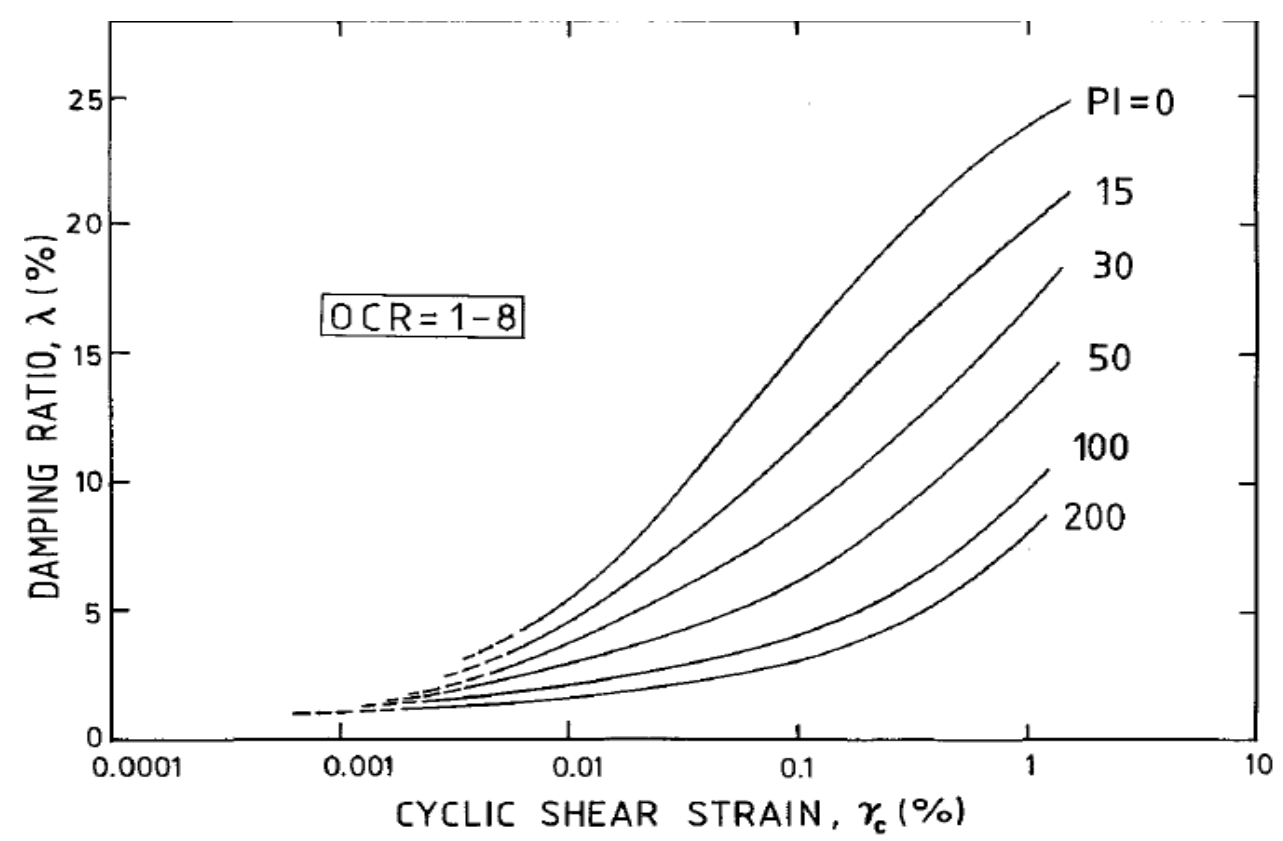

Fig 2.4 Damping ratio curves with different plasticity indexes (after Vucetic and Dobry, 1991)

Vucetic (1994) proposed three different zones of cyclic shear strain $\left(\gamma_{c}\right)$ for a generalized case of modulus reduction and damping curves. Further, he introduced two different cyclic threshold shear strains $\left(\gamma_{t l}\right.$ and $\left.\gamma_{t v}\right)$ to divide the $\gamma_{c}$ amplitudes (in semi-log scale) as very 
small strains $\left(\gamma_{c}<\gamma_{t l}\right)$, small strains $\left(\gamma_{t l}<\gamma_{c}<\gamma_{t v}\right)$ and medium to large strains $\left(\gamma_{c}>\right.$ $\left.\gamma_{t v}\right)$ as shown in Fig. 2.20. Further, he explained that soils basically exhibit linear stressstrain behaviour below $\gamma_{t l}$ amplitude and above $\gamma_{t l}$ display non-linear behaviour. In addition, below $\gamma_{t v}$ amplitude soils does not experience permanent alterations in microstructure and above $\gamma_{t v}$ level soils undergo permanent microstructural modifications, and exhibit significant nonlinear and inelastic behaviour. Furthermore, he stated that if any soil undergoes permanent changes in its microstructure, then the stiffness of the soil will be altered permanently. In addition, fully saturated soils generate permanent excess porewater pressures at undrained conditions and permanent volume change occurs in dry, partially saturated, or fully saturated soils under drained condition.

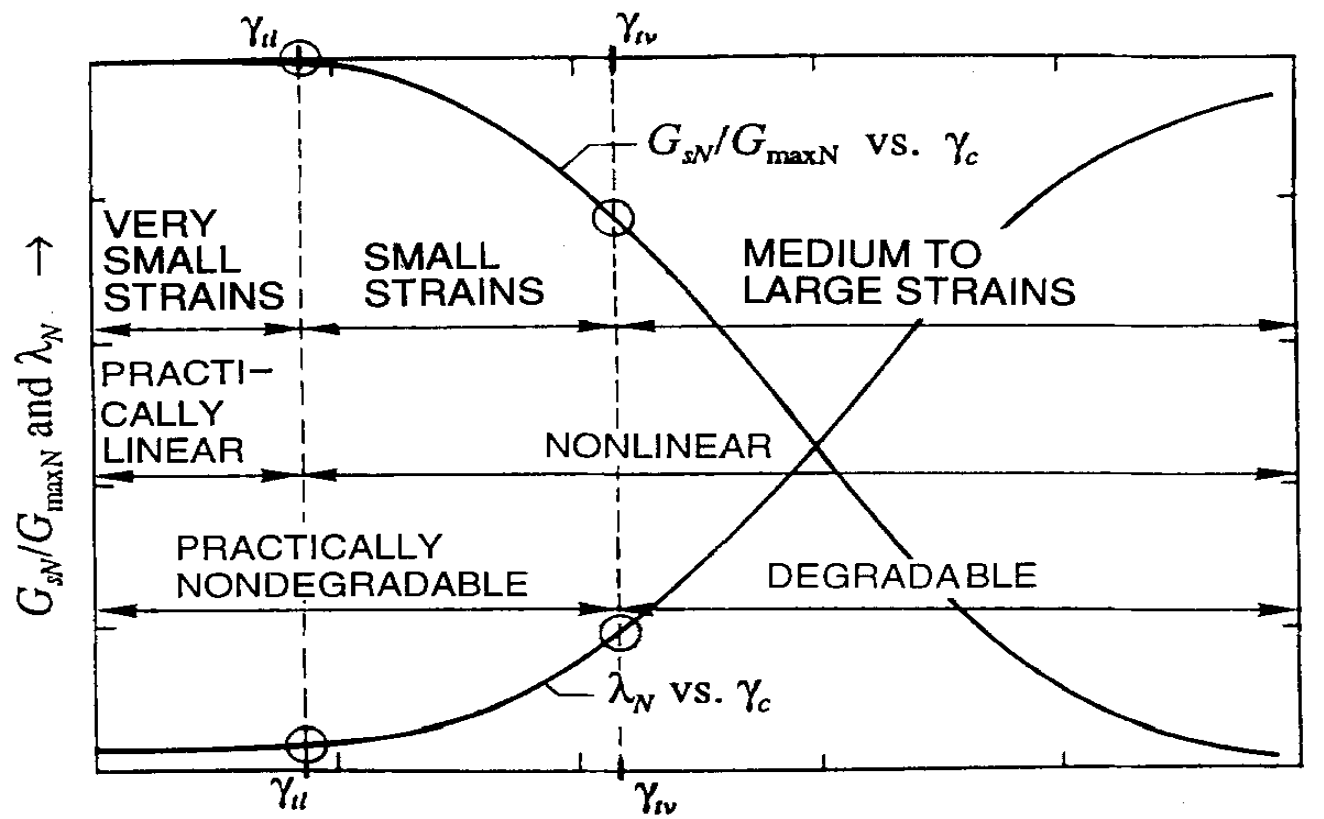

CYCLIC SHEAR STRAIN AMPLITUDE, $\gamma_{c}(\%)$ - LOG. SCALE

Fig 2.20 Shear modulus reduction and damping curves with cyclic shear strain (after Vucetic, 1994) 


\subsubsection{Factors affecting the modulus reduction and damping ratio}

Seed \& Idriss (1970) identified strain amplitude, effective mean principal stress, void ratio and number of loading cycles as factors that significantly influenced both modulus reduction and damping ratio. Further, over consolidation ratio, effective strength parameters $\left(c^{\prime}\right.$ and $\left.\phi^{\prime}\right)$, and time effects were found to have minimal influence in the modulus reduction and damping ratio.

Kokusho et al. (1982) stated that modulus reduction curves and damping curves are affected by Ip values. They illustrated a pattern as, increasing Ip values move the modulus reduction curves higher and the damping ratio curves lower. Similarly, Anderson and Richart (1976), Kim and Novak (1981), and Ishihara (1986) also suggested trends for modulus reduction and damping curves with different Ip values.

Vucetic and Dobry (1991) carried out an extensive study to investigate the impact of plasticity index (Ip) on cyclic behaviour of normally consolidated and overconsolidated clays based on experimental data obtained from several previous publications. They also reported that Ip is one of the dominant factors which strongly influenced the modulus reduction and damping parameters. For a given cyclic shear strain $\left(\gamma_{c}\right)$, increasing Ip value increases $G / G_{\max }$ and decrease $\xi$. Further, Lanzo et al, (1997) showed that modulus reduction value of sands and clays (with low Ip values) are significantly influenced by $\sigma_{v c}^{\prime}$ and OCR. On the other hand their influences were negligible in high Ip clays as shown in Fig. 2.21. 

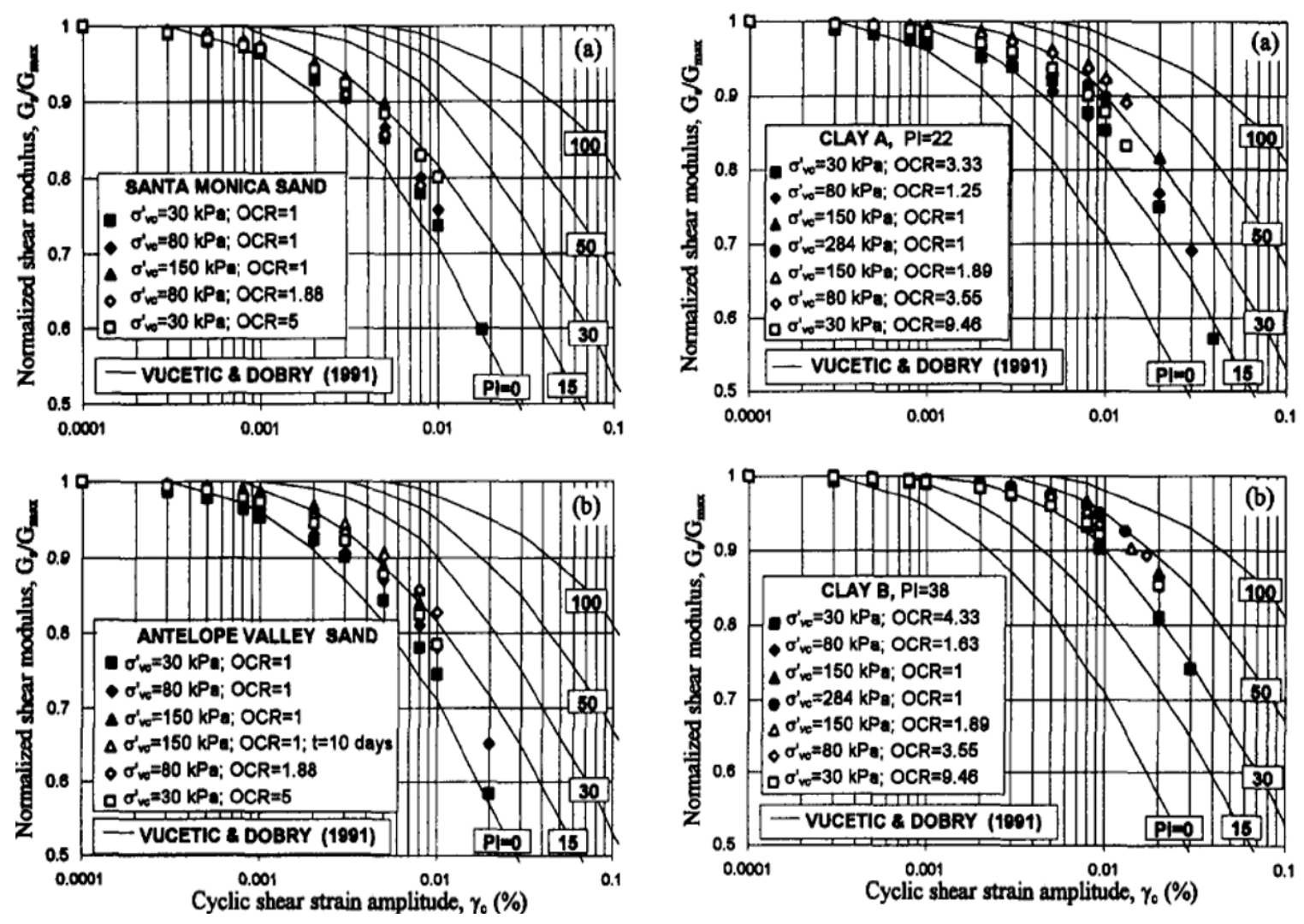

Fig 2.5 Influence of $\sigma_{v c}^{\prime}$, OCR and Ip on modulus reduction of sands and clays (after Lanzo et al., 1997).

Vucetic et al (1998) studied the factors affecting the viscous damping ratio ( $\xi$ ) of reconstituted sands and laboratory-made clays at cyclic shear strain $\left(\gamma_{c}\right)$ ranging from 0.001 to $0.04 \%$. According to their study, $\xi$ of sands and clays were independent from frequency of cyclic loading $(f)$ as $\xi$ did not get affected by $f$ ranging from 0.01 to $0.10 \mathrm{~Hz}$. Further, they noticed $\sigma_{v c}^{\prime}$ strongly dominated the damping ratio of sands and $\xi$ decreased while $\sigma_{v c}^{\prime}$ increased. Similar observation was reported by Tatsuoka et al. (1978). However, the influence of ${\sigma^{\prime}}_{v c}$ was less in $\xi$ of clean sand (Santa Monica sand) at higher $\sigma^{\prime}{ }_{v c}$ levels (Fig. 2.22). In addition Vucetic et al (1998) stated that OCR also significantly affects the $\xi$ of sands and increasing OCR decreases the $\xi$ (Fig. 2.23). Furthermore, they noticed 
the influence of $\sigma^{\prime}{ }_{v c}$ and OCR on $\xi$ of clays, but increasing Ip caused less influence of $\sigma^{\prime}{ }_{v c}$ and OCR on $\xi$. Factors that are affecting the maximum modulus, modulus reduction and damping ratio of soils were summarized by Dobry and Vucetic (1987) as shown in the Table 2.2. The conclusions reported in the table are based on extensive previous studies (Afifi and Richart 1973; Andersen 1983; Anderson and Richart 1976; Anderson and Stokoe 1978; Anderson and Woods 1975, 1976; Hardin 1978; Hardin and Black 1968; Ishihara 1986; Kim and Novak 1981; Kokusho et al. 1982; Marcuson and Wahls 1972; Seed and Idriss 1970; Vucetic and Dobry 1986).

Dobry and Vucetic (1991) strongly recommended a material-specific study on critical projects and problematic soils like sensitive clays or cemented sands. Further, they noticed the scattered data around the damping values of sensitive clays. Recent studies (e.g. Theenathayarl, 2015) confirmed that dynamic properties of sensitive Leda clay considerably deviated from the modulus reduction and damping curves reported in the literature. 

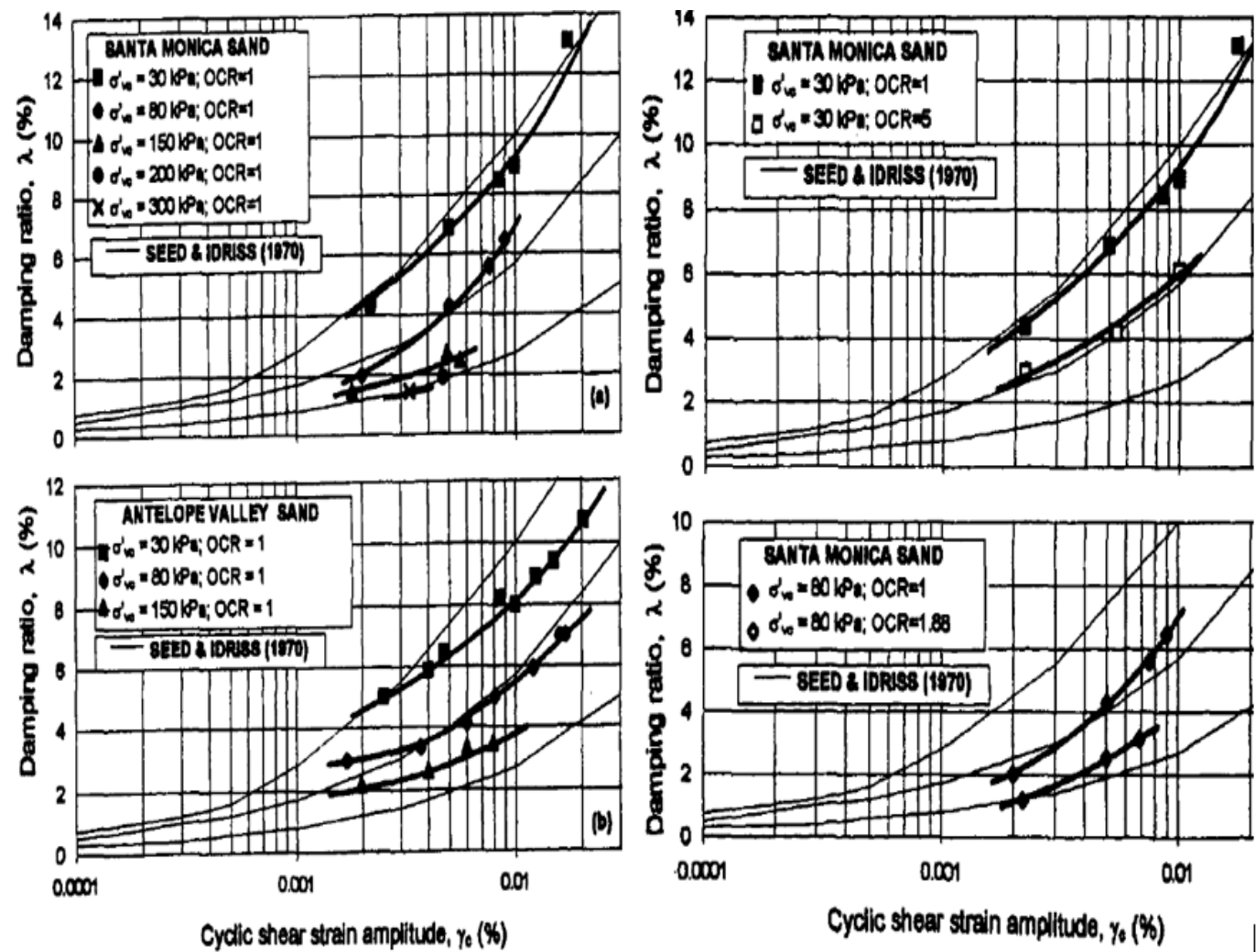

Fig 2.6 Influence of $\sigma^{\prime}{ }_{v c}$ on damping ration of sands (after Vucetic et al., 1998)

Fig 2.7 Influence of OCR on damping ration of sands (after Vucetic et al., 1998) 
Table 2.2 Influence of various factors on $G_{\max }, G_{s} / G_{m a x}$, and $\xi$ of clays (modified after Dobry and Vucetic, 1987)

\begin{tabular}{|c|c|c|c|}
\hline $\begin{array}{c}\text { Increasing } \\
\text { Factor }\end{array}$ & $\begin{array}{c}\text { Maximum Secant } \\
\text { Shear Modulus, } \\
\boldsymbol{G}_{\max }\end{array}$ & $\begin{array}{c}\text { Modulus Reduction, } \\
\boldsymbol{G}_{\boldsymbol{s}} / \boldsymbol{G}_{\max }\end{array}$ & Damping Ratio, $\boldsymbol{\xi}$ \\
\hline $\begin{array}{c}\text { Confining } \\
\text { pressure } \\
\left(\sigma^{\prime}{ }_{v c}\right)\end{array}$ & Increases with $\sigma_{v c}^{\prime}$ & $\begin{array}{c}\text { Stays constant or } \\
\text { increases with } \sigma^{\prime}{ }_{v c}\end{array}$ & $\begin{array}{c}\text { Stays constant or } \\
\text { decreases with } \sigma_{v c}^{\prime}\end{array}$ \\
\hline $\begin{array}{c}\text { Void ratio }(e) \\
\text { Geologic age } \\
\left(t_{g}\right)\end{array}$ & Decreases with $e$ & Increases with $e$ & Decreases with $e$ \\
\hline $\begin{array}{c}\text { Cementation } \\
(\mathrm{c})\end{array}$ & Increases with $t_{g}$ & May increase with $t_{g}$ & Decrease with $t_{g}$ \\
\hline OCR & Increases with OCR & May Increase with c & May decrease with c \\
\hline $\begin{array}{c}\text { Plasticity } \\
\text { Index (Ip) }\end{array}$ & $\begin{array}{c}\text { Increases with PI if } \\
\text { OCR }>1 ; \text { Stays }\end{array}$ & Increases with Ip & Decreases with Ip \\
\hline $\begin{array}{c}\text { Cyclic strain } \\
\left(\gamma_{c}\right)\end{array}$ & constant if OCR $=1$ & Decreases with $\left(\gamma_{c}\right)$ & Increases with $\left(\gamma_{c}\right)$ \\
\hline $\begin{array}{c}\text { Frequency of } \\
\text { loading }(f)\end{array}$ & Increases with $f$ & $\begin{array}{c}G_{s} \text { increases with } f \\
G_{s} / G_{\text {max }} \text { probably not } \\
\text { affected if } G_{s} \text { and } G_{m a x} \\
\text { are measured at same } f\end{array}$ & $\begin{array}{c}\text { Stays constant or } \\
\text { may increase with } f\end{array}$ \\
\hline
\end{tabular}




\section{EXPERIMENTAL PROGRAMME}

The main focus of this experimental research study is to investigate the undrained monotonic, cyclic and post-cyclic behaviour of different sensitive Leda clays obtained from Ottawa-Quebec area (Kinburn, ON, Breckenridge and Outardes-2, QC), and to estimate the dynamic properties required for site response analysis. In addition, a series of tests were conducted on Fraser River sand to establish its dynamic properties. All tests were conducted under simple shear loading condition.

Undrained monotonic, cyclic and post-cyclic tests were carried out to determine the strength properties of sensitive Leda clays. In addition, small strain tests were conducted to investigate the dynamic properties of Leda clays and Fraser River sand.

The first part of this chapter describes the simple shear device and its functions. The testing procedure is discussed in the second section including clay and sand samples preparation methods. The final part of this chapter describes the material properties of Fraser River sand and Leda clays from different sites.

\subsection{Simple shear device}

The simple shear device was introduced to geotechnical engineering in the early 1950 s (Kjellman 1951; Roscoe 1958). Since then it has been continually improved and numerous soil investigations have been conducted under simple shear over the years (e.g. Bjerrum and Landva, 1966; Ishihara and Yamazaki, 1980; Boulanger et al., 1998; Sivathayalan and Ha, 2011, etc.). The simple shear device at Carleton University is an NGI type device, and it uses a cylindrical specimen confined within a steel wire-reinforced membrane. 
Consolidation and shearing are the two basic phases of typical simple shear testing. Initially the sample will be consolidated one-dimensionally to the target consolidation stress. The wire-reinforced membrane prevents lateral deformation and imposes $K_{0}$ stress condition on the sample. The shear loads can be applied to the consolidated sample either under load or displacement controlled mode. Further, sharing can be done in either drained or undrained conditions. The undrained condition is appropriate for short term problems like soil liquefaction analysis. Undrained condition in simple shear is conveniently achieved by maintaining the sample height constant during the shearing phase. Constant sample height combined with the fixed cross-sectional area of the membrane leads to a constant volume test. The change in total vertical stress under constant volume has been shown to be equivalent to the pore water pressure which would be generated by the sample in a typical undrained test (Bjerrum and Landva, 1966; Dyvik et al., 1987).

\subsubsection{CU simple shear device}

Figure 3.1 shows a photograph of the NGI (Norwegian Geotechnical Institute) type simple shear device available at Carleton University and its components. The Model ASK DTC 148 commercial device from Seiken Inc. has been modified in-house to enable monotonic and cyclic tests with strain and stress controlled loads (Vipulanantham, 2011). A schematic diagram of this simple shear device can be seen in $\mathrm{Ha}$ (2003).

This device has top and bottom metal end platens which facilitate the testing of either 63.5 or $70 \mathrm{~mm}$ diameter of soil samples. Further, evenly spaced thin ribs on the platens minimize or prevent any slip at the sample-platen interface during the testing (Fig 3.3b). Drainage of pore water is enabled by the small circular shaped porous stones fixed at the center of each 
of these platens as seen in Fig 3.3(b). During the test, the bottom platen is clamped to the flat horizontal platform and the top platen is fastened to the rigid crossbeam arrangement, which is located in the upper part of the device.

In the CU simple shear device, the vertical consolidation stress and shear stress are applied from the bottom and the top of the sample respectively. A pneumatic piston located at the bottom of the device applies the vertical load to the sample during the consolidation process. Lateral stress is not applied externally, but mobilized on account of the $K_{0}$ conditions that prevail during consolidation. The device is competent in performing monotonic and cyclic tests at large and small strains.

A clamping mechanism is used to lock the sample at a constant height at the end of consolidation. Monotonic shearing is performed by a stepper motor (Model No. 5 624-39), which applies strain controlled load and controlled by the data acquisition and control program. Further, cyclic shearing is performed by a double acting pneumatic piston, which is controlled by electro-pneumatic transducer connected to a computer.

The height of the sample is typically chosen to be about $19.5 \mathrm{~mm}$ (for $63.5 \mathrm{~mm}$ diameter specimens) or $22.5 \mathrm{~mm}$ (for $70 \mathrm{~mm}$ diameter specimens). Such a dwarf specimen is preferred in simple shear since greater diameter to height ratios will lead to lower stress non-uniformities (Kovacs and Leo, 1981). 


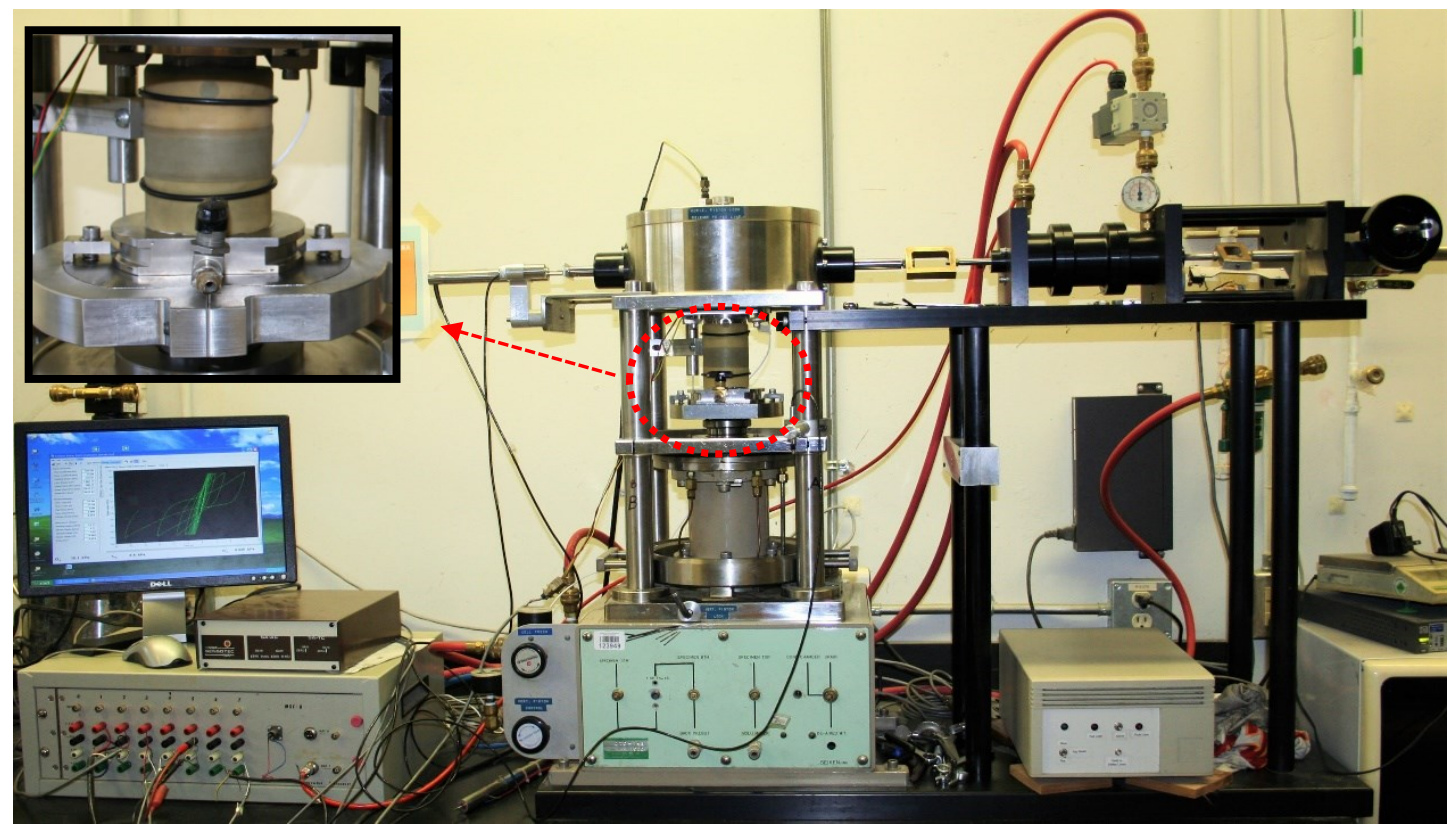

Fig 3.1 Carleton University simple shear device

\subsubsection{Measurements of stresses and strains}

Loads and displacements are measured by load cells and linear variable differential transducers (LVDT) respectively. Changes in loads or displacements manifest as differences in the output voltage of these transducers. A signal conditioner is deployed to process these changes in the voltage and filter the electrical noise. The signals are then transferred to a data acquisition card in the computer.

The top chamber has two Honeywell load cells which measure the vertical (normal) and horizontal (shear) stresses. The maximum capacity of the vertical load cell is $6000 \mathrm{~N}$. This permits to apply maximum normal stress of $1900 \mathrm{kPa}$ to $63.5 \mathrm{~mm}$ diameter sample and $1600 \mathrm{kPa}$ to $70 \mathrm{~mm}$ sample respectively. The maximum capacity of the horizontal load cell is about $( \pm) 950 \mathrm{~N}$. This translates to a maximum shear stress of about $( \pm) 300 \mathrm{kPa}$ to 
$63.5 \mathrm{~mm}$ sample and $( \pm) 250 \mathrm{kPa}$ to $70 \mathrm{~mm}$ sample respectively. These load cells have a high resolution of approximately $0.2 \mathrm{kPa}$.

Vertically fixed LVDT measures vertical displacement, which can measure up to $\pm 7.6 \mathrm{~mm}$ with a resolution of $4.0 \mu \mathrm{m}$. Horizontal displacements are measured by two LVDTs. Three LVDTs are available, and two are chosen depending on the type of testing. Larger-size horizontal LVDT can measure up to $\pm 12.7 \mathrm{~mm}$ with a resolution of $6.0 \mu \mathrm{m}$; medium size LVDT can measure up to $\pm 5.1 \mathrm{~mm}$ with a resolution of $1.0 \mu \mathrm{m}$ and small range LVDT can measure $\pm 0.5 \mathrm{~mm}$ with a resolutions of $0.05 \mu \mathrm{m}$. According to the testing requirement (large or small strain) an appropriate (medium or small range) LVDT will be chose in addition to large LVDT.

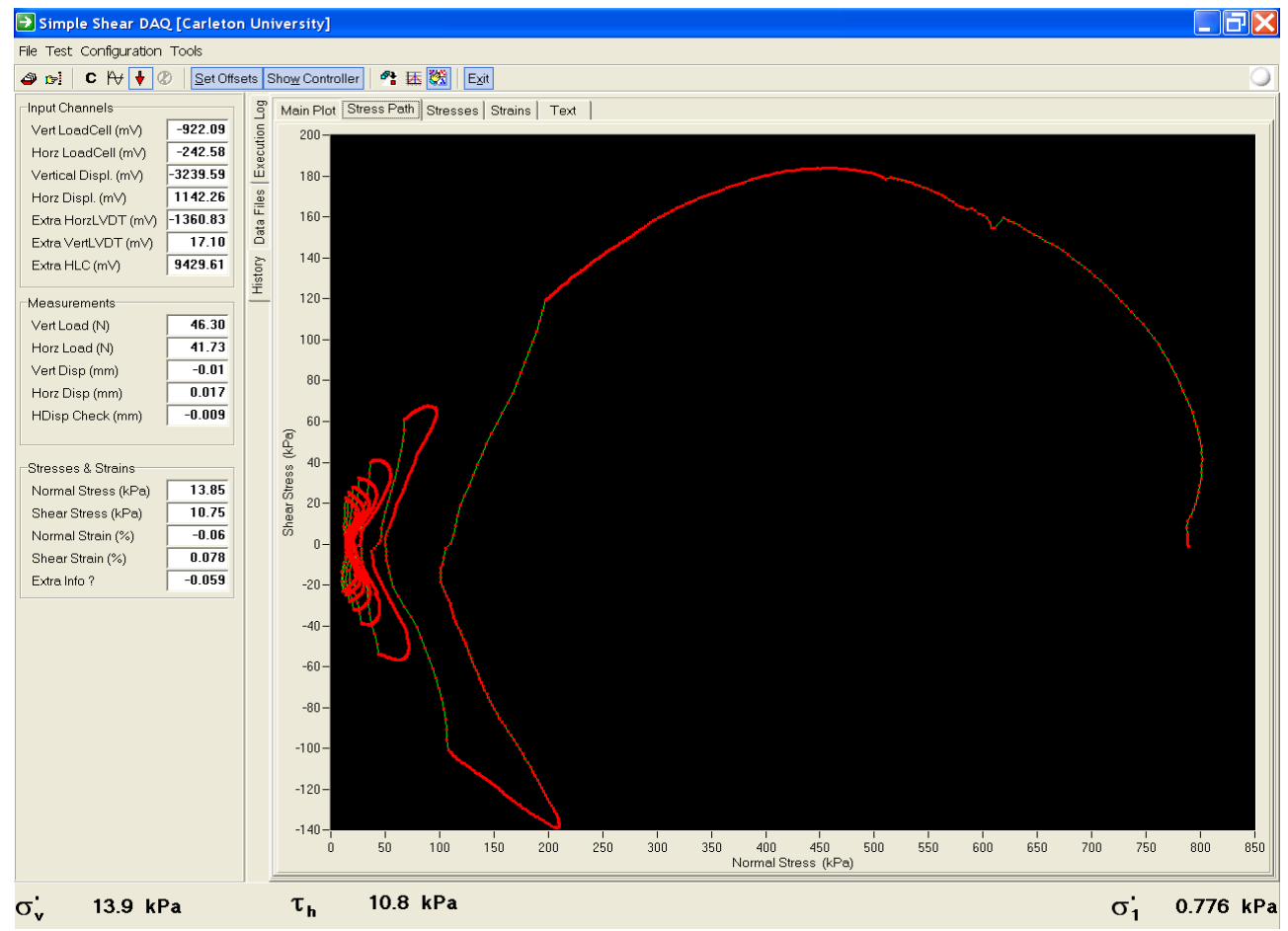

Fig 3.2 Computer interface of $\mathrm{CU}$ simple shear data acquisition program 


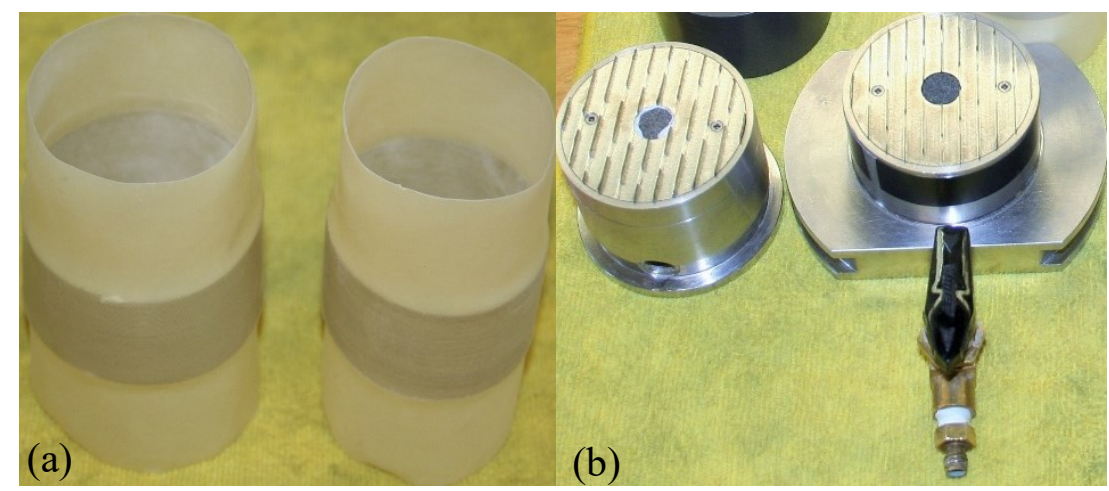

Fig 3.3 Wire reinforced rubber membranes and platens for simple shear tests. (a) 70 and $63.5 \mathrm{~mm}$ diameter membranes; (b) Top \& bottom platens from left to right respectively

\subsection{Test procedure}

High quality undisturbed sensitive Leda clay samples and reconstituted Fraser River sand samples were tested. Clearly, different methods were required for the preparation of clay and sand samples. Initially all samples were prepared away from the simple shear device and then they were carefully moved and positioned into the device. Testing was carried out in similar steps for both clays and sand samples, however less time was required to consolidate the sand specimens since the high permeability of sand allows quick dissipation of excess pore water pressure.

In all tests, first the simple shear data acquisition program was initiated on the computer and a known height dummy sample was utilized to establish a reference height in order to measure the height of the sample accurately. Later, initial readings of the load cells and LVDTs were recorded and set as offset values (or zero readings). Then the prepared sample was deployed in simple shear and shearing was carried out following the consolidation. 


\subsubsection{Preparation of simple shear mould}

In the sample preparation, either 63.5 or $70 \mathrm{~mm}$ diameter of mould was used. The initial step was preceded by placing the wire-reinforced membrane on the bottom pedestal and sealing with an O-ring. Then, two parts of split mould were positioned together around the membrane and they were held in place with a clamp. The top portion of the membrane was flipped over the top edge of the mould. After that in order to hold the membrane taut and to create the membrane-lined cavity about - $30 \mathrm{kPa}$ suction was applied through two ports in the mould.

\subsubsection{Sample preparations}

\subsubsection{Preparation of Leda clay sample}

First, unwrapped sample was trimmed few millimeters larger than the actual diameter and height of the sample using a wire saw. As presented in Fig 3.4, a cutting ring with the diameter of the sample and the height that is few millimeters taller than sample was inserted into the trimmed sample using a soil lathe. Then, a wire saw was used to level the top surface of the sample once it was collected into the ring. Later, an extension collar of the ring was inserted to facilitate trimming the sample to the necessary height $(22.5 \mathrm{~mm})$. After this, again wire saw was used to level the bottom surface of the sample and then the weight of the sample was determined. The trimmed clay particles were collected to determine the moisture content. A typical clay sample in the cutting ring is presented in Fig 3.5.

Following this, the soil sample was immediately transferred to the mould carefully, which was set up beforehand. Then, the top pedestal was placed in a way that the ribs are perpendicular to the shearing direction in order to prevent slip once the soil is placed into 
the cavity. Then the membrane was flipped back and sealed with another O-ring and initial height of sample was measured from a digital dial gauge. After that, the sample was carefully transferred to the platform of the simple shear device.

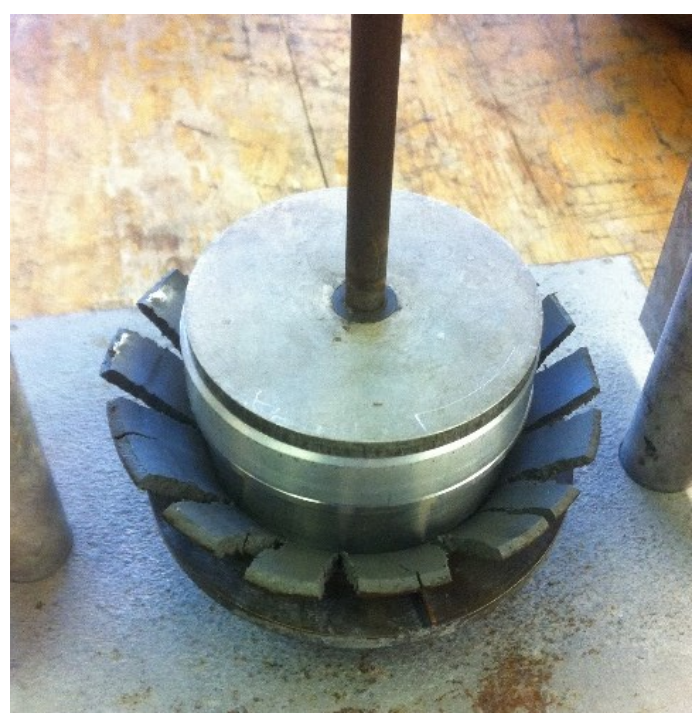

Fig 3.4 Soil lathe utilize to push the cutting ring into clay sample

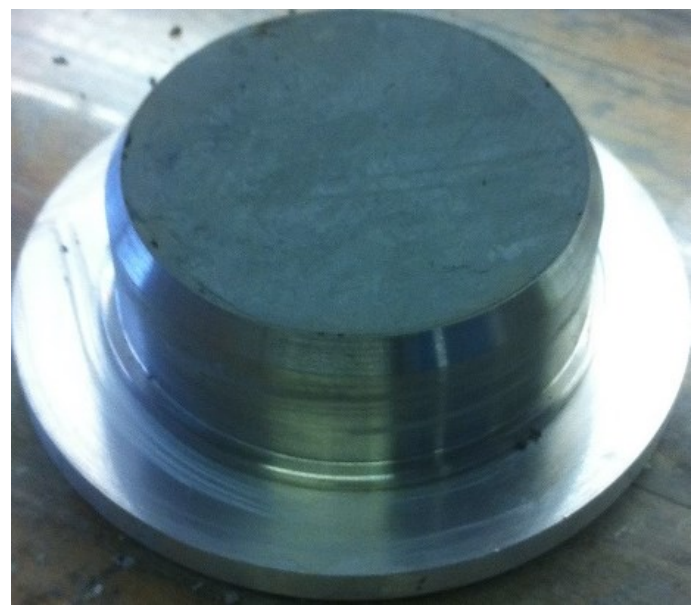

Fig 3.5 A prepared clay sample for simple shear testing 


\subsubsection{Preparation of Fraser River sand sample}

Fraser River sand (FRS) sample was reconstituted by air pluviation. A funnel was utilized to transfer a known weight of sand through the air while maintaining an approximately level surface during the deposition. Then the excess sand was siphoned off as shown in Fig 3.6 (a) to create a leveled top surface. Later, siphoned off excess sand was measured and the actual weight of the test specimen was determined. Then the top pedestal was placed with the ribs in a way that is perpendicular to the shearing direction and initial height of sample was measured using a digital dial gauge. Following this the membrane was flipped and sealed with another O-ring. During each step the height of sample was recorded as seen in Fig 3.6(b). In some cases in order to achieve the required target density, a wooden soft hammer was used to tap the table while monitoring the sample height with a digital dial gauge (before placing the O-ring). After that, the sample was transferred carefully towards the platform of simple shear apparatus.
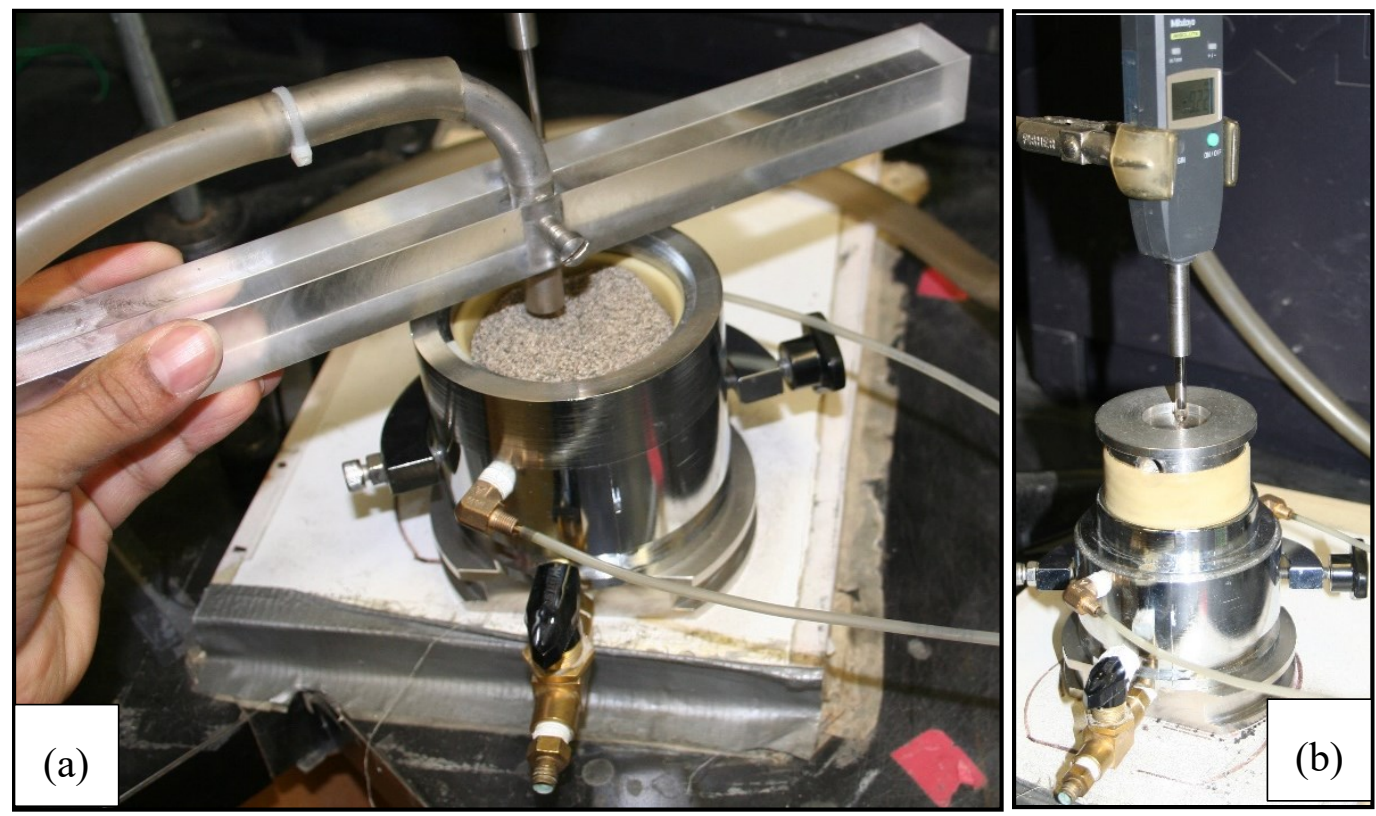

Fig 3.6 Preparation of a sample of Fraser River sand (a) siphoned off excess sand; (b) sample height from a digital dial gauge 


\subsection{Testing}

As noted earlier, consolidation and shearing are the two basic phases of typical simple shear testing. In the consolidation phase the sample was consolidated to the target stress state and the height changes were monitored. The wire-reinforced membrane prevented the lateral deformation and imposed $K_{0}$ stress condition on the sample. In the shearing phase, required undrained monotonic or cyclic loads were applied to the consolidated sample while maintaining the constant volume by keeping the sample height at constant. It should also be noted that both top and bottom pins, clamps and ribs (as shown in figure 3.7) ensure that the $\mathrm{CU}$ simple shear device properly transmits the shear forces.

\subsubsection{Consolidation phase}

Following the preparation, the sample was transferred to the base platform of the simple shear and then the platform was moved up slowly to contact with the top loading assembly by increasing the pressure in the vertical piston assembly. The initial height was recorded at a vertical stress level of about $12 \mathrm{kPa}$ to ensure the top platen has made sufficient contact. Subsequently, top and bottom pedestals were clamped firmly with their respective platforms and the split mould was removed carefully (Fig 3.7). Afterward, a predetermined consolidation stress $\left(\sigma_{\mathrm{vc}}^{\prime}\right)$ was applied by progressively increasing the pressure step by step using the vertical piston. In all circumstances, the target vertical stress was obtained with a load increment ratio of two $(\Delta \sigma / \sigma=2)$. Each step of consolidation stress was allowed for an hour and the final consolidation stress (target stress) was kept for approximately 12 hours (overnight) to ensure complete consolidation and dissipation of pore water pressure in clays. For sand, each step of consolidation stress was applied up to 
30 minutes and the final consolidation stress (target stress) was applied for an hour. Throughout the consolidation process, the drainage valve was kept open in order to facilitate drainage. During the consolidation process stresses and volumetric strains (equal to axial strain because of the constant sample area) were monitored and recorded automatically by the $\mathrm{CU}$ simple shear data acquisition program. Finally consolidated sample height was recorded at the end of consolidation.

\subsubsection{Shearing phase}

After completing the consolidation process, the vertical clamp was firmly tightened to maintain the height of consolidated sample to be constant, which facilitated constant volume testing. Also, an extra small range vertical LVDT with a resolution of $0.05 \mu \mathrm{m}$, was fixed to monitor the vertical deformations, and to make sure there was negligible vertical displacement $(\leq 0.01 \%)$ during the undrained shearing. During the shearing

process, normal Stress $\left(\sigma^{\prime}{ }_{\mathrm{vc}}\right)$, shear stress $(\tau)$, vertical and horizontal displacements were recorded by the data acquisition system.

In undrained monotonic shearing a slow shear strain rate of 5\% per hour was applied. This loading rate ensures pore-water pressure equalization within the sample during the shearing. The stress-controlled cyclic load was applied at a period (T) of $10 \mathrm{sec}$ for both clay and sand samples. At the end, sheared sample was removed from the device and carefully collected, and the weight was recorded. Later, dried sample weight was recorded to determine the water content, density and void ratio. Consequently, dried clay samples were utilized for Atterberg Limits and hydrometer tests. 


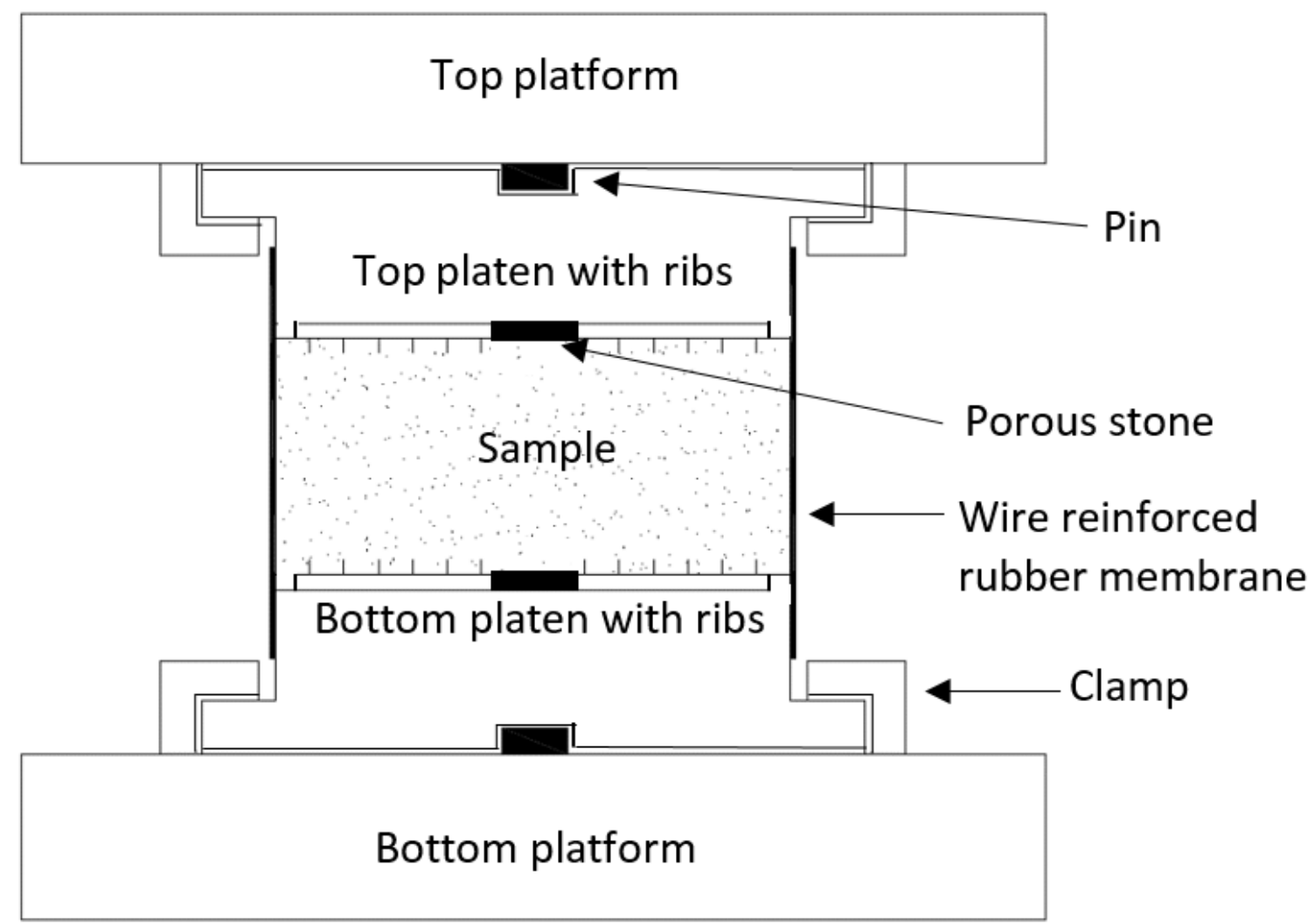

Fig 3.7 Sample setup after top and bottom pedestals were clamped firmly with their respective platforms and the split mould was removed

\subsection{Test program}

\subsubsection{Test program for Sensitive clay}

Monotonic simple shear tests were performed to evaluate the monotonic undrained strength characteristics of sensitive Leda clays under different consolidation stress levels $\left(\sigma_{\mathrm{vc}}^{\prime}\right)$. The $\sigma_{\mathrm{vc}}^{\prime}$ level varied from in-situ to normally consolidated stress level. In addition, strength reduction due to partial-remoulding on account of large quasi-cyclic loading was also evaluated.

Undrained cyclic tests were conducted at in-situ and normally consolidated stress level to determine the liquefaction characteristics of sensitive Leda clays. Characteristics were 
evaluated in terms of cyclic shear ratio $\left(\mathrm{CSR}=\tau_{c y c} / \sigma_{v c}^{\prime}\right)$ or normalized stress ratio $\left(\mathrm{NSR}=\tau_{c y c} / S_{u}\right)$. Further post-cyclic monotonic tests were carried out to investigate the post-cyclic behaviour of Leda clays. All these tests facilitated the assessment of undisturbed, partially remoulded and liquefied Leda clays' shear strength characteristics. The monotonic and cyclic tests performed in this research study are listed in the Table 3.1 and 3.2.

In addition, small strain and stress controlled quasi-cyclic tests were carried out to establish modulus reduction and damping curves of different Leda clays under different $\sigma^{\prime}{ }_{\mathrm{vc}}$ varying from 50 to $800 \mathrm{kPa}$. The strain and stress controlled tests conducted on Leda clays during this research study are listed in Table 3.3 and 3.4.

Table 3.1 Details of monotonic tests on Leda clays

\begin{tabular}{|c|c|c|c|c|c|c|}
\hline Site & Test ID & Borehole & $\begin{array}{c}\text { Block } \\
\text { sample } \\
\text { number }\end{array}$ & $\begin{array}{l}\text { Depth } \\
\text { (m) }\end{array}$ & $\begin{array}{c}\text { Consolidation } \\
\text { stress }\left(\sigma^{\prime}{ }_{\mathrm{vc}}\right) \\
(\mathrm{kPa})\end{array}$ & $\begin{array}{c}\text { Peak } \\
\mathrm{S}_{\mathrm{u}} \\
(\mathrm{kPa})\end{array}$ \\
\hline Kinburn (OC) & MON-01 & BH-GSC-JSR-02 & TO-37 & 10.36 & 75 & 34.09 \\
\hline Kinburn $(\mathrm{OC})$ & MON-01R & BH-GSC-JSR-02 & TO-37 & 10.36 & 75 & 26.98 \\
\hline Kinburn (NC) & MON-02 & BH-GSC-JSR-02 & TO-34 & 10.60 & 400 & 99.41 \\
\hline Kinburn $(\mathrm{OC})$ & MON-03 & BH-GSC-JSR-02 & TO-30 & 21.06 & 150 & 46.40 \\
\hline Kinburn (OC) & MON-03R & BH-GSC-JSR-02 & TO-30 & 21.06 & 150 & 56.37 \\
\hline $\begin{array}{l}\text { Breckenridge } \\
\text { (OC) }\end{array}$ & MON-04 & BH-GSC-BRK-01 & TO-47 & 25.58 & 150 & 51.36 \\
\hline $\begin{array}{l}\text { Breckenridge } \\
(\mathrm{NC})\end{array}$ & MON-05 & BH-GSC-BRK-01 & TO-44 & 25.94 & 400 & 93.78 \\
\hline $\begin{array}{l}\text { Outardes-2 } \\
(\mathrm{OC})\end{array}$ & MON-06 & F-03-13 & TM-2B & 10.93 & 130 & 66.47 \\
\hline $\begin{array}{l}\text { Outardes-2 } \\
\text { (NC) }\end{array}$ & MON-07 & F-03-13 & TM-2B & 10.93 & 800 & 184.13 \\
\hline
\end{tabular}


Table 3.2 Details of cyclic tests on Leda clays

\begin{tabular}{|c|c|c|c|c|c|}
\hline \multirow[b]{2}{*}{ Site } & \multirow[b]{2}{*}{ BH details } & \multirow{2}{*}{$\begin{array}{l}\text { Test } \\
\text { ID }\end{array}$} & \multicolumn{3}{|c|}{ Cyclic Tests } \\
\hline & & & $\begin{array}{l}\sigma_{\text {vc }}^{\prime} \\
(\mathrm{kPa})\end{array}$ & $\begin{array}{l}\tau_{c y c} \\
(\mathbf{k P a})\end{array}$ & CSR \\
\hline \multirow{6}{*}{ Kinburn (OC) } & BH-GSC-JSR-02, TO-37, $10.2 \mathrm{~m}$ & CYC-01 & 75 & 27.00 & 0.360 \\
\hline & BH-GSC-JSR-02, TO-35, $10.5 \mathrm{~m}$ & CYC-02 & 75 & 24.0 & 0.320 \\
\hline & BH-GSC-JSR-02, TO-35, 10.5m & CYC-03 & 75 & 26.0 & 0.347 \\
\hline & BH-GSC-JSR-02, TO-35, $10.5 \mathrm{~m}$ & CYC-04 & 75 & 28.5 & 0.380 \\
\hline & BH-GSC-JSR-02, TO-35, $10.5 \mathrm{~m}$ & CYC-05 & 75 & 22.0 & 0.293 \\
\hline & BH-GSC-JSR-02, TO-37, 10.2m & CYC-23 & 75 & 23.0 & 0.307 \\
\hline \multirow{3}{*}{ Kinburn (NC) } & BH-GSC-JSR-02, TO-34, 10.6m & CYC-06 & 400 & 70.0 & 0.175 \\
\hline & BH-GSC-JSR-02, TO-34, 10.6m & CYC-07 & 400 & 90.0 & 0.225 \\
\hline & BH-GSC-JSR-02, TO-34, 10.6m & CYC-08 & 400 & 80.0 & 0.200 \\
\hline \multirow{5}{*}{$\begin{array}{l}\text { Breckenridge } \\
\text { (OC) }\end{array}$} & BH-GSC-BRK-01, TO-47, 25.6m & CYC-09 & 150 & 41.0 & 0.273 \\
\hline & BH-GSC-BRK-01, TO-47, 25.6m & CYC-10 & 150 & 36.0 & 0.240 \\
\hline & BH-GSC-BRK-01, TO-46, 25.7m & CYC-11 & 150 & 30.0 & 0.200 \\
\hline & BH-GSC-BRK-01, TO-46, 25.7m & CYC-12 & 150 & 33.0 & 0.220 \\
\hline & BH-GSC-BRK-01, TO-46, 25.7m & CYC-13 & 150 & 38.0 & 0.253 \\
\hline \multirow{3}{*}{$\begin{array}{l}\text { Breckenridge } \\
\text { (NC) }\end{array}$} & BH-GSC-BRK-01, TO-44, 25.9m & CYC-14 & 400 & 75.0 & 0.188 \\
\hline & BH-GSC-BRK-01, TO-44, 25.9m & CYC-15 & 400 & 85.0 & 0.213 \\
\hline & BH-GSC-BRK-01, TO-44, 25.9m & CYC-16 & 400 & 69.0 & 0.173 \\
\hline \multirow{3}{*}{$\begin{array}{l}\text { Outardes-2 } \\
\text { (OC) }\end{array}$} & F-03-13, TM-2B, $10.9 \mathrm{~m}$ & CYC-17 & 130 & 53.0 & 0.408 \\
\hline & F-03-13, TM-2B, $10.9 \mathrm{~m}$ & CYC-18 & 130 & 46.0 & 0.354 \\
\hline & F-03-13, TM-2B, $10.9 \mathrm{~m}$ & CYC-19 & 130 & 62.0 & 0.477 \\
\hline \multirow{3}{*}{$\begin{array}{l}\text { Outardes-2 } \\
\text { (NC) }\end{array}$} & F-03-13, TM-2B, $10.9 \mathrm{~m}$ & CYC-20 & 800 & 129.0 & 0.161 \\
\hline & F-03-13, TM-2B, $10.9 \mathrm{~m}$ & CYC-21 & 800 & 150.0 & 0.188 \\
\hline & F-03-13, TM-2B, 10.9m & CYC-22 & 800 & 170.0 & 0.213 \\
\hline \multirow{3}{*}{ Kinburn (NC) } & BH-GSC-JSR-03, TO-09, 13.9m & CYC-24 & 300 & 55.0 & 0.181 \\
\hline & BH-GSC-JSR-03, TO-09, 13.9m & CYC-25 & 300 & 60.0 & 0.198 \\
\hline & BH-GSC-JSR-03, TO-09, 13.9m & CYC-26 & 300 & 67.0 & 0.221 \\
\hline \multirow{3}{*}{$\begin{array}{c}\text { Breckenridge } \\
\text { (NC) }\end{array}$} & BH-GSC-BRK-02, 27.6m & CYC-27 & 300 & 56.0 & 0.186 \\
\hline & BH-GSC-BRK-02, 27.6m & CYC-28 & 300 & 62.0 & 0.206 \\
\hline & BH-GSC-BRK-02, 27.6m & CYC-29 & 300 & 70.0 & 0.232 \\
\hline \multirow{3}{*}{$\begin{array}{l}\text { Outardes-2 } \\
\text { (NC) }\end{array}$} & F-03-13, 10.8m & CYC-30 & 500 & 87.0 & 0.173 \\
\hline & F-03-13, 10.8m & CYC-31 & 500 & 100.0 & 0.198 \\
\hline & F-03-13, 10.8m & CYC-32 & 500 & 120.0 & 0.238 \\
\hline
\end{tabular}


Table 3.3 Details of strain-controlled tests on Leda clays

\begin{tabular}{|c|c|c|c|c|c|}
\hline Site & Test ID & Borehole & $\begin{array}{c}\text { Depth } \\
\text { (m) }\end{array}$ & $\begin{array}{c}\sigma_{\mathrm{vc}}^{\prime} \\
(\mathrm{kPa})\end{array}$ & Description \\
\hline \multirow{9}{*}{ Kinburn } & MON-M\&D - 01 & BH-GSC-JSR-02 & 10.36 & 50 & \multirow{9}{*}{$\begin{array}{c}\gamma(\%)=0.01 \\
0.02,0.05 \\
0.1,0.2,0.5,1 \& 2\end{array}$} \\
\hline & MON-M\&D - 02 & BH-GSC-JSR-02 & 10.36 & 100 & \\
\hline & MON-M\&D - 03 & BH-GSC-JSR-02 & 10.36 & 200 & \\
\hline & MON-M\&D - 04 & BH-GSC-JSR-02 & 10.36 & 400 & \\
\hline & MON-M\&D - 05 & BH-GSC-JSR-02 & 21.06 & 50 & \\
\hline & MON-M\&D - 06 & BH-GSC-JSR-02 & 21.06 & 100 & \\
\hline & MON-M\&D - 07 & BH-GSC-JSR-02 & 21.06 & 200 & \\
\hline & MON-M\&D - 08 & BH-GSC-JSR-02 & 21.06 & 400 & \\
\hline & MON-M\&D - 09 & BH-GSC-JSR-02 & 21.06 & 800 & \\
\hline \multirow{5}{*}{ Breckenridge } & MON-M\&D - 10 & BH-GSC-BRK-01 & 25.82 & 50 & \multirow{5}{*}{$\begin{array}{c}\gamma(\%)=0.01 \\
0.02,0.05 \\
0.1,0.2,0.5,1 \& 2\end{array}$} \\
\hline & MON-M\&D - 11 & BH-GSC-BRK-01 & 25.82 & 100 & \\
\hline & MON-M\&D - 12 & BH-GSC-BRK-01 & 25.82 & 200 & \\
\hline & MON-M\&D - 13 & BH-GSC-BRK-01 & 25.82 & 400 & \\
\hline & MON-M\&D - 14 & BH-GSC-BRK-01 & 25.82 & 800 & \\
\hline \multirow{5}{*}{ Outardes-2 } & MON-M\&D - 15 & F-03-13 & 10.93 & 50 & \multirow{5}{*}{$\begin{array}{c}\gamma(\%)=0.01 \\
0.02,0.05 \\
0.1,0.2,0.5,1 \& 2\end{array}$} \\
\hline & MON-M\&D - 16 & F-03-13 & 10.93 & 100 & \\
\hline & MON-M\&D - 17 & F-03-13 & 10.93 & 200 & \\
\hline & MON-M\&D - 18 & F-03-13 & 10.93 & 400 & \\
\hline & MON-M\&D - 19 & F-03-13 & 10.93 & 800 & \\
\hline
\end{tabular}


Table 3.4 Details of stress-controlled tests on Leda clays

\begin{tabular}{|c|c|c|c|c|c|}
\hline Site & Test ID & Borehole & $\begin{array}{l}\text { Depth } \\
(\mathrm{m})\end{array}$ & $\begin{array}{c}\sigma_{\mathrm{vc}}^{\prime} \\
(\mathrm{kPa})\end{array}$ & Description \\
\hline \multirow{5}{*}{ Kinburn } & CYC-M\&D - 01 & BH-GSC-JSR-03 & 13.585 & 50 & \multirow{5}{*}{$\begin{array}{c}\tau_{c y c}(\mathrm{kPa})= \\
1,2,4,8,16,32,64\end{array}$} \\
\hline & CYC-M\&D - 02 & BH-GSC-JSR-03 & 13.585 & 100 & \\
\hline & CYC-M\&D - 03 & BH-GSC-JSR-03 & 13.585 & 200 & \\
\hline & CYC-M\&D - 04 & BH-GSC-JSR-03 & 13.585 & 400 & \\
\hline & CYC-M\&D - 05 & BH-GSC-JSR-03 & 13.585 & 800 & \\
\hline \multirow{4}{*}{ Breckenridge } & CYC-M\&D - 06 & BH-GSC-BRK-01 & 25.815 & 100 & \multirow{4}{*}{$\begin{array}{c}\tau_{c y c}(\mathrm{kPa})= \\
1,2,4,8,16,32,64\end{array}$} \\
\hline & CYC-M\&D - 07 & BH-GSC-BRK-01 & 25.815 & 200 & \\
\hline & CYC-M\&D - 08 & BH-GSC-BRK-01 & 25.815 & 400 & \\
\hline & CYC-M\&D - 09 & BH-GSC-BRK-01 & 25.815 & 800 & \\
\hline
\end{tabular}

\subsubsection{Test program for Fraser River sand}

Stress-controlled tests were carried out to establish modulus reduction and damping curves of Fraser River sand and to assess the influence of different $\sigma^{\prime}{ }_{\mathrm{vc}}$, over-consolidation ratio (OCR) and relative density (Dr) on the dynamic properties. The stress-controlled tests carried out on Fraser River sand are listed in Table 3.5. 
Table 3.5 Details of stress-controlled tests on Fraser River Sand

\begin{tabular}{|c|c|c|c|c|c|}
\hline Site & Test ID & $\begin{array}{c}\sigma_{\mathrm{vc}}^{\prime} \\
(\mathrm{kPa})\end{array}$ & Density & OCR & Description \\
\hline \multirow{4}{*}{$\begin{array}{l}\text { Fraser } \\
\text { River } \\
\text { (FRS) }\end{array}$} & S_CYC-M\&D-01 & 50 & \multirow{4}{*}{ Loose } & \multirow{4}{*}{1} & \multirow{4}{*}{$\begin{array}{c}\tau_{c y c}(\mathrm{kPa})= \\
1,2,4,8,16,32 \\
\& 64 \mathrm{kPa}\end{array}$} \\
\hline & S CYC-M\&D-02 & 100 & & & \\
\hline & S CYC-M\&D-03 & 200 & & & \\
\hline & S_CYC-M\&D-04 & 400 & & & \\
\hline \multicolumn{6}{|c|}{ Test ID: S_CYC-M\&D-01 to S_CYC-M\&D-36 } \\
\hline Site & $\sigma_{\mathrm{vc}}^{\prime}(\mathrm{kPa})$ & Density & Descriptions & Description & $\begin{array}{l}\text { Number of } \\
\text { Tests }\end{array}$ \\
\hline \multirow{3}{*}{$\begin{array}{l}\text { Fraser } \\
\text { River } \\
\text { (FRS) }\end{array}$} & \multirow{3}{*}{50 to $400 \mathrm{kPa}$} & Loose & $\begin{array}{l}\mathrm{OCR}=1,2 \& 4 \mathrm{M} \& \mathrm{D} \\
\text { (Stress Controlled) }\end{array}$ & \multirow{3}{*}{$\begin{array}{c}\tau_{c y c}(\mathrm{kPa})= \\
1,2,4,8,16,32 \\
\& 64 \mathrm{kPa}\end{array}$} & 12 \\
\hline & & Medium & $\begin{array}{l}\mathrm{OCR}=1,2 \& 4 \mathrm{M} \& \mathrm{D} \\
\text { (Stress Controlled) }\end{array}$ & & 12 \\
\hline & & Dense & $\begin{array}{l}\mathrm{OCR}=1,2 \& 4 \mathrm{M} \& \mathrm{D} \\
\text { (Stress Controlled) }\end{array}$ & & 12 \\
\hline
\end{tabular}

\subsection{Material properties of tested clay and sand}

\subsubsection{Sensitive Leda clay}

The liquid limit (LL), plastic limit (PL), plasticity index $\left(\mathrm{I}_{\mathrm{P}}\right)$, natural moisture content, density and particle size distribution have been determined for the Leda clay samples from different sites. The chemical compositions of these Leda clays have been reported by Theenathayarl (2015).

\subsubsection{Atterberg Limits}

Casagrande cup tests (ASTM D 4318) and plastic limit tests (ASTM D 4318) were conducted on different samples from Kinburn, Breckenridge, and Outardes-2 sites to determine the liquid limit (LL) and the plastic limit (PL). LL varied from 49 to 29. Kinburn samples from $11 \mathrm{~m}$ depth had the higher LL of 49 and Outardes-2 samples from $11 \mathrm{~m}$ depth had lower LL of 29. Further, plastic limit varied from 29 to 20. Breckenridge sample from 
26m depth and Kinburn samples from 11m depth had the higher PL of 29 and Outardes-2 sample had lower PL of 20. The Atterberg limits determined are generally comparable to that reported by Blanchette (2014) except for LL of Kinburn $(z=11 \mathrm{~m})$ and Breckenridge $(\mathrm{z}=26 \mathrm{~m})$ samples. These results, together with the fraction of particles smaller than the silt and clay sizes are presented in Table 3.6.

Table 3.6 Atterberg limits and other properties of Leda clays from different sites

\begin{tabular}{|l|r|r|r|r|r|r|r|}
\hline \multicolumn{1}{|c|}{$\begin{array}{c}\text { Bore Hole No / } \\
\text { Location }\end{array}$} & $\begin{array}{c}\text { Natural } \\
\text { Moisture } \\
\text { Content } \\
(\%)\end{array}$ & $\begin{array}{c}\text { Liquid } \\
\text { Limit } \\
\text { (LL) }\end{array}$ & $\begin{array}{c}\text { Plastic } \\
\text { Limit } \\
\text { (PL) }\end{array}$ & $\begin{array}{c}\text { Plasticity } \\
\text { Index (I })\end{array}$ & $\begin{array}{c}\text { Liquidity } \\
\text { Index (I })\end{array}$ & \multicolumn{2}{|c|}{\begin{tabular}{c}
\multicolumn{2}{|c|}{ Particle passing } \\
\cline { 5 - 8 }
\end{tabular}} \\
\hline $\begin{array}{l}\text { BH-GSC-JSR-02, } \\
\text { Kinburn (11m) }\end{array}$ & 79.4 & 49.4 & 29.3 & 20.1 & 2.4 & 99 & 79 \\
\hline $\begin{array}{l}\text { BH-GSC-JSR-02, } \\
\text { Kinburn (21m) }\end{array}$ & 50.4 & 47.6 & 23.2 & 24.4 & 1.1 & 99 & 59 \\
\hline $\begin{array}{l}\text { BH-GSC-BRK-01, } \\
\text { Breckenridge(26m) }\end{array}$ & 73.2 & 48.6 & 29.4 & 19.2 & 2.2 & 100 & 72 \\
\hline $\begin{array}{l}\text { F-03-13, } \\
\text { Outardes-2 (11m) }\end{array}$ & 30.1 & 29.5 & 20.3 & 9.2 & 1.0 & 90 & 27 \\
\hline
\end{tabular}

\subsubsection{Particle size distribution}

Hydrometer tests (ASTM D 422) and sieve analyses were carried out to determine the particle size distribution of the samples. Sieve analysis was carried out on samples to determine the gradation above No.200 $(75 \mu \mathrm{m})$ sieve, and hydrometer to determine the particle size distribution of the fine particles. Results showed that all particles were finer than $425 \mu \mathrm{m}$ at all sites. Percentage of particles finer than $75 \mu \mathrm{m}$ was $99 \%$ for Kinburn clays, $100 \%$ for Breckenridge clays and $90 \%$ for Outardes- 2 clays. On the other hand, Kinburn clays from $11 \mathrm{~m}$ depth had a higher percentage of clay size particles of $79 \%$ followed by 
$72 \%$ of Breckenridge samples. Outardes- 2 samples had lesser clay size particles of $27 \%$. The gradation curves of Leda clays from the four locations are presented in Fig 3.8.

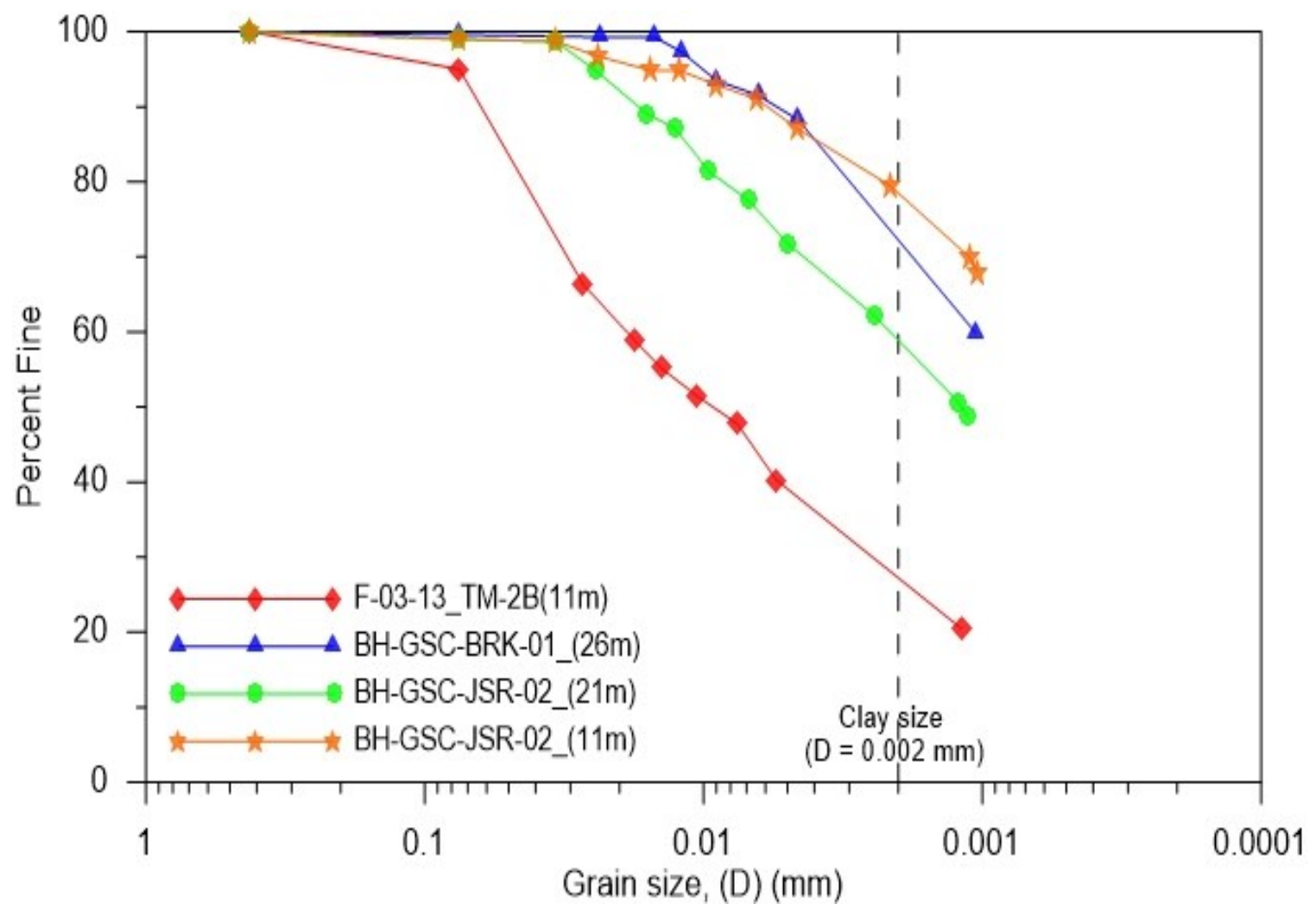

Fig 3.8 Particle size distributions of Leda clays from different sites

\subsubsection{Fraser River sand}

Fraser River sand specimens were prepared from the bulk samples obtained from the Fraser Delta in British Columbia. This sand was wet-sieved through a $0.075 \mathrm{~mm}$ sieve ( $\# 200$ sieve) to remove fine particles which permit the preparation of uniform specimens (Logeswaran, 2010). Maximum and minimum void ratio and other properties of this batch of Fraser River sand (determined according to the ASTM specifications by Logeswaran, 2010 ) are as follows: $\mathrm{e}_{\max }=0.806$ and $\mathrm{e}_{\min }=0.509$, Average particle size $\mathrm{D}_{50}=0.28 \mathrm{~mm}$, uniformity coefficient $C_{u}=2.92$, coefficient of curvature $C_{c}=1.27$ and specific gravity $G_{s}$ 
$=2.67$. Fig 3.9 shows the particle size distribution of the Fraser River sand as received and after the wet-sieving through No.200 sieve.

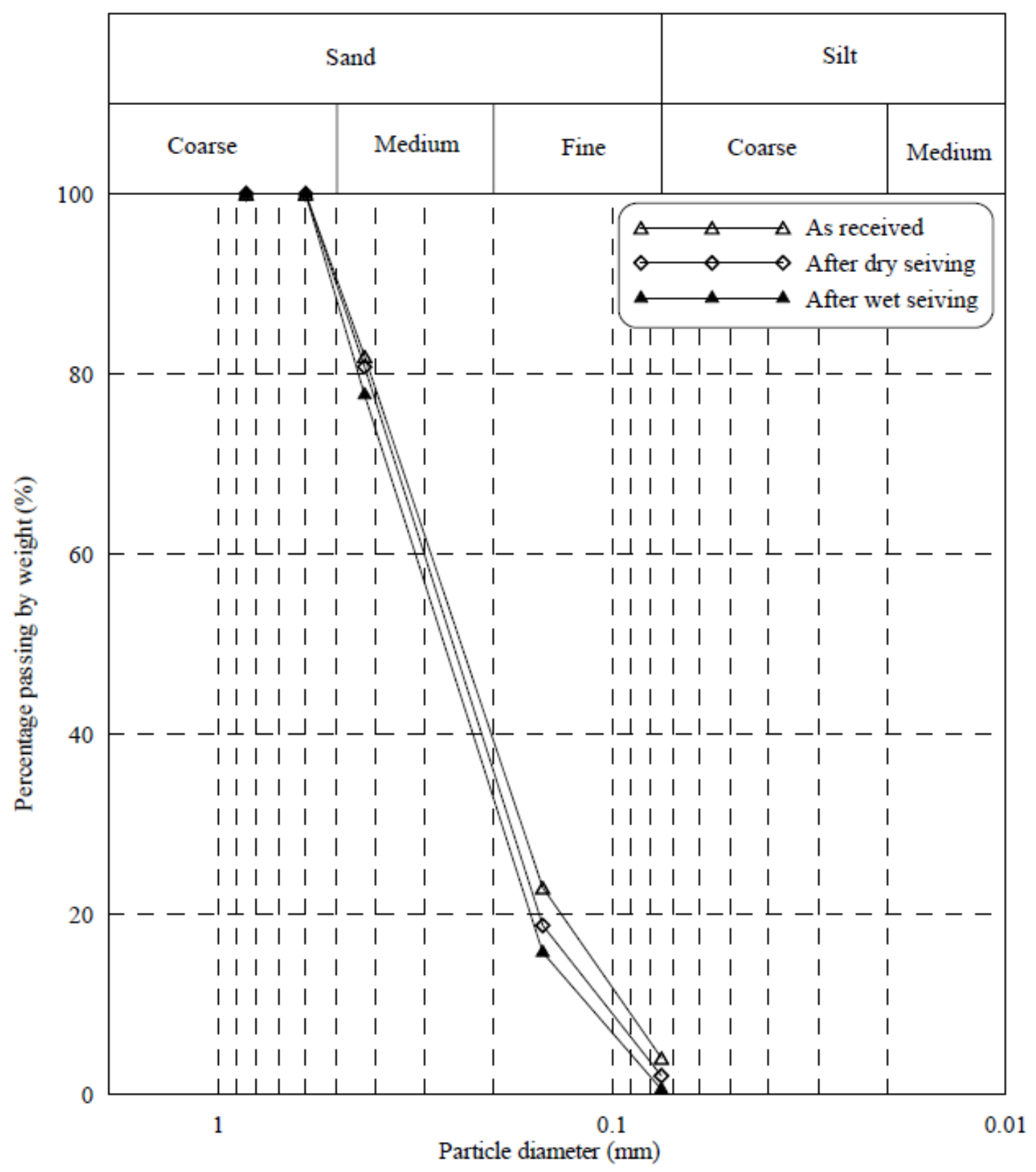

Fig 3.9 Grain size distribution of Fraser River sand (after Logeswaran, 2010) 


\section{MONOTONIC AND CYCLIC BEHAVIOUR OF LEDA CLAY}

\subsection{Introduction}

Undrained monotonic, cyclic and post-cyclic behaviour of sensitive Leda clays obtained from sites in Ottawa-Quebec region under simple shear condition are presented in this chapter. The first part of the chapter investigates the undrained monotonic behaviour of Leda clays and its dependency on different factors. It is followed by an investigation of the potential reduction in undrained shear strength due to repeated loading. Next part examines the undrained cyclic behaviour of Leda clays and the factors controlling the cyclic behaviour. Finally, the last part discusses the post-cyclic monotonic behaviour of Leda clays.

\subsection{Undrained Monotonic behaviour of Sensitive Leda clays}

Sensitive Leda clay specimens obtained using undisturbed sampling techniques from three experimental sites (Kinburn, ON, Breckenridge and Outardes-2, QC), were tested under simple shear condition. Samples from depths of $21 \mathrm{~m}$ (BH-GSC-JSR-02) and $11 \mathrm{~m}$ (BHGSC-JSR-02) were tested from Kinburn. Further, specimens from a single depth were considered for Breckenridge (BH-GSC-BRK-01, 26m) and Outardes-2, (F-03-13, TM2B, $\sim 11 \mathrm{~m})$ sites. Samples were tested under different consolidation stress levels $\left(\sigma_{\mathrm{vc}}^{\prime}\right)$, which were chosen to represent the in-situ (calculated according to the ground profile) and a higher stress state. 
All tests were carried out by following essentially identical procedures to make sure the repeatability and consistency of the testing. Strain-controlled shear loading was applied at a rate of $\gamma=5 \%$ per hour in all tests.

Fig 4.1 compares the stress-strain behaviour and stress path of sensitive Leda clays obtained from Kinburn and Breckenridge sites, tested at in-situ stress level (naturally OC). These sensitive clays show a clear peak state followed by strain softening in the stressstrain response. Initially, increasing shear strain $(\gamma)$ rapidly increases the shear stress amplitudes $(\tau)$ and reach the peak undrained shear strengths $\left(S_{u}\right)$ within a $\gamma$ range of $2 \%$ to 4\%. After reaching the peak $S_{u}$ the samples slowly strain soften, and then approach a residual state for very large $\gamma$ as seen in Fig 4.1(a). Similar observations were reported in the literature for clays (Lee, 1979; Lefebvre et al, 1989 and Theenathayarl, 2015).

During undrained shearing, excess pore water pressure $(\Delta u)$ continuously increased and caused significant reduction in effective stress $\left(\sigma_{v}^{\prime}\right)$. Due to this process, the stress path traveled towards the origin as illustrated in the Fig 4.1b. 

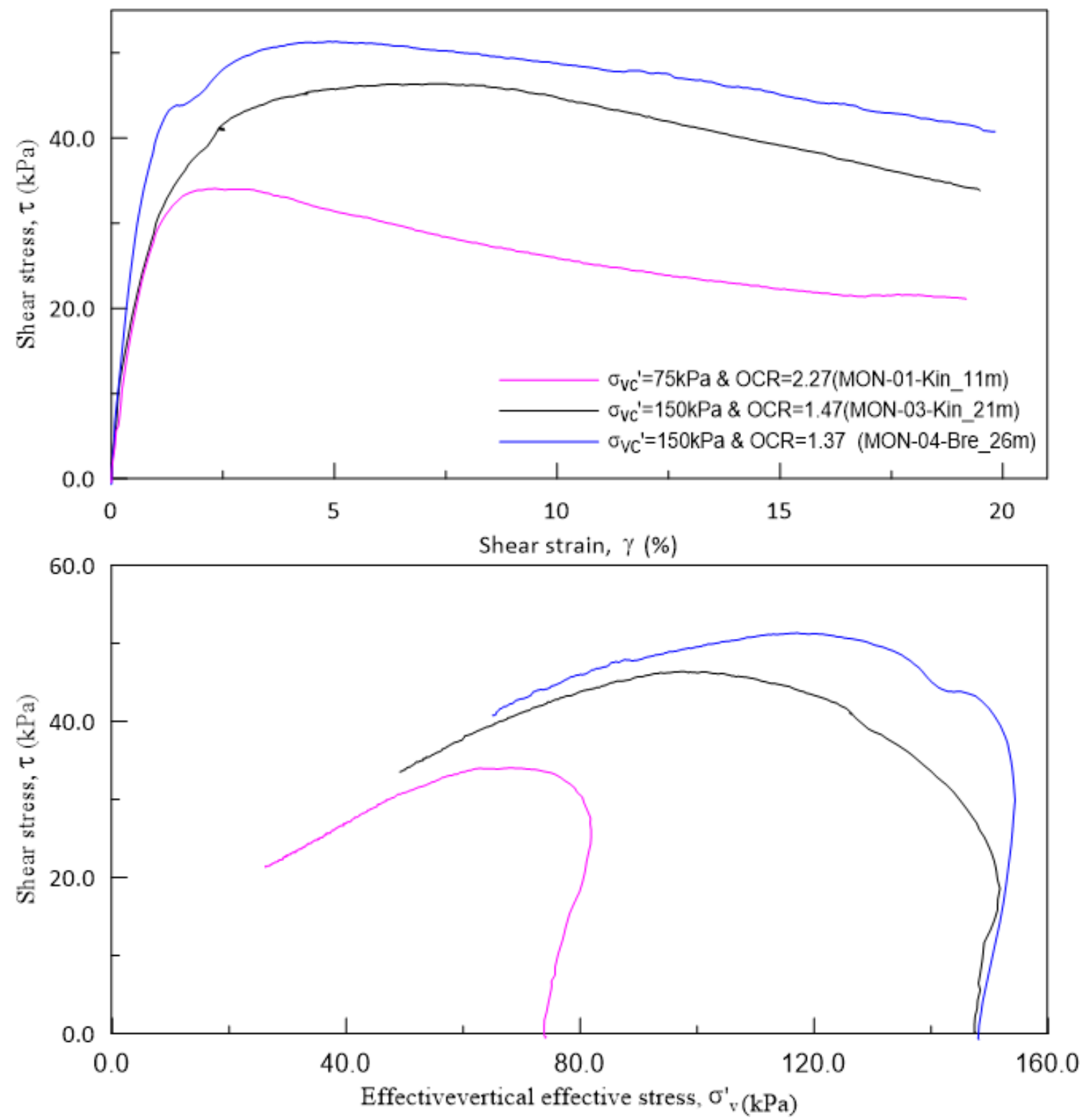

Fig 4.1 Undrained monotonic behaviour of Leda clays under in-situ $\sigma_{v c}^{\prime}$, (a) Stress strain behaviour (b) Stress path

\subsubsection{Influence of effective vertical consolidation stress in shear strength}

The undrained monotonic behaviour of sensitive Leda clays from Kinburn (21m depth), Breckenridge (26m depth) and Outardes-2 sites (11m depth) were evaluated under different consolidation stresses $\left(\sigma^{\prime}{ }_{\mathrm{vc}}\right)$. 
Test results plotted in Fig 4.2 compares the undrained peak shear strength $\left(S_{u}\right)$ of Leda clays under in-situ and higher consolidation stress levels. Kinburn samples were consolidated to $\sigma^{\prime}{ }_{\mathrm{vc}}=75$ and $400 \mathrm{kPa}$; Breckenridge samples to $\sigma_{\mathrm{vc}}^{\prime}=150$ and $400 \mathrm{kPa}$; and Outardes-2 samples to $\sigma_{\mathrm{vc}}^{\prime}=130$ and $800 \mathrm{kPa}$ to represent their in-situ state, and a higher stress level, since the pre-consolidation pressure $\left(\sigma_{\mathrm{p}}^{\prime}\right)$ for Kinburn $(11 \mathrm{~m})$, Breckenridge $(26 \mathrm{~m})$, Outardes-2(11m) were reported to be 200,195 and $400 \mathrm{kPa}$ respectively (Blanchette, 2014).

In all tests, stress-strain curves reached the peak state at low shear strain level followed by strain softening and then reached residual state. However, peak state is more clearly visible at higher $\sigma_{\mathrm{vc}}^{\prime}$ than in-situ $\sigma_{\mathrm{vc}}^{\prime}$ and also samples rapidly reached its peak $S_{u}$ between 2 to $4 \%$ of $\gamma$.

The results shown in Fig 4.2 clearly demonstrates that peak $S_{u}$ increases with $\sigma_{\mathrm{vc}}^{\prime}$ for NC samples $(\mathrm{OCR}=1)$, however the influence of $\sigma^{\prime}{ }_{\mathrm{vc}}$ is not consistent for OC Outardes-2 sample since it has higher OCR value. Further, it can be noticed that NC Kinburn and Breckenridge display essentially identical behaviour at $\sigma^{\prime}{ }_{\mathrm{vc}}=400 \mathrm{kPa}$.

Fig 4.2 shows the peak $S_{u}$ value reaches $184.1 \mathrm{kPa}$ for Outardes-2 sample under $\sigma^{\prime}{ }_{\mathrm{vc}}=800$ $\mathrm{kPa}$ (lower water content, $\mathrm{w}_{\mathrm{c}_{-} \mathrm{E} o \mathrm{C}}$ of $26 \%$ and plasticity index, Ip of 9 ) followed by Kinburn sample's peak $S_{u}$ value of $99.4 \mathrm{kPa}$ under $\sigma_{\mathrm{vc}}^{\prime}=400 \mathrm{kPa}\left(\mathrm{W}_{\mathrm{c} \_ \text {EoC }}\right.$ of $54 \%$ and Ip of 20). Further, Breckenridge sample produce peak $S_{u}$ value of $93.8 \mathrm{kPa}$ at $\sigma_{\mathrm{vc}}^{\prime}=400 \mathrm{kPa}\left(\mathrm{w}_{\mathrm{c} \_ \text {EoC }}\right.$ of $66 \%$ and Ip of 18). Additionally, Outardes-2, Breckenridge, and Kinburn samples were consolidated at $\sigma_{\mathrm{vc}}^{\prime}=130 \mathrm{kPa}\left(\mathrm{w}_{\mathrm{c}_{-} \text {EoC }}\right.$ of $28 \%$ and OCR of 3.1), $150 \mathrm{kPa}\left(\mathrm{w}_{\mathrm{c}_{-} \text {EoC }}\right.$ of $70 \%$ 
and OCR of 1.3), and $75 \mathrm{kPa}$ (with $\mathrm{w}_{\mathrm{c}_{-} \text {EoC }}$ of $82 \%$ and OCR of 2.6 ) show peak $S_{u}$ values of $66.5,51.4$ and $34.1 \mathrm{kPa}$ respectively.
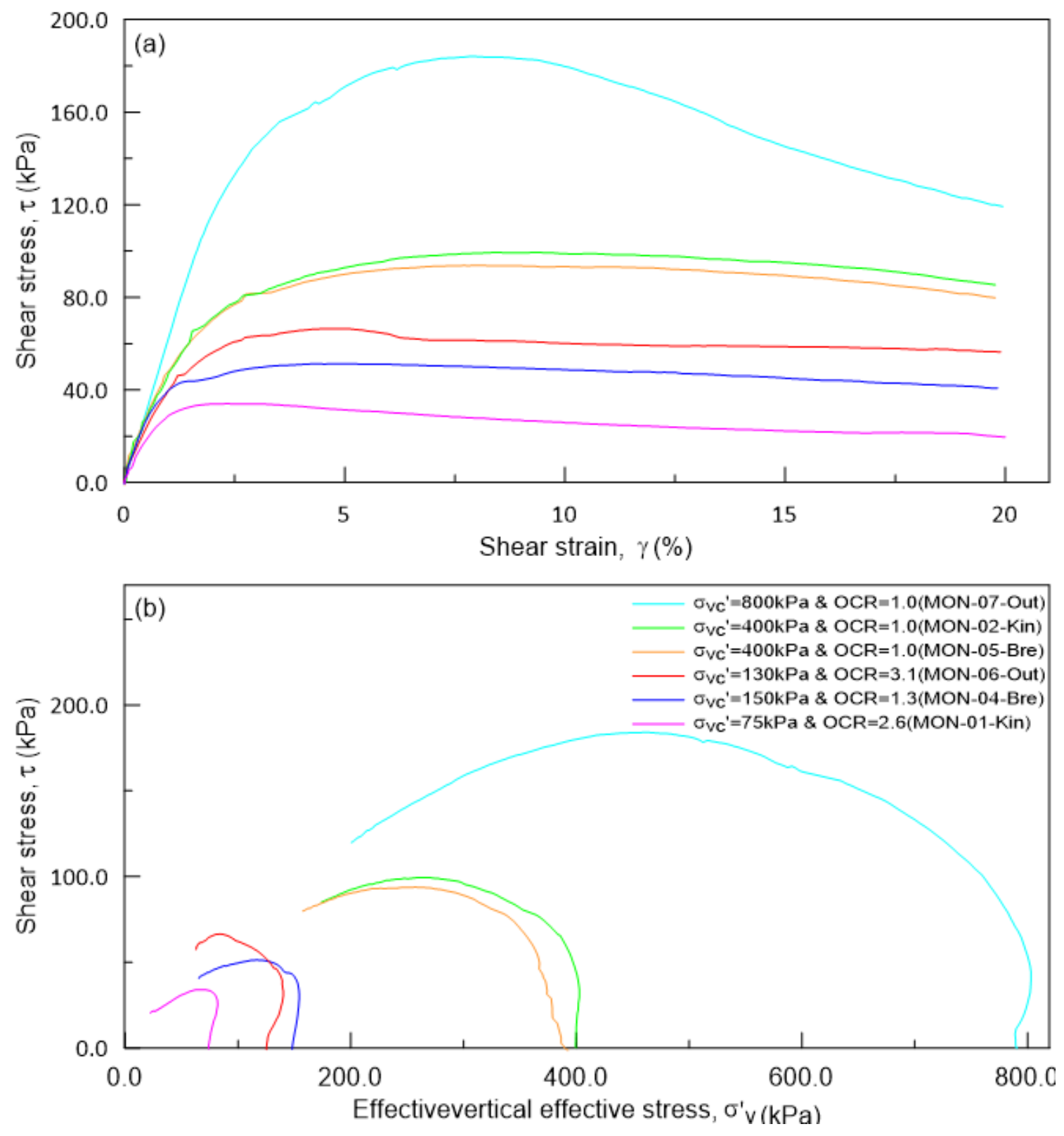

Fig 4.2 Comparison of undrained monotonic behaviour of Leda clays at OC and NC states, (a) Stress-strain behaviour (b) Stress path 


\subsubsection{Influence of over consolidation ratio}

The normalized stress-strain response, stress path and excess pore water pressure of sensitive clays are displayed in Fig 4.3 in order to compare and assess the influence of over consolidation ratio (OCR) at the undrained monotonic shearing. The results show NC Leda clays' normalized stress-strain response, excess pore water pressure and stress path curves converge within a narrow band. In contrast OC Leda clays display significantly deviated trends. Further, the figure clearly highlights the significant influence of OCR in the undrained monotonic behaviour of Leda clays. Also OC clays exhibit higher normalized peak strength $S_{u(N)}\left(=S_{u} / \sigma^{\prime}{ }_{v c}\right)$, while NC clays produce lower $S_{u(N)}$. In addition, the results present a clear difference between OC and NC Leda clays' strength envelopes.

OC Outardes-2 samples reached higher peak $S_{u(N)}$ value of 0.51 at $\sigma_{v c}^{\prime}=130 \mathrm{kPa}$ followed by $S_{u(N)}$ value of 0.46 for Kinburn sample at $\sigma_{v c}^{\prime}=75 \mathrm{kPa}$ and lower $S_{u(N)}$ value of 0.34 for Breckenridge sample at $\sigma_{v c}^{\prime}=150 \mathrm{kPa}$ (Fig 4.3a). These significant differences reflect the effect of OCR as Outardes-2, Kinburn and Breckenridge clays had OCR value of 3.1, 2.6 and 1.3 respectively. Also, it is obvious that OC sample's $S_{u(N)}$ increases with OCR. Further, similar high strength values in Outardes River clay was reported in literature by Lee (1979).

NC samples do not display significant difference in their normalized peak $S_{u(N)}$ values. NC Kinburn, Breckenridge and Outardes-2 clays, under $\sigma_{\text {vc }}^{\prime}$ value of 400,400 and 800 $\mathrm{kPa}$, produced $S_{u(N)}$ values of $0.25,0.24$ and 0.23 respectively. Researchers have previously reported that normalized behaviour of NC clays is basically identical to each other in a given material (e.g. Roscoe et al, 1958; Ladd, 1991; Theenathayarl 2015). 
NC Outardes-2 sample shows $55 \%$ reduction in the $S_{u(N)}$ value compared to OC sample. Similarly, Kinburn and Breckenridge samples display $45 \%$ and $32 \%$ reduction in the $S_{u(N)}$ values respectively as seen in the Fig 4.3(a). Reason for these outcomes is the collapse of the microstructure of the sensitive clay as effective consolidation stress increased from OC to NC state. Further, sensitive clays are known to experience significant collapse due to increased consolidation stresses. In addition, relatively larger excess pore water build-up occurs in NC clays, and that leads to lower $S_{u(N)}$ values.

Fig 4.3(b) illustrates the characteristics of normalized excess pore water pressure of both NC and OC Leda clay samples at all three sites. Under monotonic simple shear, NC clays show the continuous generation of positive excess pore pressure. As a result, all three NC samples produce lower shear strength as seen in Fig 4.3(a). On the other hand, OC Leda clays initially create negative pore pressure (dilative behaviour) and then slowly generate positive pore pressure which is more nonlinear with increasing shear strain (compared to NC clay) as illustrated in Fig 4.3(b). As a consequence of reduced excess pore water pressure generation, OC samples produce high shear strengths. However these OC samples do not display identical behaviour to each other on account of the different level of OCR. It is clear that the OCR values control the amount of negative pore pressure generation within OC samples.

In addition to stress history, the dissimilarity in plasticity index $\left(\mathrm{I}_{\mathrm{p}}\right)$, sensitivity $\left(\mathrm{S}_{\mathrm{t}}\right)$, water content at the end of consolidation (or void ratio, e) and percentage of clay particles of samples from different sites might also be accountable for the difference in the $S_{u(N)}$ values. 
Atterberg Limits and Hydrometer tests revealed that Kinburn, Breckenridge and Outardes2 samples have plasticity Index $\left(\mathrm{I}_{\mathrm{p}}\right)$ of 20,18 and 9; e (at OC state with $\sigma_{v c}^{\prime}$ ) of 2.49 (75 $\mathrm{kPa}), 2.05(150 \mathrm{kPa})$ and $0.87(130 \mathrm{kPa})$; e (at NC state with ${\sigma^{\prime}}_{v c}) 1.57(400 \mathrm{kPa}), 1.88$ $(400 \mathrm{kPa})$ and $0.72(800 \mathrm{kPa})$; percentage of clay particles is 75,72 and $28 \%$; Sensitive (St) value of 27, 14 and 352 (Blanchette, 2014) respectively as presented in Table 3.6. However, clear consistent patterns based on above factors are not noticeable. 

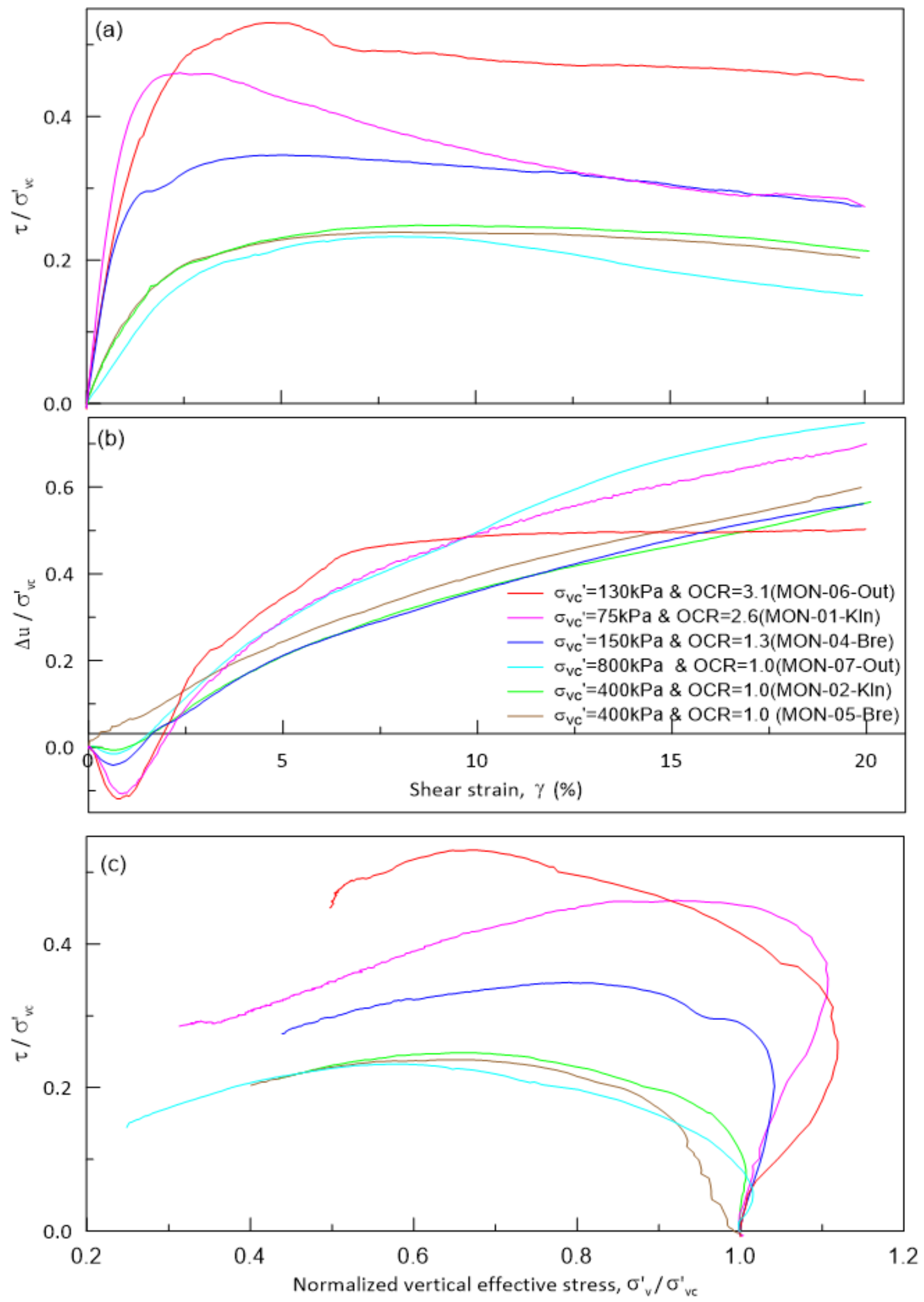

Fig 4.3 Comparison of normalized monotonic behaviour of Leda clays at OC and NC States, (a) Stress-strain behaviour, (b) pore- water pressure, (c) Stress path 


\subsubsection{Variation in monotonic behaviour due to heterogeneity with depth at a site}

The monotonic response of Leda clay from the Kinburn site, but at $11 \mathrm{~m}$ and $21 \mathrm{~m}$ of depth are compared in Fig 4.4. The differences indicate that significant variations in response can be expected even for material at a given site because of the natural variations within different soil layers. Both specimens were consolidated to in-situ stress levels, and the sample from $11 \mathrm{~m}$ depth yields a $S_{u}$ value of $34.1 \mathrm{kPa}\left(S_{u} / \sigma_{c v}^{\prime}=0.45\right)$ and the sample from $21 \mathrm{~m}$ depth displays a $S_{u}$ value of $46.4 \mathrm{kPa}\left(S_{u} / \sigma_{c v}^{\prime}=0.31\right)$. The variation in $S_{u}$ is partly explained by the different consolidation stress levels. Further, both Kinburn clays (11m and $21 \mathrm{~m}$ ) have approximately similar plasticity index (20 and 24). Nevertheless, difference in water content at the end of consolidation ( $82 \%$ and $40 \%)$ and the percentage of clay size particles $(75 \%$ and $59 \%)$ at $11 \mathrm{~m}$ and $21 \mathrm{~m}$ depths samples would have mainly influenced the variation in $S_{u}$. In addition, a higher OCR at $11 \mathrm{~m}$ depth sample $(\mathrm{OCR}=2.6)$ compared to $21 \mathrm{~m}$ depth sample $(\mathrm{OCR}=1.8)$ contribute to the higher normalized strength $\left(S_{u} / \sigma_{c v}^{\prime}=0.45\right)$ at $11 \mathrm{~m}$ depth sample. 

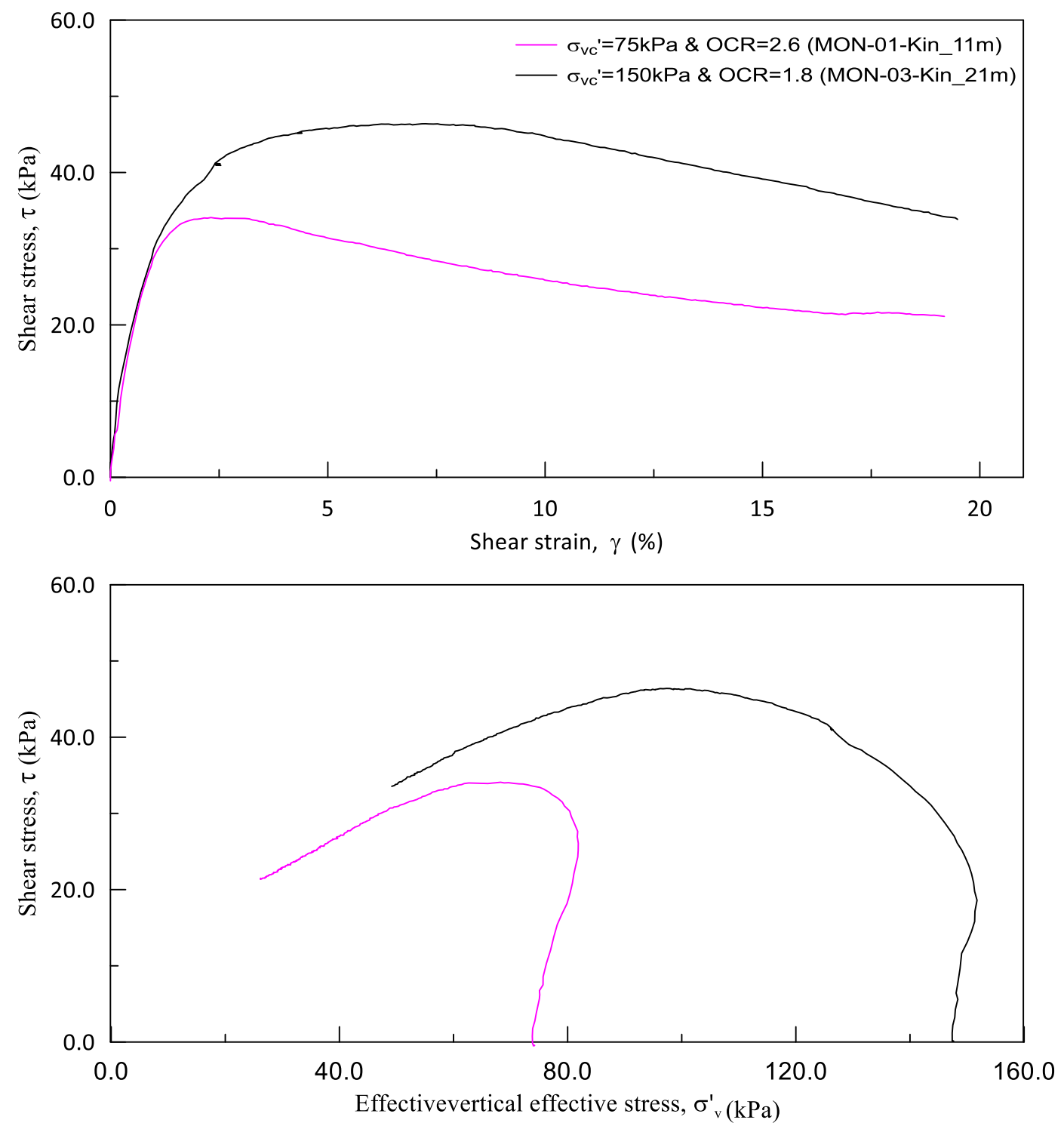

Fig 4.4 Comparison of monotonic behaviour of Kinburn clay at depth of $21 \mathrm{~m}$ and $11 \mathrm{~m}$, (a) Stressstrain behaviour (b) Stress path

\subsubsection{Strength parameters of sensitive Leda clays}

Monotonic strength parameters of sensitive Leda clays in terms of effective friction angle $\left(\phi^{\prime}\right)$ and effective cohesion $\left(c^{\prime}\right)$ are estimated from Figs. 4.5 and 4.6. Shear and effective normal stress values corresponding to peak and residual states in both OC and NC Leda clays obtained in this research study are plotted in Figs 4.5(a) and 4.6(a). Additional data 
points from similar tests on the same materials are obtained from literature (Blanchette, 2014) and presented in Fig 4.5(b-c) and 4.6(b-c) to draw best fit lines. Blanchette's research was complementary to the research reported herein and was conducted on undisturbed samples retrieved from the same sites.

Fig. 4.5 and 4.6 clearly show that Kinburn and Breckenridge clays behave similarly under monotonic loading compared to Outardes-2 samples. This is expected since Kinburn and Breckenridge sites are located on either side of the Ottawa River, whereas Outardes-2 site is located about $800 \mathrm{~km}$ away from these two sites. Additionally, Kinburn $(11 \mathrm{~m})$ and Breckenridge samples had similar initial moisture content (79\% and $73 \%)$ and clay size particles (75\% and 72\% respectively). However, Outardes-2 samples had lower initial moisture content (30\%) and clay size particles (28\%). Based on these observations, a bestfit line is drawn for values of undrained peak strength $\left(S_{u}\right)$ of OC Kinburn and Breckenridge clays, and another best-fit line is drawn for residual shear strength values as shown in Fig 4.5(b) and 4.6(b) respectively. Also best-fit lines are drawn for NC Kinburn and Breckenridge clays. Similarly, best-fit lines are drawn for OC and NC Outardes-2 clays as presented Fig 4.5(c) and 4.6(c).

\subsubsection{Peak strength parameters}

Based on the best fit lines drawn in Fig 4.5(b), OC Kinburn and Breckenridge samples show effective friction angle $\left(\phi^{\prime}{ }_{p}\right)$ of $17.3^{\circ}$ and effective cohesion $\left(c^{\prime}\right)$ of $17.4 \mathrm{kPa}$. Further, NC clays yield $\phi^{\prime}{ }_{p}$ of $23.6^{0}$. In addition, OC Outardes-2 clays display $\phi^{\prime}{ }_{p}$ of $17.9^{0}$ and $c^{\prime}$ of $37.7 \mathrm{kPa}$, and NC clays yield $\phi^{\prime}{ }_{p}$ of $22.3^{\circ}$ (Fig $4.5 \mathrm{~b}$ ). 
It should be noted that the best-fit line for the NC Kinburn and Breckenridge clays yield $S_{u}=0.430 \sigma^{\prime}{ }_{v}-8.023$ and $\mathrm{R}_{1}{ }^{2}=0.9375$. When forcing the best-fit line to intersect at zero, its yields up with $S_{u}=0.401 \sigma^{\prime}{ }_{v}$ and $\mathrm{R}_{2}{ }^{2}=0.9326$. In both cases, the $\mathrm{R}^{2}$ values are very close. Further, there is no reason to prefer $\mathrm{R}_{1}{ }^{2}$ over $\mathrm{R}_{2}{ }^{2}\left(S_{u}=0.401 \sigma^{\prime}{ }_{v}\right)$ and the effective cohesion $\left(c^{\prime}\right)$ of NC clays is expected to be zero (Fig 4.5b). Similarly in NC Outareds-2 clays, if the best-fit line does not intercept at zero then $S_{u}=0.402 \sigma^{\prime}{ }_{v}-$ 10.816 and $\mathrm{R}_{1}{ }^{2}=0.89$ and if set an intercept at zero then $S_{u}=0.379 \sigma^{\prime}{ }_{v}$ and $\mathrm{R}_{2}{ }^{2}=0.8871$. Anyhow there is no significant difference in $\mathrm{R}^{2}$ values and thus $S_{u}=0.379 \sigma^{\prime}{ }_{v}$ is preferred as a best-fit line (Fig 4.5c). 

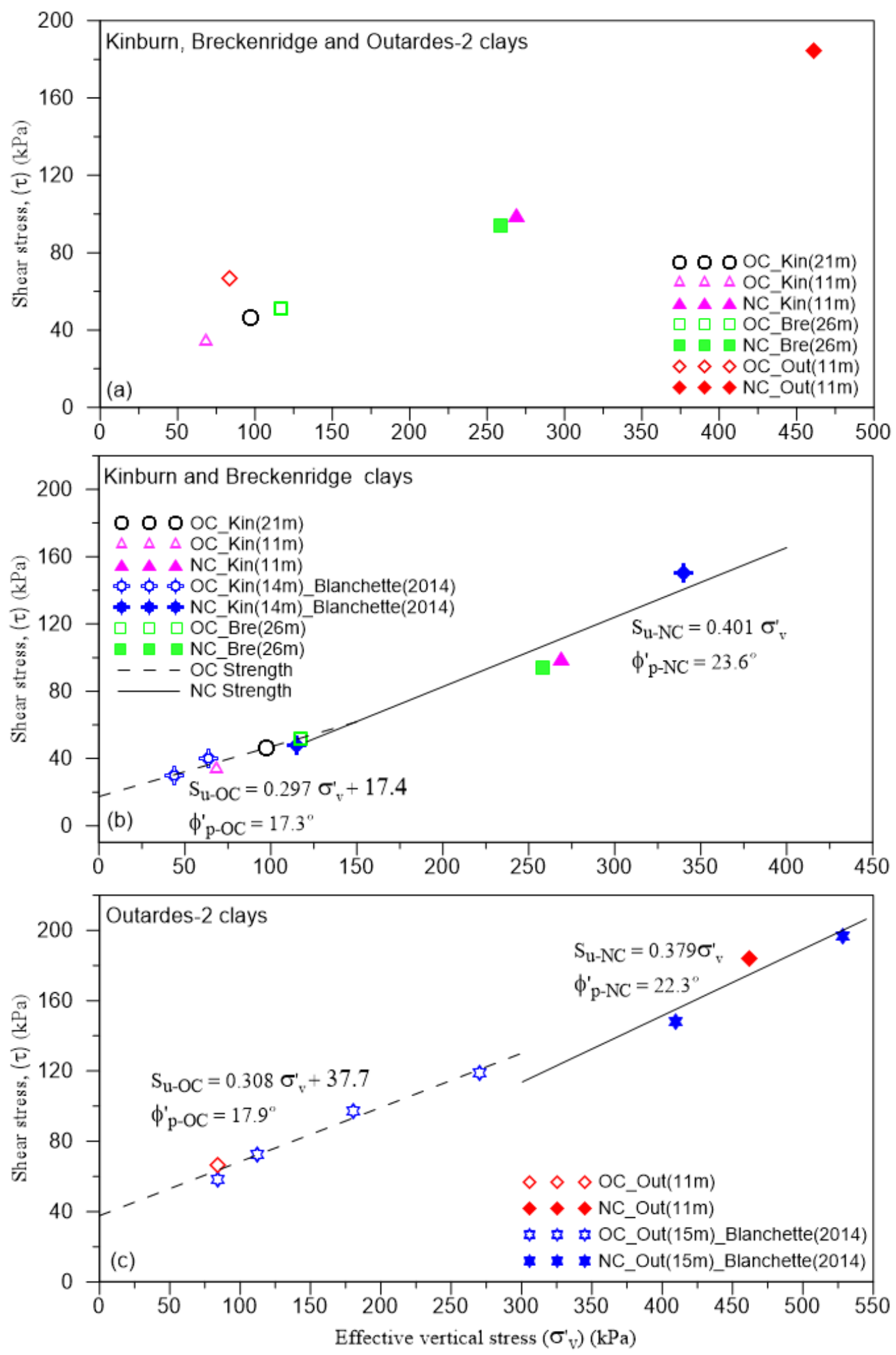

Fig 4.5 Peak strength parameters of sensitive Leda clays 


\subsubsection{Residual strength parameters}

The best fit lines established for OC Kinburn and Breckenridge samples show residual effective friction angle $\left(\phi^{\prime}{ }_{r}\right)$ of $24.1^{0}$ and effective cohesion $\left(c^{\prime}{ }_{r}\right)$ of $13.2 \mathrm{kPa}$, further NC clays produce $\phi_{r}^{\prime}$ of $32.4^{0}$ (Fig 4.6b). In addition, OC Outardes-2 clays display $\phi_{r}^{\prime}$ of $32.1^{0}$ and $c^{\prime}{ }_{r}$ of $19.5 \mathrm{kPa}$, and $\mathrm{NC}$ clays yield $\phi^{\prime}{ }_{r}$ of $35.3^{\circ}$ when the cohesion intercept is set to zero as seen in Fig 4.6c.

As explained previously, when the intercept of best-fit line for residual strength of $\mathrm{NC}$ Kinburn and Breckenridge clays are not forced to pass through the origin, the best-fit line is given by $S_{u}=0.494 \sigma^{\prime}{ }_{v}+8.68$ with an $\mathrm{R}_{1}{ }^{2}=0.976$. When the intercept is set to zero the best-fit line turns out to be $S_{u}=0.536 \sigma^{\prime}{ }_{v}$ and $\mathrm{R}_{2}{ }^{2}=0.967$. Since both $\mathrm{R}^{2}$ values are approximately equal and $c^{\prime}{ }_{r}$ of $\mathrm{NC}$ clays is expected to be zero, $S_{u}=0.536 \sigma^{\prime}{ }_{v}\left(\mathrm{R}_{2}^{2}=\right.$ 0.967) is considered as the best fit line. Similarly, if the intercept of the best fit line for the residual strength of NC Outareds- 2 clays is not fixed then $S_{u}=0.564 \sigma^{\prime}{ }_{v}+3.03$ and $\mathrm{R}_{1}{ }^{2}$ $=0.992$ gives the best-fit. But, if the intercept is set to zero then the best-fit yields $S_{u}=$

$0.578 \sigma^{\prime}{ }_{v}$ and $\mathrm{R}_{2}^{2}=0.991$. Since there is no significant difference in $\mathrm{R}^{2}$ values and $c^{\prime}{ }_{r}$ of NC clays is expected to be zero, $S_{u}=0.578 \sigma_{v}^{\prime}\left(\mathrm{R}_{2}^{2}=0.991\right)$ is chosen as best-fit line (Fig 4.6c). 

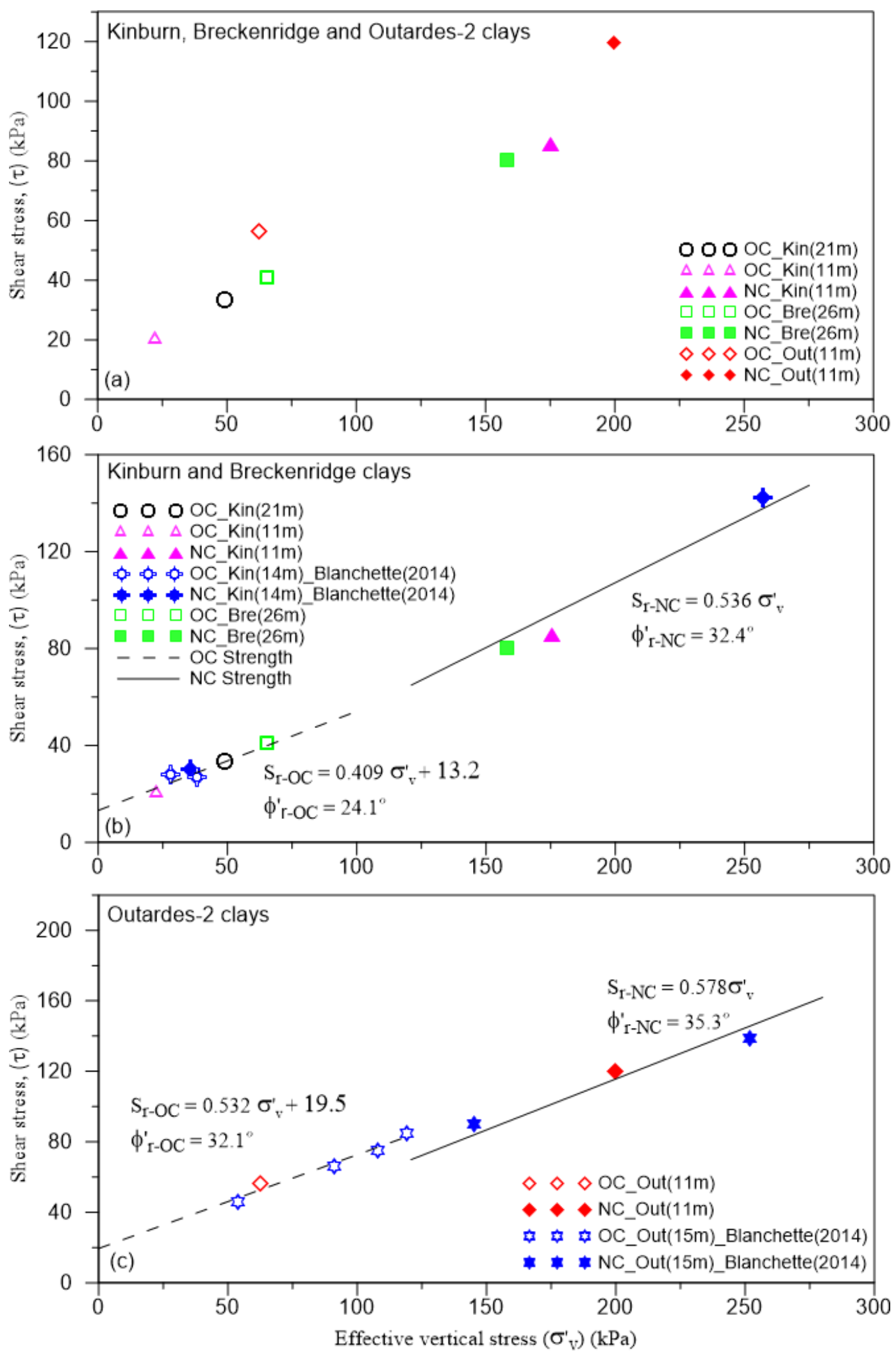

Fig 4.6 Residual strength parameters of sensitive Leda clays 


\subsection{Strength reduction}

Sensitive Leda clays are highly vulnerable when subjected to monotonic or cyclic loading because they are very sensitive to remoulding and exhibit significant loss of shear strength due to their natural structural arrangement being disturbed or damaged (Skempton et al., 1952). Therefore it is vital to assess the potential for strength reduction in Leda clays.

\subsubsection{Influence of large quasi-cyclic shearing on undrained monotonic behaviour}

This research study focuses on investigating the partial strength reduction as the clays have been subjected to relatively large strains $(\gamma=20 \%)$. For this purpose, all the undrained monotonic tests were extended to few large quasi-cyclic stresses to simulate partial remoulding upon reaching the residual state (Fig 4.7). At the end, the peak undrained shear strength $\left(S_{u}\right)$ and peak partially remoulded undrained shear strength $\left(S_{u(r)}\right)$ were compared to determine the strength reduction. Fig 4.7 clearly shows significant reduction in peak $S_{u}$ of Outardes-2 sample after being partially remoulded due to multiple large quasi-cyclic stresses. The NC Outardes-2 sample initially reaches the peak $S_{u}$ of $184.12 \mathrm{kPa}$ and after continuous large multiple quasi-cyclic shearing the peak $S_{u}$ reduced to around $18 \mathrm{kPa}$ at $\sigma_{v c}^{\prime}=800 \mathrm{kPa}$, which is about $90 \%$ of strength reduction. Similarly, all other samples were investigated and the results are summarized in the Table 4.1. Material fabric changes due to remoulding and excess pore pressure generation due to large quasi-cyclic loading are responsible for this strength reduction.

The experimental results show that peak $S_{u}$, reduced from 66.5 to $8 \mathrm{kPa}$ and from 184.1 to $18 \mathrm{kPa}$ for Outardes-2 clays; peak $S_{u}$ reduced from 51.4 to $10 \mathrm{kPa}$ and from 93.8 to 15 $\mathrm{kPa}$ for Breckenridge; and peak $S_{u}$ reduced from 34.1 to $5.5 \mathrm{kPa}$ and from 99.4 to $14 \mathrm{kPa}$ 
for Kinburn samples, after partially remoulding both $\mathrm{OC}$ and $\mathrm{NC}$ samples, respectively (Table 4.1).

Table 4.1 Comparison of strength reduction after multiple large quasi-cyclic shearing

\begin{tabular}{|c|c|c|c|c|c|c|c|}
\hline \multirow{2}{*}{ Site } & Test ID & Depth(m) & $\begin{array}{c}\sigma_{v c}^{\prime} \\
(\mathrm{kPa})\end{array}$ & $\begin{array}{c}S_{u} \\
(\mathrm{kPa})\end{array}$ & $\begin{array}{c}S_{u(r)} \\
(\mathrm{kPa})\end{array}$ & St_Partial & $\begin{array}{c}S_{u} \\
\text { Reduction } \\
(\%)\end{array}$ \\
\hline \multirow{2}{*}{ Kinburn } & MON-01 & 10.4 & 75 & 34.1 & 5.5 & 6 & 83.87 \\
\cline { 2 - 8 } & MON-02 & 10.6 & 400 & 99.4 & 14.0 & 7 & 85.92 \\
\hline \multirow{2}{*}{ Breckenridge } & MON-04 & 25.6 & 150 & 51.4 & 10.0 & 5 & 80.54 \\
\cline { 2 - 8 } & MON-05 & 25.9 & 400 & 93.8 & 15.0 & 6 & 84.01 \\
\hline \multirow{2}{*}{ Outardes-2 } & MON-06 & 10.9 & 130 & 66.5 & 8.0 & 8 & 87.97 \\
\cline { 2 - 8 } & MON-07 & 10.9 & 800 & 184.1 & 18.0 & 10 & 90.22 \\
\hline
\end{tabular}



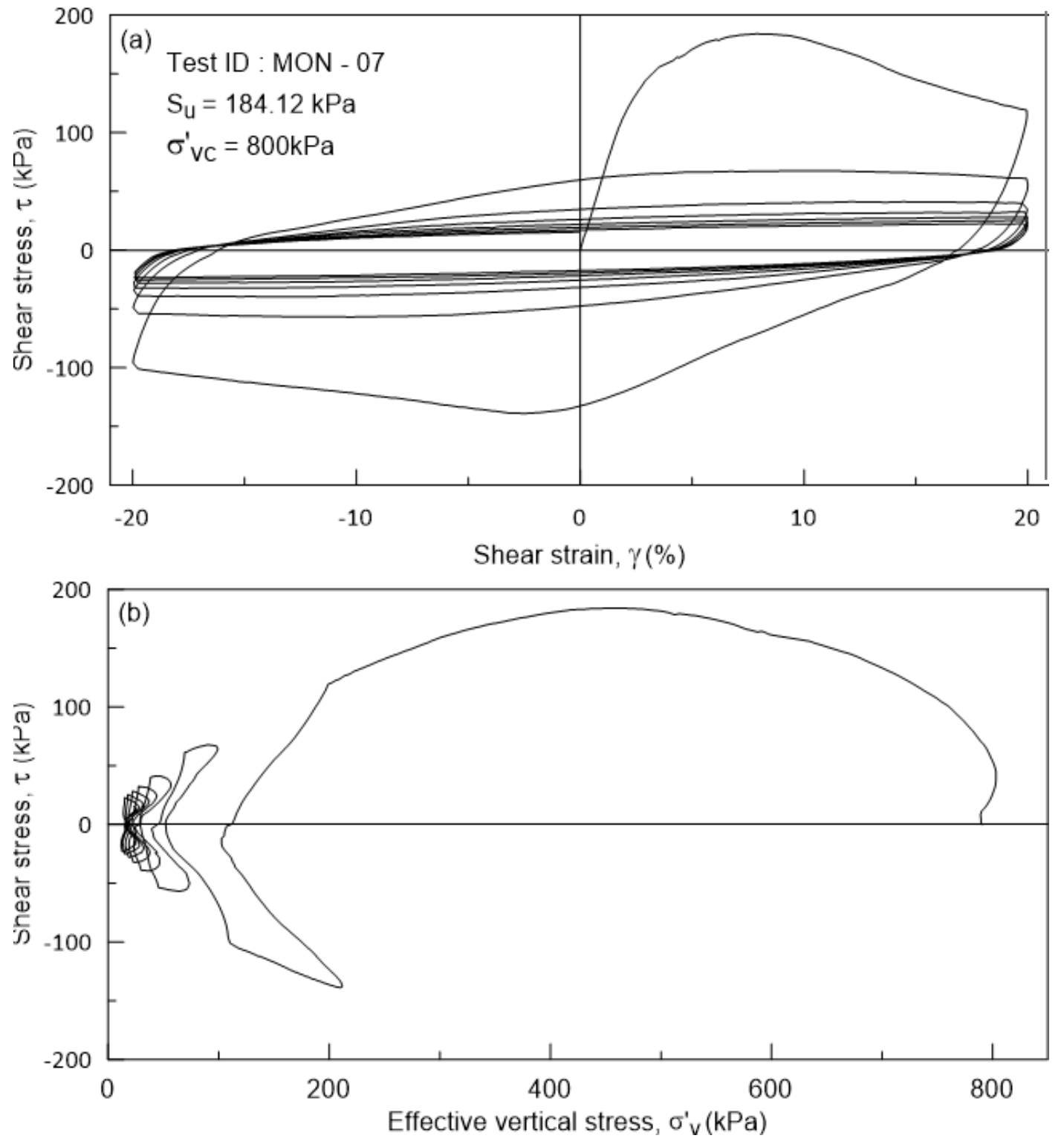

Fig 4.7 Typical monotonic behaviour of Outardes-2 clay during large strain quasi-cycles (a) Stressstrain response; (b) Stress path 


\subsection{Undrained cyclic behaviour of sensitive Leda clays}

Leda clay samples obtained from three sites were tested under undrained cyclic simple shear loading to investigate the potential behaviour of sensitive Leda clays during earthquakes. A set of Leda clay samples were taken from $11 \mathrm{~m}$ depth of borehole BH-GSC-JSR-02 (Kinburn); 26m depth of borehole BH-GSC-BRK-01 (Breckenridge) and 11m depth of borehole F-03-13 (Outardes 2) for cyclic testing. These samples are essentially identical to the monotonically tested samples. As explained in chapter 3, all samples were trimmed and prepared very carefully to minimize the disturbance and then samples were consolidated (at $K_{0}$ condition) either to in-situ or higher consolidation stress (to represent the naturally OC and NC state of clays). A constant amplitude of cyclic shear stress was applied after allowing sufficient time for consolidation (overnight in all cases). Cyclic loads were applied in the form of sine waves as shown in Fig 4.6 (a), and the loading frequency was maintained at $0.1 \mathrm{~Hz}$.

As discussed in the literature, it is not possible for clayey soils to reach "true liquefaction" condition, because of their cohesion and plasticity. While, a state of zero strength may not realize as a result of the earthquake loading, the clays can deform significantly, and thus the clay was considered "liquefied" if the shear strains exceeded 3.75\% (as recommended by NRC, 1985).

\subsubsection{Influence of cyclic shear stress, strain and number of loading cycles}

Cyclic shear stress $\left(\tau_{c y c}\right)$, cyclic shear strain $\left(\gamma_{c}\right)$ and number of loading cycles $(N)$ are the primary factors affecting the cyclic behaviour of soils. In order to investigate the undrained cyclic behaviour of sensitive Leda clays these parameters were carefully chosen. 
Amplitudes of $\tau_{c y c}$ were selected according to each sample's peak $S_{u}$ as explained below. The intensity of the loading was targeted to yield liquefaction within a range of about 5 to 500 cycles.

In order to optimize the number of cyclic tests, appropriate amplitude of cyclic shear stress $\left(\tau_{c y c}\right)$ should be predetermined. In this research study the initial $\tau_{c y c}$ was selected around $80 \%$ of peak $S_{u}$ (or cyclic stress ratio, CSR $=\tau_{c y c} / \sigma^{\prime}{ }_{v c}$ of 0.10 ), and the outcome of first test was used to select the subsequent loading intensities.

\subsubsection{Typical undrained cyclic test of sensitive clays}

The typical outcome of the undrained cyclic shear test is demonstrated in Figs 4.8 and 4.9. This test was conducted on Kinburn clay which was consolidated to in-situ vertical effective stress level under $K_{0}$ condition. The clay at this state is somewhat over consolidated (OC). Throughout this test constant $\tau_{c y c}$ of $23 \mathrm{kPa}$ was applied under vertical consolidation stress $\left(\sigma^{\prime}{ }_{v c}\right)$ of $75 \mathrm{kPa}$. The results show that 12 load cycles $(\mathrm{N})$ were required to 'liquefy' (i.e., $\gamma_{c}$ exceed 3.75\%) this particular sample.

Figs 4.8(b) and 4.9(b) show increasing number of equitant cyclic loading (N) continuously generates excess pore water pressure $(\Delta u)$, while reducing the effective stress $\left(\sigma^{\prime}{ }_{v}\right)$. Further, $\sigma_{v}^{\prime}$ travels towards the origin as cyclic shear strain $\left(\gamma_{c}\right)$ gradually increases. Because of continuous reduction in the $\sigma^{\prime}{ }_{v}$ the stiffness of sample diminishes and consequently the sample liquefied at $\mathrm{N}=12$. Similar tests were conducted at different $\sigma_{v c}^{\prime}$ and $\tau_{c y c}$ for each sites, and the results for a sample from Breckenridge are presented in Figs 4.10 and 4.11. 
Cyclic simple shear test
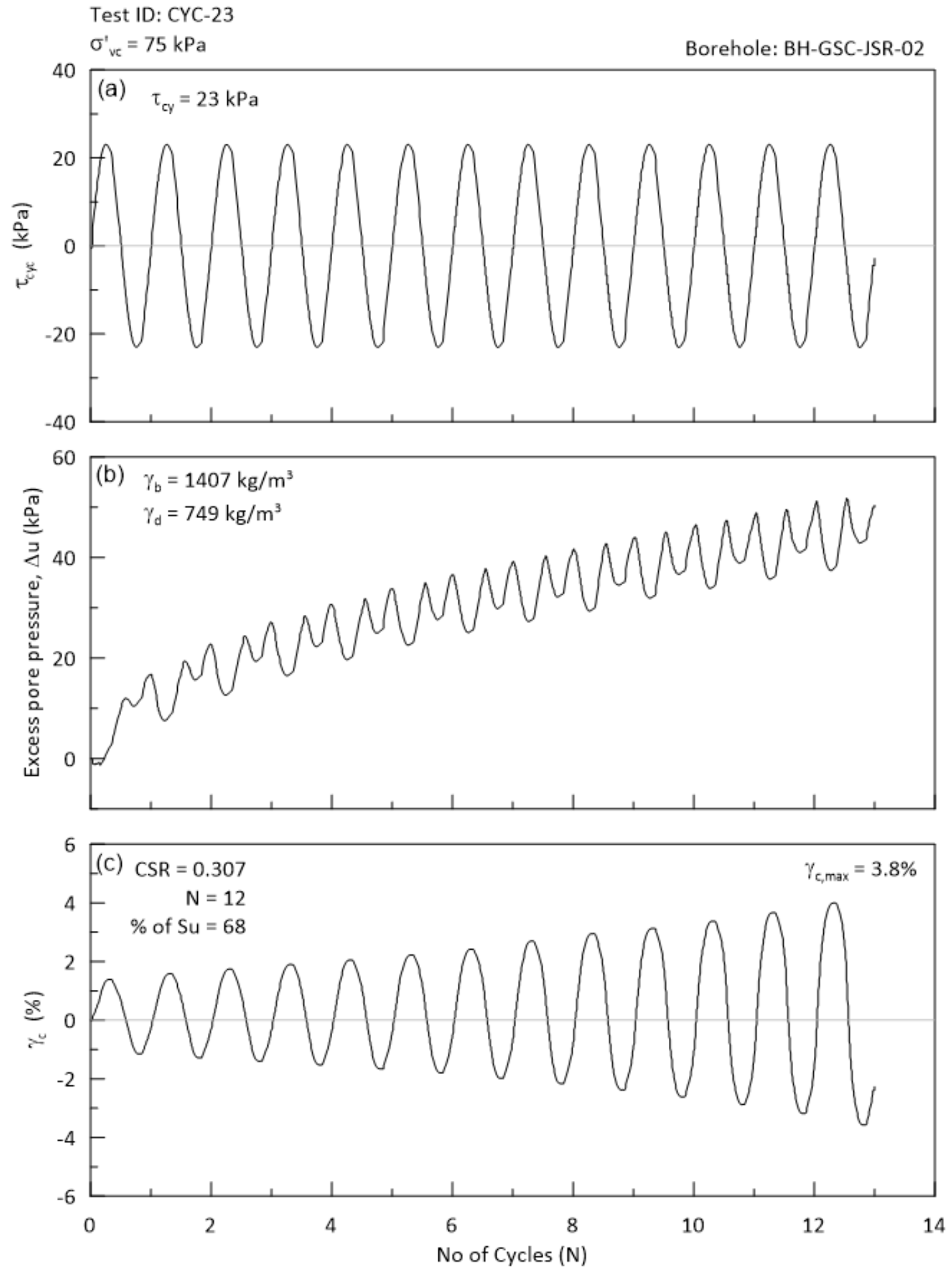

Fig 4.8 Cyclic behaviour of OC Kinburn clay (a) $\tau_{c y c}$ vs N; (b) PWP vs N; (c) $\gamma_{c}$ vs N 


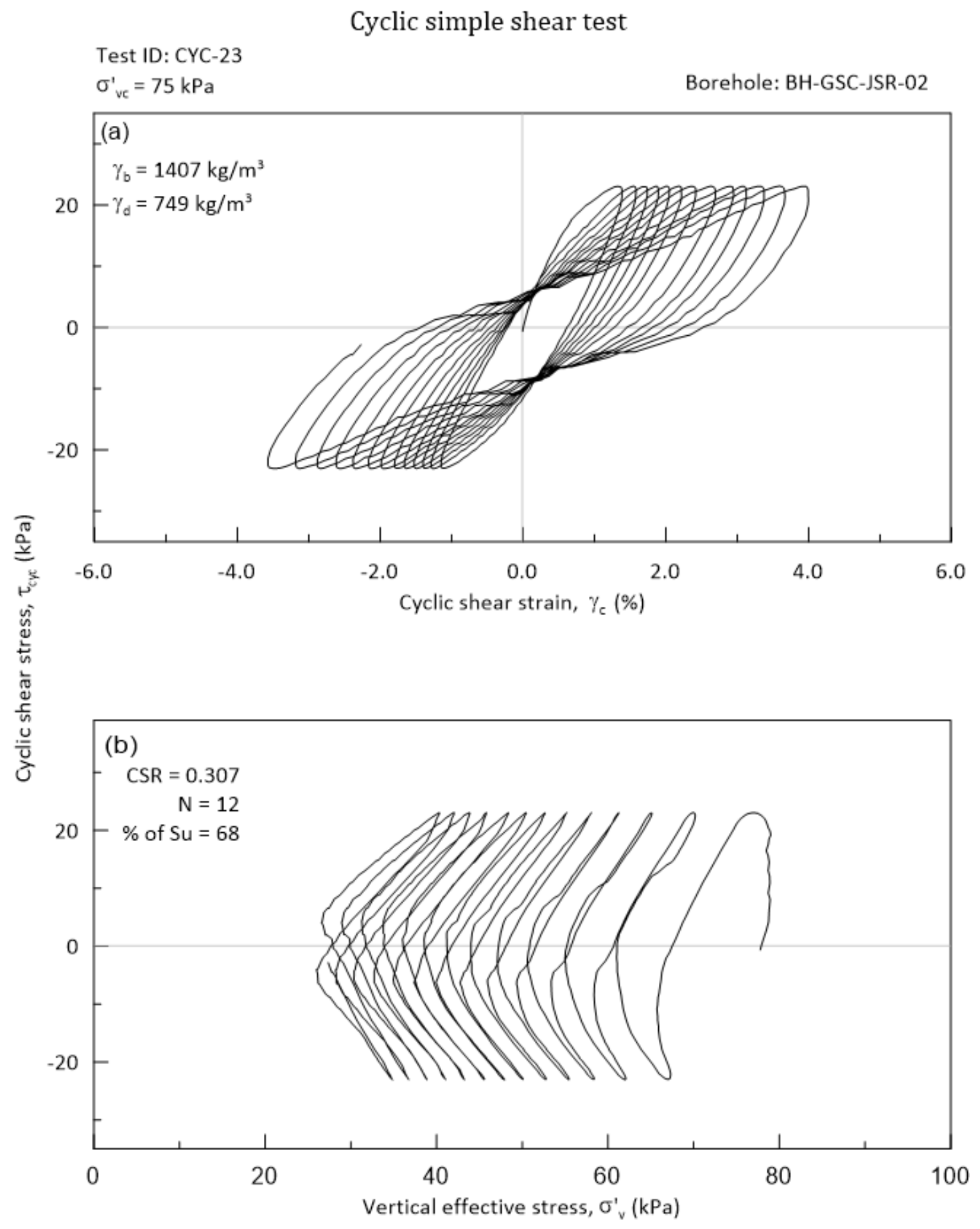

Fig 4.9 Cyclic behaviour of OC Kinburn clay (a) Stress-strain response; (b) Stress path 
Cyclic simple shear test
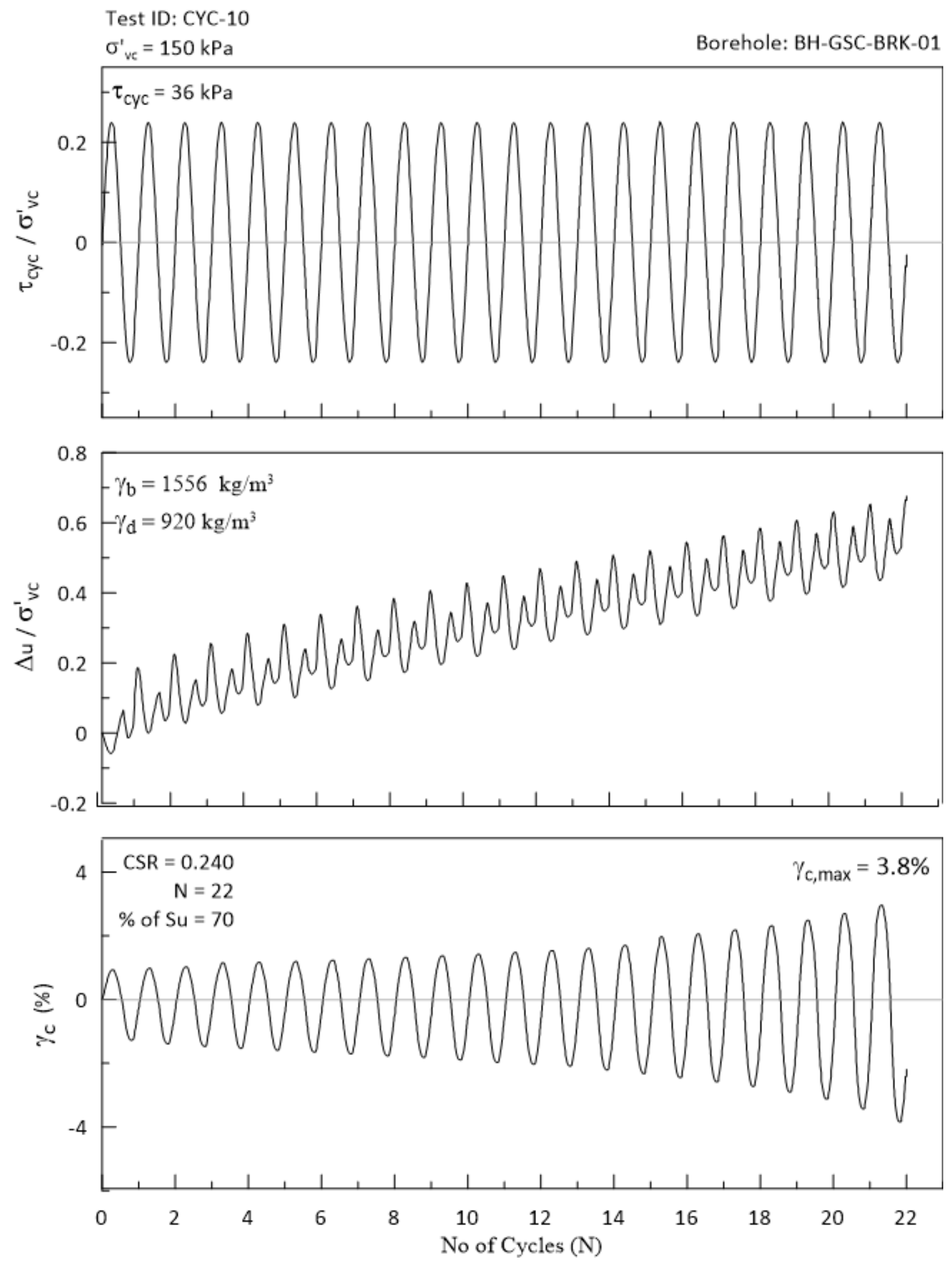

Fig 4.10 Normalized cyclic behaviour of Breckenridge clay (a) $\tau_{c y c}$ vs N; (b) PWP vs N; (c) $\gamma_{c}$ vs N 
Cyclic simple shear test

Test ID: CYC-10

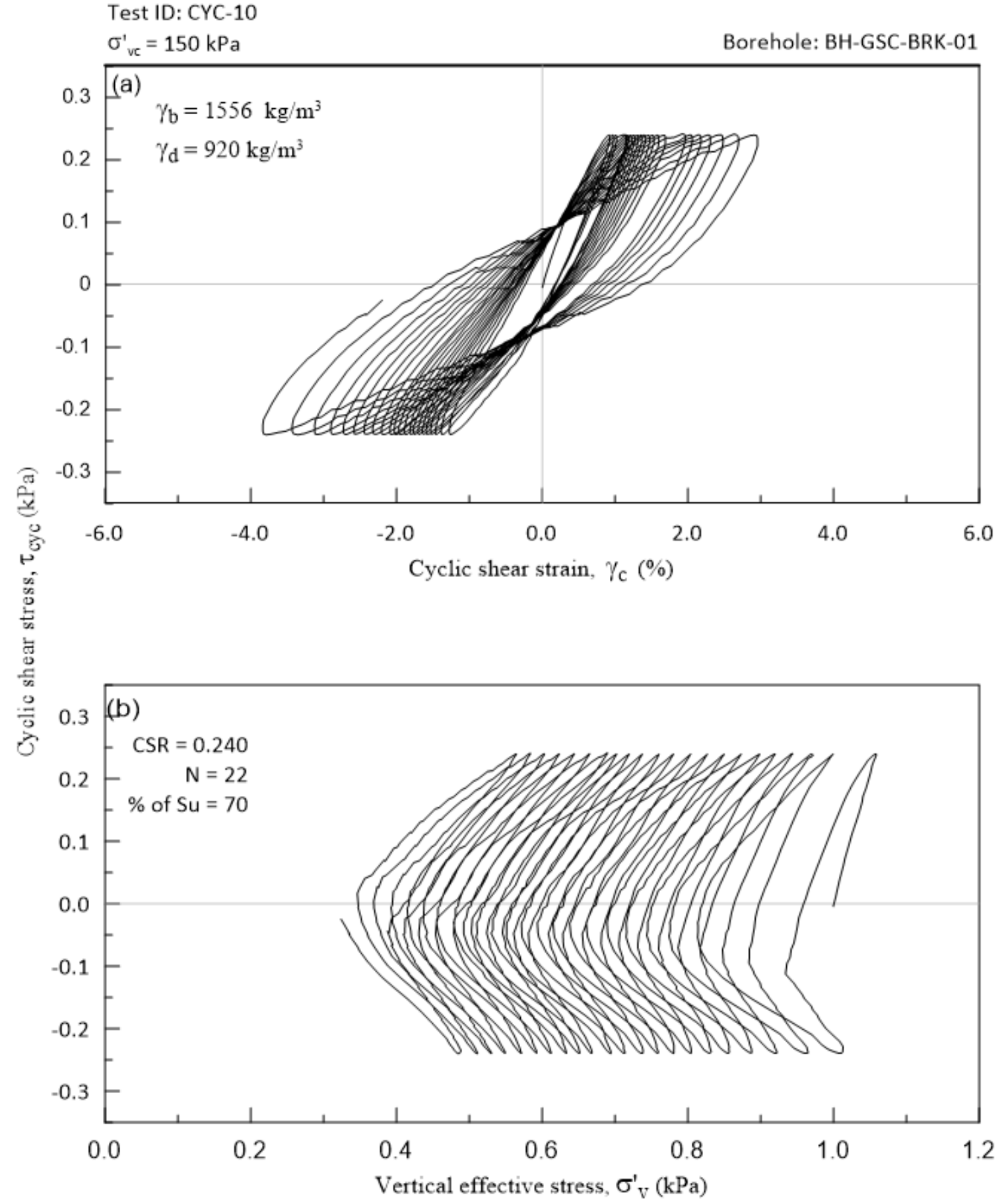

Fig 4.11 Normalized cyclic behaviour of Breckenridge clay (a) Stress-strain response; (b) Stress path 


\subsubsection{Cyclic tests at in-situ (OC) state and normally consolidated state.}

Cyclic simple shear tests were conducted on samples from Kinburn, Breckenridge and Outardes-2 sites under consolidation stress of 75, 150 and $130 \mathrm{kPa}$ respectively to investigate the cyclic response of Leda clays at in-situ (OC) stress state. Additional tests were carried out to examine the cyclic behaviour of normally consolidated Leda clays, at ${\sigma^{\prime}}_{v c}$ of $400 \mathrm{kPa}$ (Kinburn, Breckenridge) and $800 \mathrm{kPa}$ (Outardes-2). The peak shear strength $\left(S_{u}\right)$ of each of these samples determined from undrained monotonic simple shear tests (Table 4.2) was used to determine the amplitude of cyclic shear stress $\left(\tau_{c y c}\right)$.

Table 4.2 Undrained peak shear strength of OC and NC Leda clays

\begin{tabular}{|c|c|c|c|c|c|}
\hline Site & Test ID & Borehole & $\begin{array}{c}\text { Depth } \\
(\mathrm{m})\end{array}$ & $\begin{array}{c}\text { Consolidation } \\
\text { stress }\left(\sigma_{\mathrm{vc}}^{\prime},\right. \\
\mathrm{kPa})\end{array}$ & $\begin{array}{c}\text { Undrained } \\
\text { shear } \\
\text { strength }\left(S_{u},\right. \\
\mathrm{kPa})\end{array}$ \\
\hline \multicolumn{7}{|c|}{ In-situ stress state/ Over consolidated (OC) } \\
\hline Kinburn & MON-01 & BH-GSC-JSR-02 & 10.6 & 75 & 34.1 \\
\hline Breckenridge & MON-04 & BH-GSC-BRK-01 & 25.6 & 150 & 51.4 \\
\hline Outardes-2 & MON-06 & F-03-13 & 10.9 & 130 & 66.5 \\
\hline \multicolumn{7}{|c|}{ Normally consolidated (NC) state } \\
\hline Kinburn & MON-02 & BH-GSC-JSR-02 & 10.6 & 400 & 99.4 \\
\hline Breckenridge & MON-05 & BH-GSC-BRK-01 & 25.9 & 400 & 93.8 \\
\hline Outardes-2 & MON-07 & F-03-13 & 10.9 & 800 & 184.1 \\
\hline
\end{tabular}

\subsubsection{Cyclic resistance of Kinburn sensitive Leda clays}

Fig 4.12(a) shows the cyclic resistance curves for both naturally OC (in-situ material) and NC Kinburn clays (in situ clay consolidated to a higher $\sigma_{v c}^{\prime}$ ), in terms of cyclic stress ratio $\left(C S R=\tau_{c y c} / \sigma_{v}^{\prime}\right)$ with number of cycles $(\mathrm{N})$ necessary to trigger liquefaction at the given CSR. Figure 4.12(b) presents the same test results, but in the form of normalized stress 
ratio $\left(N S R=\tau_{c y c} / S_{u}\right)$ vs N. Similar data for Breckenridge and Outardes-2 tests results are illustrated in Figs 4.13 and 4.14.

The results presented in Fig 4.12(a) demonstrates that cyclic resistance when expressed in terms of CSR is highly dependent on the over consolidation ratio and only slightly reliant on the consolidation stress level. Number of cycles required for liquefaction increases as CSR reduces and it is essentially similar regardless of the stress history as both OC and NC lines are approximately parallel to each other.

Test results reveal that Kinburn samples tested at $\sigma^{\prime}{ }_{v c}=75 \mathrm{kPa}(\mathrm{OCR}=2.6)$ can withstand a significantly higher number of cycles at a given CSR compared to samples tested at $\sigma_{v c}^{\prime}$ $=300(\mathrm{OCR}=1)$ and $400 \mathrm{kPa}(\mathrm{OCR}=1)$. In other words, $\mathrm{OC}$ sensitive clays have higher cyclic resistance than NC clays. Further, if considering N of 50, Kinburn (OC) material would require a CSR value of 0.3 to liquefy, as opposed to a $\mathrm{CSR}=0.17$ for the NC clays, which is a $43 \%$ reduction in CSR.

The differences in the cyclic resistance curve are much narrower if the intensity of cyclic loading is represented by NSR, or by $\operatorname{CSR} p\left(=\tau_{c y c} / \sigma_{p}^{\prime}\right)$ as seen in the Fig 4.12(b). Further, Fig 4.12(b) shows $66 \%\left(\sigma_{v c}^{\prime}=75 \mathrm{kPa}\right), 70 \%\left(\sigma_{v c}^{\prime}=300 \mathrm{kPa}\right)$ and $69 \%\left(\sigma^{\prime}{ }_{v c}=\right.$ $400 \mathrm{kPa}$ ) of peak $S_{u}$ required to liquefy the particular OC and NC Kinburn clays at 50 or more cycles respectively.

Test results show that over-consolidation ratio (OCR) significantly influences the cyclic behaviour of the Kinburn clays. Samples tested at ${\sigma^{\prime}}_{v c}=75 \mathrm{kPa}\left(<\sigma_{p}^{\prime}\right.$ of $200 \mathrm{kPa}$; OC state) display higher CSR, and samples tested at $\sigma_{v c}^{\prime}$ of 400 and $300 \mathrm{kPa}\left(>\sigma_{p}^{\prime}\right.$ of 200 
$\mathrm{kPa}$; NC state) exhibit lower CSR. Similar patterns were observed in Breckenridge and Outardes-2 samples as presented in the Fig 4.13(a) and Fig 4.14(a).

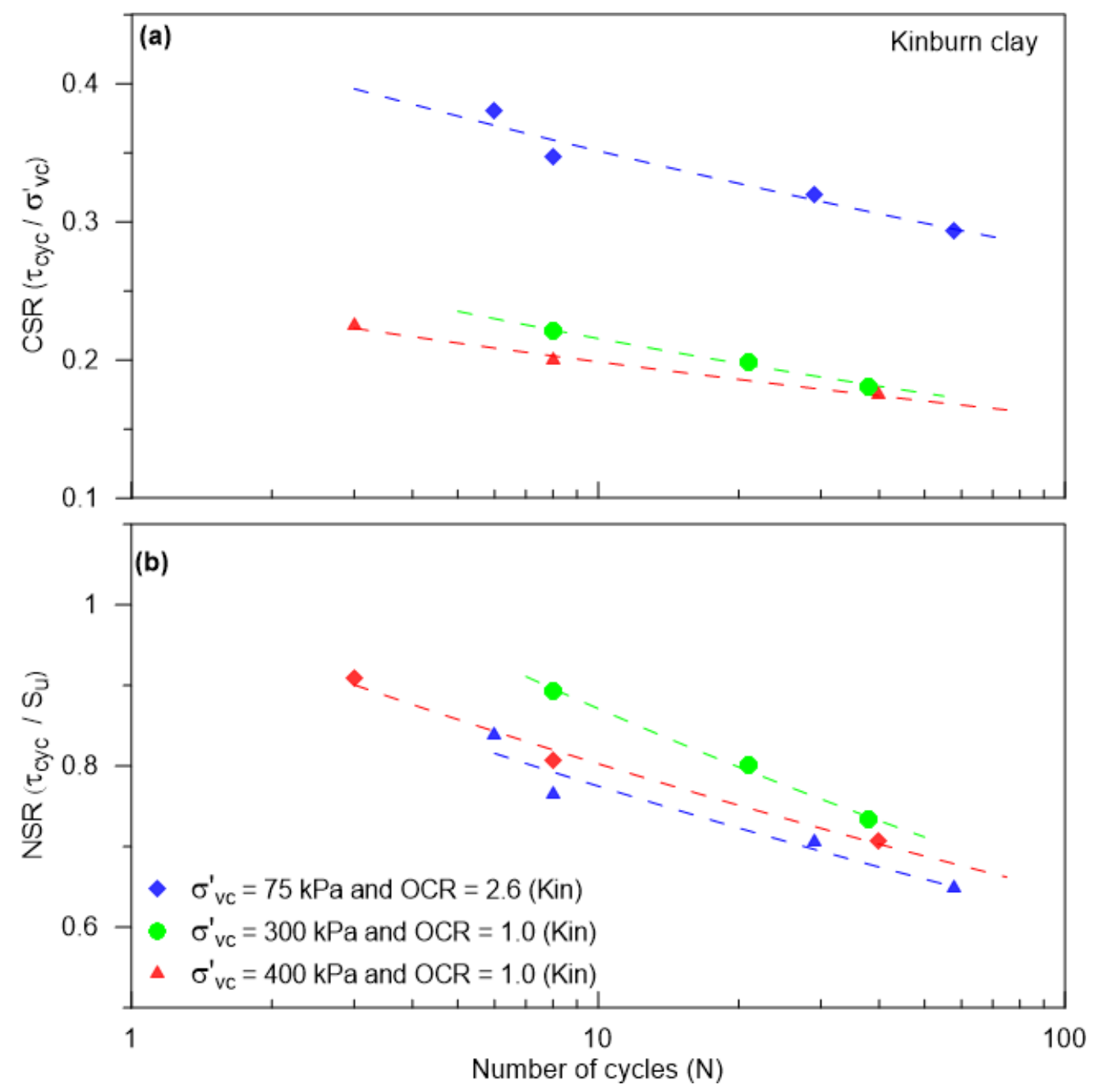

Fig 4.12 Comparisons of cyclic resistance of OC and NC Kinburn clays (a) CSR vs N \& (b) NSR vs N 

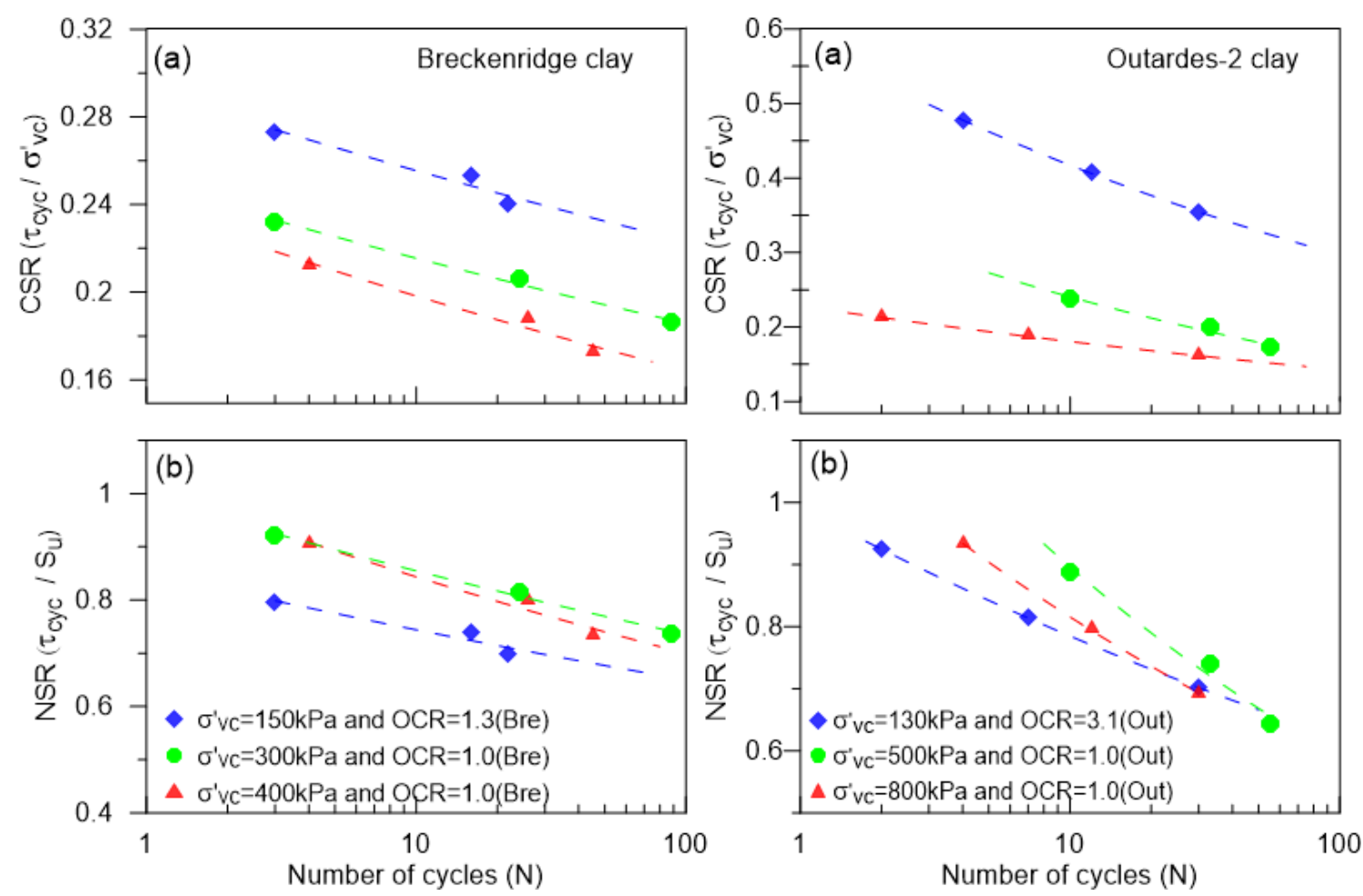

Fig 4.13 Comparisons of cyclic resistance of OC and NC Breckenridge clay (a) CSR vs $\mathrm{N}$ and (b) NSR vs $\mathbf{N}$

Fig 4.14 Comparisons of cyclic resistance of $\mathrm{OC}$ and NC Outardes-2 clays (a) CSR vs N and (b) NSR vs N

\subsubsection{Comparison of the cyclic resistance at different sites and the influence of OCR}

Fig 4.15 and Fig 4.16 compare the cyclic resistance ratio (CRR) of Kinburn, Breckenridge and Outardes-2 samples under naturally OC and NC states. Fig 4.13(a) displays a rough parallel trend between each sample tested under naturally OC state. Further, Fig 4.14 (a) shows a narrow, almost perfectly parallel relationship between each sample tested at NC state. Again this comparison shows OC Leda clays have higher CSR than NC Leda clays as previously noted in Kinburn samples.

Higher consolidation stress (NC) might be the main reason for the lower cyclic resistance in the NC clays. When sensitive clays were consolidated at a higher consolidation stress, 
which is well above sample's pre-consolidation pressure, the clay samples experience collapse or disturbance in their microstructure. This together with the increased confining stress level is presumably responsible for the rapid buildup of positive pore water pressures ( $\Delta u$ ) during the cyclic shearing. As a result, NC clays would rapidly lose their ability to support cyclic shear stresses. On the other hand, strong microstructural bonds in OC material and the stress history (associated with over consolidation) prevent quick generation of $\Delta u$ during the cyclic shearing and yield strong cyclic resistance.

Test results presented in Fig 4.15(a) shows that Outardes-2 clays have higher cyclic shear resistance than Kinburn clays, and Kinburn clays have greater cyclic resistance than Breckenridge clays. Main reason for this difference is that the samples have different OCR values. Further, OC Outardes-2 samples having higher OCR (3.1) with lower water content $\left(\mathrm{w}_{\mathrm{c}}=30 \%\right)$ and clay size particles $(28 \%)$ display higher CRR followed by OC Kinburn samples having OCR value of 2.6 which show intermediate CRR. On the other hand, OC Breckenridge samples having the lowest OCR value of 1.3 display the lowest CRR. Moreover, similar to the undrained monotonic behaviour of sensitive Leda clays, it can be noticed that OCR is the main factor influencing the cyclic behaviour of Leda clays. However, more data is required to investigate the influence of other factors like plasticity index $\left(I_{p}\right)$, sensitivity $\left(S_{t}\right)$, void ratio (e), and percentage of clay particles, etc. on cyclic behaviour of Leda clays.

Fig 4.16 (a) compares the site-specific cyclic resistance of NC Leda clays. NC Kinburn and Breckenridge clays show similar cyclic resistance regardless of the site. However, NC Outardes-2 clays reveal lower CSR, since it is a coarser material (lesser clay size particles $=28 \%)$ compared to other materials and having higher sensitivity $(\mathrm{St}=352)$. 


\subsubsection{Importance of investigating the site-specific cyclic behaviour of sensitive clays}

For design purposes, it is important to determine the cyclic resistance ratio $C R R$ of the soil corresponding to the design earthquake. The CSR that would cause liquefaction in 10 cycles $\left(C R R_{10}\right)$ is considered herein because it represents the 6.75 magnitude earthquake that can be expected in this region (around Kinburn, Breckenridge and Outardes-2 sites). Table 4.3 presents the cyclic resistance ratio and the normalized resistance ratio of 10 cycles for three different sites OC and NC Leda clays.

Table 4.4 compares the obtained cyclic resistance ratio $\left(C R R_{10}\right)$ with calculated cyclic

stress ratio $\left(C S R=0.65 * \frac{a_{\max }}{g} * \frac{\sigma_{v c}}{\sigma_{v c}^{\prime}} * r_{d}\right)$ for each of the sites at in-situ stress state (OC) and normally consolidated (NC) state. Average stress reduction coefficients $\left(r_{d}\right)$ reported by Youd et al. (2001) and peak ground acceleration (corresponding to NBCC shaking levels about $0.317 \mathrm{~g}$ for Kinburn, 0.323g for Breckenridge and $0.341 \mathrm{~g}$ for Outardes-2 sites) were considered for the CSR calculation. This analysis demonstrates that Breckenridge and Outardes-2 OC materials are not expected to liquefy (FOS = $(\mathrm{CRR} / \mathrm{CSR}) \geq 1)$ at Earthquake magnitude of 6.75 or less. However, OC Kinburn clays have the potential to liquefy since its FOS is less than 1 (FOS $=0.87)$. On the other hand under higher consolidation stress (at NC state) these Leda clays have much lower factors of safety $(\mathrm{FOS}=0.49-0.81)$ as seen in Table 4.4 and thus are susceptible to liquefaction. 
Table 4.3 Cyclic resistance ratio and normalized resistance ratio of 10 cycles

\begin{tabular}{|l|c|c|c|c|}
\hline Site & $\begin{array}{c}\text { Number of } \\
\text { equivalent } \\
\text { cycles }(\mathrm{N})\end{array}$ & $\begin{array}{c}\text { Earthquake } \\
\text { magnitude } \\
\left(\mathrm{M}_{\mathrm{w}}\right)\end{array}$ & $\begin{array}{c}\text { Cyclic } \\
\text { resistance ratio } \\
\left(\mathrm{CRR}_{10},\right. \\
\left.\tau_{c y c} / \sigma^{\prime}{ }_{v c}\right)\end{array}$ & $\begin{array}{c}\text { Normalized } \\
\text { resistance ratio } \\
\left(\mathrm{NRR}_{10}, \tau_{c y c} /\right. \\
\left.S_{u}\right)\end{array}$ \\
\hline \multicolumn{5}{|c|}{ In-situ stress state/ Over consolidated (OC) } \\
\hline Kinburn & 10 & 6.75 & 0.352 & 0.776 \\
\hline Breckenridge & 10 & 6.75 & 0.255 & 0.745 \\
\hline Outardes-2 & 10 & 6.75 & 0.418 & 0.815 \\
\hline \multicolumn{5}{|c|}{ Normally consolidated (NC) state } \\
\hline Kinburn & 10 & 6.75 & 0.197 & 0.802 \\
\hline Breckenridge & 10 & 6.75 & 0.197 & 0.842 \\
\hline Outardes-2 & 10 & 6.75 & 0.181 & 0.788 \\
\hline
\end{tabular}

Table 4.4 Comparison of CRR 10 with calculated CSR

\begin{tabular}{|l|c|c|c|}
\hline \multicolumn{1}{|c|}{ Site } & $C R R_{10}=\tau_{c y c} / \sigma_{v c}^{\prime}$ & $C S R=0.65 * \frac{a_{\max }}{g} * \frac{\sigma_{v c}}{\sigma_{v c}^{\prime}} * r_{d}$ & $\begin{array}{c}\text { Factor of } \\
\text { Safety } \\
(=\text { CRR/CSR) }\end{array}$ \\
\hline \multicolumn{4}{|c|}{ In-situ stress state/ Over consolidated (OC) } \\
\hline Kinburn & 0.352 & 0.417 & 0.87 \\
\hline Breckenridge & 0.255 & 0.252 & 1.04 \\
\hline Outardes-2 & 0.418 & 0.302 & 1.33 \\
\hline \multicolumn{4}{|c|}{ Normally consolidated (NC) state } \\
\hline Kinburn & 0.197 & 0.417 & 0.49 \\
\hline Breckenridge & 0.197 & 0.252 & 0.81 \\
\hline Outardes-2 & 0.181 & 0.302 & 0.57 \\
\hline
\end{tabular}



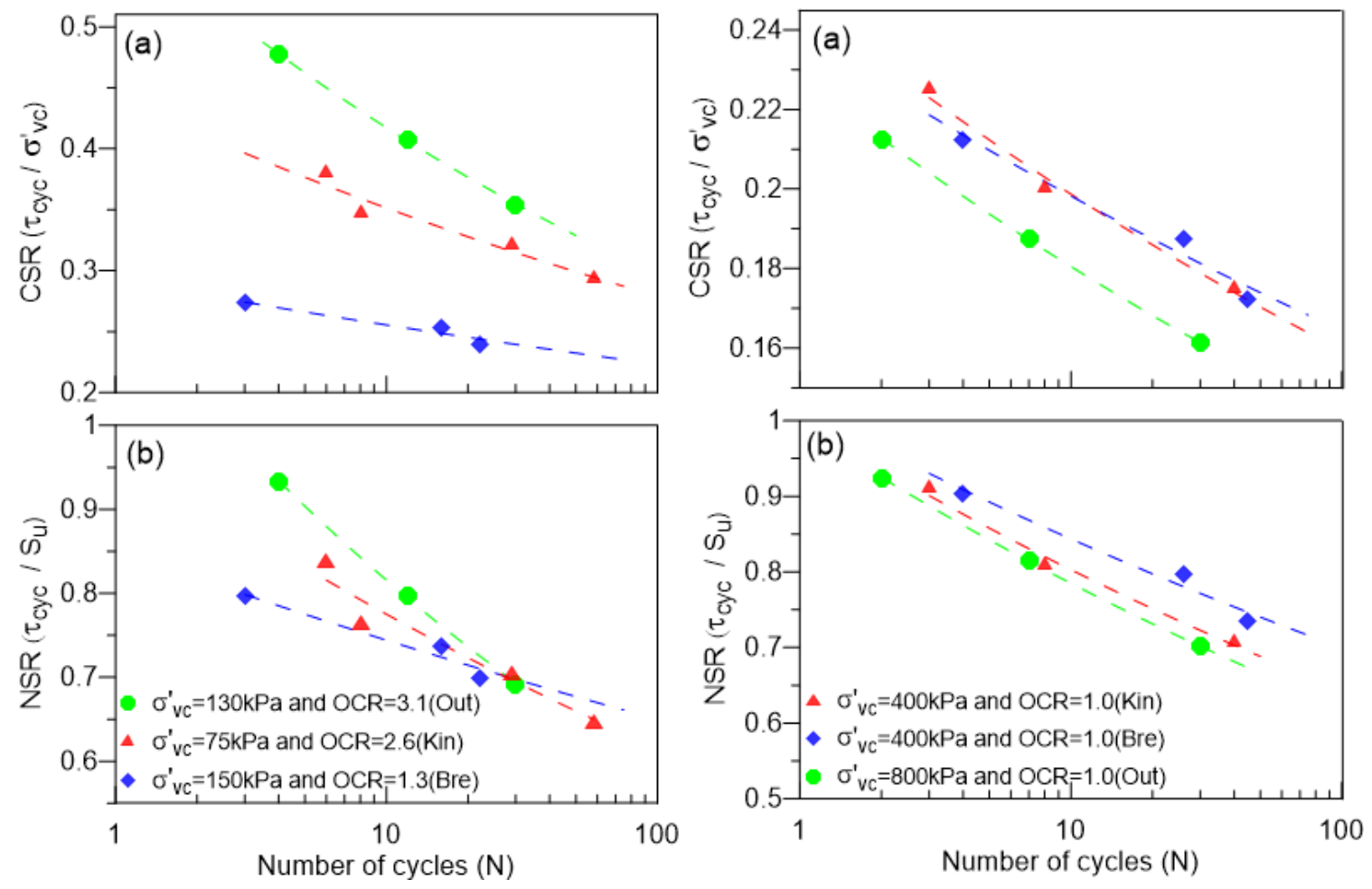

Fig 4.15 Comparison of cyclic resistance of $\mathrm{OC}$ Leda clays for different sites (a) CSR vs $\mathrm{N}$ and (b) NSR vs N

Fig 4.16 Comparison of cyclic resistance of $\mathrm{NC}$ Leda clays for different sites (a) CSR vs $\mathrm{N}$ and (b) NSR vs N

\subsection{Post cyclic behaviour of sensitive Leda clay}

Investigating the stress-strain characteristics of clays following an earthquake or liquefaction is vital since there are evidences in the literature for post-cyclic failures (e.g., Lower San Fernando Dam, 1971; Mochikoshi Tailings Dam 1978 etc.) Post-liquefaction analysis is required not only to understand the post-liquefaction strength but also to determine post-cyclic deformation characteristics of soils. In general, original monotonic undrained shear strength will be lowered due to the consequences of cyclic loading. However, the amount of reduction depends on several factors including the characteristics of clays, maximum cyclic strain level and the number of loading cycles (Idriss, 2004; Thiers and Seed, 1969; Andersen, 1976). 
In this research study, the post-cyclic behaviour of the sensitive Leda clays was assessed under simple shear condition. Post-cyclic tests were carried out on Kinburn, Breckenridge and Outardes-2 samples immediately after the cyclic tests were completed. All samples were monotonically sheared up to the large strain of $25 \%$ at a loading rate of $5 \%$ per hour.

Fig 4.17 compares the monotonic, cyclic and post-cyclic behaviour of Breckenridge clay at $\sigma_{v c}^{\prime}=150 \mathrm{kPa}$ and its normalized post-cyclic behaviour is presented in Fig 4.18. Before applying the post-cyclic monotonic load, this sample was liquefied $\left(\gamma_{c}>3.75 \%\right)$ in 22 cycles with a cyclic stress ratio of $0.24\left(\tau_{c y c}=36 \mathrm{kPa}\right.$, Test ID: CYC-10). Even though the nature of the post-cyclic monotonic behaviour is approximately similar to the undrained monotonic behaviour, Fig 4.17 clearly shows the differences in magnitude between monotonic and post-cyclic monotonic behaviour. Further, Fig 4.17(a) shows stress-strain responses of sample under monotonic loading (MON-04) sharply increased and reached the peak $S_{u}$ value of $51.5 \mathrm{kPa}$ at around $\gamma$ of $3 \%$ and then smoothly strain softened. On the other hand, post-cyclic monotonic behaviour (POST_CYC_MON-10) slowly reached its peak $S_{u\left(\mathrm{P}_{-} \mathrm{CYC}\right)}$ value of $37.1 \mathrm{kPa}$ at around $\gamma$ of $6 \%$ and then slowly strain softened. The peak post-cyclic shear strength is $72 \%$ of its monotonic peak $S_{u}$ and the normalized strength ratio $\left(S_{u\left(\mathrm{P}_{-} \mathrm{CYC}\right)} / \sigma_{v c}^{\prime}\right)$ of 0.25 .

Figs 4.17(b) and 4.18(b) show that during the post-cyclic loading initially negative excess pore water pressure ( $\Delta u)$ developed (dilative behaviour) and then subsequently positive $\Delta u$ started to build up (contraction). This happened because the end of cyclic loading clay had sustained a significant drop in effective stress $\left(\sigma_{v}^{\prime}\right)$ which is around $67 \%$ of the consolidation stress $\sigma_{v c}^{\prime}$ (during the cyclic loading $\sigma^{\prime}{ }_{v}$ reduced from 150 to around $50 \mathrm{kPa}$ ) as seen in Fig 4.17(c). 
Table 4.5 compares the normalized peak shear strength $\left(S_{u} / \sigma^{\prime}{ }_{v c}\right)$ and average normalized peak post-cyclic shear strength $\left(S_{u\left(\mathrm{P}_{-} \mathrm{CYC}\right)} / \sigma^{\prime}{ }_{v c}\right)$. Again post-cyclic tests results also showed that OC materials display a higher normalized (post-cyclic) shear strength compared to NC materials. Further, Outareds-2 material produced higher post-cyclic shear strength among other materials, since it had higher OCR, lower water content and clay size particles.

Table 4.5 Comparison of the normalized peak shear strength $\left(S_{u} / \sigma^{\prime}{ }_{v c}\right)$ and average normalized peak post-cyclic shear strength $\left(S_{u\left(\mathrm{P}_{-} \mathrm{CYC}\right)} / \sigma^{\prime}{ }_{v c}\right)$

\begin{tabular}{|c|c|c|c|}
\hline Site & $\begin{array}{c}\text { Consolidation } \\
\text { stress } \\
\left(\sigma^{\prime}{ }_{\mathrm{vc}}, \mathrm{kPa}\right)\end{array}$ & $\begin{array}{c}\text { Normalized peak } \\
\text { shear strength } \\
\left(S_{u} / \sigma^{\prime}{ }_{v c}\right)\end{array}$ & $\begin{array}{c}\text { Average normalized peak } \\
\text { post-cyclic shear strength } \\
\left(S_{u\left(\mathrm{P}_{-} \mathrm{CYC}\right)} / \sigma^{\prime}{ }_{v c}\right)\end{array}$ \\
\hline \multicolumn{5}{|c|}{ In-situ stress state/ Over consolidated (OC) } \\
\hline Kinburn & 75 & 0.46 & 0.29 \\
\hline Breckenridge & 150 & 0.34 & 0.28 \\
\hline Outardes-2 & 130 & 0.51 & 0.38 \\
\hline \multicolumn{5}{|c|}{ Normally consolidated (NC) state } \\
\hline Kinburn & 300 & 0.25 & 0.19 \\
\hline Breckenridge & 400 & 0.24 & 0.17 \\
\hline Outardes-2 & 800 & 0.23 & 0.20 \\
\hline
\end{tabular}



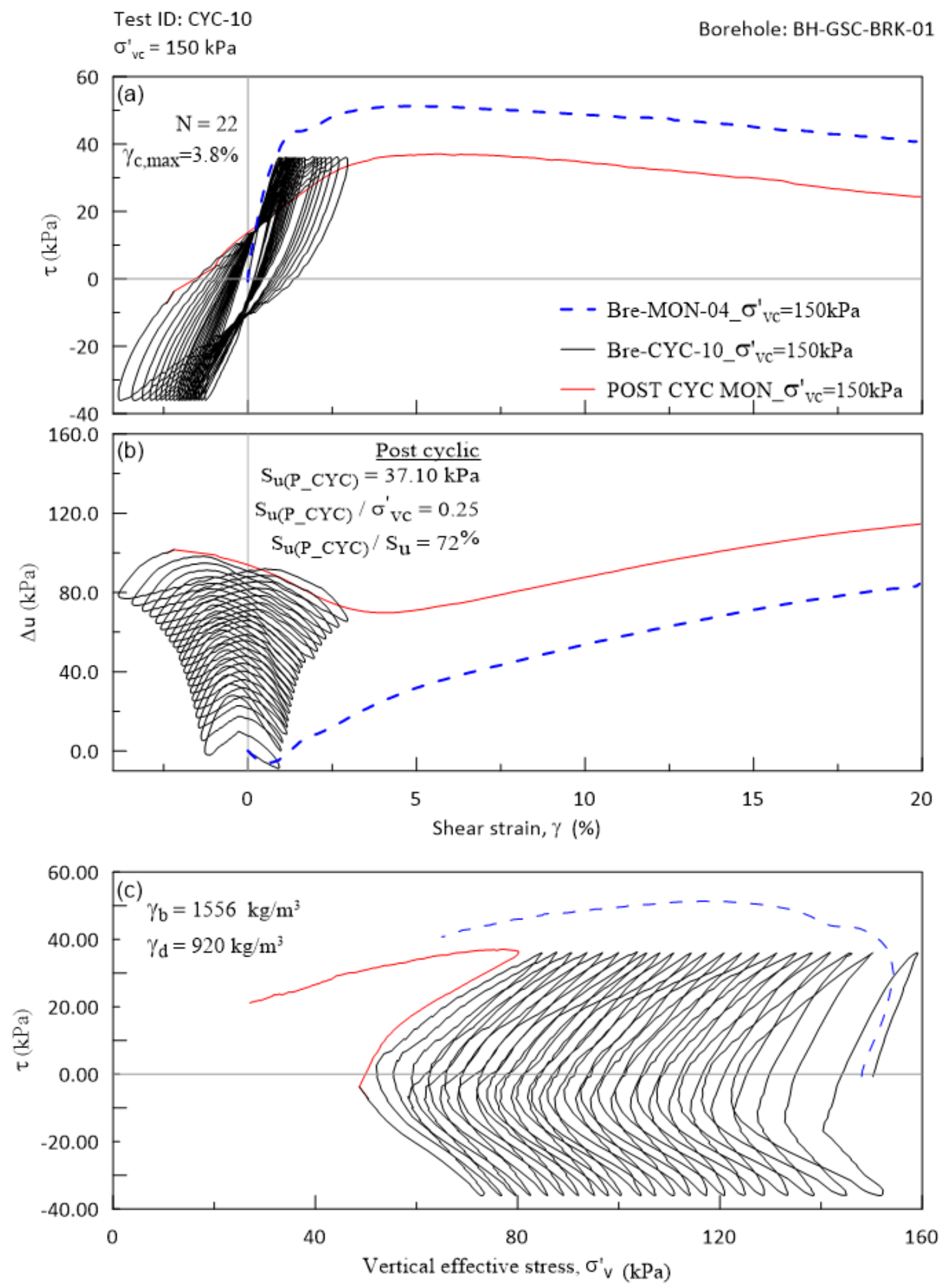

Fig 4.17 Comparison of monotonic, cyclic and post-cyclic behaviour of OC Breckenridge clay 

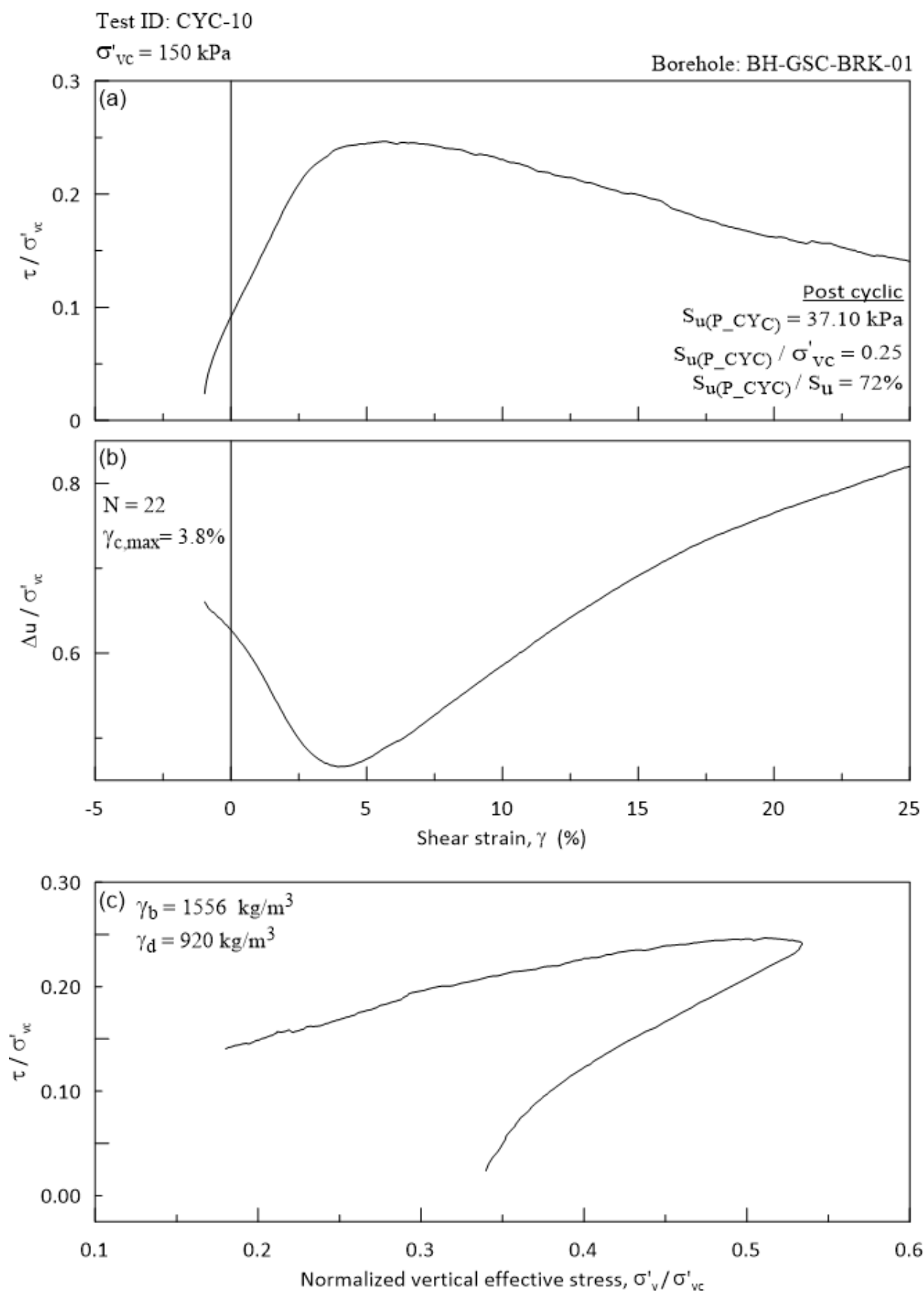

Fig 4.18 Normalized post-cyclic monotonic behaviour of Breckenridge OC Leda clay (a) Stress-strain response; (b) PWP generation; (c) Stress path. 


\section{MODULUS AND DAMPING BEHAVIOUR OF SENSITIVE LEDA CLAYS AND FRASER RIVER SAND}

\subsection{Introduction}

This chapter presents the characteristics of secant shear modulus $\left(G_{s}\right)$, shear modulus reduction $\left(G_{s} / G_{\max }\right)$ and damping ratio $(\xi)$ of sensitive Leda clay obtained from different locations in Eastern Canada (Kinburn, ON, Breckenridge, ON, and Outardes-2, QC). Further, the dynamic properties of Fraser River sand obtained from the Fraser Delta (BC) have also been reported in this chapter.

The first part of this chapter discusses the test methods used to establish modulus and damping values for sensitive clays and sand. It also evaluates the reliability of measuring dynamic properties of soils at small shear strains using CU simple shear device. The second part of this chapter analyses and discusses the characteristic of shear modulus, modulus reduction and damping curves for sensitive Leda clays obtained from different locations in Ottawa-Quebec area under different consolidation stress levels (50, 100, 200, 400 and 800 $\mathrm{kPa}$ ). Final part of this chapter examines the characteristic of shear modulus, modulus reduction and damping curves for Fraser River sand and the influence of consolidation stress levels $(50,100,200$ and $400 \mathrm{kPa})$, relative density (50,65 and 80\%) and over consolidation ratio (1,2 and 4).

\subsection{Testing methods}

\subsubsection{Single and multistage testing}

Multistage quasi-cyclic testing is an effective technique to maximize the usage of the limited undisturbed samples. This testing method facilitates a larger number of tests in spite 
of the sampling constraints. Further, by conducting a series of tests on identical undisturbed sample avoids the uncertainty due to natural heterogeneity among different samples. In addition, it has been demonstrated that the effect of staged testing on the measured behaviour is not significant provided that the applied shear strain during each stage of the loading is kept small (Theenathayarl, 2015).

In each multi-stage testing, a single sample was prepared, consolidated and initial quasicyclic shearing was conducted at shear strain amplitudes $\left(\gamma_{c}\right)$ of $0.01,0.02,0.05,0.1,0.2$, $0.5,1$ and $2 \%$, under consolidation stress $\left(\sigma^{\prime}{ }_{\mathrm{vc}}\right)$ of $50 \mathrm{kPa}$. Numbers of loading cycles were limited to two at each $\gamma_{c}$ level. After that, the sample was again consolidated at higher $\sigma_{\mathrm{vc}}^{\prime}=100 \mathrm{kPa}$ and sheared at small $\gamma_{c}$ ampilitudes. Similarly, after each shearing the sample was consolidated repeatedly under higher $\sigma_{\mathrm{vc}}^{\prime}$. A few additional tests on virgin samples were conducted to evaluate the validity of multistage quasi-cyclic testing.

Figs 5.1 and 5.2 present a comparison of single and multistage quasi-cyclic tests. A test (MON-M\&D-06) was conducted on Kinburn sample using multistage loading $\left(\sigma^{\prime}{ }_{\mathrm{vc}}\right.$ of 50, 100,200 and $400 \mathrm{kPa}$ ) and another test (MON-M\&D-20) was carried out on similar sample at single stage $\left(\sigma^{\prime}{ }_{\mathrm{vc}}\right.$ of $\left.400 \mathrm{kPa}\right)$. Test results compared in Fig. 5.1 demonstrates that there were no significant changes in stress-strain behaviours due to the multistage testing. Similarly, another set of tests were conducted under $\sigma_{v c}^{\prime}$ of $800 \mathrm{kPa}$ on Kinburn sample and the test results are compared in Fig. 5.2. Again, it is clear that the deviations in stressstrain response are not significant. Similar tests carried out by Theenathayarl (2015) on Ottawa sensitive clays have also confirmed the suitability of multistage testing for this purpose. Further, stress-controlled quasi-cyclic tests were carried out on Fraser River sand 
(FRS) to investigate its modulus and damping characteristics. Sand specimens were reconstituted in the laboratory.

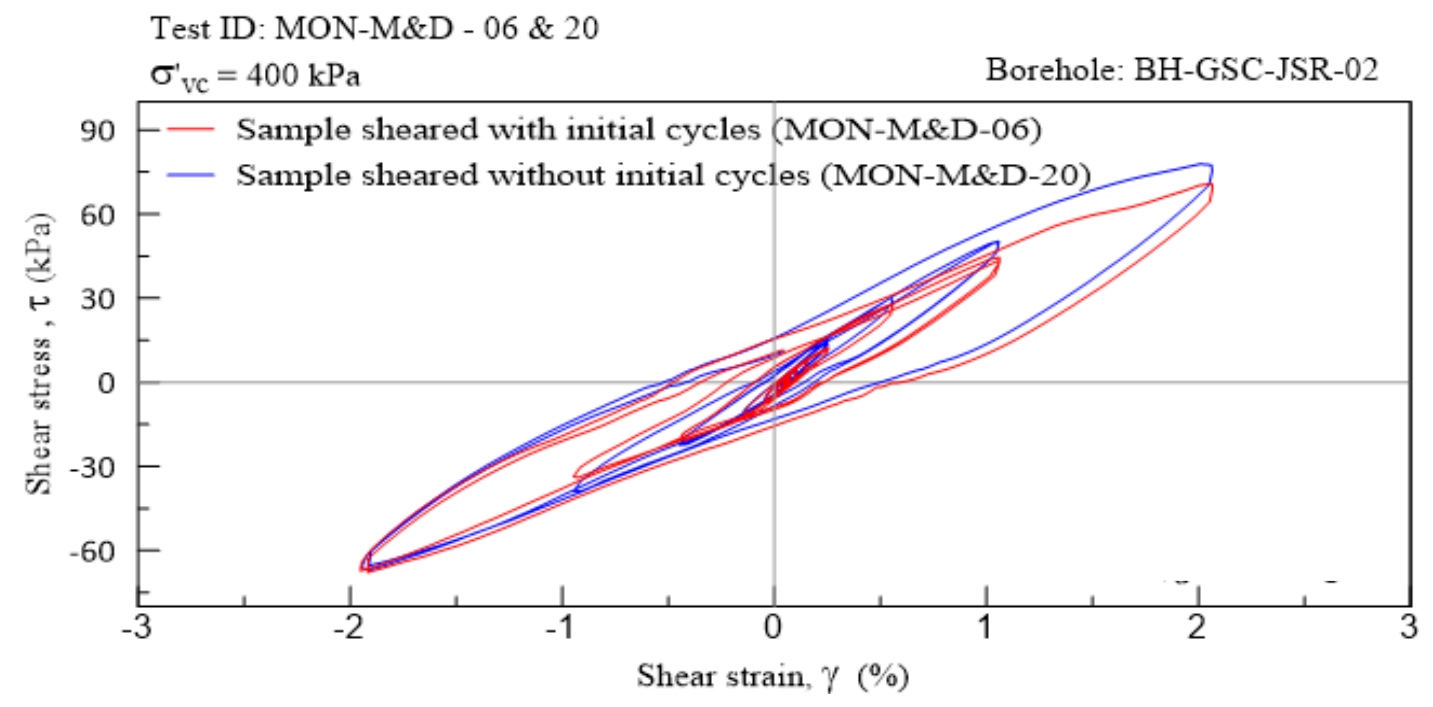

Fig 5.1 Comparison of stress-strain behaviour of Leda clays at single and multistage testing under $\sigma^{\prime}{ }_{\mathrm{vc}}$ of $400 \mathrm{kPa}$

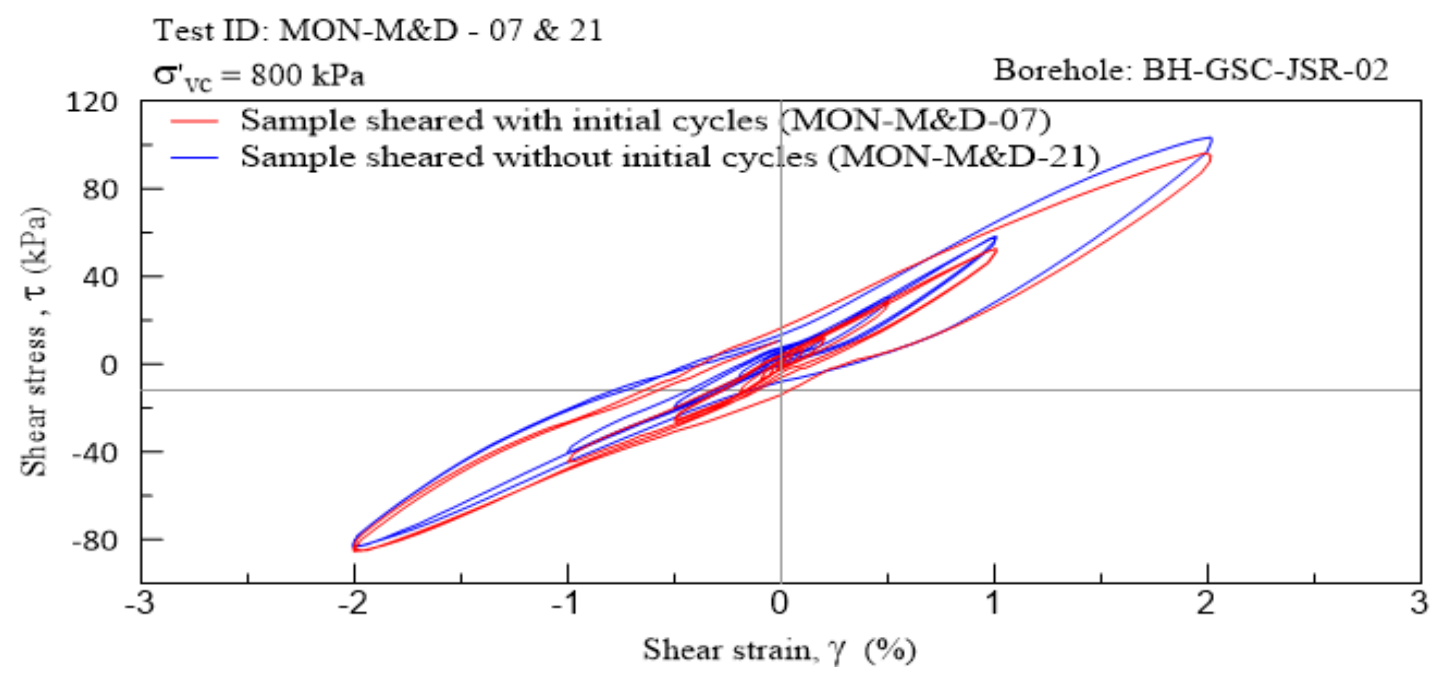

Fig 5.2 Comparison of stress-strain behaviour of Leda clays at single and multistage testing under $\sigma^{\prime}{ }_{v c}$ of $800 \mathrm{kPa}$ 


\subsubsection{Stress and strain controlled testing}

A series of stress and strain controlled quasi-cyclic tests were conducted in multistage under the simple shear condition to establish the modulus and damping characteristics of sensitive Leda clays. Strain-controlled test does not produce reliable results below $\gamma_{c}$ of $0.01 \%$ in the CU simple shear device. The main reason for this is related to the use of a mechanically driven gear-motor to apply the shear loading in strain controlled tests. A play within the gear-teeth creates faulty data at the time of stress reversal and also the system is inadequate to correct for this error, and record enough data to construct smooth stress-strain loops below $\gamma_{c}$ of $0.01 \%$. Nevertheless, this error is not significant above $\gamma_{c}$ of $0.01 \%$. Therefore, in order to establish the modulus and damping curves for Leda clays, multistage stresscontrolled tests were conducted below $\gamma_{c}$ of $0.01 \%$ and multistage strain-controlled tests were carried out above $\gamma_{c}$ of $0.01 \%$.

Stress-controlled testing provides more consistent data points than strain controlled testing and also it is suitable for very low shear strains $\left(\gamma_{c}<0.01 \%\right)$. However, a problem associated with this testing procedure was noted at very low $\gamma_{c}$ around $0.001 \%$ (which translates to about $0.18 \mu \mathrm{m}$ displacement); the initial cyclic loop slipped to one side as seen in Fig 5.3. Relatively large deformation during the first quarter cycle (about $0.005 \%$ strain or $0.90 \mu \mathrm{m}$ deformation) was unexpected given the subsequent stress-strain loop (with a $\pm 0.001 \%$ strain or or $0.18 \mu m$ deformation). A similar issue can be noted in the data reported by Theenathayarl (2015). The number the data points and their consistency within the loading cycle clearly indicate that this error is not due to electrical noise. 


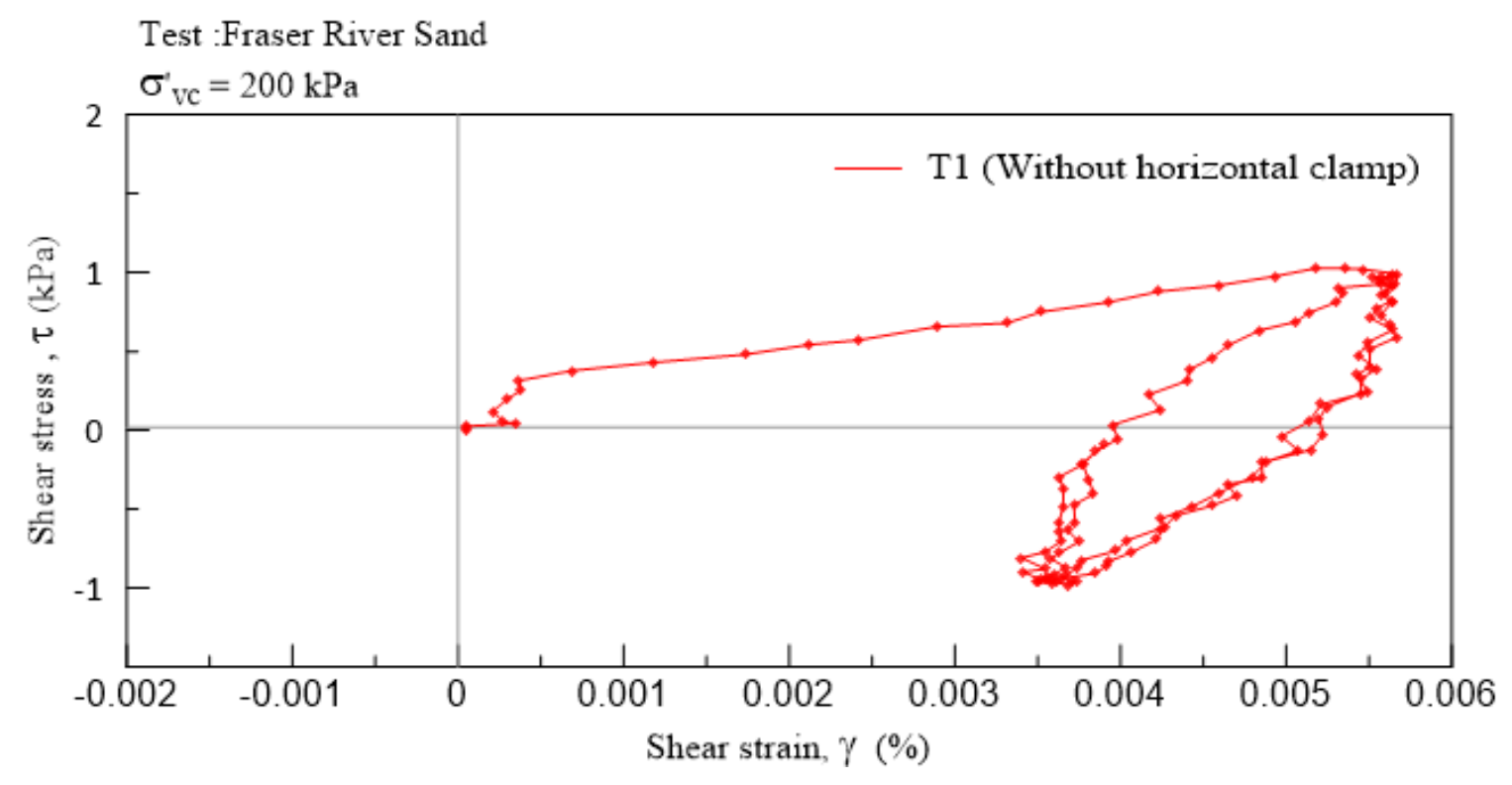

Fig 5.3 Initial stress-strain loop slipped to one side without horizontal clamp

\subsubsection{Enhancements to the small strain $\left(\gamma_{c}<0.01 \%\right)$ measurements}

A significant time and effort were invested to identify the causes of the above error in this research, and an attempt was made to fix the above-mentioned problem by making modifications to the test device. Initial examinations showed a very small ("micro") tilt within the bottom platform and a micro play between the nuts which are joining the top part of the device and the shear loading arm caused the initial slip. The original system uses a single point clamping mechanism (located at about $60 \mathrm{~cm}$ below the top platen) and even a small rotation (which is not a concern in typical simple shear tests) can be problematic in this series of tests. Based on the observed lateral movements, it was determined that the loading shafts pivots through an angle of about $0.2^{\prime \prime}\left(8.7 \times 10^{-7}\right.$ radians $)$ due to the play in the clamping system. Later, bottom platform nuts were tightened and calibrated. In addition, flat nuts and specially designed horizontal clamp were employed to provide a two 
points clamping mechanism during the shearing process as seen in Fig 5.4 and 5.5, and the outcomes showed reasonable improvements as presented in Fig 5.6.

In addition, precautions were taken in positioning and tightening the new clamp as it has to be manually placed after consolidation without affecting the stress state. This is a balancing act, and sometimes the tilt/slip (but to a lesser degree) happened even with the clamp in some tests. Nevertheless, this error was eliminated in all tests conducted on Fraser River sand by repeating the tests which were affected since there was no limitation in the availability of (reconstituted) FRS sample. But, this error was not fully eliminated in Leda clay testing due to the limitation of undisturbed samples. Therefore, only strain controlled test results were considered to establish the modulus and damping of Leda clays.

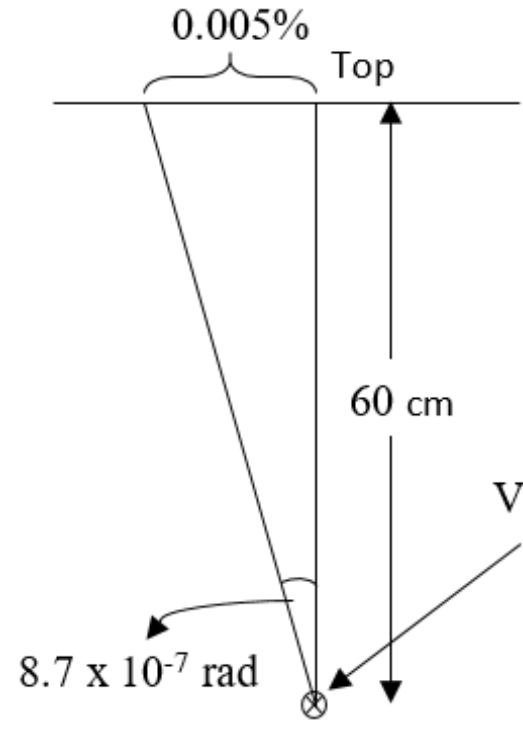

(a)

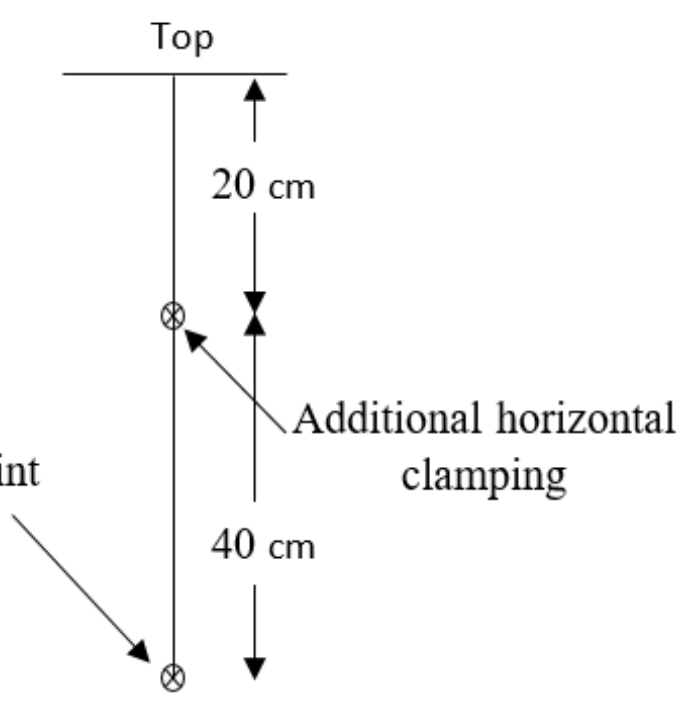

(b)

Fig 5.4 Diagram of (a) original single, and (b) new two points clamping mechanism of simple shear device 


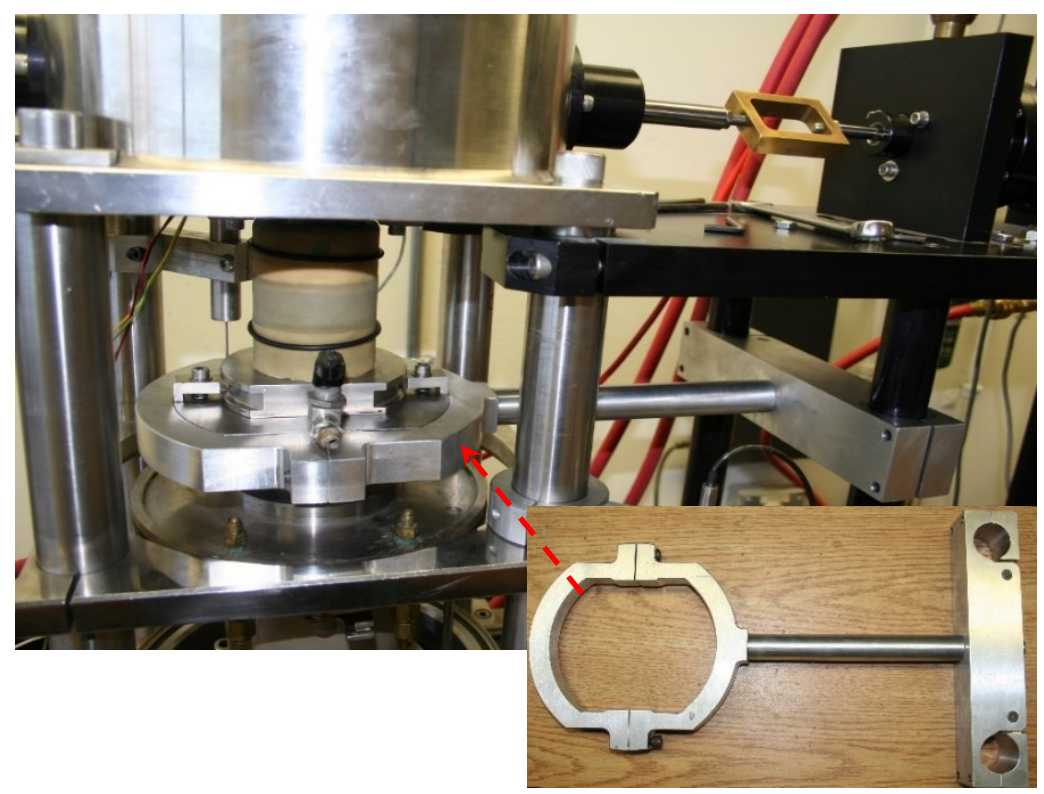

Fig 5.5 Carleton University simple shear device enhanced with horizontal clamp

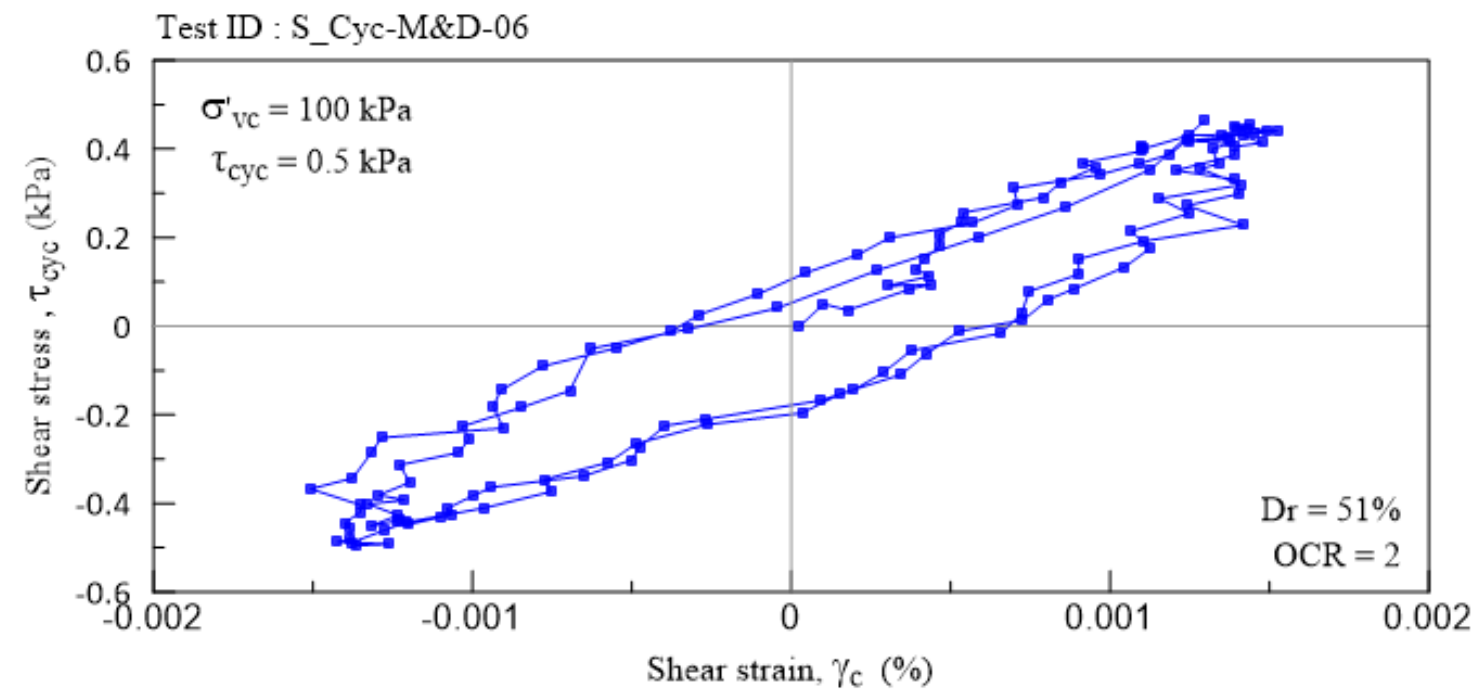

Fig 5.6 Typical stress-strain loops for Fraser River Sand under cyclic loading of $0.5 \mathrm{kPa}\left(\gamma_{c}\right.$ around $0.0015 \%)$ 


\subsubsection{Multistage strain controlled quasi-cyclic tests}

A series of multistage strain controlled quasi-cyclic tests were carried out on different batches of sensitive Leda clays obtained from Kinburn (depth of 11 and $21 \mathrm{~m}$ ), Breckenridge $(26 \mathrm{~m})$ and Outardes-2 $(11 \mathrm{~m})$ sites. A range of cyclic strain amplitudes $\left(\gamma_{c}=\right.$ 0.01 to $2 \%)$ under different consolidation stress $\left(\sigma^{\prime}{ }_{\mathrm{vc}}=50\right.$ to $\left.800 \mathrm{kPa}\right)$ were applied.

The modulus and damping values were established from the stress-strain loops obtained from these test data. The variation in the samples due to different locations, depths, and stress history are useful in determining the modulus reduction and damping curves for sensitive Leda clays. Also, they provide a better understanding of the effects of consolidation stress, plasticity, sensitivity and other factors on the dynamic properties of Eastern Canadian sensitive clays.

The characteristics of a typical strain-controlled quasi-cyclic shearing are presented in Fig 5.7. This figure demonstrates the typical behaviour of a Leda clay, which was collected from Breckenridge site at a depth of $26 \mathrm{~m}$. Different levels of small cyclic strain amplitudes were applied to the sample consolidated at ${\sigma^{\prime}}_{v c}=200 \mathrm{kPa}$. Stress-strain response, excess pore water generation and stress path are plotted in Fig 5.7 (a), (b) and (c) respectively. Increasing shear strain gradually increases the excess pore pressure generation and consequently the stress path is mobilized towards the origin. 
Test ID: Mon-M\&D - 12

Stage : 3

Borehole: BH-GSC-BRK-01
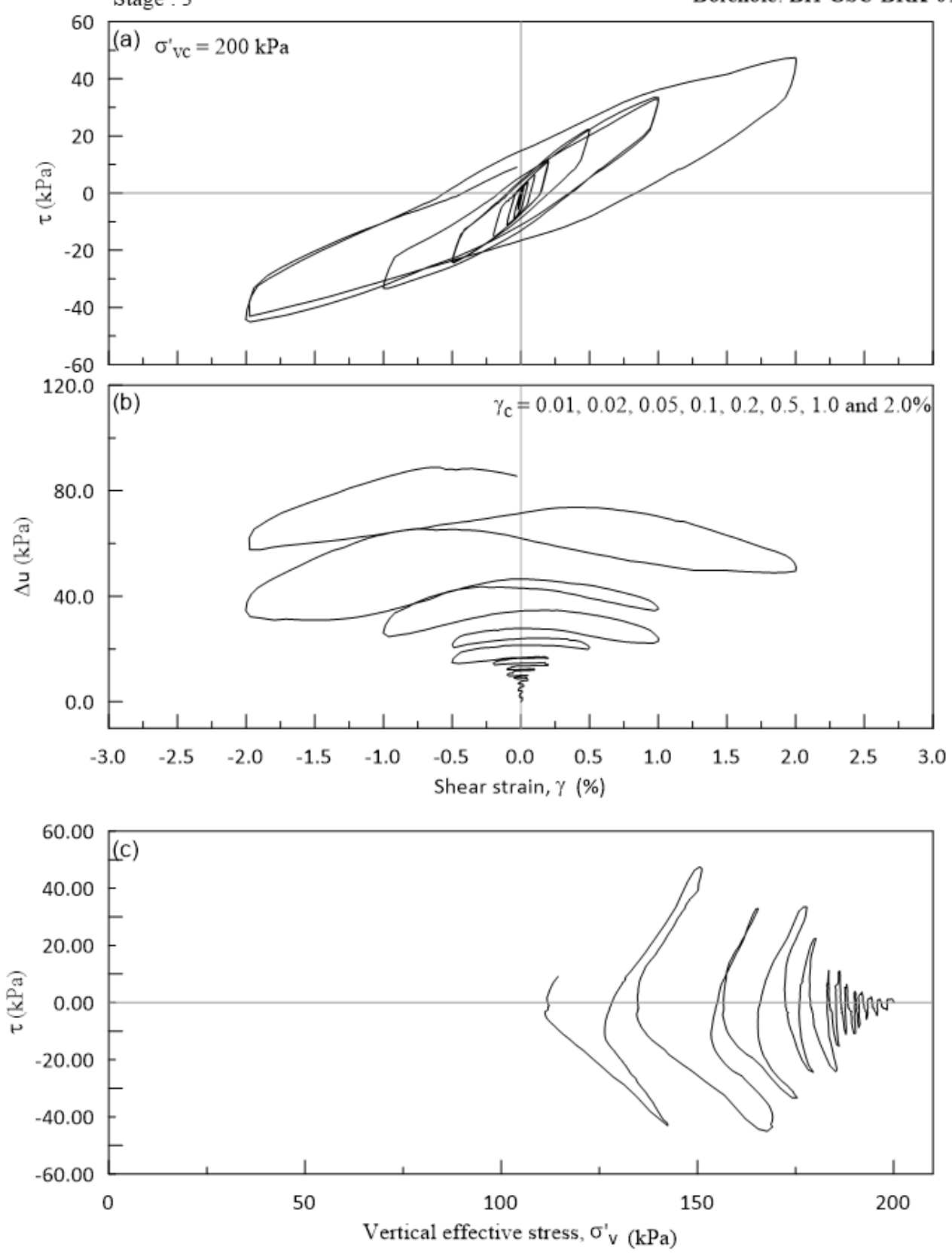

Fig 5.7 Typical behaviour of Breckenridge Leda clay during quasi-cyclic shearing (a) stress-strain behaviour, (b) variation of pore water pressure and (c) stress path 


\subsection{Characteristics of secant shear modulus and damping ratio of clays}

\subsubsection{Estimation of the secant shear modulus $\left(G_{s}\right)$ and damping ratio $(\xi)$}

A typical set of individual stress-strain loops obtained from a strain-controlled test (MonM\&D-08) is presented in Fig 5.8. Likewise, stress-strain loops for each sample under different consolidation stress levels (ranging from 50 to $800 \mathrm{kPa}$ ) were plotted and corresponding secant shear modulus $\left(G_{S}\right)$ and damping ratio $(\xi)$ were calculated according to their respective $\gamma_{c}$ amplitudes.

Secant shear modulus $\left(G_{S}\right)$ of each sample were calculated by measuring the slope of the hysteresis loops, which is the ratio of cyclic shear stress $\left(\tau_{c y c}\right)$ and corresponding cyclic strain $\left(\gamma_{c}\right)$. Damping ratios $(\xi)$ were calculated using the following equation at each $\gamma_{c}$ level.

$$
\xi=\frac{1}{2 \pi} \frac{A_{\text {loop }}}{G_{s} \gamma_{c}^{2}}
$$

During strain controlled testing, reinforced membrane and the system created a small force due to friction and membrane stiffness, which caused the additional area to stress-strain loops of the sample. This additional area was subtracted from the total area of each loop in order to calculate the actual energy absorbed by the soil during the estimation of the damping ratio $(\xi)$. Further, this additional areas or amounts of energy released as an outcome of the friction at different $\gamma_{c}$ amplitudes were already determined by Theenathayarl (2015).

Fig 5.8 and Fig 5.7(a) clearly display a continuous reduction in the slope of successive stress-strain loops as $\gamma_{c}$ increases. This observation demonstrates the degradation in the 
shear modulus of Leda clay with increasing $\gamma_{c}$. On the other hand, the area of each successive stress-strain loop significantly increased with $\gamma_{c}$, this behaviour reflects the increment in damping ratio with $\gamma_{c}$ amplitudes. Similar observations were noted in all other tests, however the rate of modulus or stiffness degradation and increment in the damping ratio varied with site-specific Leda clays and consolidation stress levels.
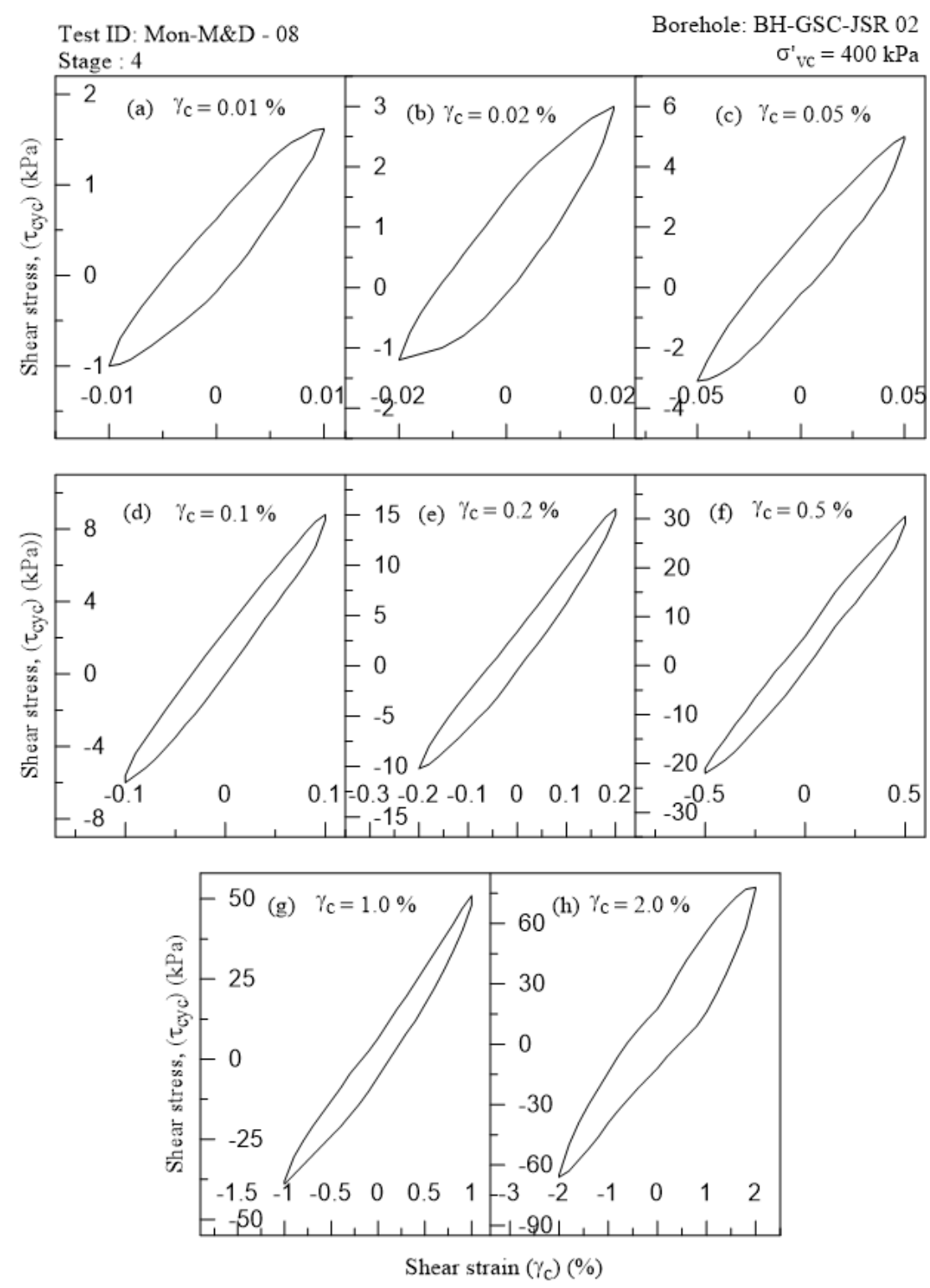

Fig 5.8 Typical stress-strain loops obtained for Kinburn sample $(21 \mathrm{~m})$ from strain controlled quasicyclic testing under $\sigma^{\prime}{ }_{v c}$ of $400 \mathrm{kPa}$. 


\subsubsection{Estimation of the maximum shear modulus and modulus reduction values of}

sensitive clays

Modulus reduction curves are established by normalizing the shear modulus $\left(G_{S}\right)$ with the maximum value of $G_{S}\left(G_{\max }\right)$ at each shear strain level. $G_{\max }$ is the peak value of shear modulus measured at very low strain level $\left(\gamma_{c}<0.001 \%\right)$ and it could be determined by resonant column or bender element tests or field tests. The simple shear device does not have sufficient resolution to accurately determine $G_{\max }$ under strain controlled loading mode. The measured $G_{s}$ values at $0.01 \%$ of strain level under strain controlled test, is obviously lesser than the actual value of $G_{\max }$. Therefore, in this research study, a different approach was adopted to determine the approximate $G_{\max }$ and to establish the modulus reduction curves for sensitive Leda clays. This particular approach was proposed by Theenathayarl (2015) to determine the approximate $G_{\max }$ for Leda clays. According to this approach the measured $G_{s}$ values at $0.01 \%$ of shear strain level is considered approximately equal to $85 \%$ of the maximum shear modulus $\left[\right.$ i.e. $\left(G_{s}\right)_{\gamma=0.01 \%} \approx 0.85 \times G_{\max }$ ]. This approximation was based on the information available in the literature (Vucetic and Dobry, 1991; Theenathayarl, 2015). From this approximation, modulus reduction values $\left(G_{s} / G_{\max }\right)$ were calculated with respect to the $\gamma_{c}$ amplitude. Research efforts are currently underway at University of Waterloo on soil samples from the same sites to determine $G_{\max }$ using the resonant column device. Once that data becomes available, these proposed modulus reduction curves could be further refined. However, for Fraser River sand, measured $G_{s}$ values at $\gamma_{c}$ of $0.001 \%$ is considered as $G_{\max }$, since the stress controlled tests were successfully conducted on Fraser River Sand. Moreover, value of $G_{s}$ at $\gamma_{c}$ of $0.001 \%$ is expected to be approximately equal to actual $G_{\max }$. 
Tests data presented in Fig 5.9 shows the dependence of shear modulus $G_{S}\left(\gamma_{c}=0.01 \%\right)$ on consolidation stress levels $\left(\sigma_{v c}^{\prime}\right)$ for Kinburn, Breckenridge and Outardes-2 samples. A significant increase in the shear modulus with consolidation stress level $\left(\sigma^{\prime}{ }_{v c}=50\right.$ to 800 $\mathrm{kPa})$ can be noticed in Fig 5.9(a-d).

In general, correlation between shear modulus and consolidation stress can be written as $G_{\max }=K \cdot\left(\sigma_{v c}^{\prime}\right)^{m}$, and the value of exponent $m$ is considered to be about 0.5 (Seed and Idriss, 1986). However, plots presented in Fig 5.9(a - d) show values of exponent $\mathrm{m}$ as 0.45, 0.35, 0.32 and 0.43 for Kinburn $(z=11 \mathrm{~m})$, Kinburn $(z=21 \mathrm{~m})$, Breckenridge $(\mathrm{z}=26 \mathrm{~m})$, and Outardes-2 $(\mathrm{z}=11 \mathrm{~m})$ clays. The variation in OCR as the effective consolidation stress changes is partly responsible for this behaviour.

Fig 5.10(a) and (b) show typical values of secant shear modulus $\left(G_{s}\right)$ and their normalized shear modulus $\left(G_{s} / G_{\text {max }}\right)$ values of Kinburn samples, obtained at the depth of $21 \mathrm{~m}$ under different consolidation stresses $\left(\sigma^{\prime}{ }_{v c}\right)$. The difference between $G_{s}$ values at successive $\sigma_{v c}^{\prime}$ of $50,100,200,400$ and $800 \mathrm{kPa}$ are approximately equal and the influence of $\sigma_{v c}^{\prime}$ on $G_{S}$ is considerably significant only below shear strain $\left(\gamma_{c}\right)$ of $0.2 \%$. Above $\gamma_{c}$ of $0.5 \%$ the effect of successive $\sigma^{\prime}{ }_{v c}$ on $G_{s}$ is less as seen in Fig 5.10(a). Further, when these $G_{s}$ values normalized with $G_{\max }$ the influence of $\sigma^{\prime}{ }_{v c}$ becomes insignificant as illustrated in Fig $5.10(\mathrm{~b})$. 


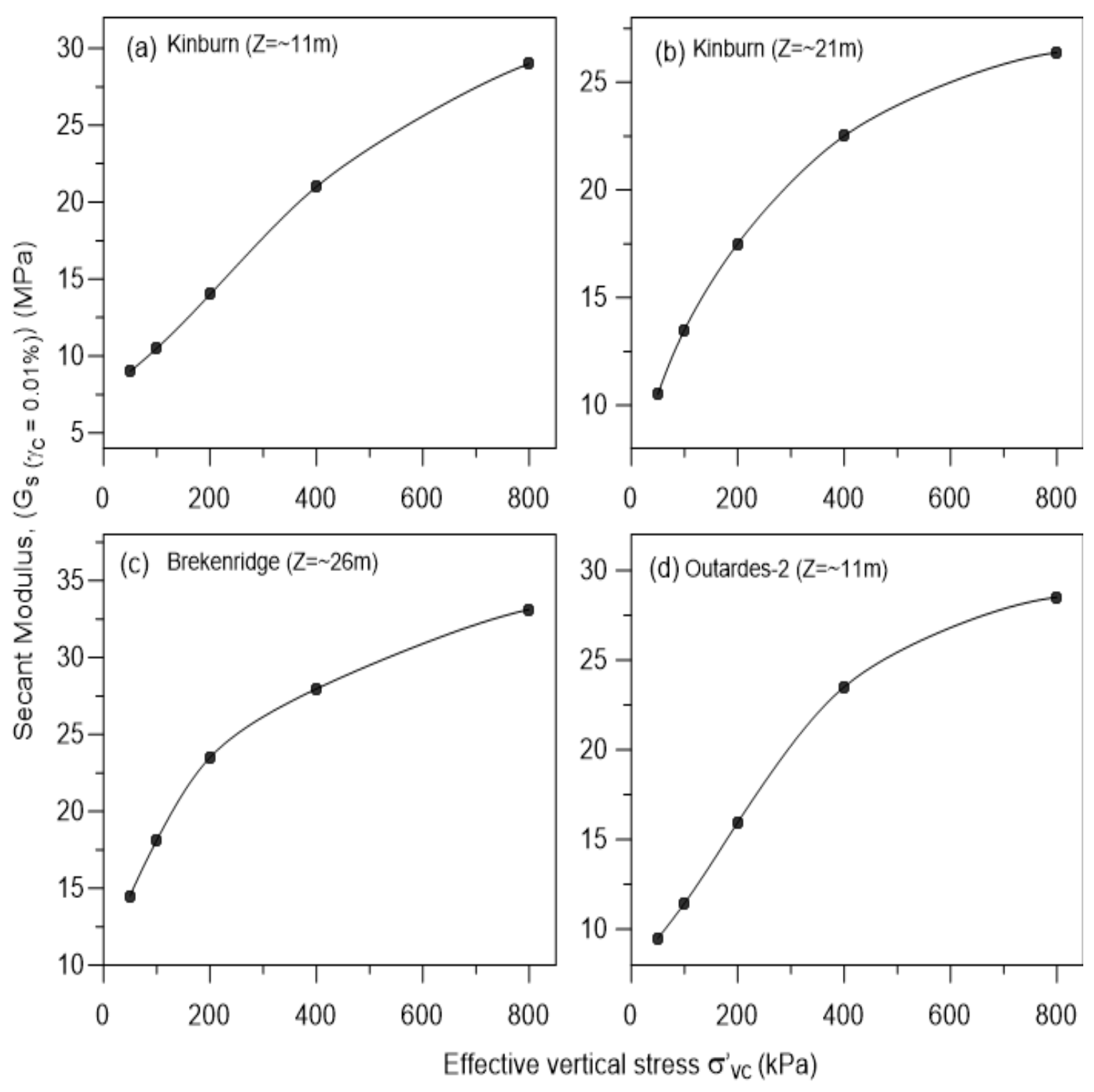

Fig 5.9 Initial shear modulus changes with consolidation stress level 

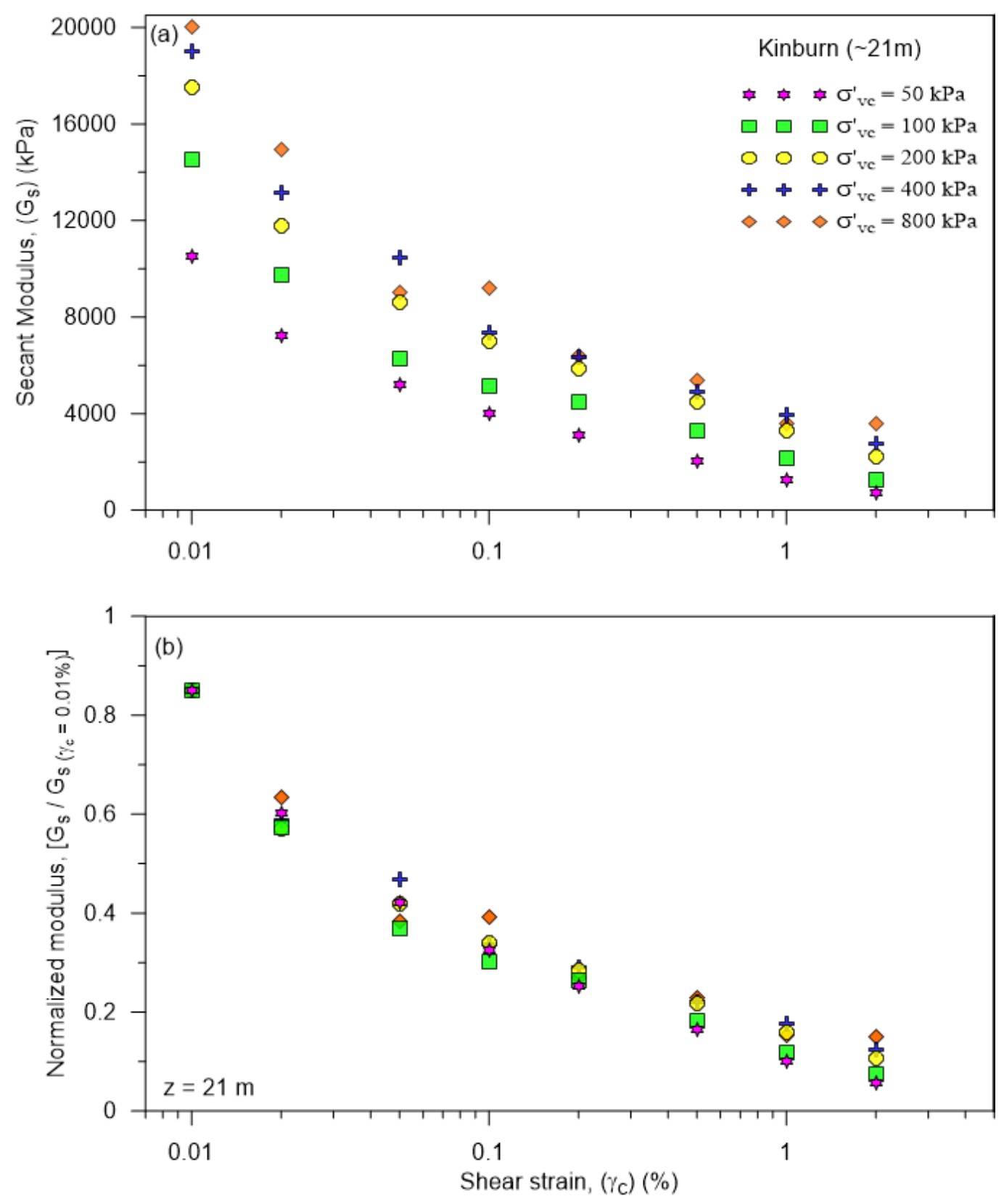

Fig 5.10 (a) Shear modulus and (b) normalized shear modulus of Kinburn clays $(\mathrm{z}=\mathbf{2 1} \mathrm{m})$ under different $\sigma^{\prime}{ }_{v c}$ levels.

\subsubsection{Modulus and damping characteristics of sensitive Leda clays}

The variation of secant shear modulus $\left(G_{s}\right)$, normalized modulus or modulus reduction $\left(G_{s} / G_{\max }\right)$, damping ratio $(\xi)$ with shear strain $\left(\gamma_{c}\right)$ amplitudes and consolidation stress 
$\left(\sigma_{\mathrm{vc}}^{\prime}\right)$ are presented in Fig 5.11 to 5.14 . These plots demonstrate the characteristics of modulus and damping of sensitive Leda clays obtained from different sites.

These plots clearly capture the general trends, as shear strain $\left(\gamma_{c}\right)$ increases the shear modulus $\left(G_{S}\right)$ and normalized modulus $\left(G_{s} / G_{\max }\right)$ decreases, and the damping ratio $(\xi)$ increases. Further, while consolidation stress $\left(\sigma_{v c}^{\prime}\right)$ increases, $G_{s}$ and $G_{s} / G_{\max }$ increase and $\xi$ decreases. Moreover, at lower strain level, the sensitive Leda clays display higher modulus and lower damping, but low modulus and high damping at higher $\gamma_{c}$ amplitude. Also, these figures show reasonably consistent values of $G_{S}, G_{S} / G_{\max }$ and $\xi$.

Results presented in Figs. 5.11(a), 5.12(a), 5.13(a) and 5.14(a) illustrate the variation of shear modulus $\left(G_{s}\right)$ value of Kinburn $(\mathrm{z}=11 \mathrm{~m})$, Kinburn $(\mathrm{z}=21 \mathrm{~m})$, Breckenridge $(\mathrm{z}=$ $26 \mathrm{~m})$ and Outardes-2 $(\mathrm{z}=11 \mathrm{~m})$ samples. A pattern commonly seen in these figures is that for a give material the shear modulus $\left(G_{S}\right)$ increases with increasing consolidation stress $\left(\sigma_{v c}^{\prime}\right)$. Also, at a given $\sigma_{v c}^{\prime}$ level, $G_{s}$ decreases with increasing $\gamma_{c}$ amplitude. Further, the $G_{S}$ of sensitive Leda clays considerably degrades between $\gamma_{c}$ of $0.01 \%$ and $0.2 \%$. After this range of $\gamma_{c}$ modulus degradation is continued but at a slower rate regardless of the $\sigma_{v c}^{\prime}$ level.

Higher $G_{s}$ value of $30.1,24.0,31.2$ and $28.5 \mathrm{MPa}$ were measured in Kinburn $(11 \mathrm{~m})$, Kinburn $(21 \mathrm{~m})$, Breckenridge $(26 \mathrm{~m})$ and Outardes-2 $(11 \mathrm{~m})$ samples at $\gamma_{c}$ of $0.01 \%$ respectively. Then these values degraded to $4.1,3.5,5.5$ and $4.8 \mathrm{MPa}$ at $\gamma_{c}$ of $2.0 \%$ respectively under ${\sigma^{\prime}}_{v c}=800 \mathrm{kPa}$. On the other hand, lower $G_{s}$ value of 9.0, 10.5, 14.5 and 9.5 $\mathrm{MPa}$ were produced by Kinburn (11m), Kinburn (21m), Breckenridge (26m) and Outardes-2 $(11 \mathrm{~m})$ samples respectively at $\gamma_{c}$ of $0.01 \%$. Then these values degraded to 1.0 , $0.7,1.0$ and $0.8 \mathrm{MPa}$ at $\gamma_{c}$ of $2.0 \%$ under ${\sigma^{\prime}}_{v c}=50 \mathrm{kPa}$ respectively. 
The variations between $G_{s}$ values at successive $\sigma^{\prime}{ }_{v c}$ are consistent for Kinburn samples obtained at depth of $21 \mathrm{~m}$ as seen in Fig. 5.12(a). However, the Kinburn samples obtained at the depth of $11 \mathrm{~m}$ display higher variation in $G_{s}$ values between $\sigma^{\prime}{ }_{v c}$ of 200 and $400 \mathrm{kPa}$, and ${\sigma^{\prime}}_{v c}$ of 400 and $800 \mathrm{kPa}$ as demonstrated in Fig 5.11(a).

The variance between $G_{s}$ values at successive $\sigma_{v c}^{\prime}$ are reasonably consistent for Breckenridge samples, (except that the difference in $G_{S}$ values between $\sigma^{\prime}{ }_{v c}$ of 200 and 400 $\mathrm{kPa}$ are higher at $\left.\gamma_{c}<0.2 \%\right)$. On the other hand, the shear modulus of Outardes-2 samples did not significantly vary depending on the consolidation stress levels above $\gamma_{c}$ of $0.1 \%$, however, greater differences can be seen in $G_{s}$ values under $\sigma^{\prime}{ }_{v c}$ of 200 and $400 \mathrm{kPa}$ at low $\gamma_{c}<0.05 \%$, as displayed in Fig. 5.12(a).

Above comparison clearly revealed that different ${\sigma^{\prime}}_{v c}$ significantly influences the shear modulus $\left(G_{S}\right)$ of sensitive Leda clays. Moreover, influence of plasticity Index $\left(\mathrm{I}_{\mathrm{p}}\right)$ on $G_{S}$ is not clear since the samples had narrow variations in the Ip values (Ip ranging from 9 to 24).

Figures 5.11(b), 5.12(b), 5.13(b) and 5.14(b) present the normalized modulus or modulus reduction $\left(G_{s} / G_{\max }\right)$ values of sensitive Leda clays at different $\sigma_{v c}^{\prime}$. After normalising the $G_{s}$ with respect to $G_{\max }$, the influence of $\sigma^{\prime}{ }_{v c}$ became insignificant and modulus reduction values under successive $\sigma_{v c}^{\prime}$ converged closely. Damping ratios $(\xi)$ versus shear strain amplitudes $\left(\gamma_{c}\right)$ are plotted in Figs. 5.11(c), 5.12(c), 5.13(c) and 5.14(c) for the site-specific sensitive Leda clays at different ${\sigma^{\prime}}_{v c}$ levels. In general, at lower $\gamma_{c}$ level $(<0.1 \%)$ the $\xi$ values converge closely regardless of ${\sigma^{\prime}}_{v c}$ level. At the same time, $\xi$ values are scattered at medium and large range of $\gamma_{c}(>0.1 \%)$. Further, at large $\gamma_{c}$ level two different converging patterns can be seen approximately above and below $\sigma_{v c}^{\prime}$ of $200 \mathrm{kPa}$. This observation 
suggests that at large $\gamma_{c}$ level, OCR might be influenced on the $\xi$ in addition to consolidation stress.

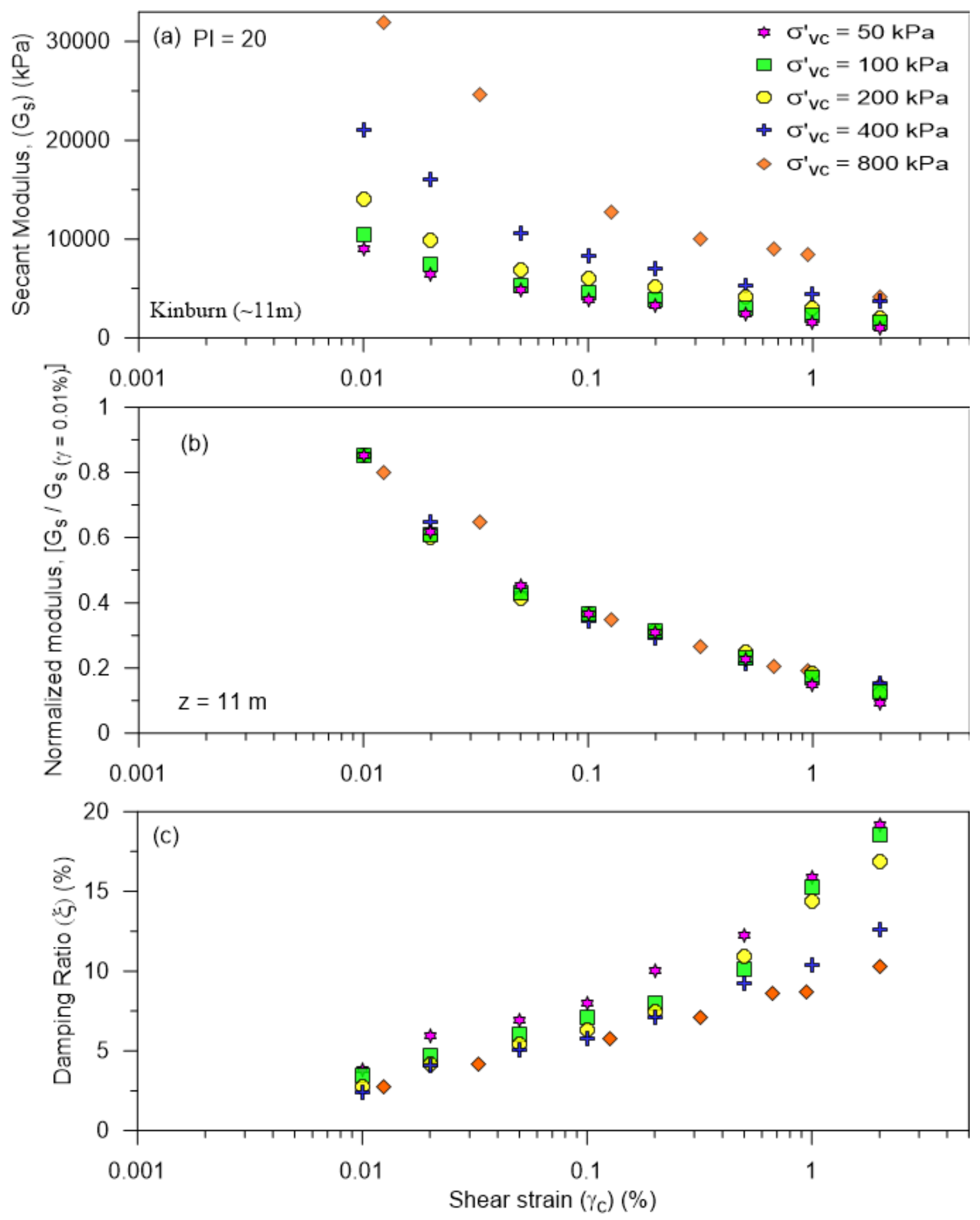

Fig 5.11 (a) $G_{s}$; (b) $G_{s} / G_{\text {max }}$; and (c) $\xi$ of Kinburn clays $(\mathrm{z}=11 \mathrm{~m})$ under different $\sigma^{\prime}{ }_{v c}$ levels 


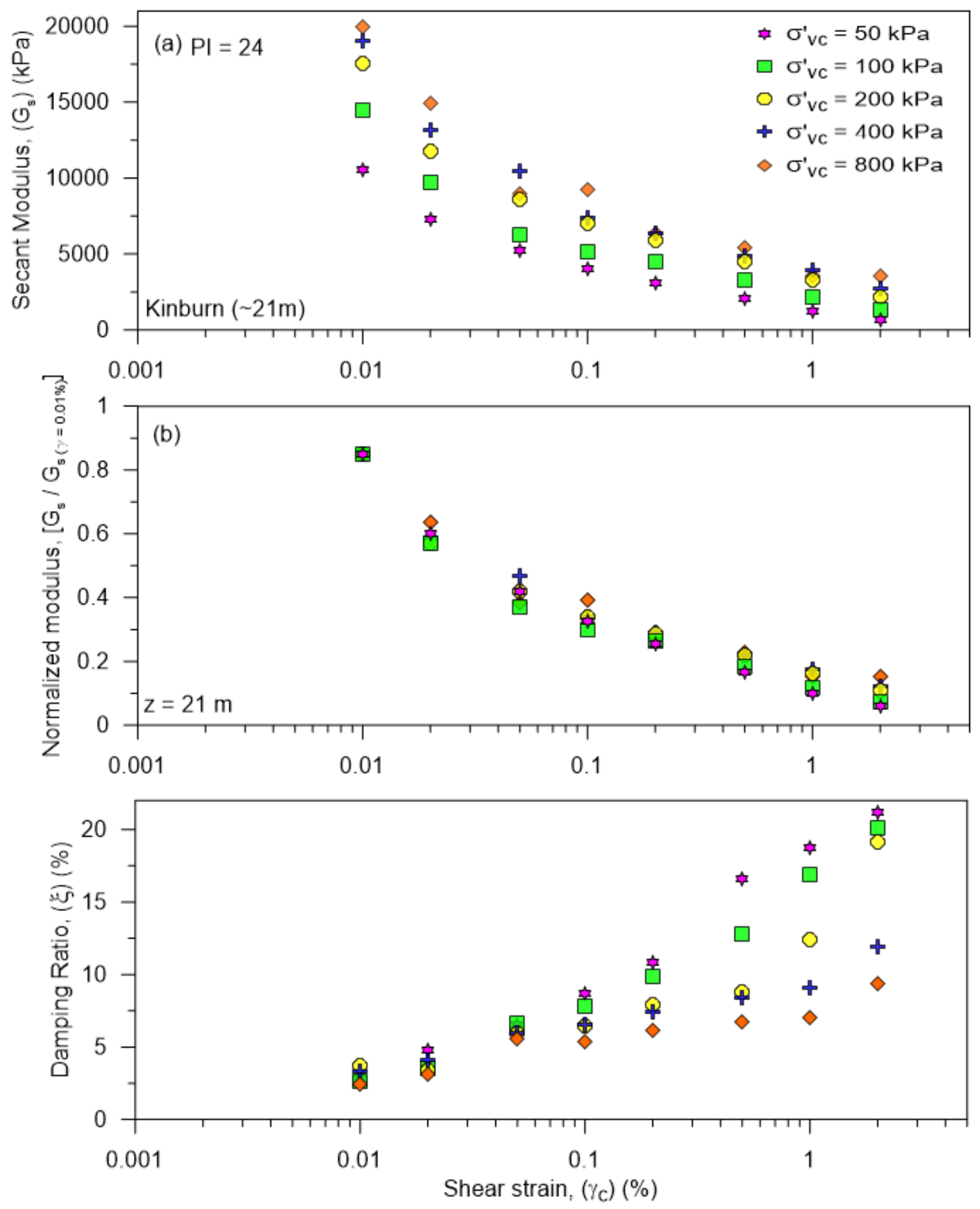

Fig 5.12 (a) $G_{s}$; (b) $G_{s} / G_{m a x}$; and (c) $\xi$ of Kinburn clays $(\mathrm{z}=21 \mathrm{~m})$ under different $\sigma^{\prime}{ }_{\mathrm{vc}}$ levels 


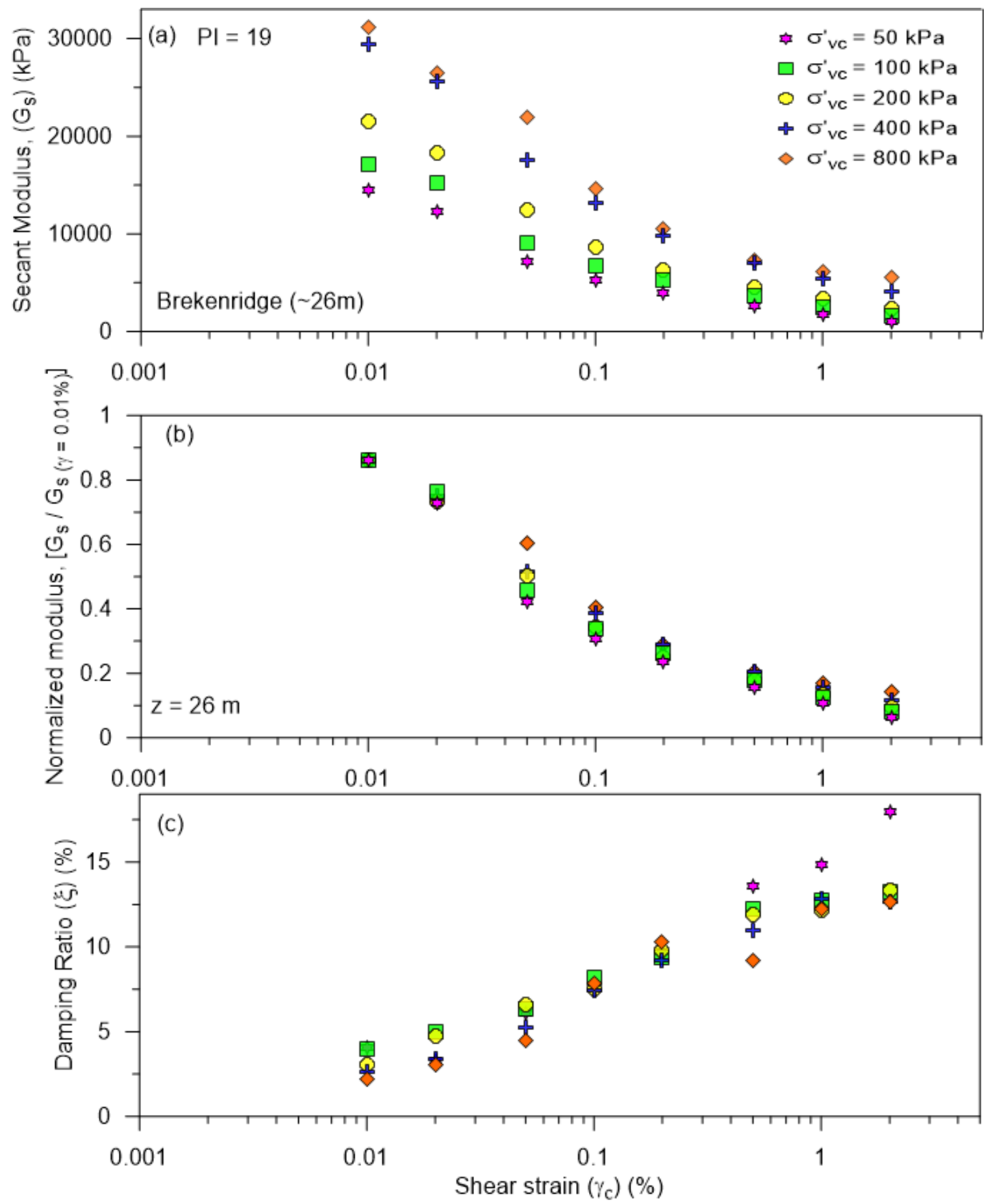

Fig 5.13 (a) $G_{s}$; (b) $G_{s} / G_{\text {max }}$; and (c) $\xi$ of Breckenridge clays $(\mathrm{z}=26 \mathrm{~m})$ under different $\sigma^{\prime}{ }_{v c}$ levels 

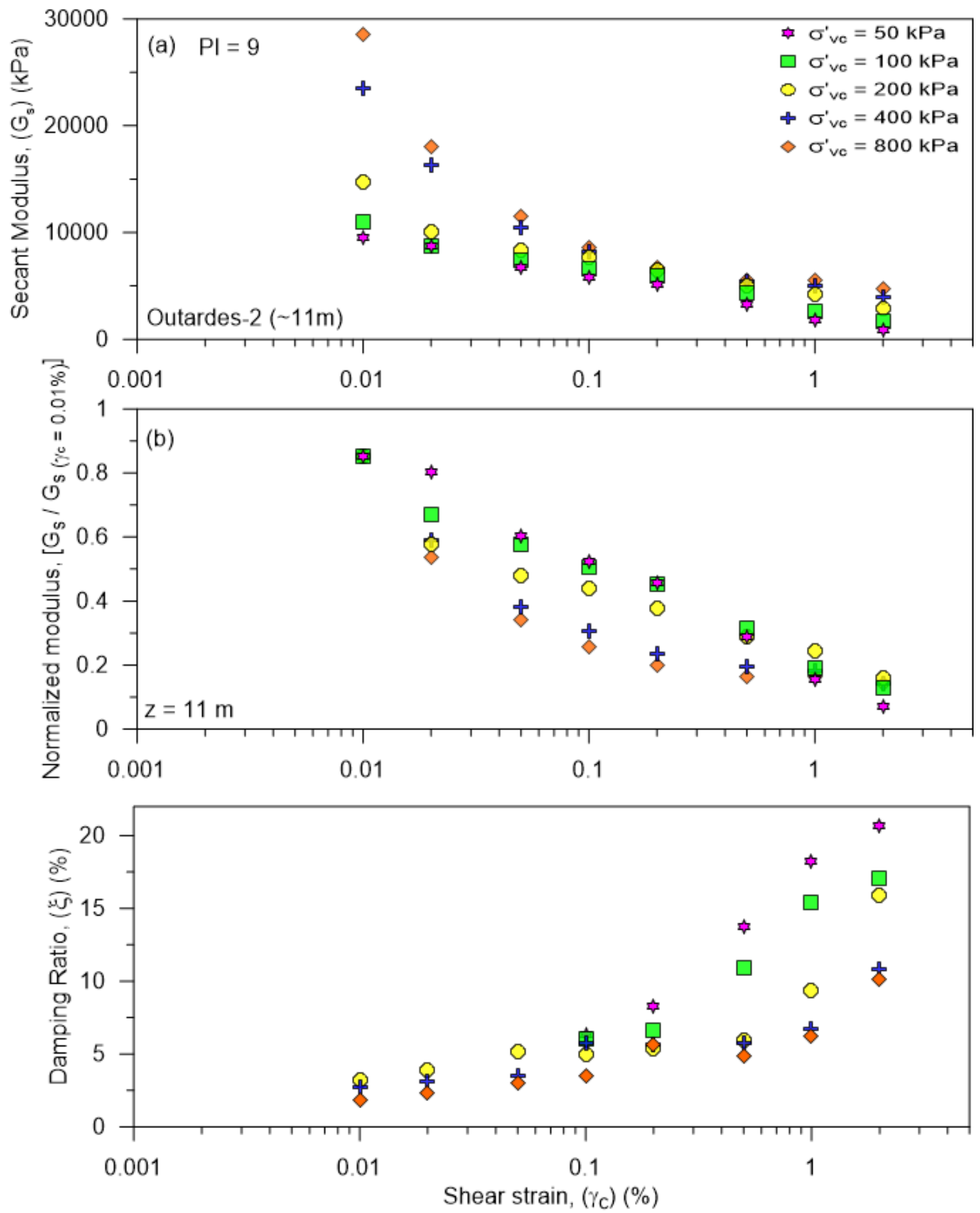

Fig 5.14 (a) $G_{s}$; (b) $G_{s} / G_{\text {max }}$; and (c) $\xi$ of Outardes-2 clays $(\mathrm{z}=11 \mathrm{~m})$ under different $\sigma^{\prime}{ }_{v c}$ levels 


\subsubsection{Modulus reduction of sensitive clays}

Best-fit lines are drawn for the above-discussed modulus reduction and damping data points in order to establish the modulus reduction and damping curve for each site. Resulting data are presented in Figs. 5.15(a-b), 5.16(a-b), 5.17(a-b) and 5.16(a-b), for Kilburn $(\mathrm{z}=11 \mathrm{~m})$, Kilburn $(z=21 \mathrm{~m})$, Breckenridge $(z=26 \mathrm{~m})$, and Outardes-2 $(z=11 \mathrm{~m})$ clays respectively. Further, the modulus reduction and damping curves proposed by Vucetic and Dobry (1991) for soils with a different plasticity index $\left(\mathrm{I}_{\mathrm{p}}\right)$ are included in the plots as a background. This was done for comparison purposes since these curves are often used in geotechnical practice as input parameters for dynamic ground response analysis in clayey soils.

Fig. 5.15 (a) shows the proposed modulus reduction curve for Kinburn samples obtained at a depth of $11 \mathrm{~m}$ with Ip value of 20. As mentioned earlier the influence of successive $\sigma^{\prime}{ }_{v c}$ is insignificant after $G_{s}$ is normalized with respect to $G_{\max }$ value and also $G_{s} / G_{\max }$ values converged reasonably close. Further, the $G_{s} / G_{\max }$ curve displays a non-liner behaviour between $\gamma_{c}$ of $0.01 \%$ and $2.0 \%$. Moreover, at medium $\gamma_{c}$ levels $\left(0.01 \%<\gamma_{c}<0.2 \%\right)$ the curve spans from curve of Ip $=0$ to 5 (proposed by Vucetic and Dobry, 1991); at larger $\gamma_{c}>0.2 \%$, it shifts to the higher Ip curves (Ip $=30$ to 200 ).

Similar behaviour is displayed by $G_{s} / G_{\max }$ curve of Kinburn samples obtained at a depth of $21 \mathrm{~m}$ with Ip value of 24 . At small $\gamma_{c}(<0.01 \%)$ the proposed $G_{s} / G_{\max }$ curve follows the Ip $=15$ (Vucetic and Dobry, 1991) curve; at medium $\gamma_{c}$ level $\left(0.01 \%<\gamma_{c}<0.5 \%\right)$ it follows in-between the curves of $\mathrm{Ip}=0$ and 15 ; and at larger $\gamma_{c}$ level $(>0.5 \%)$ it shadows higher Ip curves (Ip = $30-200)$ as presented in Fig. 5.16 (a). Further, $G_{s} / G_{\max }$ curve of Breckenridge clays with Ip value of 18 shows similarity to Kinburn samples $(z=11 \mathrm{~m})$, however the modulus degradation is higher at $\gamma_{c}$ of $0.2 \%$ and above as seen in Fig. 5.17(a). 
Outardes-2 samples with lesser Ip value of 9, reveals a slightly different trend compared to other samples. It shows more variation in $G_{s} / G_{\max }$ values at $\gamma_{c}$ range of 0.01 to $1 \%$ under different $\sigma_{v c}^{\prime}$ levels. Further, within the $\gamma_{c}$ range of 0.01 to $1 \%$ produced two different trends (OC and NC states) as shown in Fig 5.18(a). This observation suggests that modulus reduction of clays with lower Ip would have been influenced by OCR. In literature Lanzo and Vucetic (1997) also reported large variation in $G_{S} / G_{\max }$ values for low Ip clays and less variation for higher Ip clays.

In general, proposed $G_{s} / G_{\max }$ curves for different sensitive Leda clays show a slow nonliner modulus degradation at lower $\gamma_{c}$, rapid non- liner modulus degradation at medium $\gamma_{c}$ range of 0.01 to $0.5 \%$. The non-linear degradation becomes moderate with further increasing $\gamma_{c}$ and negligible degradation is noted at large strains $\left(\gamma_{c}>1 \%\right)$

\subsubsection{Damping curves of sensitive clays}

The proposed damping $(\xi)$ curves for Kinburn samples $(11 \mathrm{~m})$ with $\mathrm{Ip}$ value of 20 are presented in Fig. 5.15 (b). The damping values of particular samples are reasonably influenced by different consolidation stress levels $\left(\sigma_{v c}^{\prime}\right)$ and largely at $\gamma_{c}$ of $0.2 \%$ and above. Further, clear trends for $\mathrm{OC}$ and $\mathrm{NC} \xi$ curves are noted where the $\mathrm{OC}$ damping curve $\left(\sigma_{v c}^{\prime} \leq 200\right)$ follows between Vucetic and Dobry's Ip $=30$ and 50 curves at all range of $\gamma_{c}$.

On the other hand, $\mathrm{NC} \xi$ curve $\left(\sigma^{\prime}{ }_{v c} \geq 400\right)$ follows among the curves of Ip $=50$ and 100 at $\gamma_{c}=0.01$ to $0.8 \%$, there after shifts to the Ip $=200$ curve.

The $\xi$ curves of Kinburn samples $(\mathrm{z}=21 \mathrm{~m})$ show similar trends to the Kinburn samples obtained at depth of $11 \mathrm{~m}$. However, there is a large deviation between $\mathrm{OC}$ and $\mathrm{NC} \xi$ curves in deep depth sample and also a steep increase in OC $\xi$ values above $\gamma_{c}$ of $0.5 \%$ as 
illustrated in Fig. 5.16 (b). This outcome indicates that influence of different consolidation stresses and OCR are significant in deeper Kinburn clays with lower clay fraction (59\%) and the influence is less on shallower Kinburn clays having higher clay fraction (75\%).

Damping curves for Breckenridge samples $(\mathrm{Ip}=18)$ under different consolidation stress levels converge reasonably well and show a single pattern, which follows the Vucetic and Dobry's Ip $=50$ curve over the full range of $\gamma_{c}$ levels as shown in Fig. 5.17 (b). However, some scatter in data points noted around $\gamma_{c}$ of $0.5 \%$ and above.

Again the influence of different $\sigma^{\prime}{ }_{v c}$ and OCR can be seen in damping curve of Outares-2 clays with Ip of 9 (Fig 5.18b). Over consolidated $\xi$ curve of Outares-2 samples shadows the curve of Ip $=50$ from $\gamma_{c}$ of $0.01 \%$ to $0.8 \%$ after that it moves between curves of Ip $=$ 50 and 30. On the other hand, $\xi$ curve of NC clays follows the high Ip curve (Ip $=100$ to 200). 

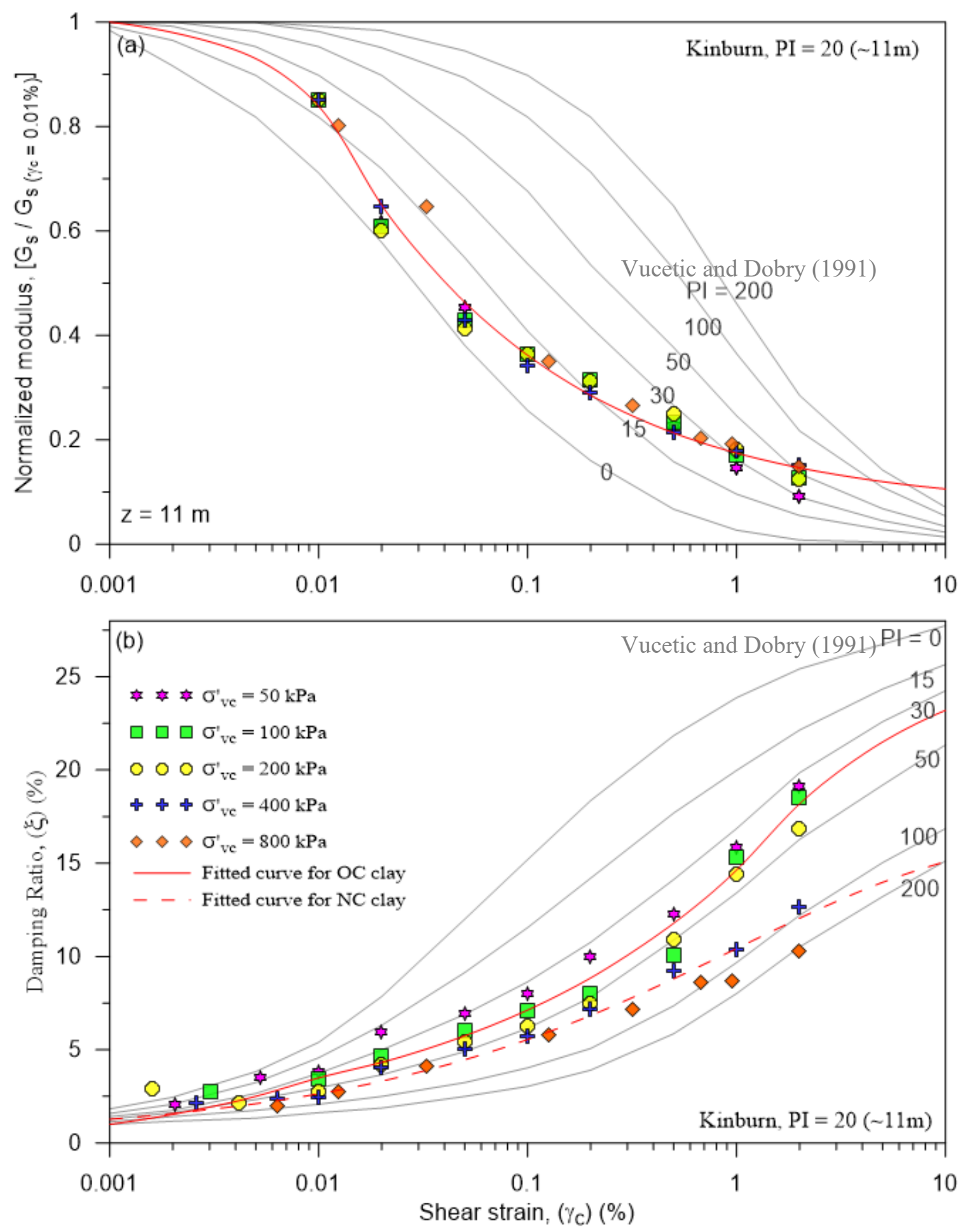

Fig 5.15 (a) Modulus reduction and (b) Damping curves of Kinburn clays $(\mathrm{z}=11 \mathrm{~m})$ under different $\sigma_{\text {vc }}^{\prime}$ levels 

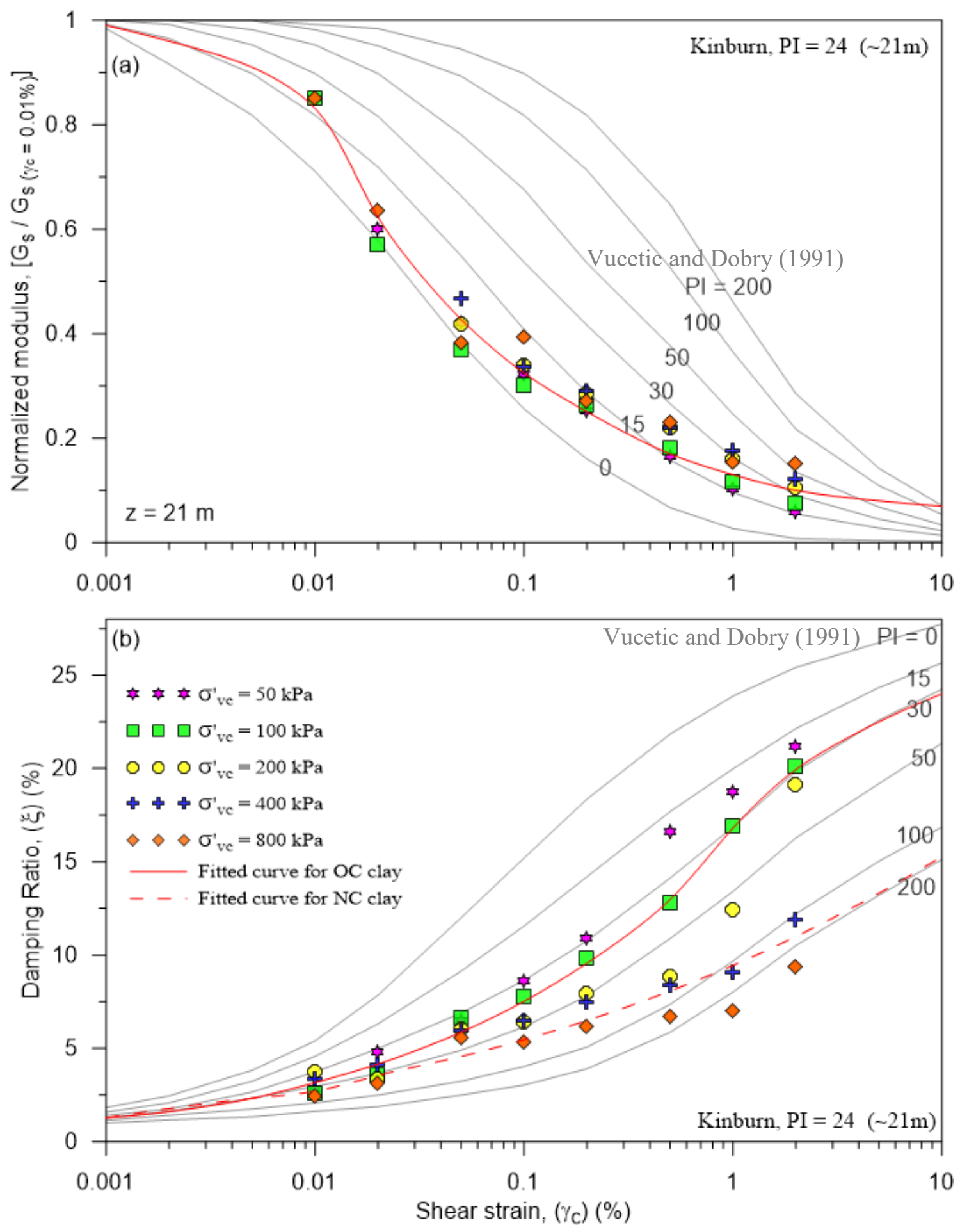

Fig 5.16 (a) Modulus reduction and (b) Damping curves of Kinburn clays $(\mathrm{z}=\mathbf{2 1 \mathrm { m } )}$ under different $\sigma_{\text {vc }}^{\prime}$ levels 

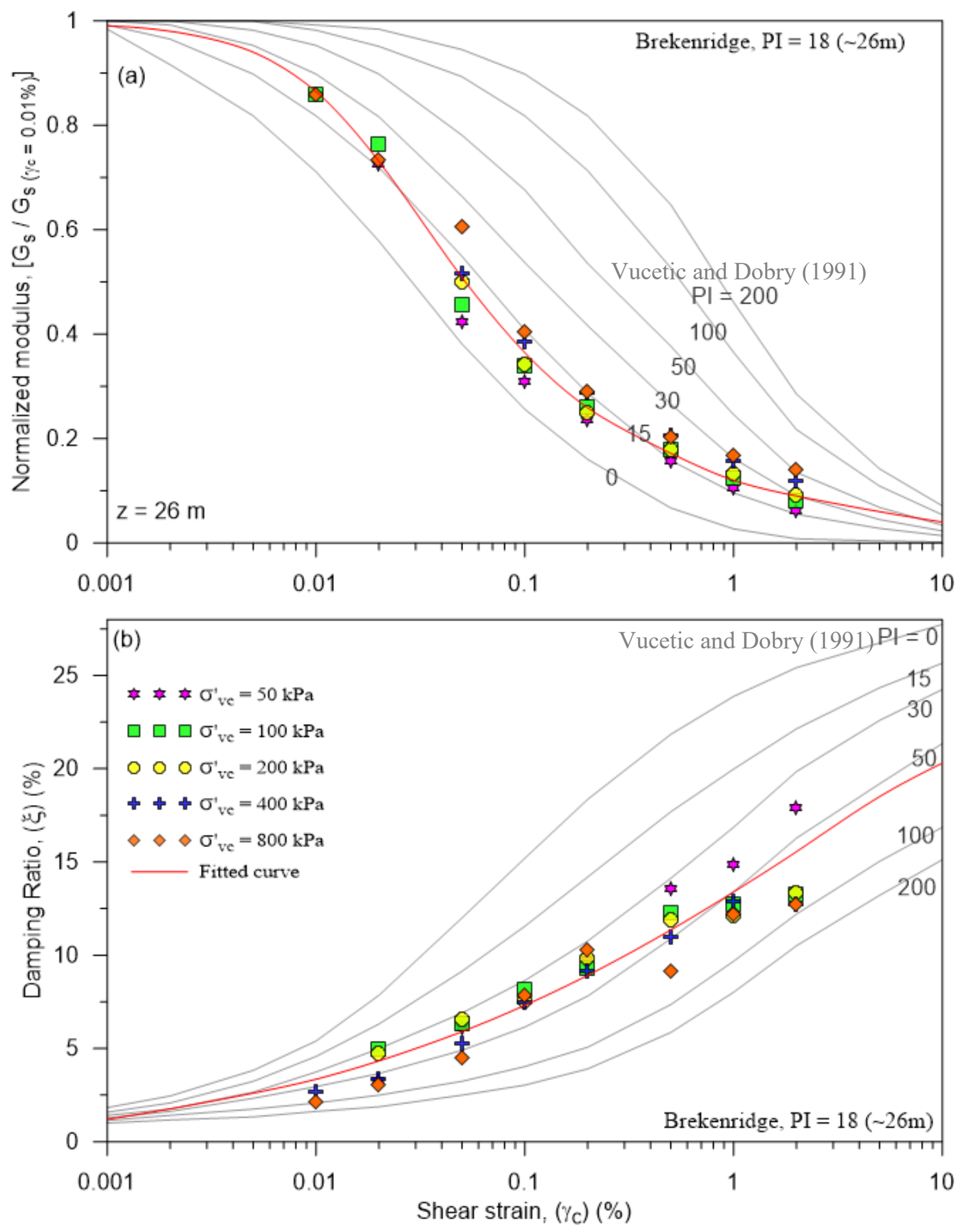

Fig 5.17 (a) Modulus reduction and (b) Damping curves of Breckenridge clays $(\mathrm{z}=\mathbf{2 1 \mathrm { m }})$ under different $\sigma_{v c}^{\prime}$ levels 

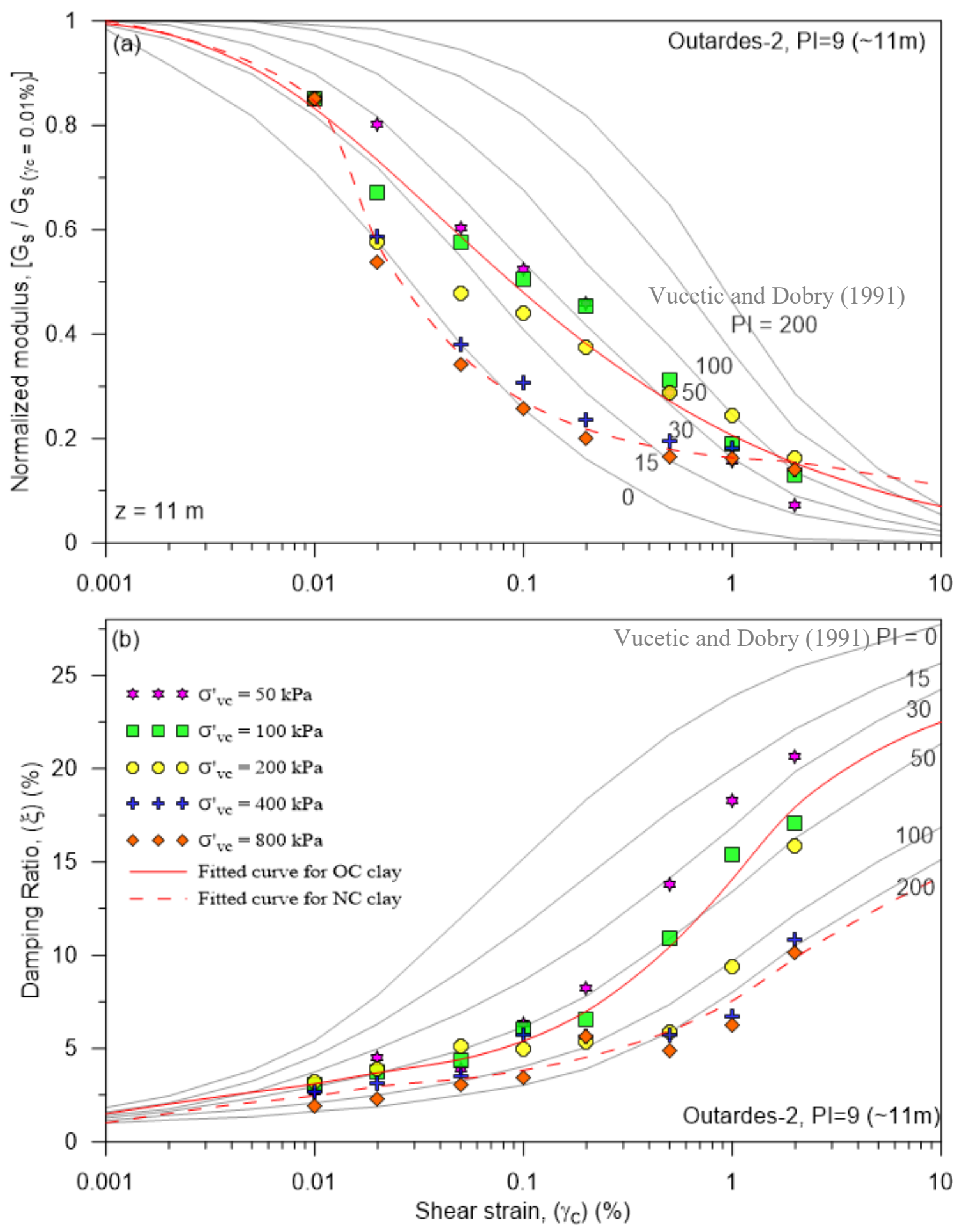

Fig 5.18 (a) Modulus reduction and (b) Damping curves of Outarded-2 clays $(\mathrm{z}=11 \mathrm{~m})$ under different $\sigma_{\text {vc }}^{\prime}$ levels 


\subsubsection{Modulus reduction and damping curves of sensitive clay for engineering analysis}

For comparison purposes, proposed modulus reduction and damping ratio curves for Kinburn $(z=11$ and $21 \mathrm{~m})$, Breckenridge $(\mathrm{z}=26 \mathrm{~m})$ and Outardes-2 $(\mathrm{z}=11 \mathrm{~m})$ Leda clays are presented in Figs 5.19 (a-b). Further, Vucetic and Dobry (1990) curves based on Ip values and Theenathayarl (2015) curves recommended for Ottawa Leda clay are included in Figs 5.19 (a-b) for comparison.

At lower shear strain level $(<0.015 \%)$, the proposed set of modulus reduction curves show a narrow band and follow the Vucetic and Dobry curves of $\mathrm{Ip}=15$ and 30, and within $\gamma_{c}$ range of $0.015 \%$ to $1 \%$. Further, they follow the curves of $\mathrm{Ip}=0$ to 30 with a wider band. At larger strain level $\left(\gamma_{c}>1.0 \%\right)$ again these $G_{s} / G_{\max }$ curves show a reasonably narrow band and follow Vucetic and Dobry curves of $\mathrm{Ip}=30$ to 200 as demonstrated in Fig. 5.19 (a). In addition, the proposed set of modulus reduction curves are consistent with the modulus reduction curves reported by Theenathayarl (2015) for Ottawa Leda clay.

The proposed set of damping curves (Fig $5.19 \mathrm{~b}$ ) show a narrow band with negligible scatter at low $\gamma_{c}(<0.015 \%)$. These curves can be approximated by the Vucetic and Dobry's Ip $=$ 50 curve. Above $\gamma_{c}$ of $0.015 \%$, two divisions are seen depending on whether the clay is normally consolidated or over consolidated. Damping curves of NC clays follow the high Ip curves (Ip 100 and 200) and $\xi$ curves of OC clays follow low Ip curves (Ip 30 and 50). Further, the proposed set of damping curves are comparable with the curves reported by Theenathayarl (2015) for Ottawa Leda clay.

Consequently, the above observations and comparisons clearly show that sensitive Leda clays do not follow any specific curve proposed by Vucetic and Dobry (1991) based on 
plasticity index (Ip) values. This finding confirms the Vucetic and Dobry's (1991) suggestion that modulus reduction and damping curve of sensitive clays might be different from their proposed curves, and independent of their Ip. Further, Theenathayarl, (2015) also reported that modulus reduction and damping curves of Ottawa sensitive clays varies from the curves proposed by Vucetic and Dobry's (1991).

The proposed set of site specific modulus and damping characteristics would be beneficial for accurate and reliable ground response analysis in this region. Further, this study pointed out the essential uniqueness of modulus and damping properties of sensitive Leda clays and also emphasized the importance of establishing site-specific modulus reduction and damping curves for a reliable ground response analysis, rather than picking a modulus and damping curve from the literature. However, this research study could not explore complete variations and factors influencing the modulus and damping of sensitive Leda clays due to the limited availability of undisturbed samples. It should also be noted that the pore fluid chemistry was not considered in the research. 

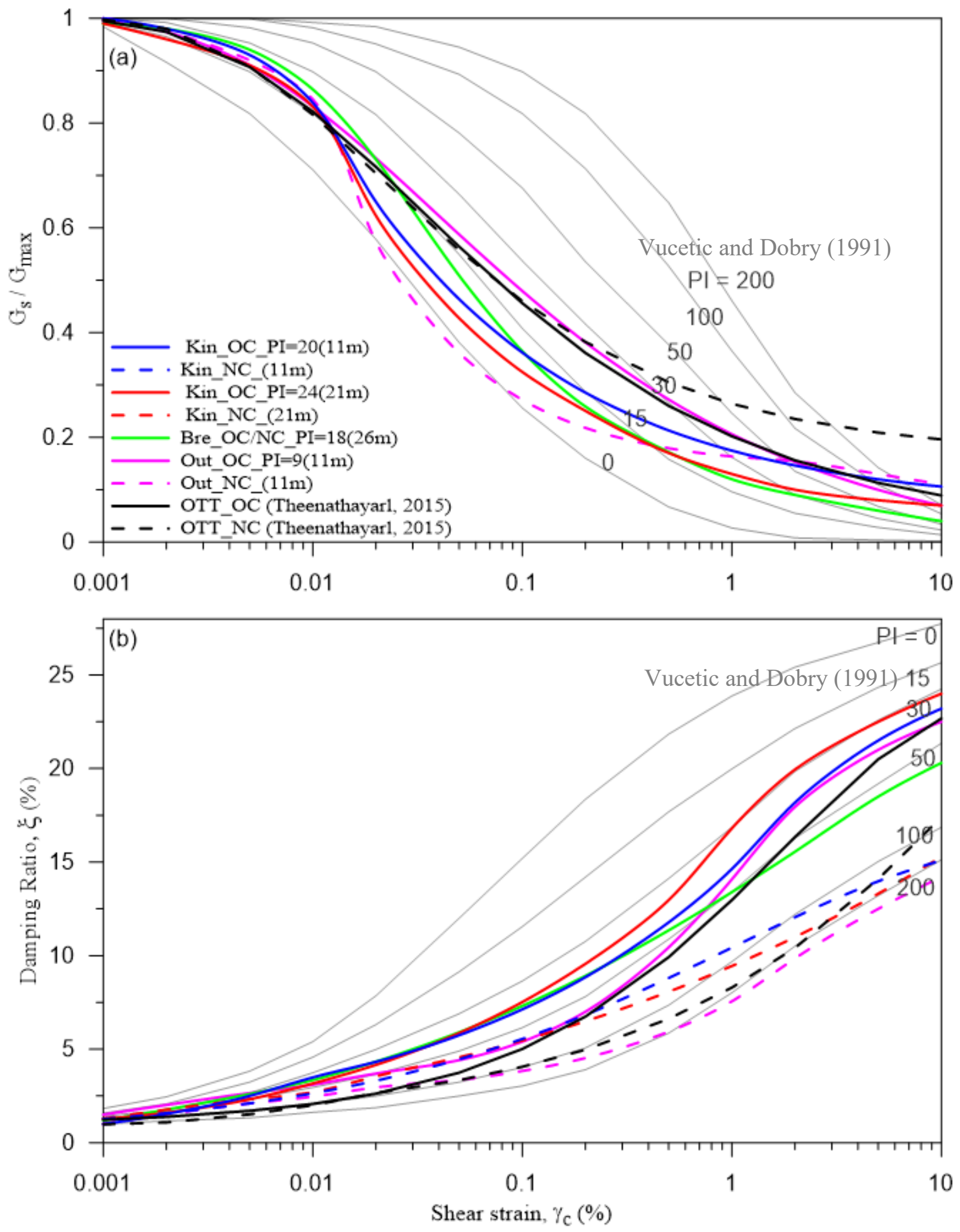

Fig 5.19 Set of (a) Modulus reduction and (b) Damping curves of Kinburn, Breckenridge and Outardes-2 clays. 


\subsection{Characteristic of shear modulus and damping ratio of Fraser River sand}

\subsubsection{Stress-controlled quasi-cyclic tests on Fraser River sand}

A series of multistage stress-controlled quasi-cyclic tests were conducted on Fraser River sand (FRS) to establish its modulus and damping characteristics over cyclic shear strain $\left(\gamma_{c}\right)$ range of $0.001 \%$ to $1 \%$. Range of subsequent small cyclic shear stress $\left(\tau_{\text {cyc }}\right)$ amplitudes were applied after each two load cycles of a given stress amplitude at a loading frequency of $0.1 \mathrm{~Hz}$. Tests were carried out under different consolidation stress levels $\left(\sigma_{\mathrm{vc}}^{\prime}=50,100,200\right.$ and $\left.400 \mathrm{kPa}\right)$, relative density $(\mathrm{Dr}=50,65$ and $80 \%)$ and over consolidation ratios $(\mathrm{OCR}=1,2$ and 4$)$ on $\mathrm{FRS}$.

\subsubsection{Estimation of secant shear modulus $\left(G_{s}\right)$, modulus reduction $\left(G_{s} / G_{\max }\right)$ and damping ratio $(\xi)$ of FRS}

A typical stress-controlled test result of reconstituted FRS specimen at $\sigma_{\mathrm{vc}}^{\prime}=100 \mathrm{kPa}$, $D_{r}=51 \%$ and OCR $=2$ is presented in Fig 5.20. This figure shows that increasing cyclic shear stress $\left(\tau_{\mathrm{cyc}}\right)$ amplitudes increase the $\gamma_{\mathrm{c}}$ level and excess pore water $(\Delta \mathrm{u})$ generation. Further, the Fig 5.20(b) demonstrates that the $\Delta \mathrm{u}$ generation is negligible at very small levels of shear strain, but is rapid and significant at successive $\tau_{\text {cyc }}$ amplitudes which caused a significant reduction in the modulus of FRS.

Fig 5.21 shows typical set of stress-strain loops of a stress-controlled test of FRS sample at $\sigma_{\mathrm{vc}}^{\prime}=100 \mathrm{kPa}, \mathrm{Dr}=51 \%$ and $\mathrm{OCR}=2$. Similar loops were obtained for each FRS sample under different consolidation stress, relative density and OCR to estimate the secant shear modulus $\left(G_{s}\right)$ and the damping ratio $(\xi)$. In addition, the value of $G_{s}$ at $\gamma_{c}$ of $0.001 \%$ is 
considered as approximate $G_{\max }$ in order to determine the $G_{s} / G_{\max }$ values at respective $\gamma_{c}$ level.
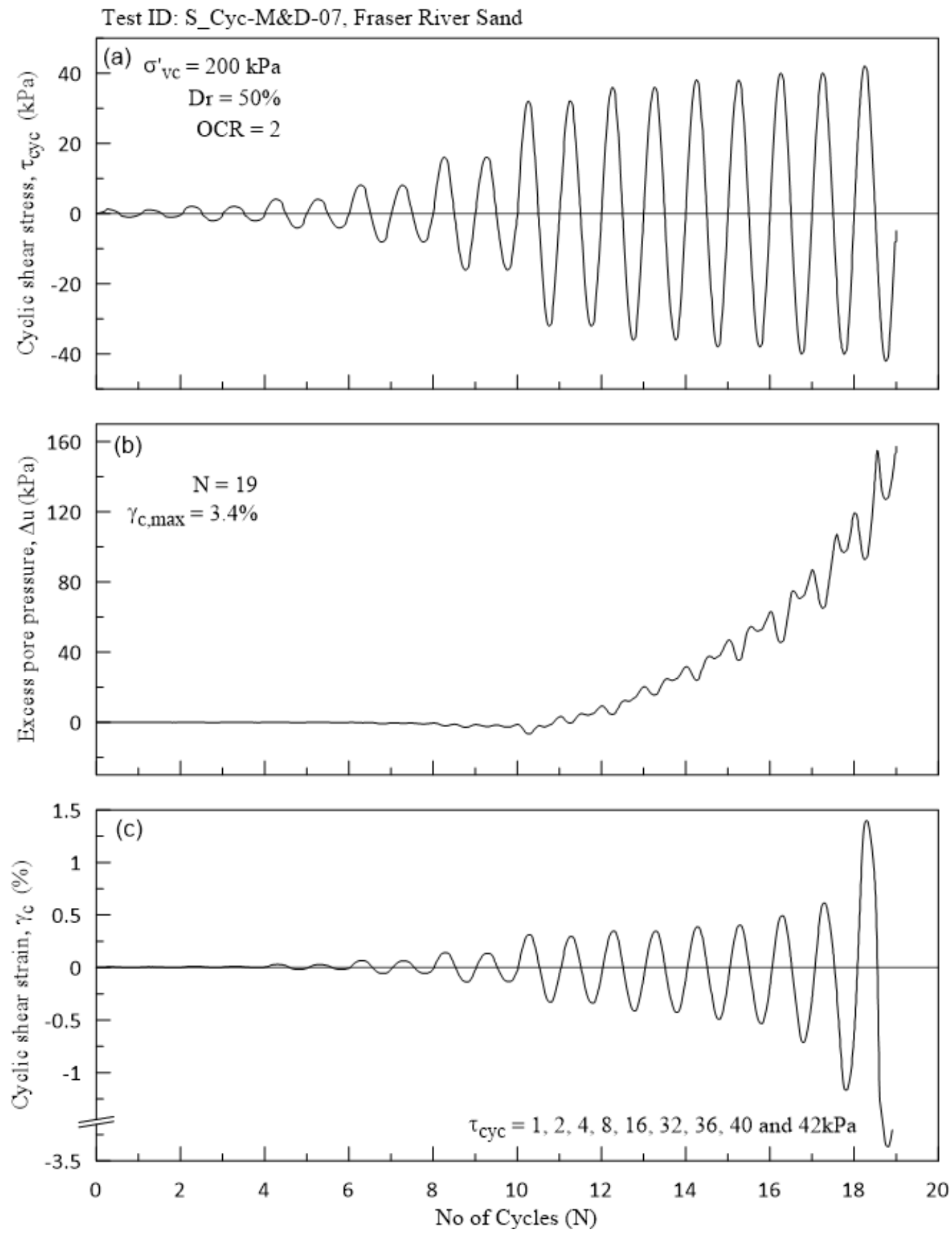

Fig 5.20 Typical behaviour of FRS during stress-controlled quasi-cyclic loading (a) $\tau_{c y c}$ with $\mathrm{N}$, (b) $\Delta u$ with $\mathrm{N}$ and (c) $\gamma_{c}$ with $\mathrm{N}$ under $\sigma^{\prime}{ }_{v c}$ of $200 \mathrm{kPa}$, Dr of $50 \%$ and OCR of 2 

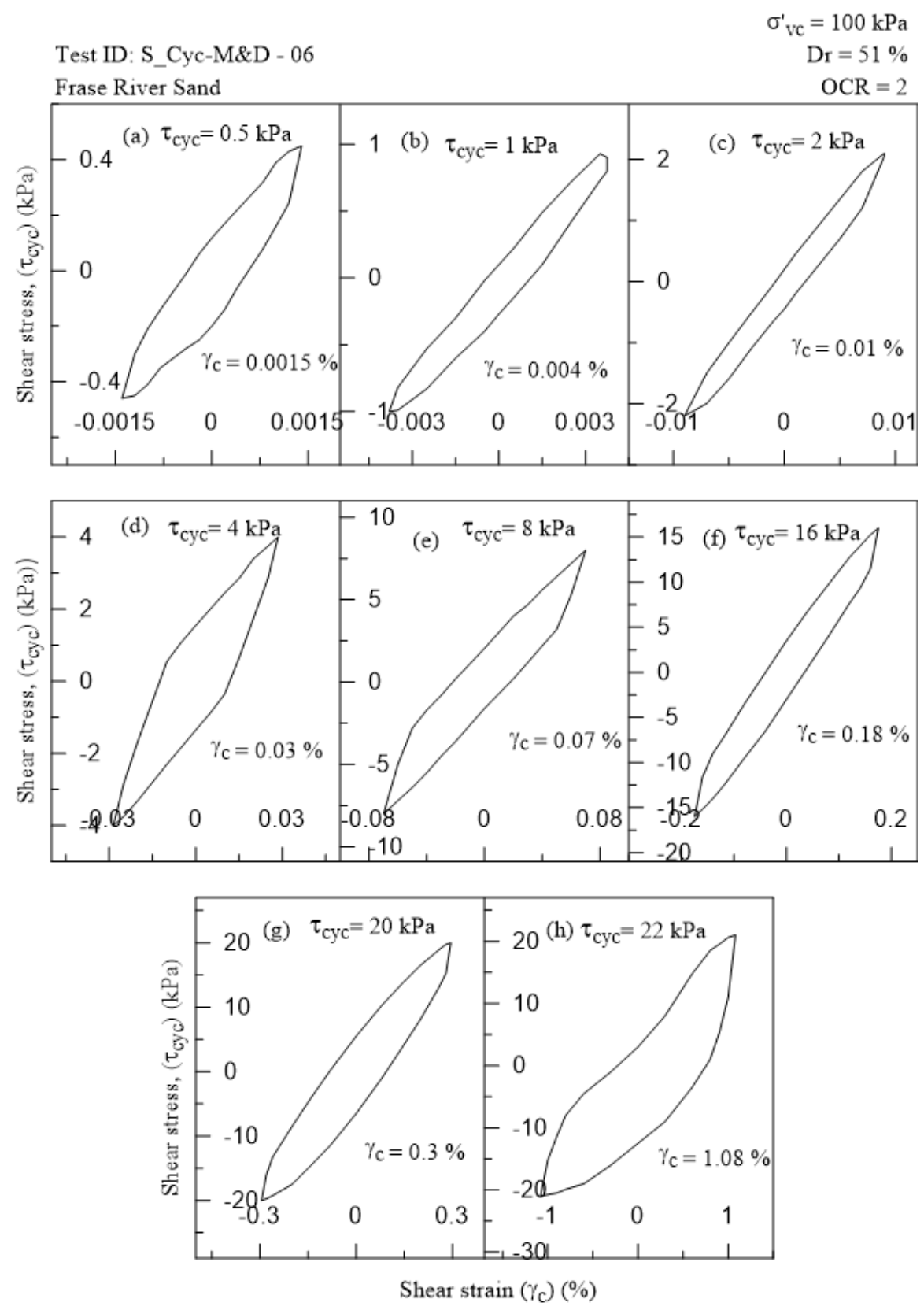

Fig 5.21 Typical stress-strain loops obtained for FRS sample from stress controlled quasi-cyclic testing under $\sigma^{\prime}{ }_{v c}$ of $100 \mathrm{kPa}$, Dr of $51 \%$ and OCR of 2

\subsubsection{Characteristic of secant shear modulus $\left(G_{s}\right)$ of Fraser River sand}

The variation of shear modulus $\left(G_{s}\right)$ with cyclic shear strain amplitude $\left(\gamma_{c}\right)$ is plotted in Fig.5.22 (a-c) for various consolidation stresses $\left(\sigma^{\prime}{ }_{\mathrm{vc}}\right)$, relative density (Dr) and over consolidation ratio (OCR) values. This figure demonstrates the influence of different $\sigma_{\mathrm{vc}}^{\prime}$ 
and OCR on reconstituted FRS sample at three different relative density levels $(\sim 50 \%$, $\sim 65 \%$ and $\sim 80 \%$ ). It can be clearly seen that the secant shear modulus $\left(G_{s}\right)$ of FRS significantly decreases with the cyclic shear strain amplitude $\left(\gamma_{c}\right)$. Further, at a given $\gamma_{c}$ amplitude, $G_{s}$ value increases with $\sigma^{\prime}{ }_{v c}$, Dr and OCR. Also it can be noticed that, the influence of successive $\sigma_{\mathrm{vc}}^{\prime}$ on $\mathrm{G}_{\mathrm{s}}$ is significant at $\gamma_{\mathrm{c}}=0.1 \%$ and below, but not at larger strains. However, the effect of OCR on $G_{s}$ of FRS is minor when comparing to the OCR range of 1 to 4 . In addition, the rate of $G_{s}$ degradation is non-linear and rapid at $\gamma_{c}$ level of 0.001 to $0.2 \%$.

Figure 5.23 shows the correlation between initial shear modulus of FRS and different $\sigma_{v c}^{\prime}$ levels. A power relationships is noted between measured initial $G_{s}\left(\gamma_{c}=0.001 \%\right)$ and $\sigma_{v c}^{\prime}$ similar to clay and the value of exponent $m$ is close to 0.5 . Further, Dr also significantly affects the initial $G_{S}$ of FRS. However the influence of OCR (varying 1 to 4 ) on initial $G_{S}$ is moderate. 
Fraser River Sand
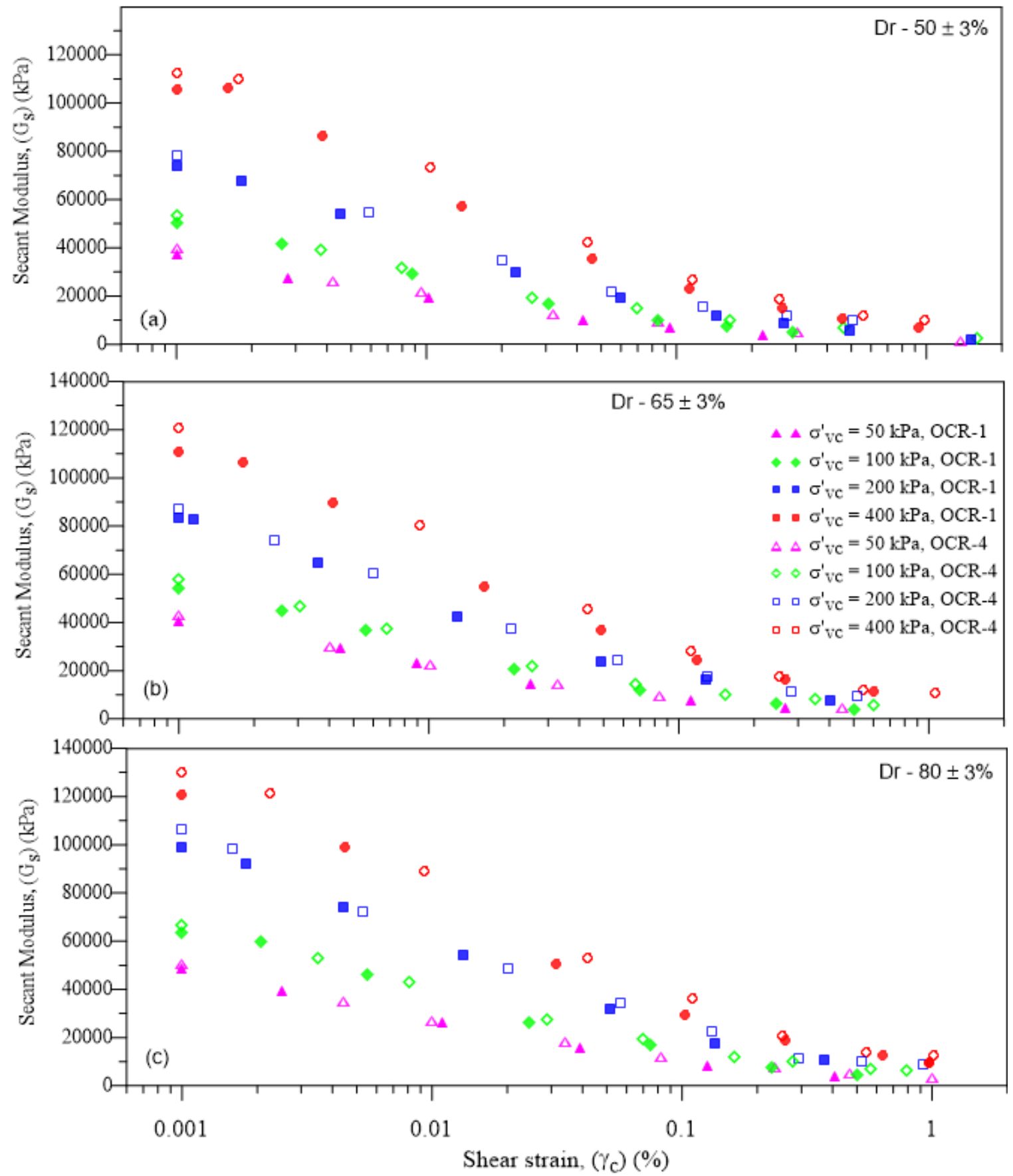

Fig 5.22 Variation of shear modulus of FRS at different ${\sigma^{\prime}}_{v c}$ and OCR: (a) Dr - 50 $\pm 3 \%$; (b) Dr - 65 $\pm 3 \%$; (c) Dr $-80 \pm 3 \%$. 


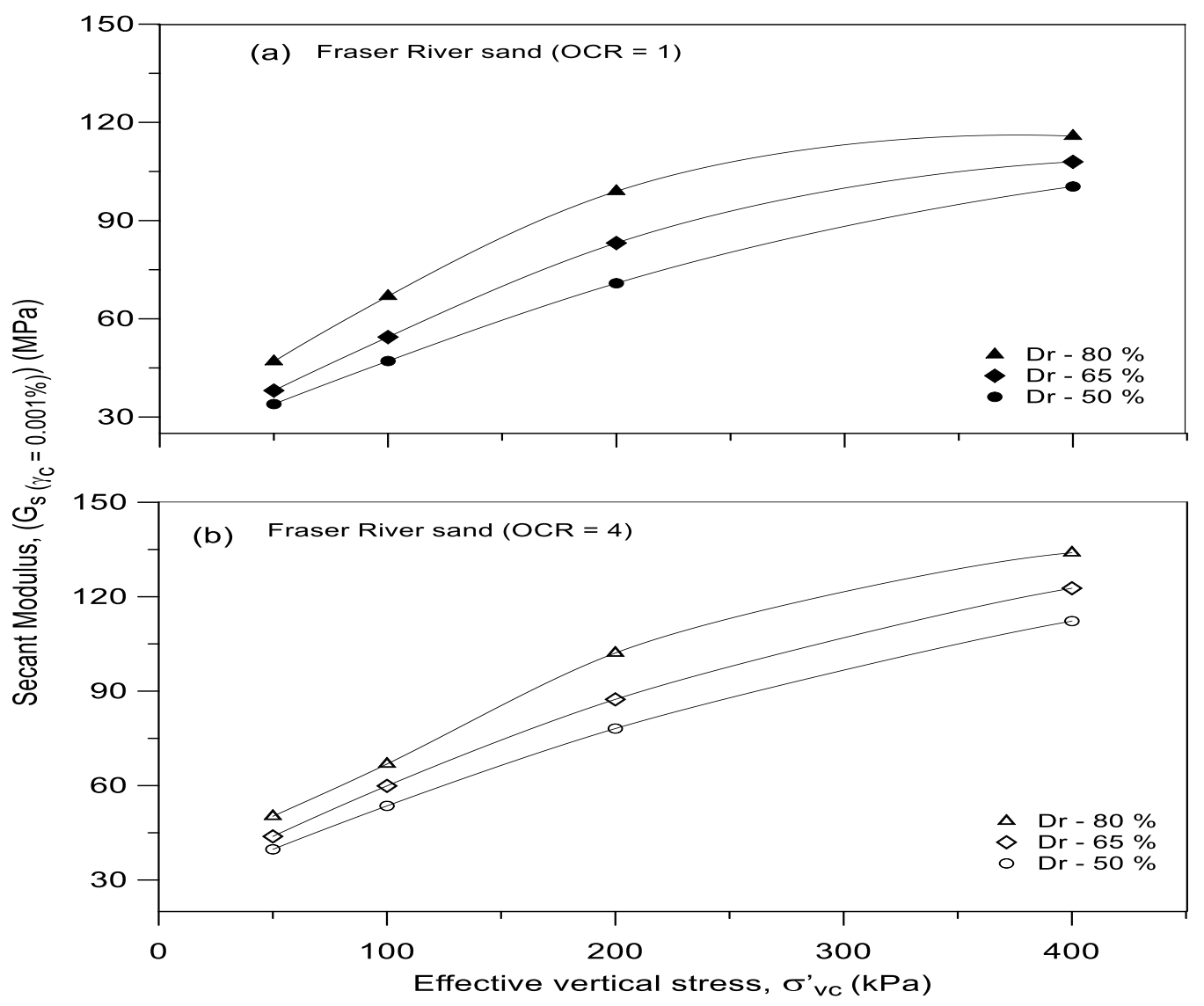

Fig 5.23 Initial shear modulus of FRS changes with consolidation stress level

\subsubsection{Modulus reduction and damping characteristic of Fraser River sand}

Modulus reduction and damping ratio of reconstituted FRS with different combination of $\sigma_{v c}^{\prime}$, OCR and Dr are shown in Figs 5.24 to 5.26. Further, best fit lines are drawn for those data points, in order to establish modulus reduction $\left(\mathrm{G}_{\mathrm{s}} / \mathrm{G}_{\max }\right)$ and damping curves (६) for Fraser River sand under varied conditions. For comparison purposes, modulus reduction and damping curves of sand proposed by Seed and Idriss (1970) with lower, average and upper boundary are included in the background. These test results clearly demonstrate the influence of relative density, consolidation stress and over consolidation ratio on modulus reduction and damping ratio of FRS. 


\subsubsection{Influence of relative density on modulus reduction and damping characteristics}

Test results presented in Figs. 5.24(a) and (b) show the variation of modulus reduction

$\left(\mathrm{G}_{\mathrm{s}} / \mathrm{G}_{\max }\right)$ and damping $(\xi)$ with different cyclic strain $\left(\gamma_{\mathrm{c}}\right)$ amplitudes and relative density (Dr) for FRS at $\sigma_{\mathrm{vc}}^{\prime}=100 \mathrm{kPa}$ and $\mathrm{OCR}=1$. In general, it can be noticed that at a given $\gamma_{\mathrm{c}}$, $\mathrm{G}_{\mathrm{s}} / \mathrm{G}_{\max }$ increases with $\mathrm{Dr}$ and degradation of $\mathrm{G}_{\mathrm{s}} / \mathrm{G}_{\max }$ is significant and it is rapid between the $\gamma_{c}$ range of 0.001 to $0.1 \%$. Further, differences in $G_{s} / G_{m a x}$ is higher between the samples having Dr of $81 \%$ and $62 \%$ compared to the variation between samples having Dr of $62 \%$ and $52 \%$. In addition, most of the time $\mathrm{G}_{\mathrm{s}} / \mathrm{G}_{\max }$ curves follow just below the Seed and Idriss's (1970) lower boundary curve. It should also be noted that the lowest attainable relative density at consolidation stress of $400 \mathrm{kPa}$ (and OCR of 4) was about $50 \%$ and hence no tests were done at looser density states.

The influence of different relative density (Dr) on the $\xi$ curve of FRS is presented in Fig.5.24 (b). As expected, increasing Dr decreases $\xi$ at any given $\gamma_{c}$ amplitude and the influence of Dr is significant above $\gamma_{c}$ of $0.01 \%$. Also, it is possible to observe a clear variation in $\xi$ curves between samples having Dr of $81 \%$ and $52 \%$, however the $\xi$ curve of Dr of $62 \%$ does not show any clear trend since damping data is scarred above $\gamma_{c}$ of $0.2 \%$. Further, $\xi$ curves stay between lower and average boundary curves at $\gamma_{c}$ range of $0.001 \%$ to $2 \%$. 

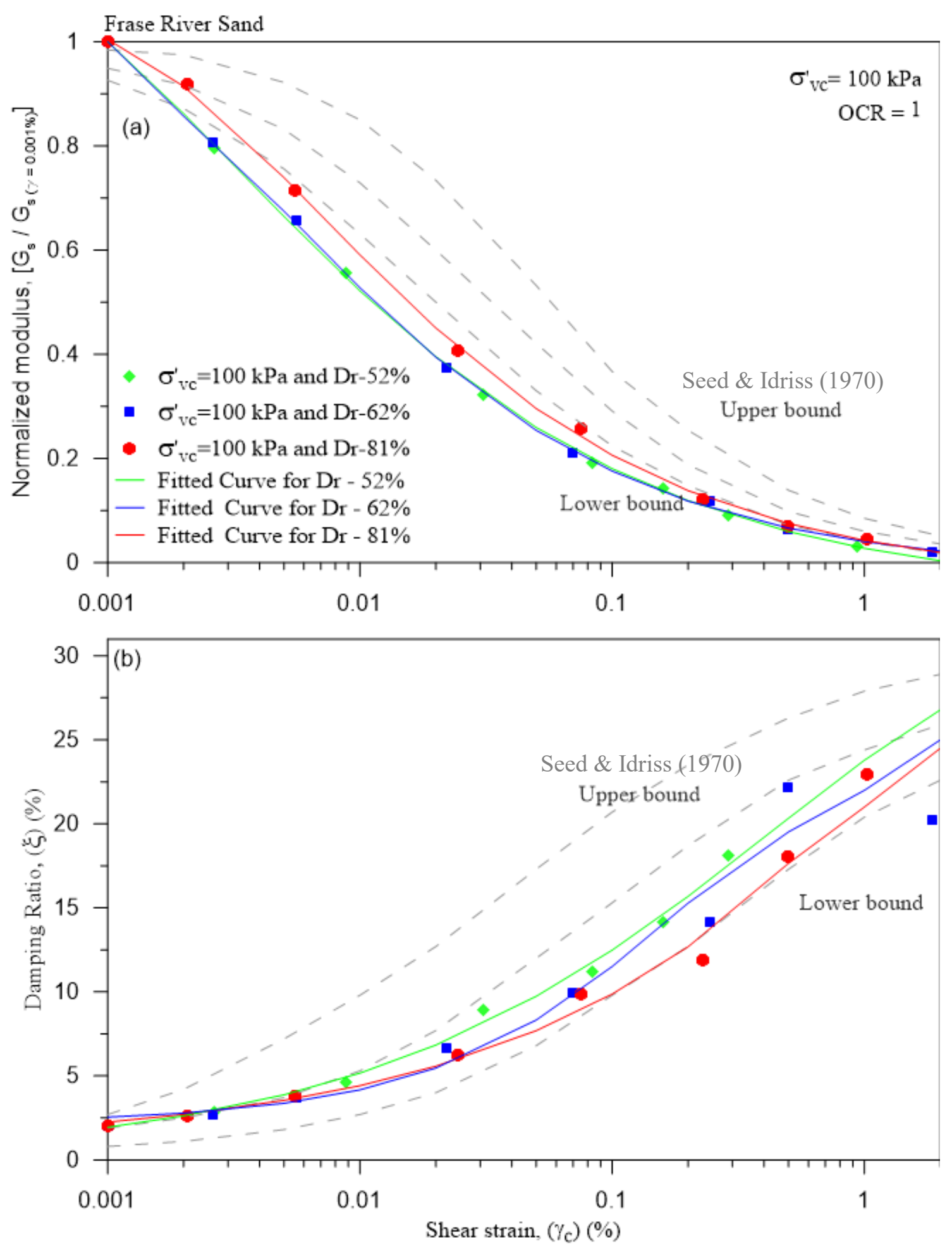

Fig 5.24 Effect of relative density on (a) $G_{s} / G_{\max }$ and (b) $\xi$ of Fraser River sand 


\subsubsection{Influence of consolidation stress on modulus reduction and damping characteristics}

Influence of different consolidation stress levels $\left(\sigma_{\mathrm{vc}}^{\prime}\right)$ on modulus reduction $\left(\mathrm{G}_{\mathrm{s}} / \mathrm{G}_{\mathrm{max}}\right)$ and damping ratio $(\xi)$ of FRS having Dr of $80 \%$ and OCR of 4 are illustrated in Figs. 5.25(a) and (b). These figures show that increasing $\sigma^{\prime}{ }_{v c}$ increases $G_{s} / G_{\max }$ and decreases $\xi$. Further, Fig 5.25 (a) demonstrates the differences in $\mathrm{G}_{\mathrm{s}} / \mathrm{G}_{\max }$ of FRS under successive increments in consolidation stress level. A gradual shift in the $G_{s} / G_{\max }$ curve can be seen as the stresses increase from 50 to $400 \mathrm{kPa}$, but the influence of consolidation stresses level on $\mathrm{G}_{\mathrm{s}} / \mathrm{G}_{\mathrm{max}}$ is is fairly minimal at $\sigma_{\mathrm{vc}}^{\prime}$ of 50,100 and $200 \mathrm{kPa}$ compared to the differences between 200 and $400 \mathrm{kPa}$. These observations suggest that higher $\sigma^{\prime}{ }_{\mathrm{vc}}$ might significantly affects $G_{s} / G_{\max }$ of FRS. In addition, the modulus reduction curve of $\sigma^{\prime}{ }_{\mathrm{vc}}=400 \mathrm{kPa}$ closely shadows the Seed and Idriss's (1970) average boundary curve and other three $G_{s} / G_{\max }$ curves follow around the lower boundary curve.

Fig. 5.25(b) shows that the influence of successive $\sigma^{\prime}{ }_{v c}$ on the damping curve of dense FRS is negligible at small strain levels. Further, it can be observed that $\xi$ under $\sigma^{\prime}{ }_{\mathrm{vc}}$ of $50 \mathrm{kPa}$, closely shadows the lower boundary curve of Seed \& Idriss (1970). On the other hand, the $\xi$ curves of $\sigma_{\mathrm{vc}}^{\prime}=100 \mathrm{kPa}$ and above fall well below the lower boundary curve at $\gamma_{\mathrm{c}}>$ $0.2 \%$. This observation suggests that, at large strain level, dense FRS having higher consolidation stress and OCR of 4 have a very low damping ratio. 
Frase River Sand
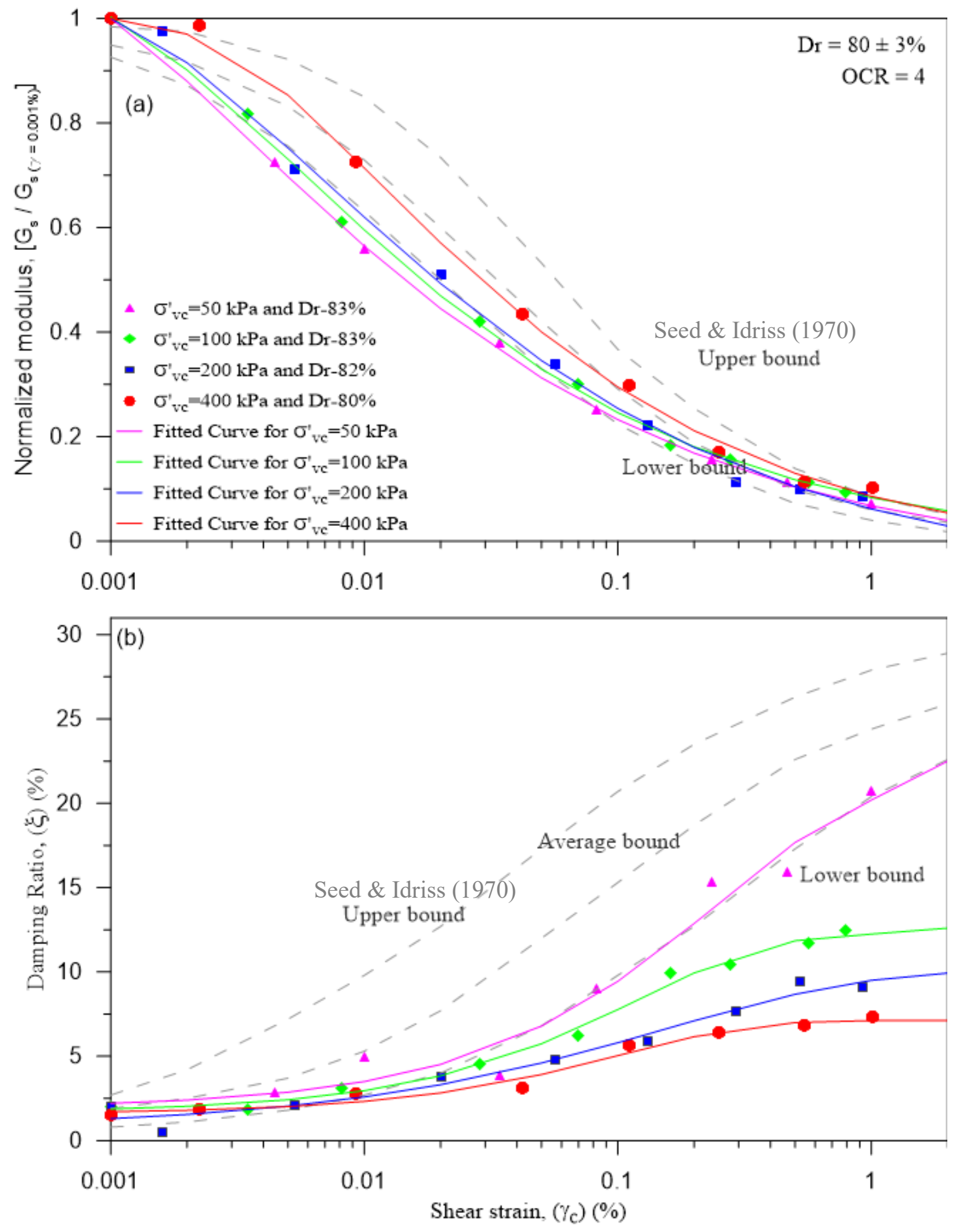

Fig 5.25 Effect of consolidation stress on (a) $G_{s} / G_{\max }$ and (b) $\xi$ of Fraser River sand 


\subsubsection{Influence of over consolidation ratio (OCR) on modulus reduction and damping characteristics}

Tests results plotted in Fig. 5.26(a-b) illustrate the effect of OCR on modulus reduction

$\left(\mathrm{G}_{\mathrm{s}} / \mathrm{G}_{\max }\right)$ and damping ratio $(\xi)$ of medium dense FRS ( $\mathrm{Dr} \sim 65 \%$ ) under $\sigma_{\mathrm{vc}}^{\prime}$ of $200 \mathrm{kPa}$.

$\mathrm{G}_{\mathrm{s}} / \mathrm{G}_{\max }$ is not significantly influenced by different $\mathrm{OCR}$ as $\mathrm{G}_{\mathrm{s}} / \mathrm{G}_{\max }$ curves converge closely, however a variation can be noticed between OCR 1 and 2 . Further, these $G_{s} / G_{\max }$ curves closely follow the lower boundary curve below $\gamma_{c}$ of $0.1 \%$ and at large $\gamma_{c}(>0.2 \%)$ the trend shifts towards upper boundary curve as presented in Fig. 5.25(a).

Damping curves plotted in Fig. 5.26(b) are not significantly affected by the OCR values at small strain levels $\left(\gamma_{c}<0.01 \%\right)$ but above $\gamma_{\mathrm{c}}$ of $0.02 \%$ it is clear that increasing OCR values significantly decrease the damping ratio $(\xi)$. The variation in $\xi$ is high between samples having OCR of 1 and 2 compared to that between OCR of 2 and 4 . This suggests a diminishing effects as OCR increases. Further, $\xi$ curve for the medium dense FRS with OCR of 1 approximately follows the average bound curve. On the other hand, $\xi$ curves for sample having OCR of 2 and 4 , follow approximately lower bound curve up to $\gamma_{c}$ of $0.03 \%$, however beyond this range of $\gamma_{c}$, those curves shift the trend and fall below the lower bound curve. 

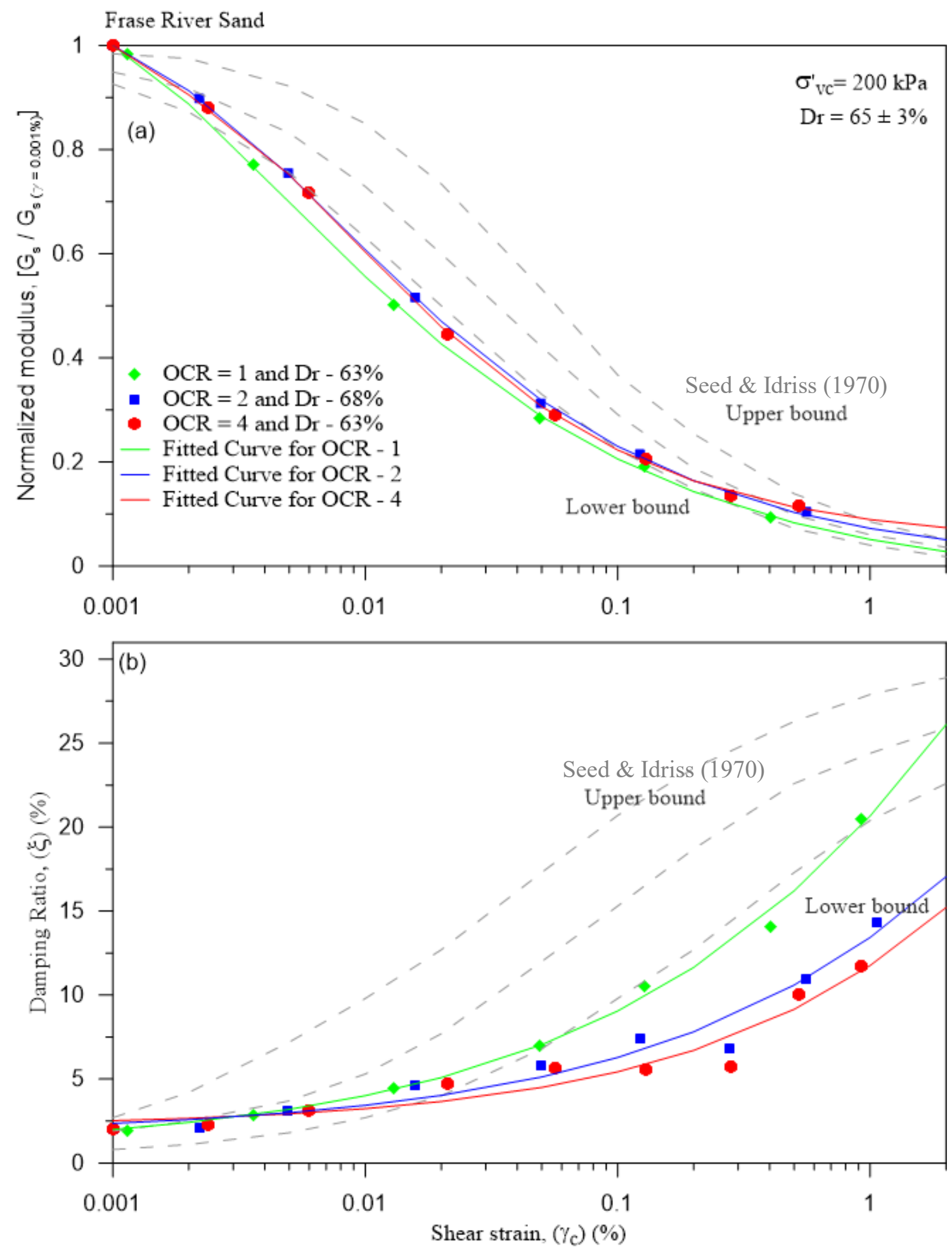

Fig 5.26 Effect of over consolidation ratio on (a) $G_{s} / G_{\text {max }}$ and (b) $\xi$ of Fraser River sand 
In summary, a series of cyclic stress controlled tests were conducted on reconstituted Fraser River sands under different consolidation stress levels $\left(\sigma_{\mathrm{vc}}^{\prime}=50,100,200\right.$ and $\left.400 \mathrm{kPa}\right)$, relative density $(\mathrm{Dr}=50,65$ and $80 \%)$ and over consolidation ratios $(\mathrm{OCR}=1,2$ and 4$)$. The tests results show consistent data for $\mathrm{G}_{\mathrm{s}} / \mathrm{G}_{\max }$ and $\xi$, however scattered data points are seen in $\xi$ curves above $\gamma_{c}$ of $0.1 \%$. Further, this study reveals that different $\sigma^{\prime}{ }_{\mathrm{vc}}$ and $\mathrm{Dr}$ significantly affects $G_{s} / G_{\max }$ and $\xi$ of Fraser River sand and the influence of OCR is minimal in $\mathrm{G}_{\mathrm{s}} / \mathrm{G}_{\max }$ and moderate in $\xi$. In addition, almost all proposed curves either follow the lower boundary curve proposed by Seed and Idriss (1970) or fall somewhat below that curve. 


\section{SUMMARY AND CONCLUSIONS}

\subsection{Summary}

Material/site specific dynamic properties of soils are essential for reliable dynamic response analysis of soils in earthquake prone regions. An experimental study was carried out to determine site-specific properties of sensitive Leda clays obtained from Ottawa-Quebec area (Kinburn, ON, Breckenridge and Outardes-2, QC) and Fraser River sand obtained from Abbotsford, BC. The tests were conducted under simple shear loading to simulate the in-situ loading conditions during earthquakes. Undrained monotonic, cyclic and post-cyclic characteristics of Leda clay were also determined using undisturbed samples, in addition to the modulus reduction and damping curves.

CU simple shear device was modified to enable confident measurements of very small strains (up to $0.001 \%$ ) required for such tests. Small strain tests can be conducted under stress or strain controlled loading mode in the modified device. Site-specific dynamic properties determined from the study have been compared to the data reported in the literature. Further, shear strength properties of sensitive Leda clays including undrained monotonic, cyclic, post-cyclic behaviour and partial-remoulded shear strength were evaluated.

\subsection{Conclusions}

\subsubsection{Undrained monotonic shear strength}

Undrained monotonic behaviour of sensitive Leda clays was assessed under simple shear condition. Samples were tested under both in-situ and higher consolidation stress 
levels $\left(\sigma^{\prime}{ }_{\mathrm{vc}}\right)$ ranging between 75 to $800 \mathrm{kPa}$ to represent the naturally over consolidated and normally consolidated states.

In general, during the undrained monotonic shearing, sensitive Leda clays display typical strain softening behaviour. Further, the peak state is reached at shear strain amplitude of $4 \%$ or less. Consolidation stress profoundly affects the shear strength, and normalized $S_{u} / \sigma_{v c}^{\prime}$ leads to relatively constant strength ratio at a given OCR. The highest peak undrained shear strength $\left(S_{u}\right)$ measured in these tests was of $184 \mathrm{kPa}$ (NC Outardes-2 sample at $\sigma^{\prime}{ }_{\mathrm{vc}}=800 \mathrm{kPa}$ ) and the lowest $S_{u}$ measured was $34.1 \mathrm{kPa}$ (OC Kinburn sample at $\sigma_{\mathrm{vc}}^{\prime}=75 \mathrm{kPa}$ and $\mathrm{OCR}=2.6$ ). Moreover, significant influence of $\sigma_{\mathrm{vc}}^{\prime}$ on the undrained monotonic behaviour was noticed. All normally consolidated clays revealed an essentially constant normalized strength ratio of about 0.25 regardless of the site.

Overconsolidated (OC) Leda clays show considerable increment in normalized undrained shear strength $\left(S_{u(N)}\right)$ and it reveals that peak $S_{u(N)}$ is dependent on the OCR. OC Kinburn and Breckenridge clays have effective friction angle $\left(\phi_{p}^{\prime}\right)$ of $17.3^{\circ}$ and effective cohesion $\left(c^{\prime}\right)$ of $17.4 \mathrm{kPa}$. At NC state both clays showed $\phi_{p}^{\prime}$ of $22.6^{0}$ but with negligible cohesion. On the other hand, OC Outardes-2 clays produced $\phi_{p}^{\prime}$ of $17.9^{\circ}$ and $c^{\prime}$ of $37.7 \mathrm{kPa}$ (while NC clays displayed $\phi_{p}^{\prime}$ of $22.3^{0}$ with negligible cohesion). Lower strength parameters in Kinburn and Breckenridge clays can be attributed to the relatively higher clay content at the sites.

\subsubsection{Undrained cyclic and post-cyclic shear strength}

Typical stress-strain responses are seen throughout undrained cyclic shearing of sensitive Leda clays obtained from different locations. Further, during the cyclic testing, increasing 
shear strain rapidly built up excess pore pressure, and consequently the stress path mobilized towards the origin, which eventually caused the sample to liquefy $\left(\gamma_{c}>3.75 \%\right)$.

Undrained cyclic strength considerably increases with $\sigma^{\prime}{ }_{\mathrm{vc}}$ in Leda calys. However, cyclic resistance ratio (CRR) significantly reduces as $\sigma^{\prime}{ }_{\mathrm{vc}}$ changes from the in-situ (naturally OC) to NC state. OC clays produced higher cyclic resistance in general, and OC Outardes-2 clay yielded the highest CRR possibly on account of its high OCR, lower water content and clay content. The influence of $I_{p}$ in OC clays is not noticeable but a slight influence of $I_{p}$ on CRR of NC clays was noticed. But, firm conclusions cannot be drawn on this regard as many other parameters (percent clay particles, sensitivity etc.) also changed across the sites.

This experimental study shows that Breckenridge and Outardes-2 sites not expected to liquefy at in-situ stress level (naturally OC state). However, OC Kinburn clays have the potential to liquefy. Further, cyclic resistance, quantified by CRR, decreased significantly if the clays are normally consolidated. Therefore, precautionary measures might be necessary when founding heavy structures on these clays. This study shows that at least $70 \%$ of the peak $\mathrm{Su}(\mathrm{NRR})$ is required to 'liquefy' the Leda clays from these sites within 50 cycles.

Post-cyclic monotonic tests carried out on the liquefied Leda clays reflect a behaviour similar to typical monotonic stress-strain, but with somewhat lower peak strength. However, the peak state is reached slowly at larger shear strain level $(\gamma>6 \%)$. Further, the post-cyclic peak shear strength varied from $64 \%$ to $88 \%$ of the corresponding monotonic peak shear strength. The average post cyclic strength was about $75 \%$. 


\subsubsection{Dynamic properties of soils}

\subsubsection{Modulus and damping characteristics of Sensitive Leda clays}

Modulus reduction and damping curves have been established for sensitive Leda clays from three sites. The influence of stress level $\sigma_{v c}^{\prime}$ on $G_{S}$ was found to be somewhat significant at lower $\gamma_{c}(<0.2 \%)$ but negligible at large $\gamma_{c}(>0.5 \%)$. As expected, a power relationship is noted between measured initial $G_{S}\left(\gamma_{c}=0.01 \%\right)$ and $\sigma_{v c}^{\prime}$. Moreover, effects of Ip on $G_{S}$ is not clear since the samples had only narrow variations in the Ip values (ranging from 9 to 24$)$.

Proposed modulus reduction $\left(G_{s} / G_{\max }\right)$ and damping $(\xi)$ curves captured the general trends; as $\gamma_{c}$ increases $G_{s}$ and normalized modulus $\left(G_{s} / G_{\max }\right)$ decreases, and the damping ratio $(\xi)$ increases. Also data show reasonably consistent values of $G_{s}, G_{s} / G_{\max }$ and $\xi$. In general, proposed site-specific $G_{s} / G_{\max }$ curves show a slight non- liner modulus degradation at lower $\gamma_{c}(<0.01 \%)$ and rapid non- liner modulus degradation at medium $\gamma_{c}$ level $(0.01$ to $0.5 \%)$. However, the degradation becomes moderate with further increasing $\gamma_{c}$ and negligible degradation is noted at strains exceeding about $1 \%$. Moreover, modulus reduction of sensitive Leda clays display a negligible effect of OCR and $\sigma^{\prime}{ }_{v c}$ within the tested range of OCR and $\sigma^{\prime}{ }_{v c}$

Proposed modulus reduction $\left(G_{S} / G_{\max }\right)$ curves of sensitive Leda clays follow the Vucetic and Dobry's lower Ip curves $(0-15)$ at lower to medium $\gamma_{c}$ levels and they shadow the higher Ip curves $(30-200)$ at larger $\gamma_{c}$. Further, proposed set of modulus reduction curves show reasonably narrow band between them. However, modulus reduction of Outardes-2 clays show slight influence of OCR, possibly due to the amount of clay size particles. 
Proposed set of damping curves display a narrow band at lower $\gamma_{c}(<0.015 \%)$ and these curves can be approximated with the Ip $=50$ curve proposed by Vucetic and Dobry (1991). Further, two different sets of $\xi$ curves are established above medium $\gamma_{c}$ level based on the consolidated states (NC or naturally OC). Moreover, $\xi$ curves of NC clays follow the higher Ip curves (Ip $=100$ and 200) proposed by Vucetic and Dobry (1991) and $\xi$ curves of OC clays follow lower Ip curves (Ip $=30$ and 50). However, the influence of OCR and $\sigma_{v c}^{\prime}$ noticed in the $\xi$ curves and the effect of Ip is not clear (Ip ranging from 9 to 24). This experimental study demonstrates that sensitive Leda clays do not continuously follow any specific modulus reduction and damping ratio curve proposed by Vucetic and Dobry (1991) based on Ip values.

\subsubsection{Modulus and damping characteristics of Fraser River sand}

Modulus reduction and damping curves are established for reconstituted Fraser River sand (FRS) using stress-controlled quasi-cyclic testing. Tests were carried out under different consolidation stress levels $\left(\sigma_{\mathrm{vc}}^{\prime}=50,100,200\right.$ and $\left.400 \mathrm{kPa}\right)$ at three different relative densities ( $\mathrm{Dr}=50,65$ and 80\%) states. $\mathrm{NC}$ sand, and sands with $\mathrm{OCR}=2,4$ were considered.

These test results demonstrate that Dr, $\sigma^{\prime}{ }_{v c}$ and OCR affect the shear modulus $\left(G_{s}\right)$ of FRS. Specifically, increasing $\sigma^{\prime}{ }_{\mathrm{vc}}$ and density significantly increase the $\mathrm{G}_{\mathrm{s}}$ values. The influence of $\sigma^{\prime}{ }_{\mathrm{vc}}$ is very significant at lower $\gamma_{\mathrm{c}}$ levels $\left(\gamma_{\mathrm{c}}<0.1 \%\right)$. However, the effect of OCR (ranging from 1 to 4 ) on $G_{s}$ is minimal based on the limited test data. Further, the $G_{s}$ values increase with Dr, $\sigma^{\prime}{ }_{\mathrm{vc}}$ and $\mathrm{OCR}$ at all strain levels. In addition, the rate of $\mathrm{G}_{\mathrm{s}}$ degradation is non-linear and rapid at small $\gamma_{c}(0.001$ to about $0.2 \%)$. Similarly, modulus reduction 
$\left(\mathrm{G}_{\mathrm{s}} / \mathrm{G}_{\max }\right)$ values increase with $\mathrm{Dr}, \sigma_{\mathrm{vc}}^{\prime}$ and OCR and all proposed $\mathrm{G}_{\mathrm{s}} / \mathrm{G}_{\max }$ curves are close to the average and lower boundary curves proposed by Seed and Idriss's (1970).

Test results show that difference in Dr affects the $\xi$ curves of FRS and increasing Dr decrease the $\xi$. Also, variation in $\xi$ is relatively insignificant at very small strains, but significant at $\gamma_{\mathrm{c}}$ ranging from medium to large. Further, the influence of $\sigma^{\prime}{ }_{\mathrm{vc}}$ on $\xi$ curves is observed however the influence is negligible at small strain levels. In addition, increasing OCR decreases the $\xi$ values somewhat, and also the influence of OCR is more visible at $\gamma_{c}$ of $0.02 \%$ and above. Measured damping curves are close to the lower boundary curves reported by Seed and Idriss (1970) in the literature. 


\section{REFERENCES}

Afifi, S. S., and Richart, F. E., Jr. (1973). "Stress-history effects on shear modulus of soils." Soils Found, 13(1), 77-95.

Alshawmar, F. (2014). "Evaluation of Compressibility, Anisotropy and At-rest Lateral Earth Pressure in Champlain Sea Clays.” MASc Thesis, Carleton University, Ottawa, p 84-97

Andersen, K. H., Rosenbrand, W. F., Brown, S. F., \& Pool, J. H. (1980). “Cyclic and static laboratory tests on Drammen clay.” Journal of the Geotechnical Engineering Division, 106(5), 499-529.

Andersen, K. H. (1983). "Strength and deformation properties of clay subjected to cyclic loading." Report No. 52412-8, Norwegian Geotechnical Institute, Oslo, Norway.

Andersen, K. H., Kleven, A., \& Heien, D. (1988). “Cyclic soil data for design of gravity structures.” Journal of Geotechnical Engineering, 114(5), 517-539.

Anderson, D. G., and Richart, F. E., Jr. (1976). "Effects of straining on shear modulus of clays." Journal of Geotechnical Engineering, Div., ASCE, 102(9), 975-987.

Anderson D. G., and Stokoe K H. (1978). "Shear Modulus: A Time-Dependent Soil Property”. ASTM Special Technical Publication. 66-90.

Anderson, D. G., and Woods, R. D. (1976). "Time-dependent increase in shear modulus of clay." Journal of Geotechnical Engineering, Div., ASCE, 102(5), 525-537.

Ansal, A. M., \& Erken, A. (1989). "Undrained behaviour of clay under cyclic shear stresses.” Journal of Geotechnical Engineering, 115(7), 968-983.

Azzouz, A. S., Malek, A. M., \& Baligh, M. M. (1989). "Cyclic behaviour of clays in undrained simple shear.” Journal of Geotechnical Engineering, 115(5), 637-657.

Bishop, A. W. (1966). "The strength of soils as engineering materials." Geotechnique, 16(2), 91-128.

Bjerrum, L., \& Landva, A. (1966). "Direct simple shear tests on a Norwegian quick clay." Geotechnique, 16(1), 1-20. 
Blanchette, J.D. (2014). "Interim progress report: Outardes-02 site, Kinburn site and Breckenridge site.” University Laval, Quebec, p 33-79.

Boulanger, R. W., Meyers, M. W., Mejia, L. H., \& Idriss, I. M. (1998). "Behaviour of a fine-grained soil during the Loma Prieta earthquake." Canadian Geotechnical Journal, 35(1), 146-158.

Boulanger, R. W., \& Idriss, I. M. (2004). "Evaluating the potential for liquefaction or cyclic failure of silts and clays (p. 131)." Center for Geotechnical Modeling, Dept. of Civil and Environmental Engineering, Univ. of California, Davis.

Boulanger, R. W., \& Idriss, I. M. (2006). "Liquefaction susceptibility criteria for silts and clays.” Journal of geotechnical and geoenvironmental engineering, 132(11), 1413-1426.

Bray, J. D., Sancio, R. B., Riemer, M. F., \& Durgunoglu, T. (2004 a). "Liquefaction susceptibility of fine-grained soils." In Proc., 11th Int. Conf. on Soil Dynamics and Earthquake Engineering and 3rd Int. Conf. on Earthquake Geotechnical Engineering (Vol. 1, pp. 655-662). Stallion Press, Singapore.

Bray, J. D., Sancio, R. B., Durgunoglu, T., Onalp, A., Youd, T. L., Stewart, J. P., Seed, R. B., Cetin, O. K., Bol, E., Baturay, M. B., Christensen, C., and Karadayilar, T. (2004b). "Subsurface characterization at ground failure sites in Adapazari, Turkey." Journal of geotechnical and geoenvironmental engineering, 130(7), 673-685.

Bray, J. D., \& Sancio, R. B. (2006). “Assessment of the liquefaction susceptibility of finegrained soils." Journal of geotechnical and geoenvironmental engineering, 132(9), 1165-1177.

Casagrande, A., \& Carillo, N. (1944). "Shear failure of anisotropic materials.” Journal of Boston Society of Civil Engineers, 31(4), 74-81.

Casagrande, A., \& Wilson, S. D. (1951). "Effect of rate of loading on the strength of clays and shales at constant water content." Geotechnique, 2(3), 251-263.

Castro, G., (1969), "Liquefaction of Sands", PhD Thesis, Harvard University, Cambridge, Massachusetts, p 182-248. 
Castro, G., \& Christian, J. T. (1976). "Shear strength of soils and cyclic loading." Journal of Geotechnical and Geoenvironmental Engineering, 102(ASCE\# 12387).

Craig, R. F. (2004). “Craig's soil mechanics.” CRC Press.

Crawfordc, B., and Jarrettp. M. (1967). “Landslide on the Toulnustouc River”. Quebec: Discussion. Canadian Geotechnical Journal, 4(4), pp. 175-177.

Dobry, R., \& Vucetic, M. (1987). "State-of-the-art report: Dynamic properties and response of soft clay deposits." Proceedings International Symposium on Geotechnical Engineering of Soft Soils, Vol. 2, 51 - 87.

Dyvik, R., Berre, T., Lacasse, S., \& Raadim, B. (1987). “Comparison of truly undrained and constant volume direct simple shear tests." 37(1), 3 - 10.

Eden, W. J., \& Mitchell, R. J. (1970). “The mechanics of landslides in Leda clay.” Canadian Geotechnical Journal, 7(3), 285-296.

Finn, W. D. L., Ledbetter, R. H., Fleming, R. L. M., Templeton, A. E. M., Forrest, T. W., \& Stacy, S. T. (1991). "Dam on liquefiable foundation: Safety assessment and remediation." In Proceedings, 17th International Conference on Large Dams, Vienna (pp. 530-554).

Gadd, N. (1962). “Surficial geology of Ottawa map-area Ontario and Quebec.” Geol. Sutv. Can., Paper 62(16):4.

Ha, D. (2003). "Effect of Initial Stress State on the Undrained Cyclic Behaviour of Sands." MASc Thesis, Carleton University, Ottawa, Canada, p 39-150.

Hardin, B. O. (1978). "The nature of stress-strain behaviour for soils", Proc. of ASCE Geotechnical Engineering Division Specialty Conference on Earthquake Engineering and Soil Dynamics, (1), 3-90.

Hardin, B. O., and Black, W. L. (1968). "Vibration modulus of normally consolidated clay." J. Soil Mech. Found. Div., ASCE, 94(2), 353-369.

Hardin, B. O., and Drnevich, V. P. (1972). "Shear modulus and damping in soils: design equations and curves." Soil Mech. and Pound. Div., ASCE, 98(7), 667- 692. 
Houston, W. N., \& Herrmann, H. G. (1980). "Undrained cyclic strength of marine soils." Journal of Geotechnical and Geoenvironmental Engineering, 106 (ASCE 15503).

Hsu, C. C., \& Vucetic, M. (2006). "Threshold shear strain for cyclic pore-water pressure in cohesive soils." Journal of Geotechnical and Geoenvironmental engineering, 132(10), 1325-1335.

Idriss, I. M., Dobry, R., \& Sing, R. D. (1978). "Nonlinear behaviour of soft clays during cyclic loading." Journal of Geotechnical and Geoenvironmental Engineering, 104(ASCE 14265).

Idriss, I. M. (1999). "An update to the Seed-Idriss simplified procedure for evaluating liquefaction potential." Proc., TRB Workshop on New Approaches to Liquefaction, January, Publication No. FHWA-RD-99-165, Federal Highway Administration.

Ishibashi, I. (1992). "Discussion of "Effect of Soil Plasticity on Cyclic Response" by Malden Vucetic and Ricardo Dobry (January, 1991, Vol. 117, No. 1).” Journal of Geotechnical Engineering, 118(5), 830-832.

Ishibashi, I., \& Zhang, X. (1993). "Unified Dynamic Shear Moduli and Damping Ratios of Sand and Clay." Soils and Foundations, 33 (1), 182 - 191.

Ishihara, K., and Okada, S., (1978), "Yielding of Over consolidated Sand and Liquefaction Model under Cyclic Stresses", Soils and Foundations, 18(1):57-71.

Ishihara, K., Sadekawa, M., Tanaka, Y., (1978), "Effects of Over consolidation on Liquefaction Characteristics of Sands Containing Fines", Dynamic Geotechnical Testing, ASTM, STP 654, 246-264.

Ishihara, K., and Takatsu, H., (1979), "Effects of over consolidation and $K_{o}$ conditions on the Liquefaction Characteristics of Sand", Soils and Foundations, 19(4):59-68.

Ishihara, K. and F. Yamazaki (1980). "Cyclic simple shear tests on saturated sand in multidirectional loading", Soil and Foundations, 20, (1), 45-59.

Ishihara, K. (1986). "Evaluation of soil properties for use in earthquake response analysis." Geo-mechanical Modelling in Engineering Practice, R. Dingar and J. A. Student, eds., A. Balkema, Rotterdam, the Netherlands, 241-275. 
Ishihara, K. (1993). "Liquefaction and flow failure during earthquakes." Geotechnique, 43(3), 351-415.

Ishihara, K. (1996). "Soil behaviour in earthquake engineering." Clarendon, Oxford.

Jacobsen, L. S. (1930). "Steady forced vibrations as influenced by damping." Trans. ASME, 52(15), 169-181.

Jamiolkowski, M., Ladd, C. C., Germaine, J. T., Lancellotta, R. (1985). "New developments in field and laboratory testing of soils." 11 th International Conference on Soil Mechanics and Foundation Engineering 57-153. San Francisco.

Johnston, W. (1917). Pleistocene and recent deposits in the vicinity of Ottawa, with a description of the soils. Geo. Surv. Can., Mem. 101:69.

Jung, Y. H., Choo, J., Cho, W., \& Chung, C. K. (2013). "Patterns of Nonlinear Shear Stiffness Degradation of Reconstituted Clay with Different Stress Histories." Marine Geo-resources \& Geo-technology, 31(4), 309-331.

Kakoli, S.T.N. (2005). "Behaviour of sensitive clay under cyclic loading." MASc Thesis, Concordia University, Montreal, Canada, p 3-22.

Karrow, P. (1961). "The Champlain Sea and its sediments.” R. F. Legget (Editor), Soils in Canada. Roy. Soc. Can. Spec. Publ. 3:97-108.

Kenney, T. C. (1964). "Sea level movements and the Boston," Nicolet, Ottawa and Oslo. Geotechnique 14:203-230

Kim, T. C., \& Novak, M. (1981). "Dynamic properties of some cohesive soils of Ontario." Canadian Geotechnical Journal, 18(3), 371-389.

Kjellman, W. (1951). "Testing the Shear Strength of Clay in Sweden", Geotechnique, 2, No.3, 225-232.

Kokusho, T., Yoshida, Y., \& Esashi, Y. (1982). "Dynamic properties of soft clay for Wide strain range." Soils and Foundations, 22 (4), $1-18$.

Kovacs, W. D., \& Leo, E. (1981). "Cyclic simple shear of large scale sand samples: effects of diameter to height ratio." In First International Conference on Recent Advances in 
Geotechnical earthquake Engineering and Soil Dynamics (1981: April 26-May 3; St. Louis, Missouri). Missouri S\&T (formerly the University of Missouri-Rolla).

Kramer, S. L. (1996). “Geotechnical Earthquake Engineering.” Prentice-Hall.

Krizek, R. J., McLean, F. G., and Giger, M. W. (1974). "Effect of particle characteristics on wave velocity," Geotechnical Engineering. Div., ASCE, 100(1), 89-94.

Kuribuyashi, E., Iwasaki, T., and Tatsuoka, F. (1974). "Effects of stress conditions on dynamic properties of sands," Bulletin Intl. of Seismology and Earthquake Engineering, Vol. 12, Tokyo, Japan.

Ladd, C. C. (1991). "Stability evaluation during staged construction." Journal of Geotechnical Engineering, 117(4), 540-615.

Lanzo, G., Vucetic, M., \& Doroudian, M. (1997). "Reduction of shear modulus at small strains in simple shear." Journal of geotechnical and geoenvironmental engineering, 123, 1035-1042.

Lanzo, G., Pagliaroli, A., Tommasi, P., \& Chiocci, F. L. (2009). "Simple shear testing of sensitive, very soft offshore clay for wide strain range." Canadian Geotechnical Journal, 46(11), 1277-1288.

Larewh, G., and Leonardgs, A., (1962). "A repeated load strength criterion". Proc. Highway Research. Board, Vol.41, p 529-556.

Lee, K. L. (1979). "Cyclic strength of a sensitive clay of eastern Canada." Canadian Geotechnical Journal, 16(1), 163-176.

Lefebvre, G., \& Rochelle, P. L. (1974). "The analysis of two slope failures in cemented Champlain clays." Canadian Geotechnical Journal, 11(1), 89-108.

Lefebvre, G., \& Leboeuf, D. (1987). "Rate effects and cyclic loading of sensitive clays." Journal of Geotechnical Engineering, 113(5), 476-489.

Lefebvre, G., LeBoeuf, D., \& Demers, B. (1989). "Stability threshold for cyclic loading of saturated clay." Canadian Geotechnical Journal, 26(1), 122-131. 
Locat, J., Lefebvre, G., \& Ballivy, G. (1985). "Mineralogy, chemistry, and physical properties interrelationships of some sensitive clays from Eastern Canada." Canadian Geotechnical Journal, 21(3), 530-540.

Logeswaran, P (2010) "Behaviour of sands under generalized loading and drainage conditions." PhD Thesis, Carleton University, Ottawa, Canada, p 52-74.

Loiselle,A., Massiéra, M., and Sainani, U., R., (1971). "A Study of the Cementation Bonds of the Sensitive Clays of the Outardes River Region." Canadian Geotechnical Journal, 9(4): 516-519.

Malek, A. M., Azzouz, A. S., Baligh, M. M., \& Germaine, J. T. (1989). "Behaviour of foundation clays supporting compliant offshore structures." Journal of Geotechnical Engineering, 115(5), 615-636.

Marcuson, W. F., III, and Wahls, H. E. (1972). "Time effects on the dynamic shear modulus of clays." J. Soil Mech. Found. Div., ASCE, 98(12), 1359-1373.

Matsui, T., Ohara, H., and Ito, T. (1980). "Cyclic stress-strain history and shear characteristics of clay." Journal of Geotechnical Engineering. Div., ASCE, 106(10), 1101-1120.

Mitchell, R. J. (1970). "On the yielding and mechanical strength of Leda clays." Canadian Geotechnical Journal, 7(3), 297-312.

Mitchell, R. J. (1975). "Strength parameters for permanent slopes in Champlain Sea clays." Canadian Geotechnical Journal, 12(4), 447-455.

Mitchell, R. J., \& King, R. D. (1976). "Cyclic loading of an Ottawa area Champlain Sea clay." Canadian Geotechnical Journal, 14(1), 52-63.

Mortezaie, A. R., \& Vucetic, M. (2013). "Effect of Frequency and Vertical Stress on Cyclic Degradation and Pore Water Pressure in Clay in the NGI Simple Shear Device." Journal of Geotechnical and Geoenvironmental Engineering, 139(10), 1727-1737.

Mourn, J., Loken, T., Torrance, J.K. (1971). "A Geochemical Investigation of the Sensitivity of a Normally Consolidated Clay from Drammen, Norway." Geotechnique 21(4), pp. 329-340. 
NBCC (2005). "National Building Code of Canada (NBC)." Associate Committee on the National Building Code, National Research Council of Canada, Ottawa, ON.

Ogawa, S. (1973). "Dynamic shear test results and its application," Tsuchi-to-Kiso, Japanese Society of Soil Mechanics and Foundation Engineering, pp. 33-40.

Ohara, S., and Matsuda, H. (1988). "Study on settlement of saturated clay layer induced by cyclic shear." Soils Found. 28(3), 103-113.

Okur, D. V., \& Ansal, A. (2007). "Stiffness degradation of natural fine grained soils during cyclic loading." Soil Dynamics and Earthquake Engineering, 27(9), 843-854.

Peacock, W. H., \& Bolton, S. E. E. D. (1968). "Sand liquefaction under cyclic loading simple shear conditions." Journal of Soil Mechanics \& Foundations Div.

ProShake Version 1.11, (2001). “User’s Manual for Proshake: Ground Response Analysis Program” EduPro Civil Systems Inc., Redmond, WA, USA.

Quinn, P., D. Hutchinson, D., \& Rowe, R., (2007). "Toward a Risk Management Framework: Sensitive Clay Landslide Hazards Affecting Linear Infrastructure in Eastern Canada”. 1st North American Landslide Conference, Vail.

Rankka, K., Andersson-Sköld, Y., Hultén, C., Larsson, R., Leroux, V., \& Dahlin, T. (2004). “Quick clay in Sweden.” Report 65, Swedish Geotechnical Institute, Linköping.

Rasmuseen, K. (2012). “An Investigation of Monotonic and Cyclic Behaviour of Leda Clay." MASc Thesis, University of Western Ontario, London, Ontario, Canada, p 150192.

Raymond, G. P., Gaskin, P. N., \& Addo-Abedi, F. Y. (1979). "Repeated compressive loading of Leda clay.” Canadian Geotechnical Journal, 16(1), 1-10.

Roscoe, K. H., Schofield, A., \& Wroth, C. P. (1958). "On the yielding of soils." Geotechnique, 8(1), 22-53.

Rosenqvist, I. T. (1953). "Considerations on the sensitivity of Norwegian quick-clays." Geotechnique, 3(5), 195-200.

Sangrey, D. A., Henkel, D. J., \& Esrig, M. I. (1969). "The effective stress response of a saturated clay soil to repeated loading." Canadian Geotechnical Journal, 6(3), 241-252. 
Sangrey, D. A. (1972 a). "On the causes of natural cementation in sensitive soils." Canadian Geotechnical Journal, 9(1), 117-119.

Seed, H. B., \& Chan, C. K. (1966). "Clay strength under earthquake loading conditions." Journal of Soil Mechanics \& Foundations Division, 92(ASCE\# 4723 Proceeding).

Seed, H. B., \& Idriss, I. M. (1970). "Soil moduli and damping factors for dynamic response analyses."

Seed, H.B. (1979). "Considerations in the earthquake-resistant design of earth and rock fill dams", Geotechnique, Vol. XXIX, No. 3, pp. 213-263.

Seed, H. B., \& Idriss, I. M. (1982). "Ground motions and soil liquefaction during earthquakes (Vol. 5).” Oakland, CA: Earthquake Engineering Research Institute.

Seed, H. B., Idriss, I. M., \& Arango, I. (1983). "Evaluation of liquefaction potential using field performance data.” Journal of Geotechnical Engineering, 109(3), 458-482.

Seed, H. B., Wong, R. T., Idriss, I. M., \& Tokimatsu, K. (1986). "Moduli and damping factors for dynamic analyses of cohesion-less soils." Journal of Geotechnical Engineering, 112(11), 1016-1032.

Seed, R. B., Cetin, K. O., Moss, R. E., Kammerer, A. M., Wu, J., Pestana, J. M., ... \& Faris, A. (2003). "Recent advances in soil liquefaction engineering: a unified and consistent framework." In Proceedings of the 26th Annual ASCE Los Angeles Geotechnical Spring Seminar: Long Beach, CA.

Shannon and Wilson Inc. (1964), "Report on Anchorage Area Soil Studies, Alaska to U.S. Army Engineer District Anchorage, Alaska", Seattle, Washington.

Sivathayalan, S., and Ha, D. (2004). "Effect of initial stress state on the cyclic simple shear behaviour of sands". In Proceedings of the International Workshop on Cyclic Behaviour of Soils and Liquefaction Phenomena. Edited by T. Triantafyllidis. Taylor \& Francis Group, London. pp. 207-214.

Sivathayalan, S., \& Ha, D. (2011). "Effect of static shear stress on the cyclic resistance of sands in simple shear loading." Canadian Geotechnical Journal, 48(10), 1471-1484. 
Silvestri, V., Karam, G., Tonthat, A., \& St-Amor, Y. (1989). "Direct and Simple Shear Testing of Two Canadian Sensitive Clays.” ASTM Geotechnical Testing Journal, 12(1), $11-21$.

Skempton, A.W., \& Northey, R.D. (1952). “The Sensitivity of Clays.” Geotechnique, 3(1): $30-53$.

Stokoe, K. H., II, Darendeli, M. B., Andrus, R. D., and Brown, L. T. (1999). "Dynamic soil properties: Laboratory, field and correlation studies." Proc., 2nd Int. Conf. on Earthquake Geotechnical Engineering, Vol. 3, Lisbon, Portugal, 811-845.

Theenathayarl, T. (2015) "Behaviour of sensitive Leda clay under simple shear loading." MASc Thesis, Carleton University, Ottawa, Canada, p 117-136.

Thiers, G. R., and Seed, H. B. (1969). "Strength and stress-strain characteristics of clays subjected to seismic loads." ASTM STP 450, Symposium on Vibration Effects of Earthquakes on Soils and Foundations, ASTM, 3-56.

Torrance, J. K. (1999), "Physical, Chemical and Mineralogical Influences on the Rheological of Remoulded Low-activity Sensitive Marine Clays," Applied Clay Science, 14, 199-223.

Vaid, Y.P., and Chern, J.C. (1985). "Cyclic and monotonic undrained response of sands." In Proceedings of Advances in the Art of Testing Soils under Cyclic Loading Conditions, Detroit, pp. 120-147.

Vaid, Y. P., Robertson, P. K., \& Campanella, R. G. (1979). "Strain rate behaviour of SaintJean-Vianney clay.” Canadian Geotechnical Journal, 16(1), 34-42.

Vaid, Y.P., Sivathayalan, S., Eliadorani, A., and Uthayakumar, M. (1996). "Characterisation of static and dynamic liquefaction of sands. Laboratory testing at U.B.C”., CANLEX Technical Report No. 04/96

Vaid, Y. P., \& Thomas, J. (1995). "Liquefaction and post liquefaction behaviour of sand." Journal of Geotechnical Engineering, 121(2), 163-173.

Vipulanantham, M. (2011). "Initial stress state and stress history effects on liquefaction susceptibility of sands." MASc Thesis, Carleton University, Ottawa, Canada, p 162. 
Vucetic, M., \& Dobry, R. (1988). "Degradation of marine clays under cyclic loading." Journal of Geotechnical Engineering, 114(2), 133-149.

Vucetic, M., \& Dobry, R. (1991). “Effect of soil plasticity on cyclic response.” Journal of geotechnical engineering, 117(1), 89-107.

Vucetic, M. (1994). "Cyclic threshold shear strains in soils." Journal of Geotechnical engineering, 120(12), 2208-2228.

Vucetic, M., Lanzo, G., \& Doroudian, M. (1998). "Damping at small strains in cyclic simple shear test." Journal of geotechnical and geoenvironmental engineering, 124(7), 585-594.

Wang, W. (1979). "Some findings in soil liquefaction." Earthquake Engineering Department, Water Conservancy and Hydroelectric Power Scientific Research Institute.

Wichtmann, T., Andersen, K. H., Sjursen, M. A., \& Berre, T. (2013). “Cyclic tests on highquality undisturbed block samples of soft marine Norwegian clay." Canadian Geotechnical Journal, 50(4), 400-412.

Woods, R. D. (1994). "Laboratory measurement of dynamic soil properties.” ASTM Special Technical Publication, 1213, 165-165.

Yan, L., \& Byrne, P. M. (1990). "Simulation of downhole and crosshole seismic tests on sand using the hydraulic gradient similitude method." Canadian Geotechnical Journal, 27(4), 441-460.

Youd, T. L., Idriss, I. M., Andrus, R. D., Arango, I., Castro, G., Christian, J. T., \& Stokoe, K. H. (2001). "Liquefaction resistance of soils: summary report from the 1996 NCEER and 1998 NCEER/NSF workshops on evaluation of liquefaction resistance of soils.” Journal of Geotechnical and Geoenvironmental Engineering, 127(10), 817-833.

Zergoun, M., \& Vaid, Y. P. (1994). "Effective stress response of clay to undrained cyclic loading.” Canadian Geotechnical Journal, 31(5), 714-727. 